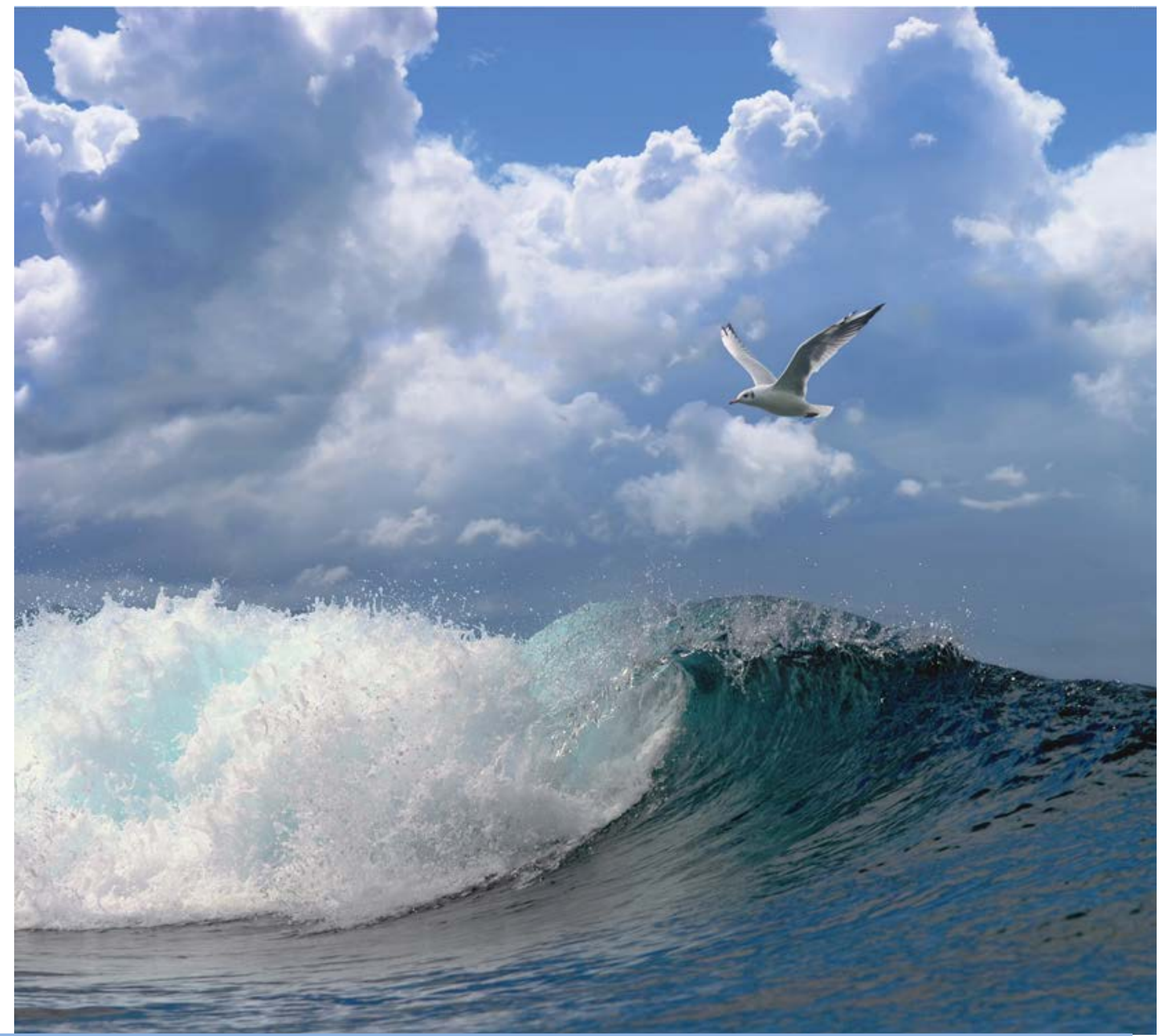

Data rapport: Monitoring vooroeververdedigingen 2016: macrofauna in zacht substraat langs de zuidkust van Schouwen-Duiveland

Locaties Burghsluis, Schelphoek en Zierikzee

Auteurs: Vincent Escaravage, Martine van den Heuvel-Greve, Marijn Tangelder \& Mario de Kluijver.1

(1) Stichting Zeeschelp
Wageningen University \&

Research Rapport C089/17 


\section{Data rapport: Monitoring vooroeververdedigingen 2016: macrofauna in zacht substraat langs de zuidkust van Schouwen-Duiveland}

Locaties Burghsluis, Schelphoek en Zierikzee

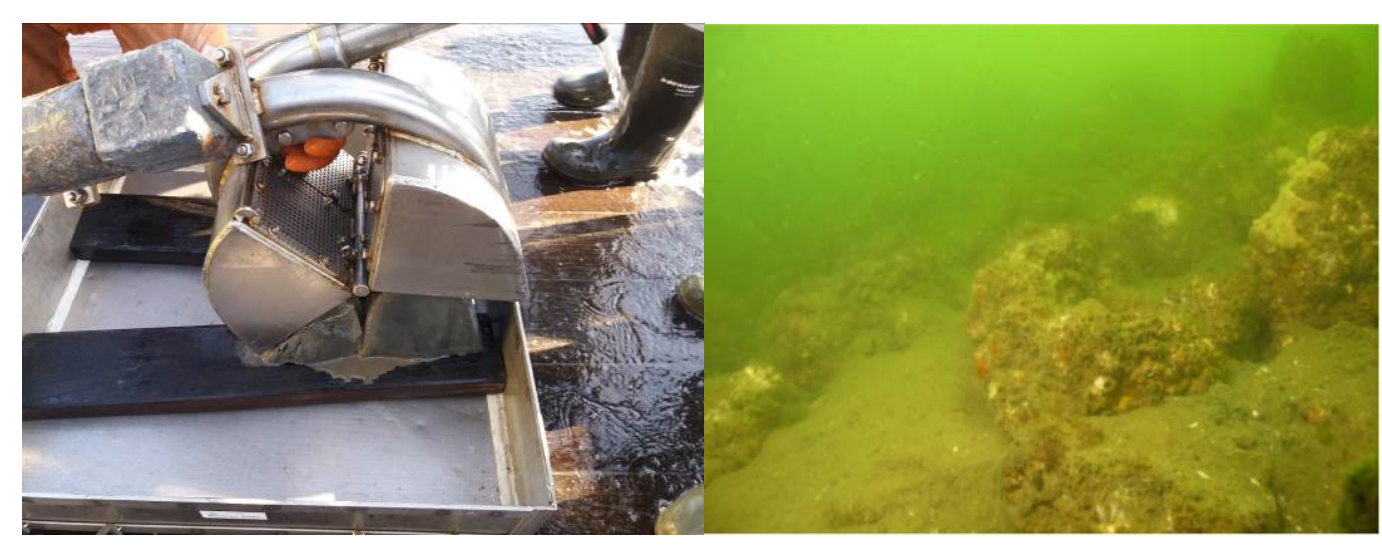

Auteur(s):

Vincent Escaravage, Martine van den Heuvel-Greve, Marijn Tangelder \& Mario de Kluijver ${ }^{1}$ ${ }^{1}$ Stichting Zeeschelp

Opdrachtgever: RWS Zee en Delta / RWS WVL

T.a.v. Silvana Ciarelli

Poelendaelesingel 18

4335 J A Middelburg

Publicatiedatum: 24 november 2017 
Escaravage, V., M. van den Heuvel-Greve, M. Tangelder \& M. de Kluijver, 2017. Data rapport: Monitoring vooroeververdedigingen 2016: macrofauna in zacht substraat langs de zuidkust van Schouwen-Duiveland; Locaties Burghsluis, Schelphoek en Zierikzee. Wageningen Marine Research C089/17.; 60 blz.; 21 tabellen.; referenties. Wageningen UR (University \& Research) in samenwerking met Stichting Zeeschelp.

Foto's omslag: Mario de Kluiver

Dit rapport is gratis te downloaden van https://doi.org/10.18174/426708

Wageningen Marine Research verstrekt geen gedrukte exemplaren van rapporten.

Wageningen Marine Research Wageningen UR is ISO 9001:2008 gecertificeerd.

\section{(c) 2017 Wageningen Marine Research}

Wageningen Marine Research, onderdeel van Stichting DLO.

KvK nr. 09098104

IMARES BTW nr. NL 8113.83.696.B16.

Code BIC/SWIFT address: RABONL2U

IBAN code: NL 73 RABO 0373599285
De Directie van Wageningen Marine Research is niet aansprakelijk voor gevolgschade, noch voor schade welke voortvloeit uit toepassingen van de resultaten van werkzaamheden of andere gegevens verkregen van Wageningen Marine Research; opdrachtgever vrijwaart Wageningen Marine Research van aanspraken van derden in verband met deze toepassing. Dit rapport is vervaardigd op verzoek van de opdrachtgever hierboven aangegeven en is zijn eigendom. Niets uit dit rapport mag weergegeven en/of gepubliceerd worden, gefotokopieerd of op enige andere manier gebruikt worden zonder schriftelijke toestemming van de opdrachtgever. 


\section{Inhoud}

$1 \quad$ Samenvatting $\quad 2$

$2 \quad$ Inleiding $\quad 4$

2.1 Achtergrond $\quad 4$

2.2 Aanleiding $\quad 5$

2.3 Doel van de monitoring $\quad 5$

3 Methoden $\quad 6$

$\begin{array}{lll}3.1 & \text { Bemonstering en locaties } & 6\end{array}$

$\begin{array}{lll}3.1 .1 & \text { Monsterlocaties } & 6\end{array}$

3.1.2 Bemonsteringstechnieken 9

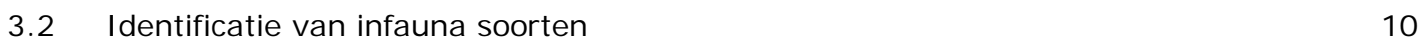

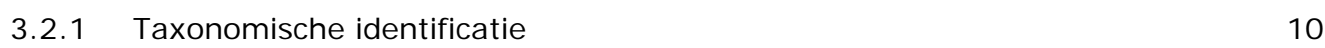

3.2.2 Analyse van diversiteit, dichtheden en gemeenschappen 11

$\begin{array}{ll}3.3 & \text { Sedimentkarakteristieken } \\ 3.42\end{array}$

$\begin{array}{ll}3.4 & \text { Sedimentdikte metingen } \\ 3.5 & 13\end{array}$

$\begin{array}{llr}3.5 & \text { Werkverdeling } & 13\end{array}$

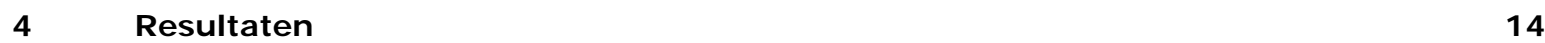

$\begin{array}{lll}4.1 & \text { Monsterlocaties } & 14\end{array}$

4.2 Taxonomische samenstelling van de bodemdiergemeenschappen (2009-2016) 16

4.2.1 Dominante soorten en taxonomische klassen 16

4.3 Karakteristieken van de infauna uit de 2016 monstercampagne $\quad 18$

$\begin{array}{lll}\text { 4.3.1 Aantal soorten } & 18\end{array}$

$\begin{array}{lll}\text { 4.3.2 Dichtheid } & 19\end{array}$

$\begin{array}{ll}\text { 4.3.3 Taxonomische samenstelling } & 20\end{array}$

$\begin{array}{lll}4.4 & \text { Vergelijkingen tussen monsterjaren en locaties } & 22\end{array}$

$\begin{array}{lll}4.4 .1 & \text { Soortendiversiteit } & 22\end{array}$

$\begin{array}{lll}\text { 4.4.2 Dichtheid } & 23\end{array}$

4.4.3 Taxonomische samenstelling $\quad 24$

4.4.4 Aanwezigheid van de typische (Natura 2000) soorten 25

4.4.5 Bodemgemeenschappen 26

4.4.6 Sedimentsamenstelling en sediment dikte 29

4.4.7 Relaties tussen gemeenschappen en omgevingsfactoren 30

$5 \quad$ Conclusies en aanbevelingen $\quad 32$

$6 \quad$ Kwaliteitsborging $\quad 35$

$\begin{array}{llr}7 & \text { Literatuur } & 36\end{array}$

$8 \quad$ Verantwoording $\quad 37$

$\begin{array}{llr}9 & \text { Bijlagen } & 38\end{array}$ 


\section{$1 \quad$ Samenvatting}

Dit rapport biedt een overzicht van de resultaten uit een monstercampagne m.b.t. infauna en sediment. De monitoring is uitgevoerd in 2016 naar aanleiding van de vooroeververdedigingen bij locaties Burghsluis, Schelphoek en Zierikzee die daar hebben plaats gevonden.

De monitoring heeft als doel de sedimentatiesnelheid waar te nemen na de bestortingen van 2009 en 2014, en de dikte en samenstelling (korrelgrootte) van de sedimentafzetting te karakteriseren op de verschillende locaties. Waarnemingen met betrekking tot de kolonisatie van deze sedimentafzetting door mogelijk ook kenmerkend Natura 2000 soorten van het habitattype 1160 van de Oosterschelde behoren ook tot doel van de monitoring.

De infauna (in/op de bodem levende fauna die op $1 \mathrm{mmm}$ maaswijdte zeef achterblijft) en sediment karakteristieken zijn bepaald door bemonsteringen van het zachte substraat. Bemonstering van ondiepe stations is duikend uitgevoerd m.b.v. steekbuizen, in drie diepte zones: 0-5, >5-10, >10-20 meter - NAP. De diepere stations (>15 meter - NAP) zijn bemonsterd met behulp van een Van Veen happer vanaf een schip.

Op basis van de huidige waarnemingen kan geconcludeerd worden dat, met betrekking tot de sedimentatie, op sommige locaties zoals Schelphoek-oost, Schelphoek-west II en Zierikzee, al twee jaar na een bestorting voldoende sediment is opgehoopt voor de ontwikkeling van bodemdiergemeenschappen. Op andere locaties, zoals Schelphoek-midden, loopt het afzetten van sediment langzamer. De sedimentafzettingen blijken in het algemeen vrij slibrijk te zijn.

Evenals het sedimentatieproces vertoont de kolonisatie van het sediment door bodemdieren sterke verschillen tussen de onderzochte locaties. Waar in Schelphoek-oost, Schelphoek-west II en Zierikzee bodemdiergemeenschappen zich ontwikkelen die zeer vergelijkbaar zijn met de gemeenschappen die aanwezig waren voor de bestorting, loopt de kolonisatie van de slibrijke sedimentlaag op andere locaties, zoals Burghsluis, achter.

De resultaten laten geen stelselmatige verschuiving zien in de taxonomische samenstelling van de bodemdiergemeenschap. Het is dus niet mogelijk om, op de tijdschaal van jaren, een taxonomische groep aan te wijzen die selectief bevorderd zou zijn door het beschikbaar komen van een nieuwe sedimentafzetting.

Door de relatieve lage dichtheden waarmee de meeste kenmerkende N2000 soorten in de monsters voorkomen, behoren waarnemingen van deze soorten tot de toevaltreffers. Daardoor valt er dus over de afwezigheid van die soorten in de monsters van een locatie weinig zinvols te concluderen met betrekking tot die locatie.

Ook vinden ontwikkelingen in bodemdiergemeenschappen plaats zoals een explosieve toename in individuele dichtheid (vooral bij Oligochaeta) in Schelphoek-midden en Zierikzee respectievelijk vijf en zeven jaar na de bestorting, die de interpretatie van de veranderingen i.r.t. de ingrepen sterk kan bemoeilijken.

Deze bevindingen laten zien hoe moeilijk het is om veranderingen en/of verschillen kwantitatief te detecteren. Om het onderscheidend vermogen van de monitoring te verhogen worden de volgende aanpassingen van het monitoringsprogramma aanbevolen:

- meerjarige monitoringsopzet in tijd en ruimte waarmee de response van het benthos op de ingreep afgewogen kan worden tegenover de natuurlijke bronnen van variatie.

- $\quad$ homogene bemonsteringsmethodes

- $\quad$ het gebruik van replica's op elke monsterlocatie 
De omvang en samenstelling van de sedimentafzetting op de bestortingen blijken zeer variabel te zijn op de verschillende locaties en dieptes, waardoor geen eenduidige beeld uit die gegevens te halen valt. Rekening houdend met het belang van de bodemkarakteristieken voor de vestiging van bodemdieren is een beter begrip van de processen die de sediment accumulatie en erosie aansturen een vereiste voor de correcte interpretatie van de waarnemingen en het eventueel formuleren van voorstellen voor aanvullende maatregelen. 


\section{$2 \quad$ Inleiding}

\section{$2.1 \quad$ Achtergrond}

Sinds 2009 worden op verschillende locaties in de Ooster- en Westerschelde

dijkversterkingswerkzaamheden uitgevoerd waarbij de vooroever (het deel onder water) is voorzien van een bestorting. De vooroeverbestortingen worden uitgevoerd in zogenaamde "clusters" die de fasering van de uitvoering vertegenwoordigen: Cluster 1 (2009-2010), Cluster 2 (2011-2014) en Cluster 3 (gepland in 2017/2018) (Figuur 1). Voor de vooroeverbestortingen is tot nu toe gebruik gemaakt van staalslakken, breukstenen en zeegrind.

In de periode 2009-2015 is monitoring uitgevoerd om de ontwikkeling van levensgemeenschappen op de harde en in de zachte substraten na de vooroeververdediging te volgen. Tevens zijn in deze periode gehalten aan zware metalen gemeten in o.a. mosselen, oesters en wieren op verschillende locaties in de Oosterschelde en Westerschelde met het oog op mogelijke uitloging van deze stoffen uit staalslakken en breukstenen.

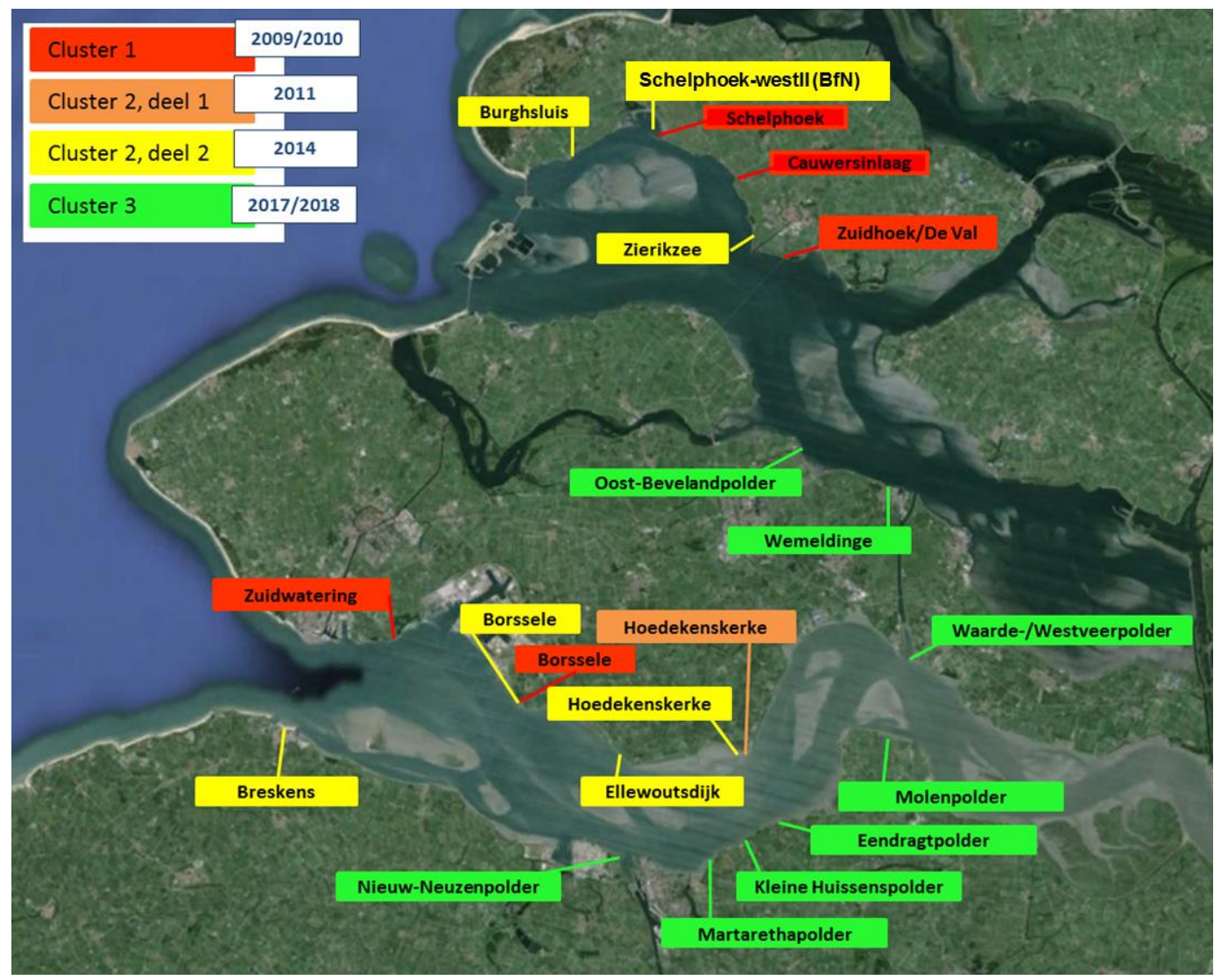

Figuur 1. Vooroeverbestortingen die zijn uitgevoerd (rood, geel en oranje) en gepland staan (groen) in de Ooster- en Westerschelde. De in dit rapport beschreven resultaten betreft monitoring van de locaties bij Schelphoek (bestort in 2009/2010), Schelphoek-west II (Building for Nature locatie), Zierikzee en Burghsluis (de laatste drie bestort in 2014) in de Oosterschelde. 


\section{$2.2 \quad$ Aanleiding}

Rijkswaterstaat wil aanvullende maatregelen nemen om het ecologische herstel van verdedigde vooroevers te verbeteren door het aanbrengen van een zogenaamde 'eco-toplaag'. Deze toplaag is gepland om aangebracht te worden op een aantal reeds verdedigde locaties langs de zuidkust van Schouwen-Duiveland, te weten:

- de vooroevers bij locaties Burghsluis, Schelphoek en Zierikzee (Figuur 1). Deze zijn verdedigd in 2014. Voor deze vooroeververdediging is gebruik gemaakt van zeegrind en breuksteen. Bij locatie Schelphoek-west II is in het kader van een 'Building for Nature' project zeegrind, zandsteen en breuksteen gestort (Bijlage 2).

- $\quad$ de vooroever bij locatie Schelphoek (Figuur 1). Deze is verdedigd in 2009. Hierbij is gebruik gemaakt van staalslakken en breuksteen.

Het toekomstig conceptontwerp van deze eco-toplaag voor de studielocaties is opgenomen in $\mathbf{B} \mathbf{i j l a g e}$ 1.

\subsection{Doel van de monitoring}

Omdat de Oosterschelde een Natura 2000 gebied is, is een passende beoordeling nodig om effecten van de nieuw aangebrachte vooroevers (inclusief ecotoplaag) te kunnen beoordelen. Daarom heeft Rijkswaterstaat aan Wageningen Marine Research gevraagd om onderzoek te doen naar de huidige natuurwaarden van de hierboven vermelde studielocaties, met focus op de benthische macrofauna van het zachte substraat (infauna). Hiertoe is de aanwezigheid van sediment, de karakteristieken ervan en de bodemlevensgemeenschappen (infauna) op de desbetreffende locaties gemonitord.

Meer in detail heeft het huidige project als doel de volgende karakteristieken te bepalen op de vooroevers van de Oosterschelde locaties Burghsluis, Schelphoek, Schelphoek-westl I, Zierikzee en de referentielocatie Schelphoek-ref:

a. Sedimentdikte op Cluster 1 locatie Schelphoek en Cluster 2.2 locaties Burghsluis, Schelphoek-west II en Zierikzee in de Oosterschelde, inclusief een referentielocatie;

Vraag: Hoe snel treedt sedimentatie op de verschillende locaties na de bestortingen van 2009 en 2014 in vergelijking met de referentielocatie?

b. Korrelgrootte (D50 methode) en slibgehalte $(<63 \mu \mathrm{m})$ van sediment op Cluster 1 locatie Schelphoek en Cluster 2.2 locaties Burghsluis, Schelphoek-west II en Zierikzee in de Oosterschelde, inclusief een referentielocatie;

Vraag: Wat is de kwantiteit (sedimentdikte) en de kwaliteit (korrelgrootte en slibgehalte) van het gesedimenteerd materiaal op de verschillende locaties ?

C. Infaunagemeenschappen in sediment op Cluster 1 locatie Schelphoek en Cluster 2.2 locaties Burghsluis, Schelphoek-west II en Zierikzee in de Oosterschelde, inclusief een referentielocatie;

Vraag: Heeft rekolonisatie van zacht substraat plaats gevonden na de bestortingen van 2009 en 2014 ? Zo ja, welke soorten zijn voornamelijk aanwezig/dominant in vergelijking met de $\mathrm{T}=0$ situatie (vóór de bestortingen) en referentielocatie ?

Vraag: Welke van de waargenomen zacht substraat soorten zijn ook kenmerkende Natura 2000

soorten van het habitattype 1160 van de Oosterschelde? 


\section{Methoden}

\subsection{Bemonstering en locaties}

\subsubsection{Monsterlocaties}

Vanaf 2009 zijn verschillende stortlocaties gemonitord zowel in de Oosterschelde als in de Westerschelde (Figuur 1). In 2016 zijn vier stortlocaties onderzocht, te weten Burghsluis (Figuur 2), Schelphoek-west II (Figuur 3), Schelphoek (Figuur 3) en Zierikzee (Figuur 4) en een referentielocatie Schelphoek-ref (Figuur 3). De monitoring is gericht op:

- Infauna en sedimentkarakteristieken: infauna bemonstering in drie diepte zones (0-5, >5-10, >10-20 meter-NAP). Bemonstering van het zachte substraat is al duikend uitgevoerd m.b.v. steekbuizen. Bodemmonsters zijn gebruikt om in/op de bodem levende macrofauna soorten (bodemfauna die op een zeef met een maaswijdte van $1 \mathrm{~mm}$ achterblijft) te karakteriseren. Ook zijn sedimentkarakteristieken bepaald. Daarnaast zijn tevens diepere stations bemonsterd (>15 meter - NAP) met behulp van een Van Veen happer vanaf een schip.

- Sedimentdikte bepalingen: sedimentdikte is bepaald langs raaien door vanaf de waterlijn tot ca. 15 meter diepte iedere $50 \mathrm{~cm}$ in de waterbodem te prikken met een maatstok en de dikte van de sedimentlaag op het harde substraat te noteren.

Tabel 1. Overzicht van het bemonsteringsplan van de monitoringslocaties in 2016: Burghsluis, Schelphoekwest II, Schelphoek, Zierikzee en Schelphoek-ref. De cijfers geven het aantal monsters aan die genomen zijn.

$\diamond=$ sedimentdikte is bepaald vanaf de laagwaterlijn tot circa 15 meter diepte

De geel arceerde vakken geven de monsters aan die in het kader van het RAAKPRO Building for Nature project zijn genomen (apart onderzoekstraject, Tangelder et al. 2017).

\begin{tabular}{|c|c|c|c|c|c|c|c|c|c|c|}
\hline Locatie & Burghsluis & \multicolumn{4}{|c|}{$\begin{array}{l}\text { Schelphoek-west II } \\
\text { (BFN) }\end{array}$} & \multicolumn{3}{|c|}{ Schelphoek } & Zierikzee & Schelphoek-ref \\
\hline Jaar van bestorting & 2014 & \multicolumn{4}{|c|}{2014} & \multicolumn{3}{|c|}{$2009 / 2010$} & 2014 & Niet recentelijk \\
\hline Bestortingsmateriaal* & Zeegrind & \multicolumn{4}{|c|}{$\begin{array}{c}\text { Zeegrind, zandsteen, } \\
\text { breuksteen }\end{array}$} & \multicolumn{3}{|c|}{ Staalslakken } & Zeegrind & Oude bestorting \\
\hline Deellocaties raaien & & 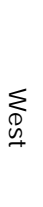 & $\begin{array}{l}\sum_{0} \\
0 \\
0 \\
1 \\
3 \\
\frac{0}{0} \\
\frac{0}{0} \\
\frac{1}{3}\end{array}$ & $\begin{array}{l}0 \\
0 \\
0 \\
1 \\
3 \\
3.0 \\
\frac{0}{0} \\
\frac{0}{3}\end{array}$ & O & $\sum_{\substack{\infty \\
\swarrow}}$ & $\begin{array}{l}\frac{3}{0} \\
\frac{0}{0} \\
\frac{1}{1}\end{array}$ & $\begin{array}{l}\text { O } \\
\text { पn }\end{array}$ & & \\
\hline \multicolumn{11}{|l|}{$\begin{array}{l}\text { Diepten (m-NAP) } \\
\text { steekbuis infauna en } \\
\text { sedimentkarakteristieken } \\
\text { transect }\end{array}$} \\
\hline $0-5$ & 1 & 2 & & 1 & 2 & 1 & 1 & & 1 & 1 \\
\hline$>5-10$ & 1 & & 2 & 1 & & 1 & 1 & & 1 & 1 \\
\hline$>10-20$ & 1 & 2 & 2 & 1 & 2 & 1 & 1 & & 1 & 1 \\
\hline \multicolumn{11}{|l|}{$\begin{array}{l}\text { Diepte Van Veen happen } \\
\text { (m - NAP) }\end{array}$} \\
\hline Ca $20-40$ & 3 & & & & & 3 & 1 & 5 & & 3 \\
\hline \multicolumn{11}{|l|}{$\begin{array}{l}\text { Diepte (m-NAP) } \\
\text { sedimentdikte transect }\end{array}$} \\
\hline $0-20$ & $\diamond$ & $\diamond$ & $\diamond$ & $\diamond$ & $\diamond$ & $\diamond$ & $\diamond$ & & & $\diamond$ \\
\hline
\end{tabular}

* Alle ondiepe stations op 0-5 meter - NAP van de verdedigde vooroevers betreffen breuksteen.

In Tabel 1 is een overzicht gegeven van de in 2016 bemonsterde locaties met een weergave van het aantal monsters per dieptezone. De bemonsteringen die in het kader van het RAAKPRO Building for Nature project zijn uitgevoerd worden ook hier gerapporteerd. Hieronder worden de karakteristieken van elke monitoringslocatie weergegeven: 
Locatie Burghsluis (Figuur 2): hier is eind 2014 de vooroever versterkt met zeegrind. In de golfzone en de intergetijdenzone is de vooroever verzwaard met breukstenen. In 2010 heeft een T0 monitoring van infauna op deze locatie plaatsgevonden. In 2016 zijn er infauna monsters genomen m.b.v. steekbuizen en er zijn monsters genomen met een Van Veen happer vanaf een schip (Bijlage 1).

Locatie Schelphoek-west II (Figuur 3): hier is eind 2014 de vooroever versterkt met zeegrind. In de golfzone en de intergetijdenzone is de vooroever verzwaard met breukstenen. Op het zeegrind zijn zogenaamde 'ecoriffen' aangebracht van zandsteen en breuksteen. De kolonisatie en ontwikkeling van deze riffen is gevolgd vanuit het RAAKPRO Building for Nature project. De resultaten zijn apart gerapporteerd in Tangelder et al. (2017). In Bijlage 2 is het oorspronkelijk ontwerp van de 'ecoriffen' opgenomen. In 2010 heeft een T0 monitoring plaatsgevonden op deze locatie en in 2014 heeft ook monitoring van infauna op deze locatie plaatsgevonden. In 2016 zijn er infauna monsters genomen m.b.v. steekbuizen en er zijn monsters genomen met een Van Veen happer vanaf een schip

Locatie Schelphoek-west/midden/oost (Figuur 3): hier is in 2009/2010 de vooroever bestort met staalslakken. In de golfzone en de intergetijdenzone is de vooroever verzwaard met breukstenen. Bij locatie Schelphoek-midden is de kreukelberm verlengd en liggen tot circa 7-8 meter diepte breukstenen op de staalslakken. In 2009 (T0), 2010, 2011 en 2014 heeft ook monitoring van infauna op deze locatie plaatsgevonden. Ondiepe locaties werden bemonsterd door duikers m.b.v. steekbuizen langs een transect dwars op de kustlijn (0-5m - NAP, >5-10m - NAP en >10-20 m - NAP). In 2016 zijn er infauna monsters genomen m.b.v. steekbuizen en er zijn monsters genomen met een Van Veen happer vanaf een schip (Bijlage 1 ).

Locatie Zierikzee (Figuur 4): hier is eind 2014 de vooroever versterkt met zeegrind. In de golfzone en de intergetijdenzone is de vooroever verzwaard met breukstenen. In 2010 (T0) en 2013 ( $2^{\mathrm{e}}$ T0) heeft ook monitoring van infauna op deze locatie plaatsgevonden (Bijlage 1). In 2016 zijn er infauna monsters genomen m.b.v. steekbuizen

Referentielocatie Schelphoek-ref: om rekening te kunnen houden met autonome veranderingen in de Oosterschelde die niets te maken hebben met het wel/niet aanbrengen van vooroeververdedigingen is de referentielocatie "Schelphoek-ref" ten oosten van Schelphoek gemonitord (20-40m-NAP). Op deze locatie heeft geen bestorting plaats gevonden. (Figuur 3). 


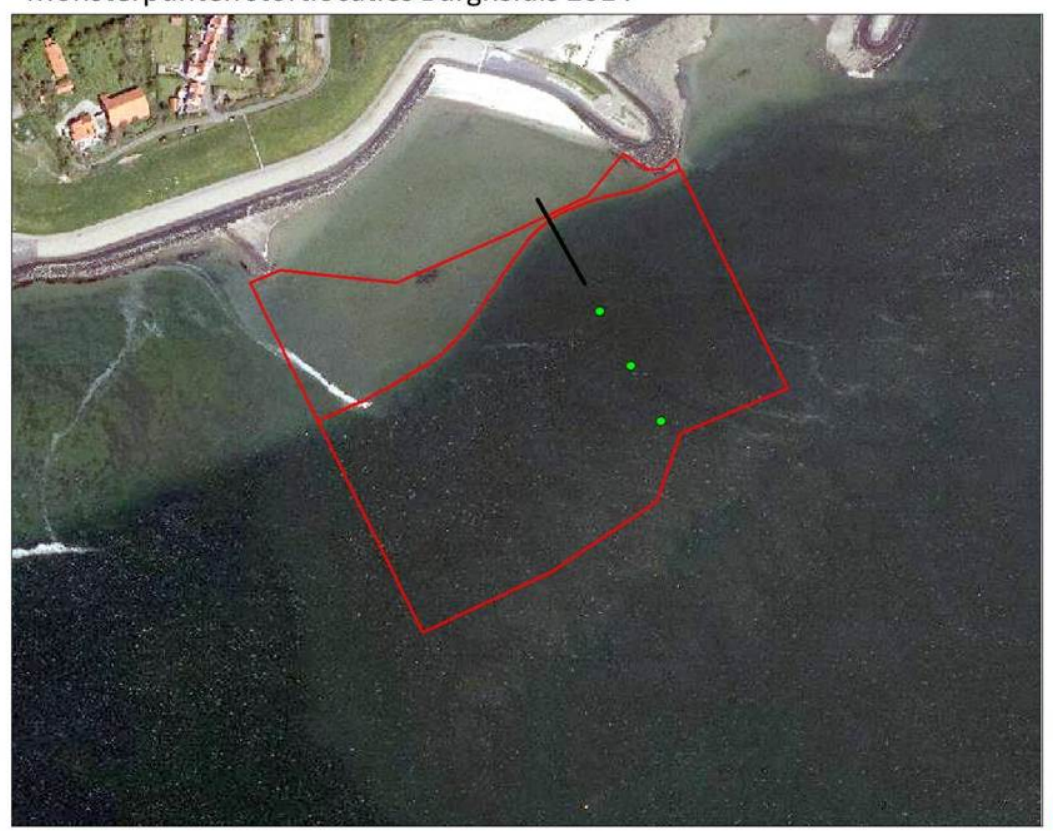

Figuur 2. De vooroever bij Burghsluis (bestort in 2014). De rode lijn geeft de begrenzing van het stortvak aan. De zwarte lijn vertegenwoordigd het transect waar op drie dieptezones met steekbuizen is bemonsterd door duikers: 0-5m - NAP, >5-10m - NAP en >10-20 m - NAP. De groene stippen geven de plekken aan waar de monsters genomen zijn met een Van Veen happer vanaf een schip. Bron: Robert Jentink, Rijkswaterstaat.

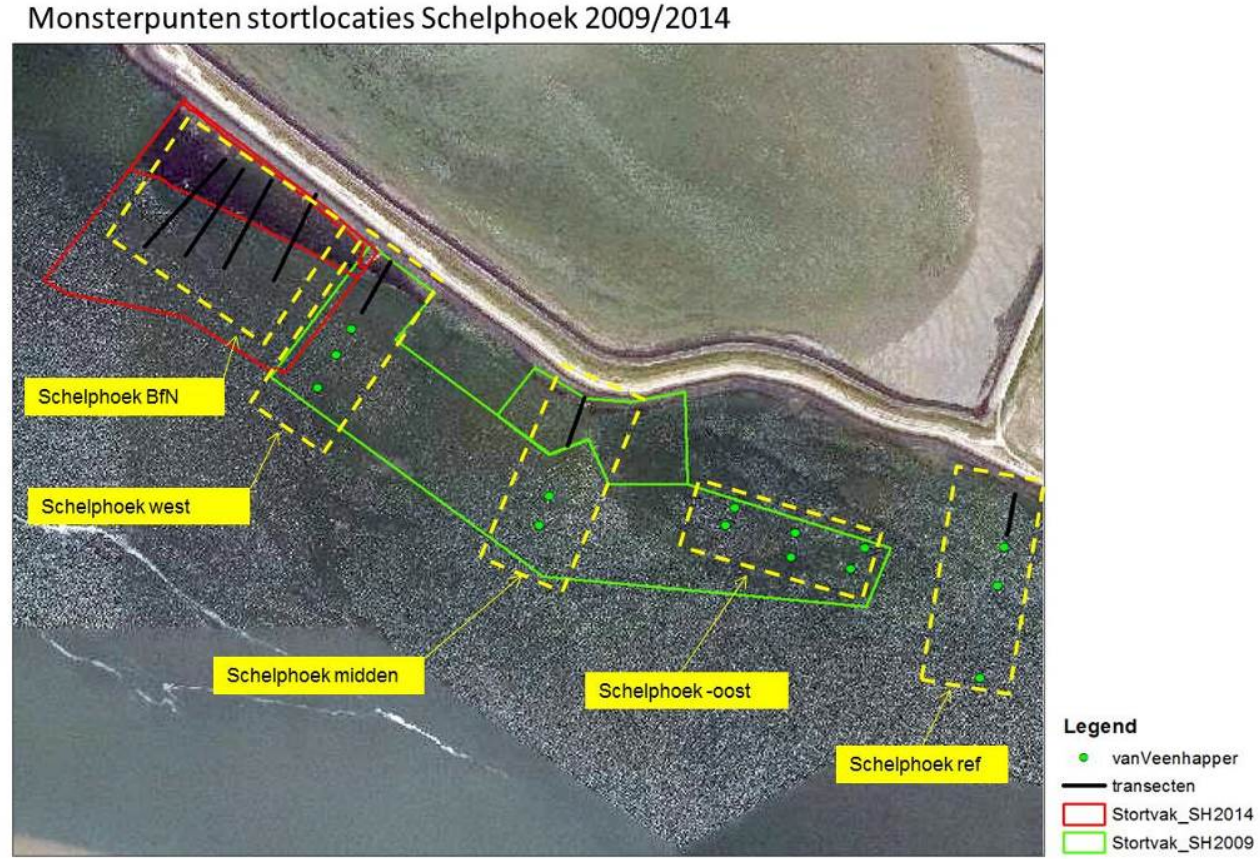

Figuur 3. De vooroever bij Schelphoek. De rode lijn geeft de begrenzing aan van het stortvak van de Building for Nature locatie Schelphoek-west II (bestort in 2014) en de groene lijn van locatie Schelphoek (bestort in 2009, onderverdeeld in Schelphoek west, midden en oost) en de referentielocatie (Schelphoek ref) die niet recentelijk is bestort. De gele labels en arcering geven de monsterlocaties aan. De zwarte lijnen vertegenwoordigen transecten waar op drie dieptezones in de vijf monsterlocaties met steekbuizen is bemonsterd door duikers: 0-5m - NAP, >5-10m - NAP en >10-20 m - NAP. De groene stippen geven de plekken aan waar de monsters genomen zijn met een Van Veen happer vanaf een schip. Bron: Robert Jentink, Rijkswaterstaat. 
Monsterpunten stortlocaties Zierikzee 2014

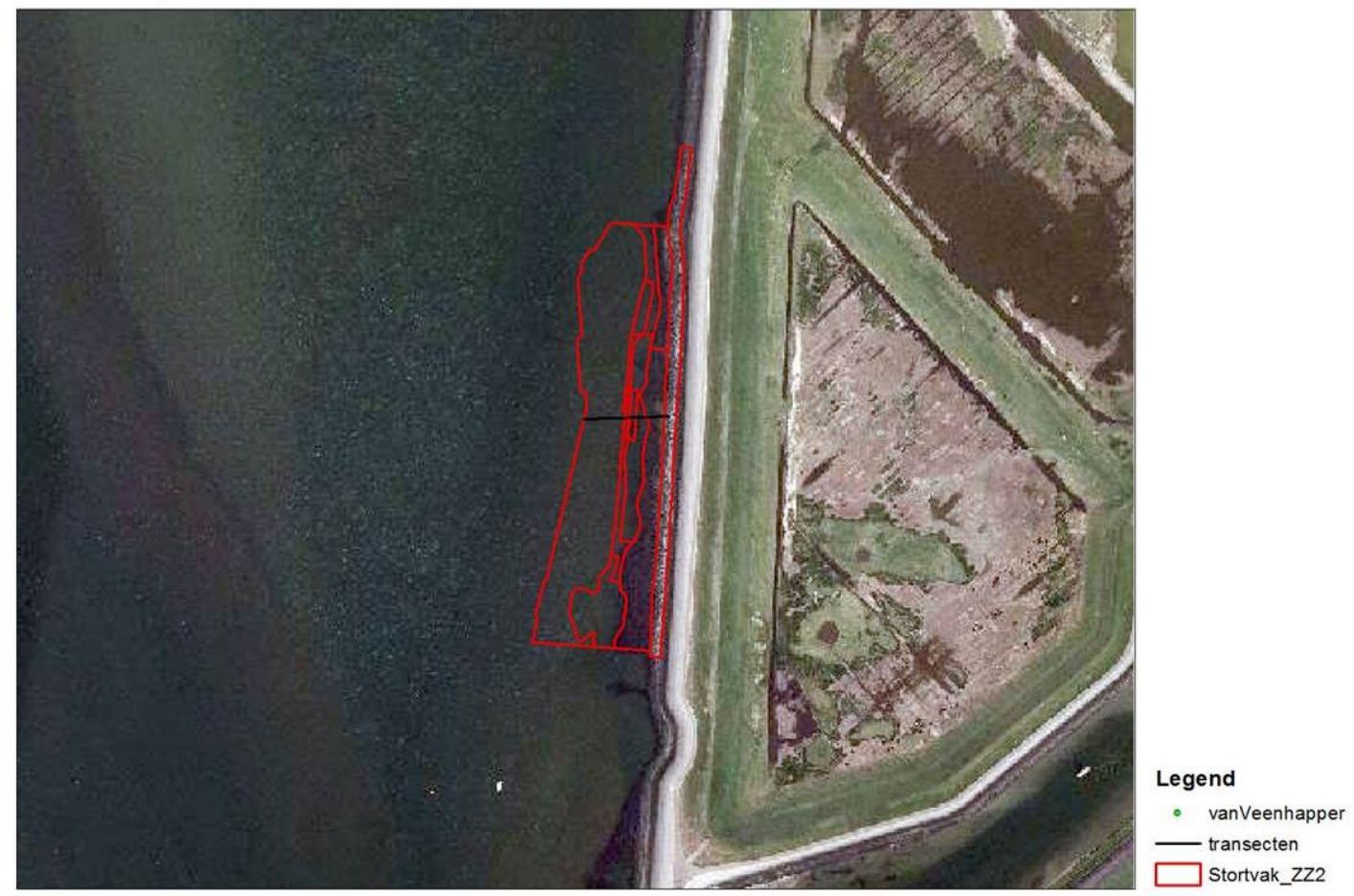

Figuur 4. De vooroever bij Zierikzee (Cluster 2). De rode lijn geeft de begrenzing van het stortvak aan. De zwarte lijn vertegenwoordigd het transect waar op drie dieptezones met steekbuizen is bemonsterd door duikers: 0-5m - NAP, >5-10m - NAP en >10-20 m - NAP. Bij locatie Zierikzee zijn geen Van Veen happen genomen. Bron: Robert Jentink, Rijkswaterstaat.

\subsubsection{Bemonsteringstechnieken}

\section{Bemonstering met steekbuizen}

De bemonstering met steekbuizen is duikend uitgevoerd door Stichting Zeeschelp op drie diepten per locatie (Tabel 1). Omdat er op uiteenlopende diepten is bemonsterd omwille van duik-technische redenen, zijn diepten ingedeeld in drie diepten klassen, 0-5m, 5-10m en 10-20m, zodat vergelijking makkelijker is. Bij de referentielocatie Schelphoek-ref hebben nooit vooroeverbestortingen plaatsgevonden. Op deze locatie zijn ook drie diepten bemonsterd. De bemonsteringen zijn uitgevoerd in augustus en september 2016. Bij elke locatie en op elke diepte is één monster genomen bestaande uit zes steekbuizen ( $65 \mathrm{~mm}$ diameter) met een totaal oppervlak van $0,02 \mathrm{~m}^{2}$. Voorwaarde voor bemonstering is dat de te bemonsteren laag sediment minimaal $30 \mathrm{~cm}$ dik is (lengte van de steekbuis). De monsters zijn vervolgens over een $1 \mathrm{~mm}$ zeef gezeefd en gefixeerd met borax gebufferde formaline (4\%). Voor verdere details over de methodiek zie De Kluijver et al. (2012).

\section{Bemonstering met Van Veen happer}

Op de diepere stations (>-15 m N.A.P.) is met behulp van een Van Veen happer vanaf een schip sediment bemonsterd op 15 stations (Tabel 1). De bemonstering is uitgevoerd in september 2016. Per station is een Van Veen hap genomen t.b.v. infauna analyse en sediment karakterisering (voor beschrijving methode, zie 3.3). Het bemonsterde oppervlakte van de Van Veen happer is $0,1 \mathrm{~m}^{2}$. Bij een niet geslaagde hap zijn tot 3 pogingen gedaan om een goed sediment monster te verkrijgen. Als na drie pogingen geen geschikt monster verkregen kon worden is genoteerd wat de reden is waarom er geen geschikt monster genomen kon worden (te weinig sediment aanwezig, te veel kiezels/grind in de happer, e.d.) en het station verlaten. Bij de huidige analyse is aangenomen dat de monsters genomen met de Van Veen happer een effectieve oppervlakte hebben van $0,1 \mathrm{~m}^{2}$ (=nominale oppervlakte).

Het gebruik van twee verschillende bemonsteringstechnieken verhindert een directe vergelijking tussen monsters uit het ondiepe en diepe deel m.b.t. het aantal soorten en de bodemdieren dichtheden:

- de trefkans van een bepaalde soort, inverse functie van de dichtheid, neemt toe van het monsteroppervlak van $0,02 \mathrm{~m}^{2}$ met de steekbuizen naar $0,1 \mathrm{~m}^{2}$ met de Van Veen happer. 
- de kans om meer soorten waar te nemen neemt toe met het aantal individuen in een monster.

In Bijlage 3 zijn de resultaten van een verkennende studie naar de effecten van de monstertuigen op de waarnemingen weergegeven. Daaruit blijkt dat het gebruik van twee verschillende monstertuigen (Van Veen happer en steekbuizen) tot verschillen in aantal soorten kan leiden waardoor de huidige vergelijkingen beperkt moeten worden tot monsters verkregen uit dezelfde monstertuigen. Deze beperking is bedoeld om verwarring tussen bemonsteringsartefact en ecologisch signaal te vermijden.

\subsection{Identificatie van infauna soorten}

Infauna is hier gebruikt een verzamelnaam voor dieren die in of op zachte bodems leven (Figuur 5). De monitoring richt zicht op de aanwezige macrofauna $(>1 \mathrm{~mm}$ ) in het sediment dat is neergeslagen op de nieuwe bestorting.

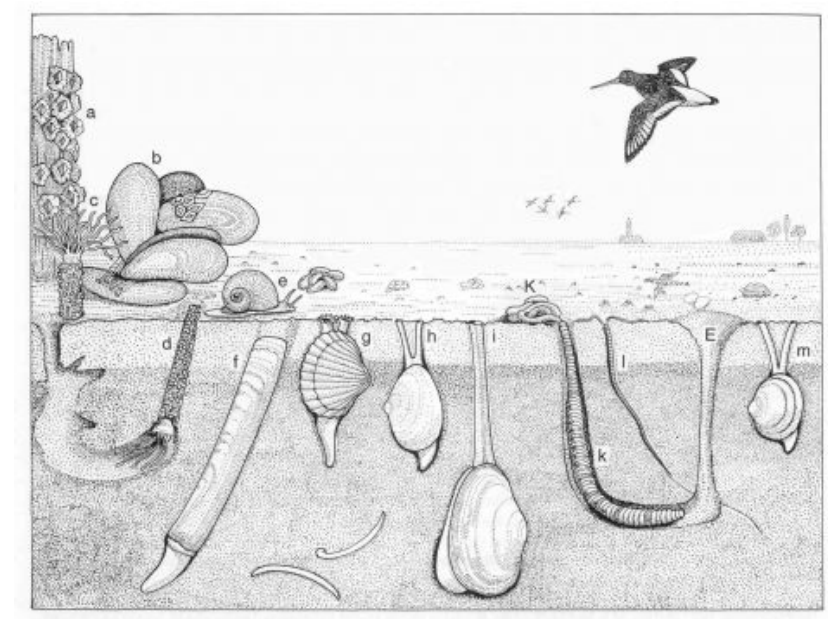

Figuur 5. Infauna zijn bodemdieren die leven in/op "zacht substraat" van bijvoorbeeld zand of slib (bron: www.senckenberg.de).

\subsubsection{Taxonomische identificatie}

Het uitzoeken van de monsters en determinatie van soorten heeft plaatsgevonden in het laboratorium van Wageningen Marine Research in Yerseke. De organismen in de monsters zijn geïdentificeerd, waar mogelijk tot op soort niveau, en geteld om de dichtheden te kunnen bepalen. Door de manier van bemonsteren kan het voorkomen dat fragmenten van een organisme aanwezig zijn in het monster, vooral wat betreft wormen. Alleen wormfragmenten met een kop worden gebruikt ter bepaling van de dichtheid.

De monitoring vindt plaats in de maanden augustus/september wanneer veel organismen in juveniele stadia aanwezig zijn. Hierdoor is het niet altijd mogelijk om de organismen tot soort niveau op naam te brengen. In dit geval is er een hoger taxonomisch niveau gehanteerd. Van de soorten Capitella capitata en Polycirrus spp. zijn voornamelijk juveniele en half volwassen exemplaren aangetroffen (met een lengte van $1 \mathrm{~cm}$ of kleiner daar waar volwassen exemplaren 3-4 cm in lengte zijn). Mediomastus fragilis is in het verleden niet onderscheiden van kleine exemplaren van Heteromastus. In dit rapport zijn beide soorten als Heteromastus filiformis geteld.

Sommige exemplaren bleken lastig tot op soortniveau te determineren:

Abra (spec.): juveniel exemplaar.

- Aoridae: kan het geslacht Aora of Microdeutopus zijn.

- Arenicola: de soortnaam kan niet geïdentificeerd worden als de kop, of een stukje van de kop, ontbreekt; waarschijnlijk Arenicola marina.

- Actinaria: ordeniveau voor alle anemonen, hiervoor is geen determinatie op soortsniveau gebeurd.

- Ammothea: juveniel exemplaar.

- Ensis (spec.): deze soort kon niet geïdentificeerd worden doordat het juveniele waren of alleen de topjes van de schelp aanwezig waren; hoogstwaarschijnlijk Ensis directus. 
- $\quad$ Eteone (spec.): kleine en incomplete exemplaren.

- Glycera tridactyla: verwisseling mogelijk met Glycera alba.

- Glycera (spec.): juveniele stadia en incomplete exemplaren .

- Hesionidae: juveniele stadium. Alleen Kefersteinia cirrata gevonden.

- Hemichordata, moeilijk te determineren, mogelijk gaat het om Saccoglossus spec.

- Microdeutopus (spec.): de identificatie sleutel geeft alleen kenmerken van volgroeide mannelijke exemplaren. Als er een juveniel of vrouwtje aantroffen wordt kan, deze niet geïdentificeerd worden; alleen Microdeutopus anomalus gevonden.

- Neoamphitrite (spec.): incompleet exemplaar, waarschijnlijk Neoamphitrite figulus.

- Nephtys (spec.): klein exemplaar.

- Polycirrus (spec.): juveniele exemplaren.

- Polynoidae: juveniele en incomplete exemplaren.

- $\quad$ Ruditapes philippinarum: bij kleine exemplaren verwisseling met Ruditapes decussatus mogelijk, deze zijn aangeduid als "spec".

- Sabella (spec.): in juveniele stadia zijn soorten van dit genus zeer lastig te onderscheiden.

Een andere reden waarom sommige organismen niet op soortniveau gebracht konden worden, is dat er soms te weinig kenmerken ontwikkeld of aanwezig zijn waardoor er wel gezien wordt dat ze tot hetzelfde hogere taxonomische niveau behoren maar niet onderscheiden kunnen worden op soortniveau:

\section{- $\quad$ AMPHIPODA}

- $\quad$ Eumida (spec.) kan de soort Eumida sanguinea of Eumida bahusiensis zijn.

- $\quad$ Eteone (spec.): kan de soort Eteone longa, Eteone flava of Eteone foliosa zijn.

- Eteoninae: kan het genus Eteone, Hesionura, Eulalia of Eumida zijn.

- $\quad$ Nephtys (spec.): kan de soort Nephtys caeca, Nephtys cirrosa, Nephtys longosetosa of Nephtys hombergii zijn.

- Ophiuroidae: kan het genus Ophiura of Ophiotrix zijn.

- Oligochaeta, Caprellidae, Nemertea, Ostracoda en Tanaidacea worden niet op soortnaam gebracht.

- $\quad$ Anemonen, viltkokeranemoon (Cerianthus lloydii), slibanemoon (Sagartia troglodytes) en eventueel andere soorten benoemen we tot Actiniaria.

Ook zijn er kolonievormende zakpijpen aangetroffen, maar omdat deze soorten op hardsubstraat leven en dus niet tot de infauna behoren, zijn deze niet meegenomen in de analyses. Verschillende organismen hebben recentelijk een nieuwe benaming gekregen. Om de correcte benaming te hanteren controleren we deze in WoRMS (www.marinespecies.org/). In Tabel 2 is een overzicht gegeven van de meest recente en correcte benamingen die voor deze rapportage zijn gehanteerd.

Tabel 2. Soorten die recent een nieuwe benaming hebben gekregen (check: 16 juni 2015)

\begin{tabular}{|l|l|}
\hline Oude benaming & $\begin{array}{l}\text { Nieuwe } \\
\text { geaccepteerde } \\
\text { benaming }\end{array}$ \\
\hline Autolytus (spec.) & Myrianida (spec.) \\
\hline Autolytus edwardsi & Myrianida edwardsi \\
\hline Corophium sextonae & Monocorophium sextonae \\
\hline Melita obtusata & Abludomelita obtusata \\
\hline Nereis diversicolor & Hediste diversicolor \\
\hline Nereis longissima & Eunereis longissima \\
\hline Nereis virens & Alitta virens \\
\hline
\end{tabular}

\begin{tabular}{|l|l|}
\hline Oude benaming & $\begin{array}{l}\text { Nieuwe } \\
\text { geaccepteerde } \\
\text { benaming }\end{array}$ \\
\hline Ruditapes spec. & Venerupis (Ruditapes) \\
\hline Scolelepis fuliginosa & Malacoceros fuliginosus \\
\hline Scoloplos armiger & Scoloplos (Scoloplos) armiger \\
\hline Terebellidae & Seraphsidae \\
\hline
\end{tabular}

\subsubsection{Analyse van diversiteit, dichtheden en gemeenschappen}

Diversiteit: soortenrijkdom (d.w.z. het aantal soorten/taxa per monster) is gebruikt als een maat voor de diversiteit van de gemeenschap. Voor de interpretatie van de data is het van belang te benadrukken dat de gepresenteerde gegevens gebaseerd zijn op verschillende taxonomische niveaus. In deze analyses heeft een individu geïdentificeerd op soortniveau hetzelfde gewicht als een individu geïdentificeerd op een hoger taxonomisch niveau. De methode voor identificatie is daarom consistent gehouden over de verschillende monitoringsjaren, zodat deze analyses nog steeds relevant zijn. 
Voor de huidige analyse zijn de monsters ingedeeld in drie niveaus van soortendiversiteit: Hoog, Middel en Laag. Het gemiddelde niveau is gekozen als het interkwartiel $(25 \%-75 \%)$ interval van de verdeling van het aantal soorten per monster. Soortendiversiteit boven en onder het interkwartielinterval behoren vervolgens tot de Hoge en Lage niveaus van soortendiversiteit.

Als externe maatlaat voor de interkwartielwaarden is er gebruik gemaakt van de MWTL Oosterschelde 1992-2010 dataset (opgevraagd bij RWS Helpdesk Water). Daar het monsteroppervlak voor MWTL gelijk is met $0,015 \mathrm{~m}^{2}$ wordt de interkwartielbegrenzingen berekend voor monsters van 0,02 en $0,1 \mathrm{~m}^{2}$ door toepassing van een correctie factor $\left(\mathrm{dS}=\mathrm{dA}^{0.4}\right)$ volgens de bevindingen in Escaravage et al. (2009). De interkwartielintervallen zijn berekend als 5 tot 19 soorten voor de steekbuizen monsters en 8 tot 28 soorten voor de van Veen Happer. Deze waarden zijn gebruikt in het vervolg voor het indelen van de monsters in de Hoog, Midden en Laag niveaus van soortendiversiteit.

Dichtheid: De dichtheid van een soort geeft inzicht in de mate waarin de soort voorkomt. De waarnemingen verkregen uit de monsters zijn omgerekend naar aantallen per $\mathrm{m}^{2}$ via de formule: $X=n /(6 \times 0,003318)$ voor de steekbuizen en $X=n / 0,1$ voor de Van Veen happer Hierbij is $X$ de dichtheid uitgedrukt in het aantal individuen per $\mathrm{m}^{2}, \mathrm{n}$ is het aantal individuen per monster en 0,003318 en 0,1 zijn de oppervlakten in $\mathrm{m}^{2}$ van de gebruikte steekbuis (per monster zijn er 6 steekbuizen genomen) en van Veen happer. Voor de huidige analyse zijn de monsters, zoals voor de soortenrijkdom, ingedeeld in drie niveaus van dichtheid: Hoog, Middel en Laag. Omdat dichtheid sterk afhankelijk is van gebied en seizoen is gebruik gemaakt van de verdeling binnen de huidige monstercampagne als maatlaat i.p.v. Het gemiddelde niveau is gekozen als het interkwartiel (25\% 75\%) interval van de verdeling van de dichtheden tussen de monsters. Soortenrijkdom boven en onder het interkwartiel-interval behoren vervolgens tot de Hoge en Lage niveaus van dichtheid.

Aanwezigheid van typische ( Natura 2000) soorten: De aanwezigheid van typische Natura 2000 soorten (lijst in

Bijlage 4) in de monsters is gebruikt als een indicatie voor de kwaliteit van het habitat en de veranderingen daarin tijdens het kolonisatie proces na de bestorting en tussen ongestoorde en verstoorde locaties.

Onderscheid tussen organismen van hard en zacht substraat: De bestorting zorgt voor een verhoogde aanwezigheid van hardsubstraat op de zeebodem wat zou kunnen leiden tot een toename in de aanwezigheid van fauna van hardsubstraat in de monsters met als resultaat een mogelijke toename in de soortendiversiteit die wel anders geïnterpreteerd dient te worden dan wanneer het zou gaan om enkel soorten van zacht substraat.

Gemeenschappen: Om mogelijke veranderingen in de gemeenschappen in kaart te brengen, is een clusteranalyse uitgevoerd op basis van 275 locaties bemonsterd in de periode 2009-2016 in de Oosterschelde en de Westerschelde. De analyses zijn uitgevoerd met de statistische softwarepakketten MVSP (Kovach, 1999), Primer (Clarke \& Gorley, 2006) en Permanova (Anderson et al., 2008). De clusteranalyse ('Average-linkage') is uitgevoerd op de matrix van de 'Bray-Curtis'coëfficiënten berekend tussen de locaties op basis van de logaritmisch getransformeerde dichtheden. Vervolgens is een inverse analyse uitgevoerd waarmee het onderscheid is gemaakt tussen dominante soorten ( $\mathrm{n}>100$ ind. $\mathrm{m}^{-2}$ ), karakteristieke soorten voor een cluster en soorten beperkt tot een cluster (Kaandorp, 1986).

\subsection{Sedimentkarakteristieken}

Op locaties waar infauna is bemonsterd zijn ook de sedimentkarakteristieken bepaald (Tabel 1). De korrelgroottesamenstelling is, ten gunste van de consistentie met voorafgaande jaren, bepaald volgens de standaard methode in gebruik bij Stichting Zeeschelp. De sedimentkarakteristieken van de bovenste centimeter van de sedimentlaag zijn bepaald door monsters te zeven over 7 gekalibreerde zeven (2.8-0.053 mm). De korrelgroottesamenstelling is vervolgens berekend als de relatieve bijdrage van de verschillende fracties aan het totaal drooggewicht uitgedrukt in percentage. 
Omdat de verdeling van de fracties niet normaal bleek te zijn, is op basis van de dominante fracties een typologie voor de bodemsedimenten opgesteld (Tabel 3). Een bimodale verdeling van de korrelgrootte samenstelling (bv. grof en fijn) wordt beschouwd als een teken van verstoring; in dergelijke gevallen wordt het sediment aangeduid als een verstoord "(dis)" grover type.

Tabel 3. Typologie voor de bodemsediment

\begin{tabular}{|c|c|c|c|c|c|c|c|c|}
\hline Type sediment: & $\mathrm{I}$ & II & III & IV & $\mathrm{V}$ & VI & VII & VIII \\
\hline dominante fractie in mm & $>2.8$ & $2.8-1.4$ & $1.4-0.6$ & $0.6-0.3$ & $0.3-0.15$ & $0.15-0.09$ & $0.09-0.05$ & $<0.05$ \\
\hline \multirow[t]{2}{*}{ Benaming } & \multicolumn{2}{|c|}{ schelprest } & zeer & grof zand & fijn zand & zeer & ultra & slib \\
\hline & & & grof zand & & & fijn zand & fijn zand & \\
\hline
\end{tabular}

Naast de korrelgroottesamenstelling zijn in 2011-2015 ook de percentages aan organische en droge stof gemeten. Deze percentages zijn gemeten in de bovenste zes $\mathrm{cm}$ van het bodemsediment, door de monsters te drogen bij $70^{\circ} \mathrm{C}$ (droog) en vijf uur te verassen bij $525 \circ \mathrm{C}$ (organisch). Ook is het zoutgehalte gemeten.

In 2016 zijn op de stations van de vooroeververdediging ook sedimentmonsters verzameld voor analyse uitgevoerd door RWS volgens de eigen gestandaardiseerde protocollen:

- Grootteverdeling minerale fractie 16-2000 $\mu \mathrm{m}$ d.m.v. laserdiffractie.

- Grootteverdeling minerale fractie $<16 \mu \mathrm{m}$ d.m.v. gravimetrie.

- Gehalte aan humus (gelbstof) d.m.v. waterstofperoxide oxidatie.

- Gehalte aan kalk houdende carbonaten door zoutzuur oplossing.

De resultaten van deze metingen zijn weergegeven in Bijlage $\mathbf{5}$ en Bijlage 6. Deze zijn gebruikt voor een vergelijking tussen de methoden van Stichting Zeeschelp en die van het analytisch lab van RWS

(Bijlage 7). Uit die analyse blijkt een degelijk overeenkomst aanwezig te zijn tussen de korrelgrootte en organische koolstof bepalingen zoals uitgevoerd door Stichting Zeeschelp en door het analytische laboratorium van RWS. Op basis van die vergelijking is de verwachting dat het gebruik van de meetgegevens aangeleverd door Stichting Zeeschelp of van RWS tot vergelijkbare resultaten/conclusies zou moeten leiden voor de huidige studie.

\subsection{Sedimentdikte metingen}

De sedimentdikte is bepaald door tussen 0 en 15 meter - NAP iedere $50 \mathrm{~cm}$ door de waterbodem te prikken met een meetstok en de dikte van het fijne sediment op te meten in een kwadrant van 50x50 cm. Op 6 raaien (Burghsluis, Schelphoek-West II-midden-oost, Schelphoek-west, Schelphoek-midden, Schelphoek-oost-Referentie en Zierikzee, Tabel $\mathbf{1}$ ) is op deze wijze de dikte van de sedimentlaag bepaald. Voor het project RAAKPRO Building for Nature is aanvullend de dikte bepaald op drie andere locaties: Schelphoek-West II-west, Schelphoek-West II-west-midden en Schelphoek-West II-oost (zie Bijlage 4)

\subsection{Werkverdeling}

Voor deze monitoring heeft Stichting Zeeschelp het duikend veldwerk uitgevoerd t.b.v. de bemonstering van infauna, sediment en het meten van de sedimentdikte. De bemonstering met de Van Veen happer is uitgevoerd door Wageningen Marine Research.

De gemeenschapsanalyse voor infaunagemeenschappen is uitgevoerd door Stichting Zeeschelp. De determinatie, dataverwerking en datarapportage voor infauna is uitgevoerd door Wageningen Marine Research. 


\section{$4 \quad$ Resultaten}

\subsection{Monsterlocaties}

Tabel 4 geeft een overzicht van de met steekbuis bemonsterde locaties in 2016 en geeft aan welke vergelijkingen gemaakt kunnen worden tussen locaties die door de jaren heen bemonsterd zijn met betrekking tot de effecten van de vooroeververdediging op de bodemdieren. De naast elkaar liggende monsterlocaties 'Schelphoek-west II BFN midden-oost' (2016) en 'Schelphoek-west II' (2010, 2014) worden onderling vergeleken.

Tabel 4. Monstercodes van de locaties bemonsterd m.b.v. steekbuizen in 2016. Ti: aantal jaren tussen bemonstering en bestorting ( $T X>1$ jaar voor een bestorting, T0 kort ervoor, Ti met i voor het aantal jaren erna) en [INFnnn] de codering voor de locaties bemonsterd met behulp van steekbuizen tussen 2009 en 2016. De arceringen wijzen op de monsters die bruikbaar zijn voor een vergelijking tussen 2016 en eerdere jaren. De niet eerder bemonsterde locatie Schelphoek-west II BFN midden-oost is vergeleken met de dichtbij gelegen locatie Schelphoek-west II (2010-2014). Met grijs lettertype de niet bemonsterde locaties of locaties zonder infauna (zie tekst). De rode dubbellijnen staan voor de bestortingen.

\begin{tabular}{|c|c|c|c|c|c|c|c|}
\hline Locaties & $\begin{array}{l}\text { Diepte } \\
\text { Klasse }\end{array}$ & 2009 & 2010 & 2011 & 2013 & 2014 & 2016 \\
\hline Burghsluis & $00 \quad 05$ & & $\begin{array}{c}\text { TX } \\
{[\text { INF19] }}\end{array}$ & & & & $\begin{array}{c}\text { T2 } \\
\text { [I NF245] }\end{array}$ \\
\hline Burghsluis & $05 \_10$ & & $\begin{array}{c}\text { TX } \\
{[\mathrm{INF20]}}\end{array}$ & & & & $\begin{array}{c}\text { T2 } \\
\text { [INF244] }\end{array}$ \\
\hline Burghsluis & 1020 & & $\begin{array}{c}\mathrm{TX} \\
{[\mathrm{INF} 21]}\end{array}$ & & & & $\begin{array}{c}\mathrm{T} 2 \\
\text { [INF243] }\end{array}$ \\
\hline Schelphoek-midden & $00 \quad 05$ & & & $\begin{array}{c}\text { T2 } \\
{[\mathrm{INF65]}}\end{array}$ & & $\begin{array}{c}\text { T5 } \\
\text { [INF161] }\end{array}$ & $\begin{array}{c}T 7 \\
{[\text { INF251] }}\end{array}$ \\
\hline Schelphoek-midden & $05 \quad 10$ & & & & & $\begin{array}{c}\text { T5 } \\
\text { [INF160] }\end{array}$ & \begin{tabular}{|c|} 
T7 \\
[I NF250]
\end{tabular} \\
\hline Schelphoek-midden & 1020 & & & $\begin{array}{c}\text { T2 } \\
\text { [INF64] } \\
\end{array}$ & & $\begin{array}{c}\text { T5 } \\
\text { [INF159] }\end{array}$ & \begin{tabular}{|c|} 
T7 \\
[INF249]
\end{tabular} \\
\hline Schelphoek-oost-ref & $00 \quad 05$ & & & & & & $\begin{array}{c}\text { T7 } \\
\text { [INF248] }\end{array}$ \\
\hline Schelphoek-oost-ref & $05 \_10$ & & & & & & $\begin{array}{c}\mathrm{T} \\
\text { [INF247] }\end{array}$ \\
\hline Schelphoek-oost-ref & 1020 & & & & & & $\begin{array}{c}\text { T7 } \\
\text { [INF246] }\end{array}$ \\
\hline Schelphoek-west & $00 \quad 05$ & $\begin{array}{c}\mathrm{TO} \\
{[\mathrm{INF} 1]}\end{array}$ & & $\begin{array}{c}\text { T2 } \\
{[\text { INF63] }}\end{array}$ & & $\begin{array}{c}\text { T5 } \\
\text { [INF158] }\end{array}$ & $\begin{array}{c}\text { T7 } \\
\text { [INF239] }\end{array}$ \\
\hline Schelphoek-west & $05 \quad 10$ & $\begin{array}{c}\text { T0 } \\
\text { [INF2] }\end{array}$ & & $\begin{array}{c}\text { T2 } \\
\text { [INF62] }\end{array}$ & & $\begin{array}{c}\text { T5 } \\
\text { [INF157] }\end{array}$ & $\begin{array}{c}\text { T7 } \\
\text { [INF238] }\end{array}$ \\
\hline Schelphoek-west & 1020 & $\begin{array}{c}\text { T0 } \\
\text { [INF3] }\end{array}$ & & $\begin{array}{c}\text { T2 } \\
{[\text { INF61] }}\end{array}$ & & $\begin{array}{c}\text { T5 } \\
\text { [INF156] }\end{array}$ & $\begin{array}{c}\text { T7 } \\
\text { [INF237] }\end{array}$ \\
\hline Schelphoek-west II BFN midden-oost & $00 \_05$ & & $\begin{array}{c}\mathrm{TX} \\
{[\mathrm{INF22]}}\end{array}$ & & & $\begin{array}{c}\text { T0 } \\
{[\mathrm{BfN} 3]}\end{array}$ & $\begin{array}{c}\mathrm{T} 2 \\
\text { [INF236] }\end{array}$ \\
\hline Schelphoek-west II BFN midden-oost & $05 \quad 10$ & & $\begin{array}{c}\mathrm{TX} \\
\text { [INF23] }\end{array}$ & & & $\begin{array}{c}\mathrm{TO} \\
{[\mathrm{BfN} 2]}\end{array}$ & $\begin{array}{c}\text { T2 } \\
\text { [INF235] } \\
\end{array}$ \\
\hline Schelphoek-west II BFN midden-oost & $10 \quad 20$ & & $\begin{array}{c}\mathrm{TX} \\
{[\mathrm{INF24]}} \\
\end{array}$ & & & $\begin{array}{c}\mathrm{T} 0 \\
{[\mathrm{BfN} 1]}\end{array}$ & $\begin{array}{c}\text { T2 } \\
\text { [INF234] }\end{array}$ \\
\hline Zierikzee & $00 \quad 05$ & & $\begin{array}{c}\text { TX } \\
\text { [INF106] }\end{array}$ & & $\begin{array}{c}\text { TX } \\
\text { [INF149] }\end{array}$ & & $\begin{array}{c}\text { T2 } \\
\text { [INF242] }\end{array}$ \\
\hline Zierikzee & $05 \_10$ & & $\begin{array}{c}\text { TX } \\
\text { [INF105] }\end{array}$ & & & & \begin{tabular}{|c|} 
T2 \\
[INF241]
\end{tabular} \\
\hline Zierikzee & 1020 & & $\begin{array}{c}\text { TX } \\
\text { [INF104] }\end{array}$ & & $\begin{array}{c}\text { TX } \\
\text { [INF147] }\end{array}$ & & $\begin{array}{c}\mathrm{T} 2 \\
\text { [INF240] }\end{array}$ \\
\hline Schelphoek-west II BFN oost1 & 00_05 & & & & & & $\begin{array}{c}\mathrm{T2} \\
{[\mathrm{BfN} 7]}\end{array}$ \\
\hline Schelphoek-west II BFN oost1 & 1020 & & & & & & $\begin{array}{c}\mathrm{T} 2 \\
{[\mathrm{BfN} 6]}\end{array}$ \\
\hline Schelphoek-west II BFN oost2 & $00 \quad 05$ & & & & & & $\begin{array}{c}\text { T2 } \\
{[\mathrm{BfN} 9]}\end{array}$ \\
\hline Schelphoek-west II BFN oost2 & $10 \_20$ & & & & & & \begin{tabular}{|c|}
$\mathrm{T} 2$ \\
{$[\mathrm{BfN} 8]$}
\end{tabular} \\
\hline Schelphoek-west II BFN west-midden 1 & $00 \quad 05$ & & & & & & $\begin{array}{c}\mathrm{T} 2 \\
{[\mathrm{BfN} 5]}\end{array}$ \\
\hline Schelphoek-west II BFN west-midden 1 & $05 \quad 10$ & & & & & & \begin{tabular}{|c|}
$\mathrm{T} 2$ \\
{$[\mathrm{BfN} 4]$}
\end{tabular} \\
\hline Schelphoek-west II BFN west-midden2 & $00 \quad 05$ & & & & & & $\begin{array}{c}\mathrm{T} 2 \\
{[\mathrm{BfN} 11]}\end{array}$ \\
\hline Schelphoek-west II BFN west-midden2 & $05 \_10$ & & & & & & \begin{tabular}{|c|}
$\mathrm{T} 2$ \\
{$[\mathrm{BfN} 10]$}
\end{tabular} \\
\hline
\end{tabular}

Op een aantal locaties was de sedimentlaag onvoldoende dik om de infauna te bemonsteren zoals tussen de breuksteen op locatie Schelphoek-midden voor diepteklasse 0-5, 5-10, >20 en op 
staalslakken op locatie Schelphoek-oost 2 (>20). Op locatie Burghsluis (diepte klassen 0-5 en 5-10) is geen infauna gevonden.

In afwezigheid van gerepliceerde bemonstering is het niet mogelijk om de afwezigheid van bodemdieren in de monsters uit locatie Burghsluis (strata 0-5, 5-10 m) statistisch representatief te beschouwen voor die locatie. Daardoor blijven deze waarnemingen buiten beschouwing in de vergelijking met waarnemingen uit eerdere jaren.

Tabel 5 geeft een overzicht van de locaties bemonsterd m.b.v. een Van Veen happer in 2016 en geeft aan welke vergelijkingen gemaakt kunnen worden tussen de dicht bij elkaar liggende locaties Schelphoek oost (1-6) zeven jaar na de bestorting van 2009 en Schelphoek referentie waar geen bestorting plaatst gevonden heeft.

Tabel 5. Monstercodes van de locaties bemonsterd m.b.v. een Van Veen happer in 2016. Ti met i voor het aantal jaren na een bestorting en TX waar geen bestorting plaats gevonden heeft en [VVnn] de codering voor de locaties. De arceringen wijzen op de monsters die bruikbaar zijn voor een vergelijking tussen de monsters uit de bestorte vs niet bestorte locaties (zie tekst). Met grijs lettertype de niet bemonsterde locatie (zie tekst). De rode dubbellijnen ligt tussen de groepen van locaties die vergeleken kunnen worden i.v.m. de effecten van de bestorting op de infauna

\begin{tabular}{|l|l|c|}
\hline \multicolumn{1}{|c|}{ Locaties } & \multicolumn{1}{|c|}{$\begin{array}{c}\text { Diepte } \\
\text { Klasse }\end{array}$} & $\begin{array}{c}\text { Monster } \\
\text { code }\end{array}$ \\
\hline Burghsluis 1 & $>20$ & T2 [VV3] \\
\hline Burghsluis 2 & $>20$ & T2 [VV2] \\
\hline Burghsluis 3 & $10 \_20$ & T2 [VV1] \\
\hline Schelphoek oost 1 & $>20$ & T7 [VV13] \\
\hline Schelphoek oost 2 & $>20$ & T7 [VV14] \\
\hline Schelphoek oost 3 & $>20$ & T7 [VV11] \\
\hline Schelphoek oost 4 & $>20$ & T7 [VV9] \\
\hline Schelphoek oost 5 & $>20$ & T7 [VV10] \\
\hline Schelphoek oost 6 & $>20$ & T7 [VV12] \\
\hline \hline Schelphoek referentie 1 & $>20$ & TX [VV17] \\
\hline Schelphoek referentie 2 & $>20$ & TX [VV16] \\
\hline Schelphoek referentie 3 & $>20$ & TX [VV15] \\
\hline Schelphoekmidden 1 & $>20$ & T7 [VV8] \\
\hline Schelphoek west 1 & $>20$ & T7 [VV6] \\
\hline Schelphoek-west 2 & $>20$ & T7 [VV5] \\
\hline Schelphoek-west 3 & $>20$ & T7 [VV4] \\
\hline
\end{tabular}




\subsection{Taxonomische samenstelling van de bodemdiergemeenschappen (2009-2016)}

\subsubsection{Dominante soorten en taxonomische klassen}

\section{Voorkomenfrequentie}

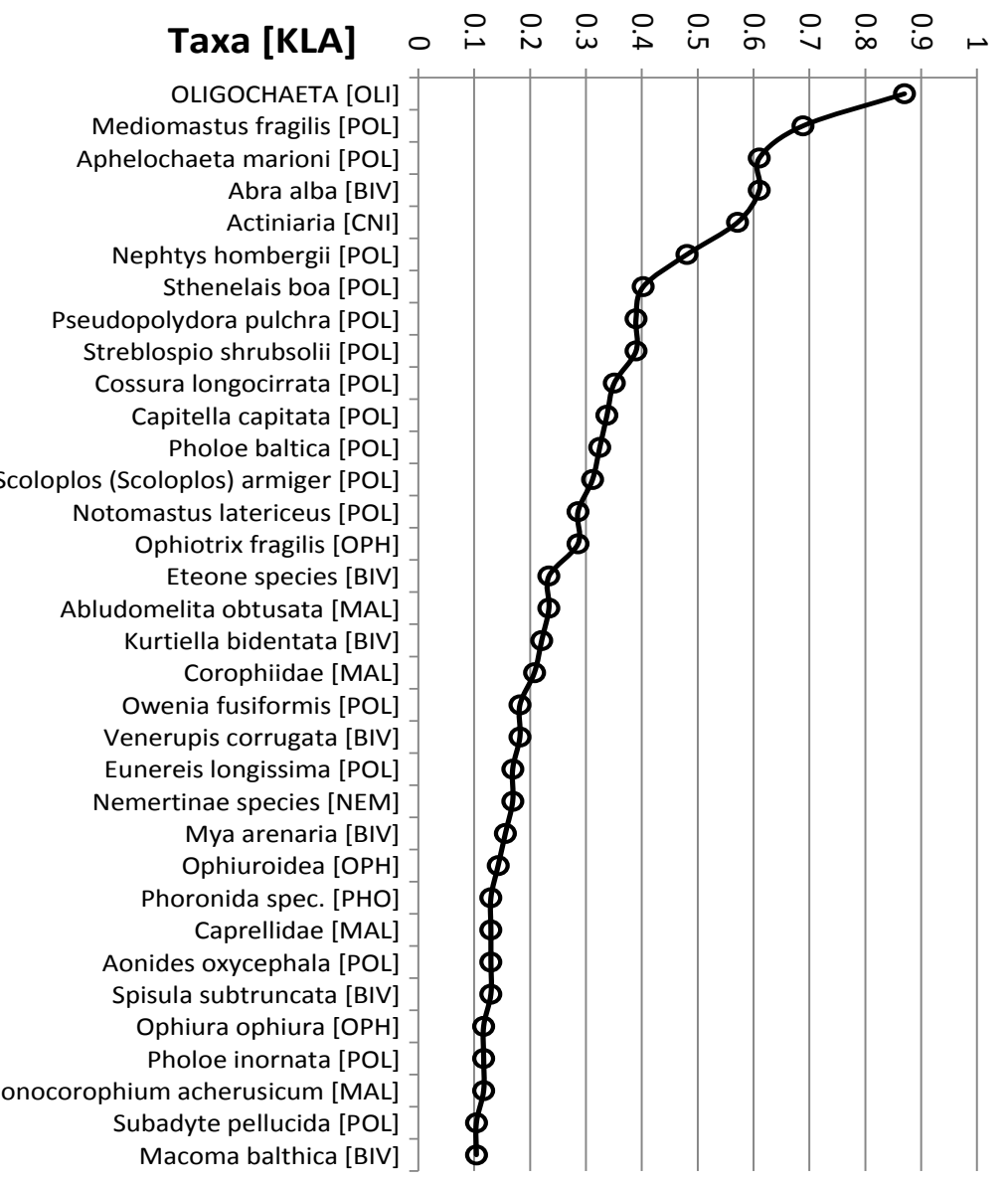

Figuur 6. Taxa [KLASSE] met frequentie van voorkomen (>0.1) in de volledige dataset (VOV_2009-2016).

De drie taxonomische klassen die het meest voorkomen in de monitoring van de vooroevers op deze locaties zijn Polychaeta (Mediomastus fragilis, Aphelochatea marioni, Nephtys hombergii, Streblospio shrubsolii, Capitella capitata, Eteone spec.), Oligochaeta (niet op soortniveau onderscheiden) en Bivalvia (Abra alba, Kurtiella bidentata, Venerupis corrugata, Mya arenaria, Spisula subtruncata, Macoma balthica), aangetroffen in respectievelijk 96, 87 en 83 procent van de monsters (figuur 6 en 7). De Cnidaria (Actiniaria), Malacostraca (Abludomelita obtusata, Corophiidae, Caprellidae), Ophiuroidea (Ophiotrix fragilis, Ophiuroidea, Ophiura ophiura) en Gastropoda (Crepidula fornicata, Nassarius spec., Buccinum undatum) zijn beduidend minder frequent dan de eerste drie genoemde klassen aangetroffen, in respectievelijk 57, 53, 42 en $21 \%$ van de monsters.

Met betrekking tot de dichtheden zijn ook de Oligochaeta, Polychaeta en de Bivalvia de dominantste groepen in de volledige dataset. 


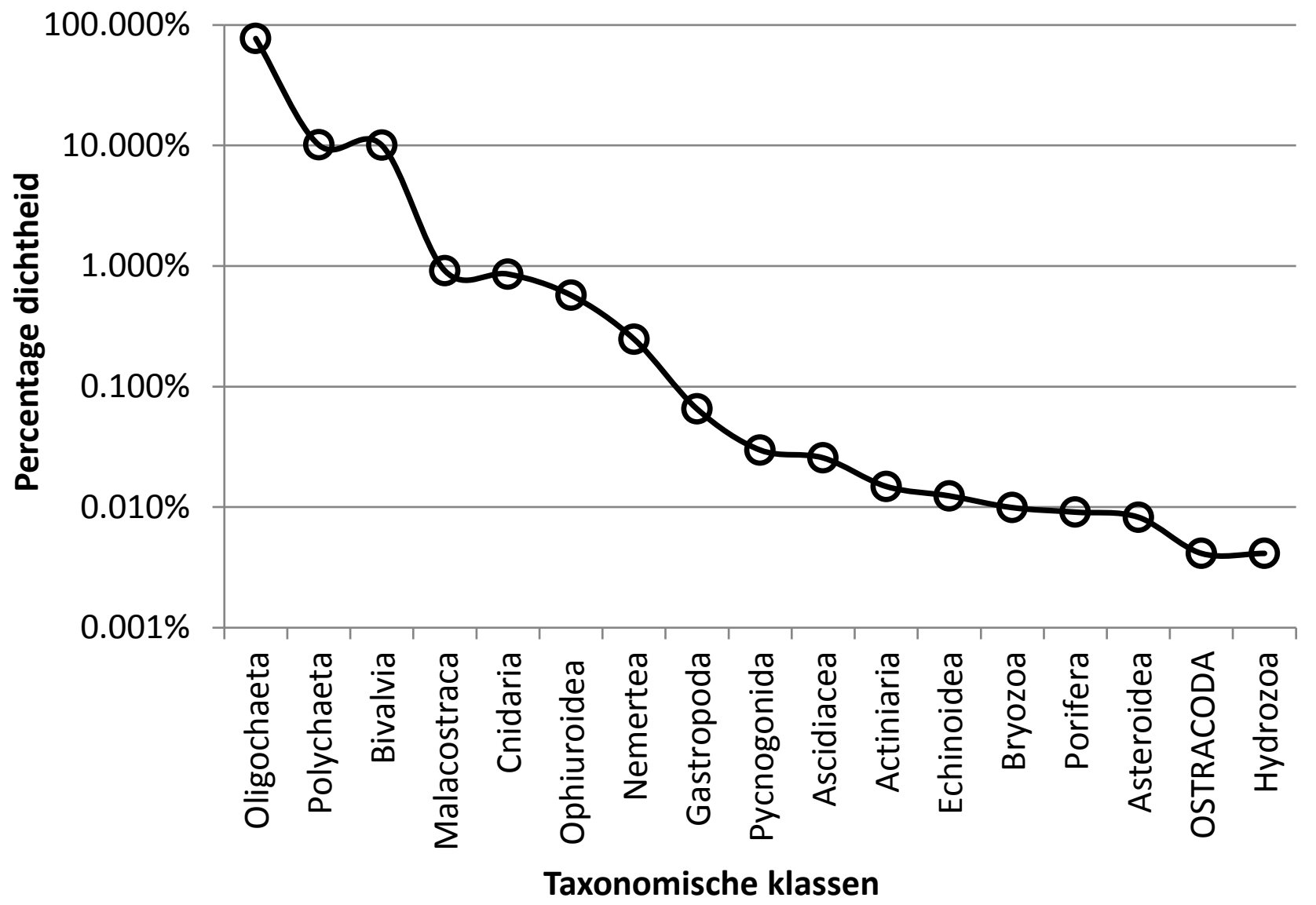

Figuur 7. Relatieve bijdrage aan de totale dichtheid (percentage; let op de logaritmische schaal van de $Y$ as) van de verschillende taxa in de volledige dataset (VOV_2009-2016). 


\subsection{Karakteristieken van de infauna uit de 2016 monstercampagne}

Hieronder volgt een beknopt overzicht van de infauna monsters verzameld in 2016 m.b.t. het aantal soorten de individuele dichtheid en de taxonomische samenstelling.

\subsubsection{Aantal soorten}

De soortenaantallen waargenomen in de monsters verzameld m.b.v. steekbuizen in 2016 (Tabel 6) bevinden zich in de middenmoot t.o.v. de Oosterschelde op basis van de gegevens uit het MWTL programma (zie 3.2.2). Daarbij vallen de afwezigheid van infauna monsters uit Burghsluis locaties in diepte klassen 0-5 en 5-10 en het gebrek van geschikt sediment in dezelfde dieptestrata bij Schelphoek-midden op. Op de meeste locaties liggen de soortenaantallen in de diepste delen (10-20) beduidend hoger dan in ondiepere locaties (0-5 en 05-10). Een dergelijke gradiënt ontbreekt op locatie Zierikzee.

Tabel 6. Aantal soorten waargenomen op locaties bemonsterd m.b.v. steekbuizen in 2016 met onderscheid van de diepteklassen waar de monsters plaats vinden. De kleur code wijst naar een Hoog, Midden en Laag niveau van soortendiversiteit (zie 3.2.2). Doorgekruist: mislukte bemonstering door de aanwezigheid van breukstenen; grijs gearceerd: monsterlocatie niet bemonsterd.

\begin{tabular}{|l|c|c|c|}
\hline Locaties Diepteklassen: & $\mathbf{0 - 5}$ & $\mathbf{0 5 - 1 0}$ & $\mathbf{1 0 - 2 0}$ \\
\hline Burghsluis & 0 & 0 & 8 \\
\hline Schelphoek-midden & 10 & 12 & 9 \\
\hline Schelphoek-oost-ref & 7 & 6 & 12 \\
\hline Schelphoek-west & 7 & 10 & 23 \\
\hline Schelphoek-west II BFN midden-oost & 11 & & 16 \\
\hline Schelphoek-west II BFN oost1 & 4 & & 13 \\
\hline Schelphoek-west II BFN oost2 & 10 & 8 & \\
\hline Schelphoek-west II BFN west-midden1 & 6 & 11 & \\
\hline Schelphoek-west II BFN west-midden2 & 9 & 8 & 6 \\
\hline Zierikzee & & & \\
\hline
\end{tabular}

De soortenaantallen waargenomen in de monsters die m.b.v. de Van Veen happer zijn verzameld in 2016 (Tabel 7) zijn voor ca een derde aan de hoge kant ( $>75^{\text {ste }}$ percentiel) en gemiddeld in de overige monsters t.o.v. de Oosterschelde op basis van de gegevens uit het MWTL programma (zie 3.2.2). Waar alle drie monsters uit locatie 'Schelphoek referentie' een hoge score behalen m.b.t. het aantal soorten zijn vergelijkbare niveaus van diversiteit ook waargenomen in monsters uit andere locaties waardoor geen eenduidig verschil in soortendiversiteit aantoonbaar is tussen de monsterlocaties..

Tabel 7. Aantal soorten waargenomen op locaties bemonsterd m.b.v. van Veen happer in 2016. De kleur code wijst naar een Hoog, Midden en Laag niveau van soortendiversiteit (zie 3.2.2).

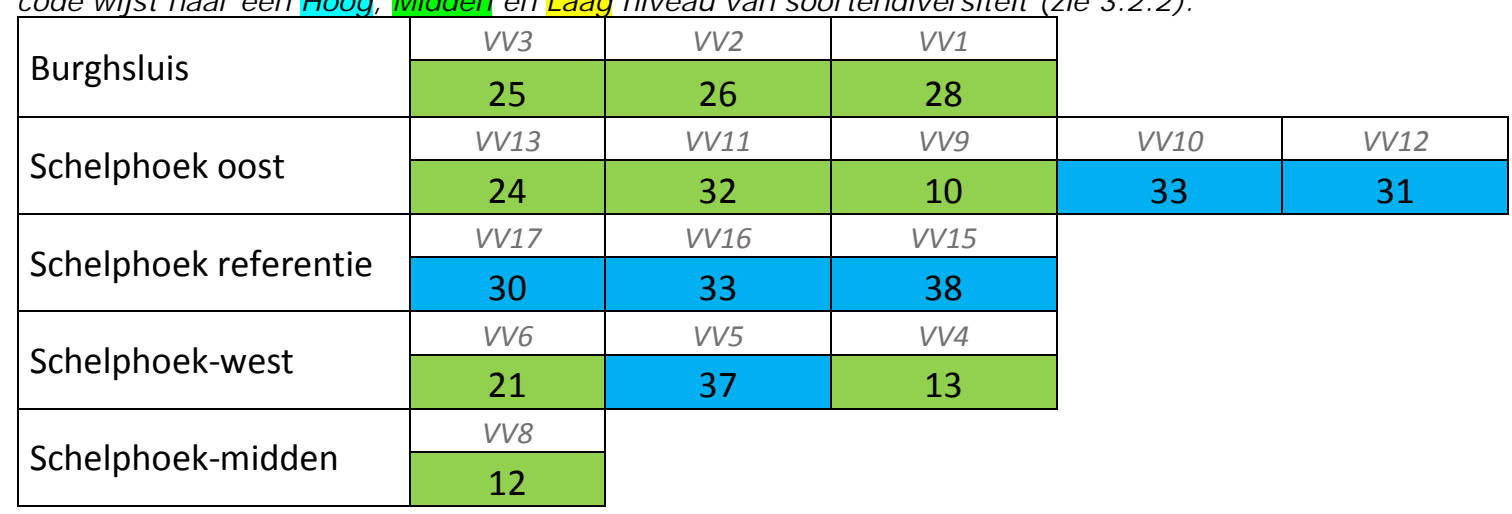




\subsubsection{Dichtheid}

Zoals waargenomen voor de soortenrijkdom zijn de waarden van dichtheid in de steekbuizen monsters beduidend hoger (ca 1 orde grootte) op de diepere locaties (10-20) met uitzondering van de locatie Zierikzee waar de dichtheid met de diepte afneemt (Tabel 8).

Tabel 8. Infauna dichtheid $\left(\mathrm{N} / \mathrm{m}^{2}\right)$ waargenomen op locaties bemonsterd m.b.v. steekbuizen in 2016. De kleur code wijst naar een Hoog, Midden en Laag niveau van dichtheid (zie 3.2.2). Doorgekruist: mislukte bemonstering door de aanwezigheid van breukstenen; grijs gearceerd: monsterlocatie niet opgenomen in de planning.

\begin{tabular}{|l|c|c|c|}
\hline Locaties Diepteklassen: & $\mathbf{0 - 5}$ & $\mathbf{0 5 - 1 0}$ & $\mathbf{1 0 - 2 0}$ \\
\hline Burghsluis & 0 & 0 & 804 \\
\hline Schelphoek-midden & & & 55299 \\
\hline Schelphoek-oost-ref & 1306 & 3064 & 22652 \\
\hline Schelphoek-west & 804 & 703 & 11602 \\
\hline Schelphoek-west II BFN midden-oost & 804 & 1055 & 15771 \\
\hline Schelphoek-west II BFN oost1 & 3114 & & 12305 \\
\hline Schelphoek-west II BFN oost2 & 201 & & 2762 \\
\hline Schelphoek-west II BFN west-midden1 & 1959 & 1105 & \\
\hline Schelphoek-west II BFN west-midden2 & 1055 & 2059 & \\
\hline Zierikzee & 4470 & 2361 & 1356 \\
\hline
\end{tabular}

De infauna dichtheden waargenomen in de Van Veen monsters laten een hoge mate van variatie zien met de hoogste dichtheden aan de Oostelijke kant van Schelphoek (Schelphoek Oost en Schelphoek referentie) (Tabel 9).

Tabel 9. Infauna dichtheid $\left(\mathrm{N} / \mathrm{m}^{2}\right)$ waargenomen op locaties bemonsterd m.b.v. van Veen happer in 2016 De kleur code wijst naar een Hoog, Midden en Laag niveau van dichtheid (zie 3.2.2).

\begin{tabular}{|c|c|c|c|c|c|}
\hline \multirow{2}{*}{ Burghsluis } & VV3 & VV2 & $V V 1$ & & \\
\hline & 14310 & 21420 & 10314 & & \\
\hline \multirow{2}{*}{ Schelphoek oost } & VV13 & VV11 & VV9 & VV10 & VV12 \\
\hline & 55180 & 145480 & 1620 & 51670 & 55630 \\
\hline \multirow{2}{*}{ Schelphoek referentie } & VV17 & $V V 16$ & VV15 & & \\
\hline & 59075 & 153570 & 51697 & & \\
\hline \multirow{2}{*}{ Schelphoek-west } & VV6 & VV5 & VV4 & & \\
\hline & 64400 & 41060 & 18330 & & \\
\hline \multirow{2}{*}{ Schelphoek-midden } & VV8 & & & & \\
\hline & 17230 & & & & \\
\hline
\end{tabular}




\subsubsection{Taxonomische samenstelling}

Voor het huidige overzicht zijn de waarnemingen (individuele dichtheden) opgesomd per taxonomische klassen (Figuur 8). Op alle locaties (m.u.v. Zierikzee) zijn hoge dichtheden waargenomen in de diepere delen die vooral toe te schrijven zijn aan Oligochaeta, Bivalvia en Polychaeta.
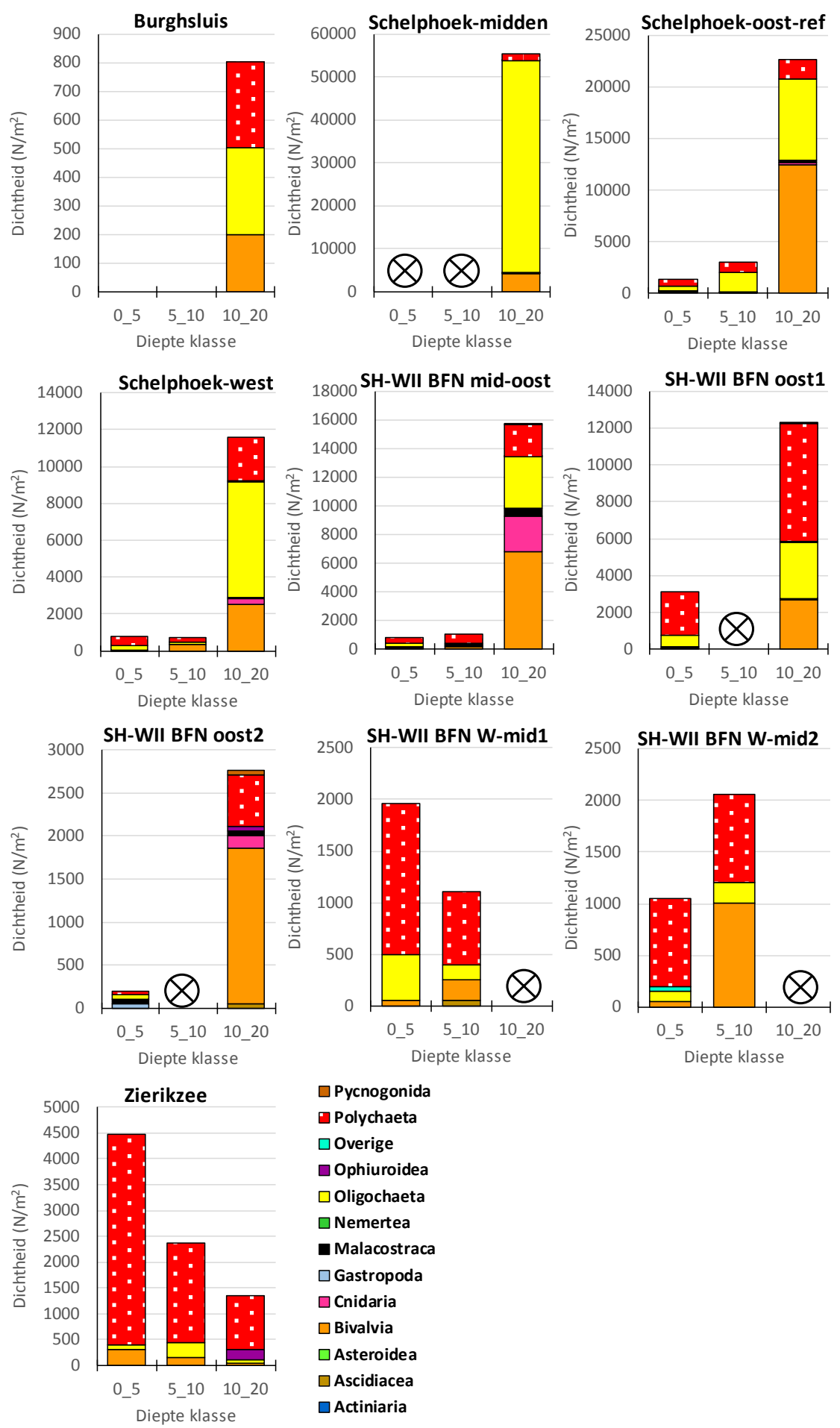
$\square$ Pycnogonida
$\square$ Polychaeta
$\square$ Overige
- Ophiuroidea
$\square$ Oligochaeta
$\square$ Nemertea
- Malacostraca
$\square$ Gastropoda
$\square$ Cnidaria
$\square$ Bivalvia
$\square$ Asteroidea
$\square$ Ascidiacea
$\square$ Actiniaria

Figuur 8. Dichtheid van de taxonomische klassen waargenomen op locaties bemonsterd m.b.v. steekbuizen in 2016. "SH" staat als afkorting voor Schelphoek. Een kruis betekent dat er geen monster is genomen op de desbetreffende locatie. 
De infauna dichtheden op de locaties bemonsterd m.b.v. de Van Veen happer zijn sterk gedomineerd door de Oligochaeta (Figuur 9). Na uitsluiting van de Oligochaeta zoals in onderste grafiek in Figuur 9 is gedaan, blijken Bivalvia en Polychaeta het merendeel van de resterende dichtheid voor hun rekening te nemen.
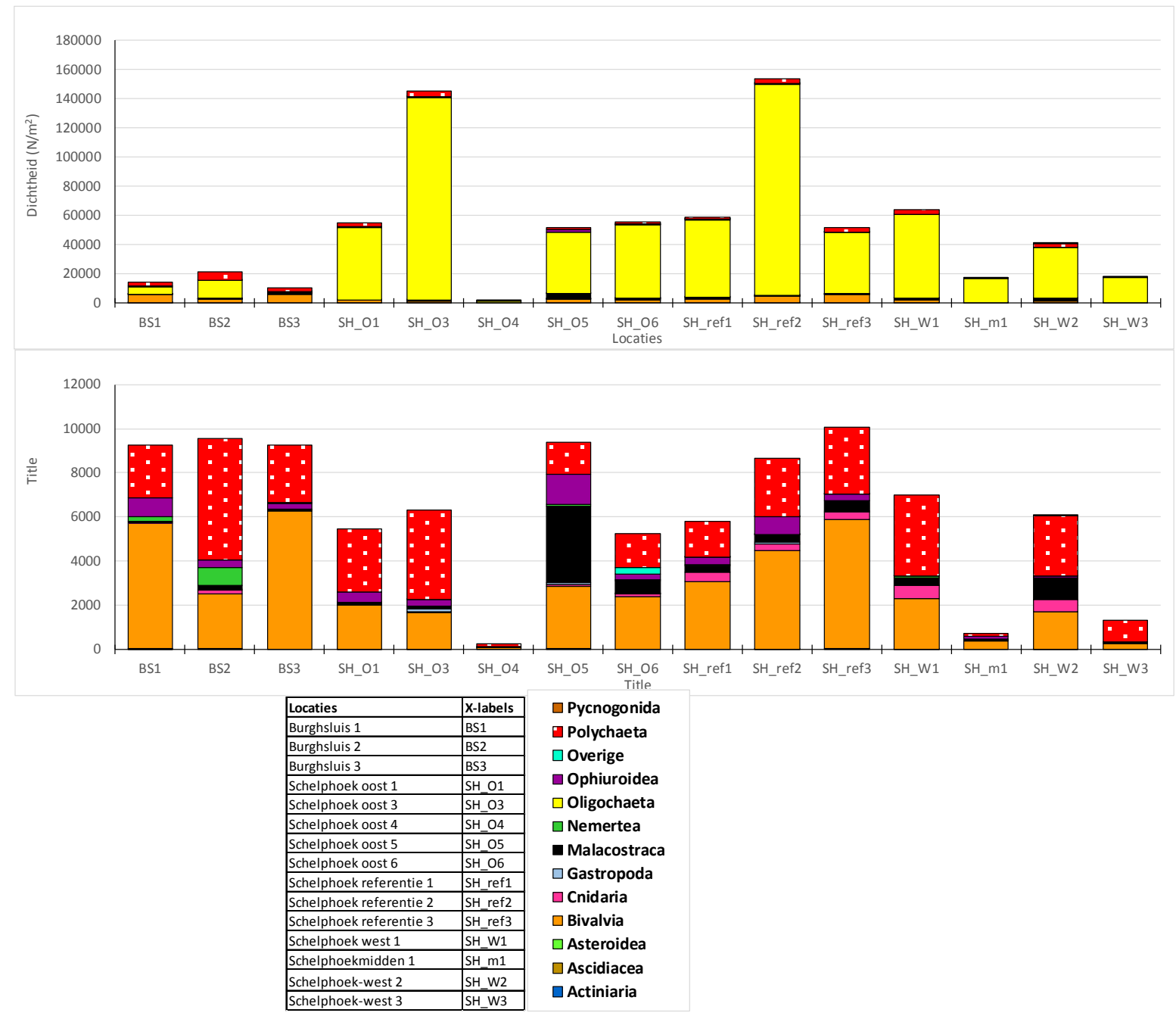

Figuur 9. Dichtheid van de taxonomische klassen waargenomen op locaties bemonsterd m.b.v. de van Veen happer in 2016. De afkortingen gebruikt op de x-as zijn verklaard in bijgevoegde tabel. Bovenste grafiek, alle taxa samen, onderste grafiek dichtheid met uitzondering van de Oligochaeta. 


\subsection{Vergelijkingen tussen monsterjaren en locaties}

Voor deze vergelijkingen is gebruik gemaakt van het vergelijkingsschema in Tabel 4 tussen monsterjaren na een bestorting en tussen bestorte locaties en het nabij gelegen referentie gebied bij Schelphoek.

\subsubsection{Soortendiversiteit}

Met uitzondering van Schelphoek (midden en west), waar een hogere soortendiversiteit is waargenomen in eerdere waarnemingen, is de soortendiversiteit in de steekbuismonsters van 2016 op locaties Zierikzee en Burghsluis goed vergelijkbaar of zelfs hoger (Zierikzee) dan de eerdere waarnemingen (Tabel 10).

Tabel 10. Aantal soorten waargenomen op locaties bemonsterd m.b.v. steekbuizen in 2016 en in eerdere jaren (ter vergelijking) De kleur code wijst naar een Hoog, Midden en Laag niveau van soortendiversiteit (zie 3.2.2). Waar meerdere monsters genomen waren per locatie (verschillende dieptes), is de gemiddelde waarde weergegeven. De rode dubbellijnen staan voor de bestortingen.

\begin{tabular}{|l|c|c|c|c|c|c|}
\hline \multicolumn{1}{|c|}{ locaties } & 2009 & 2010 & 2011 & 2013 & 2014 & 2016 \\
\hline Burghsluis & & 7 & & & & 8 \\
\hline Schelphoek-midden & & & 19 & & 24 & 9 \\
\hline Schelphoek-west & 16 & & 11 & & 6 & 9 \\
\hline Schelphoek-westll & & 11 & & 12 & & 13 \\
\hline Zierikzee & & 2 & & 8 & & 8 \\
\hline
\end{tabular}

Op de drie locaties van het referentie gebied bij Schelphoek zijn hoge niveaus in diversiteit waargenomen (Tabel 11). In het nabij gelegen bestorte gebied "Schelphoek oost" is dat het geval in drie van de vijf locaties, in de twee overige locaties is het niveau van soortendiversiteit gemiddeld.

Tabel 11. Aantal soorten waargenomen op locaties bemonsterd m.b.v. van Veen happer in 2016 op bestorte locaties bij Schelphoek oost, vergeleken met een nabij gelegen referentie gebied. De kleur code wijst naar een Hoog, Midden en Laag niveau van soortendiversiteit (zie 3.2.2). De rode dubbellijnen ligt tussen de groepen van locaties die vergeleken kunnen worden.

\begin{tabular}{|l|c|}
\hline \multicolumn{1}{|c|}{ locaties } & N/m2 \\
\hline Schelphoek oost 1 & 24 \\
\hline Schelphoek oost 3 & 32 \\
\hline Schelphoek oost 4 & 10 \\
\hline Schelphoek oost 5 & 33 \\
\hline Schelphoek oost 6 & 31 \\
\hline \hline Schelphoek referentie 1 & 30 \\
\hline Schelphoek referentie 2 & 33 \\
\hline Schelphoek referentie 3 & 38 \\
\hline
\end{tabular}




\subsubsection{Dichtheid}

Patronen in dichtheid tussen de monsterjaren (steekbuis bemonstering) en tussen de bestorte en referentie locaties (Van Veen happer bemonstering) komen goed overeen met de waarnemingen m.b.t. soortenrijkdom (vergelijk Tabel 12 en Tabel 13 met Tabel 10 en Tabel 11).

De individuele dichtheden gemeten in Schelphoek-midden zijn hoger (tussen 12000 en 149000 ind $/ \mathrm{m}^{2}$ ) dan op alle overige locaties (tussen 800 en $5900 \mathrm{ind} / \mathrm{m}^{2}$ ) bemonsterd in dezelfde jaren (Tabel 12). De laagste dichtheid komt voor in Burghsluis (2016) twee jaar na de bestorting. In Schelphoek west (2011), Schelphoek-west II (2016) en Zierikzee (2016) waren de individuele dichtheden, ook twee jaar na de bestorting, van vergelijkbaar omvang dan in het jaar net voor de bestorting. De laagste dichtheid werd waargenomen in locaties Zierikzee met slechts 151 individuen per $\mathrm{m}^{2}$ in 2010, vier jaar voor de eerste bestorting.

Tabel 12. Infauna dichtheid $\left(\mathrm{N} / \mathrm{m}^{2}\right)$ waargenomen op locaties bemonsterd m.b.v. steekbuizen in 2016 en in erdere jaren (ter vergelijking) De kleur code wijst naar een Hoog, Midden en Laag niveau van dichtheid (zie 3.2.2). Waar meerdere monsters genomen zijn per locatie (verschillende dieptes), is de gemiddelde waarde weergegeven. De rode dubbellijnen staan voor de bestortingen.

\begin{tabular}{|l|c|c|c|c|c|c|}
\hline \multicolumn{1}{|c|}{ locaties } & 2009 & 2010 & 2011 & 2013 & 2014 & 2016 \\
\hline Burghsluis & & 9945 & & & & 804 \\
\cline { 1 - 7 } Schelphoek-midden & & & 12707 & & 149021 & 55299 \\
\cline { 1 - 4 } Schelphoek-west & \multirow{2}{*}{3466} & & 3164 & & 3332 & 4370 \\
\cline { 1 - 4 } Schelphoek-westll & & 1741 & & 3298 & & 5877 \\
\hline Zierikzee & & 151 & & 3214 & & 2729 \\
\hline
\end{tabular}

Tabel 13. Infauna dichtheid $\left(\mathrm{N} / \mathrm{m}^{2}\right)$ waargenomen op locaties bemonsterd m.b.v. van Veen happer in 2016 op bestorte locaties bij Schelphoek oost, vergeleken met een nabij gelegen referentie gebied. De kleur code wijst naar een Hoog, Midden en Laag niveau van dichtheid (zie 3.2.2). De rode dubbellijnen ligt tussen de groepen van locaties die vergeleken kunnen worden

\begin{tabular}{|l|c|}
\hline Locaties & $\mathbf{N} / \mathbf{m}^{\mathbf{2}}$ \\
\hline Schelphoek oost 1 & 55180 \\
\hline Schelphoek oost 3 & 145480 \\
\hline Schelphoek oost 4 & 1620 \\
\hline Schelphoek oost 5 & 51670 \\
\hline Schelphoek oost 6 & 55630 \\
\hline \hline Schelphoek referentie 1 & 59075 \\
\hline Schelphoek referentie 2 & 153570 \\
\hline Schelphoek referentie 3 & 51697 \\
\hline
\end{tabular}

De individuele dichtheden zijn in vijf van de negen Van Veen monsters van dezelfde ordegrootte dan de maximale waarde getroffen in de steekbuis monsters (ca 50.000) en ca drie keer hoger in Schelphoek oost 3 en Schelphoek referentie 2 (tabel 13).

De dichtheid waargenomen op Schelphoek oost 4 (1620 individuen per $\mathrm{m}^{2}$ ) valt op vergeleken met de overige monsters verzameld op de locatie Schelphoek oost en kan zeer vermoedelijk toegeschreven worden aan lokale omstandigheden die niet representatief zijn voor deze locatie.

Met het buiten beschouwing houden van dit monster valt de sterk overeenkomst op in de individuele dichtheden tussen de locatie Schelphoek oost (monsters 1,3,5 en 6), slechts twee jaar na de bestorting, en de referentie locatie (monsters 1,2 en 3). 


\subsubsection{Taxonomische samenstelling}

Twee jaar na de bestorting zoals bemonsterd in Schelphoek-midden, Schelphoek-west en Zierikzee valt geen stelselmatige verschuiving op in de taxonomische samenstelling van de bodemdieren gemeenschap. Het is dus niet mogelijk om, op deze tijdschaal, een taxonomische groep aan te wijzen die selectief bevorderd zou zijn door het beschikbaar komen van een nieuwe sedimentafzetting. Wel opmerkelijk voor de huidige gegevens is de explosieve toename van Oligochaeten in 2014-2016 die exclusief plaats vindt op locaties Schelphoek-midden (ondiep/steekbuis monsters) en Schelphoekoost, Schelphoek-referentie (diep/Van Veen monsters) respectievelijk vijf en zeven jaar na de bestorting. Het is aannemelijk dat deze lokale ontwikkelingen niets te maken hebben met de bestorting in het kader van de vooroeververdediging.
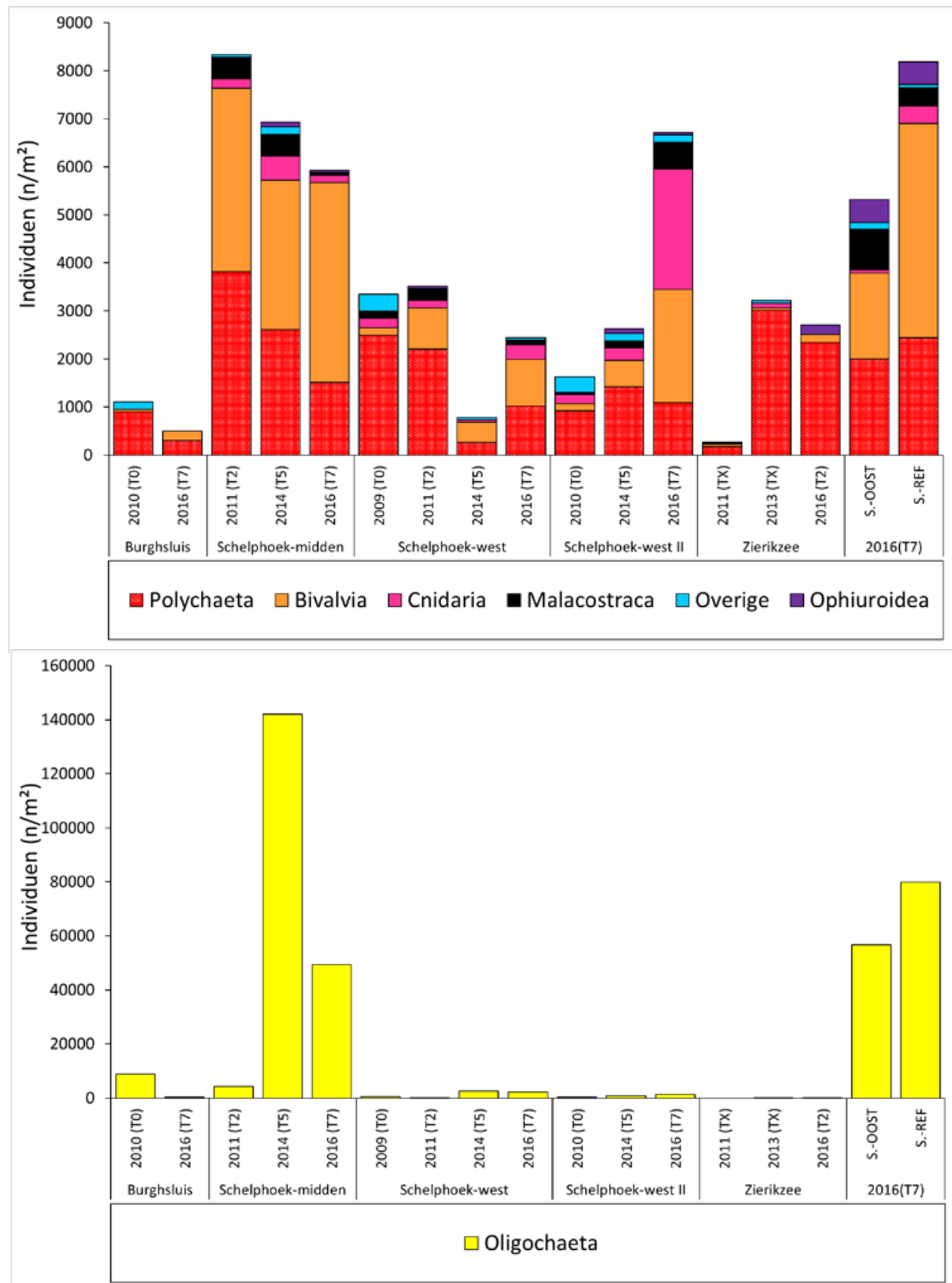

Figuur 10. Dichtheid van de taxonomische klassen waargenomen op locaties die vergeleken kunnen worden m.b.t. de tijdspanne na een bestorting ( $X$ - as vinr: Steekbuis locaties Burghluis t.m. Zierikzee) of tussen een bestorte locatie (X-as, laatste vak rechts: S.-OOST, Schelphoek-oost) en een referentie locatie (S.-REF, Schelphoek-referentie) in 2016 (T7, 7 jaar na de bestorting in S.-OOST). Bovenste grafiek, alle taxa samen zonder de Oligochaeta, onderste grafiek Oligochaeta. 


\subsubsection{Aanwezigheid van de typische (Natura 2000) soorten}

Van de tien typische soorten beschreven voor het habitattype 1160 (Grote baaien,

Bijlage 4) zijn er zes aangetroffen op de locaties beschouwd binnen de huidige studie (Tabel 14).

Tabel 14. Typische (Natura 2000) soorten zoals aangetroffen in de huidige studie met frequentie van voorkomen (\%) en bijbehorende gemiddelde dichtheid $\left(\mathrm{N} / \mathrm{m}^{2}\right)$.

\begin{tabular}{|l|c|c|}
\hline \multicolumn{1}{|c|}{ Typische (N2000) soorten } & Frequentie (\%) & Dichtheid $\left(\mathrm{N} / \mathrm{m}^{2}\right)$ \\
\hline Nephtys hombergii & 48 & 111 \\
\hline Mytilus edulis & 9 & 489 \\
\hline Carcinus maenas & 5 & 10 \\
\hline Lanice conchilega & 5 & 25 \\
\hline Cerastoderma edule & 1 & 50 \\
\hline Echinocardium cordatum & 1 & 151 \\
\hline Metridium senile & 0 & 0 \\
\hline Arenicola marina & 0 & 0 \\
\hline Hediste diversicolor & 0 & 0 \\
\hline Urothoe poseidonis & 0 & 0 \\
\hline
\end{tabular}

De afwezigheid van de zeeanjelier (Metridium senile) en de wadpier (Arenicola marina) in de huidige monsters (zie

Bijlage 4 en Tabel 14) kan waarschijnlijk verklaard worden door de relatief geringe dikte aan sediment waargenomen op de meeste locaties (zie 3.4.5). Dit maakt deze plekken minder geschikt voor deze relatief diepgravende organismen. Door de relatieve lage dichtheden waarmee de meeste typische soorten in de monsters voorkomen (Tabel 15 en Tabel 16) behoren de waarnemingen tot toevaltreffers, waardoor over de afwezigheid ervan weinig zinvols te concluderen valt. Wel vallen de hoge dichtheden aan mosselen op in twee Van Veen monsters verzameld bij locatie Schelphoek oost (Tabel 16). Deze waarnemingen wijzen op een herstel van mosselbanken op de stortlocatie.

Tabel 15. Dichtheid aan typische (N2000) soorten aangetroffen op stortlocaties in 2016 en eerdere jaren (ter vergelijking). De rode dubbellijnen ligt tussen de groepen van locaties die vergeleken kunnen worden. De grijze arcering wijst op de afwezigheid van bemonstering voor de desbetreffende jaar en locatie

\begin{tabular}{|l|l|c|c|c|c|c|c|}
\hline Locaties & \multicolumn{1}{|c|}{ N2000 Soort } & 2009 & 2010 & 2011 & 2013 & 2014 & 2016 \\
\hline \multirow{2}{*}{ Burghsluis } & Echinocardium cordatum & & 151 & & & & 0 \\
\hline & Nephtys hombergii & & 201 & & & & 100 \\
\hline Schelphoek-midden & Mytilus edulis & & & 0 & & 0 & 50 \\
\hline Schelphoek-west & Nephtys hombergii & 84 & & 100 & & 50 & 50 \\
\hline \multirow{2}{*}{ Schelphoek-west II } & Lanice conchileqa & & 50 & & & 0 & 0 \\
\hline & Nephtys hombergii & & 200 & & & 184 & 50 \\
\hline \multirow{2}{*}{ Zierikzee } & Cerastoderma edule & & & 50 & 0 & & 0 \\
\hline & Nephtys hombergii & & & 50 & 151 & & 100 \\
\hline
\end{tabular}

Tabel 16. Dichtheid aan typische (N2000) soorten aangetroffen bij Schelphoek, vergeleken met een nabij gelegen referentie gebied. De rode dubbellijnen ligt tussen de groepen van locaties die vergeleken kunnen worden.

\begin{tabular}{|l|l|c|}
\hline Locaties & \multicolumn{1}{|c|}{ N2000 Soort } & 2016 \\
\hline Schelphoek oost 1 & Carcinus maenas & 10 \\
\hline \multirow{2}{*}{ Schelphoek oost 5 } & Carcinus maenas & 10 \\
\cline { 2 - 3 } & Mytilus edulis & 2230 \\
\hline \multirow{2}{*}{ Schelphoek oost 6 } & Carcinus maenas & 10 \\
\cline { 2 - 3 } & Mytilus edulis & 960 \\
\hline \multirow{2}{*}{ Schelphoek referentie 1 } & Carcinus maenas & 10 \\
\hline Schelphoek referentie 2 & Mytilus edulis & 30 \\
\hline \multirow{2}{*}{ Schelphoek referentie 3 } & Lanice conchilega & 10 \\
\cline { 2 - 3 } & Mytilus edulis & 20 \\
\hline
\end{tabular}




\subsubsection{Bodemgemeenschappen}

Dit hoofdstuk biedt een overzicht van de gemeenschapsanalyse uitgevoerd door Stichting Zeeschelp (de Kluiver, 2016), voor aanvullende informatie is de volledige bijdrage van Stichting Zeeschelp toegevoegd in Bijlage $\mathbf{1 1}$.

Het karakteriseren van de infauna gemeenschappen volgens de methode beschreven in hoofdstuk 3.2.2 levert een geordende tabel op met weergave van het voorkomen van de infauna soorten in de verschillende gemeenschapsvarianten zoals weergeven in Bijlage 9. In totaal zijn er 33 clusters gevonden, waarvan 28 in de Oosterschelde (en 13 in de Westerschelde) voorkwamen (Tabel 17). Deze 33 clusters zijn gebruikt bij het onderscheiden van vier dominante gemeenschappen ( $A, B, G$ en $\mathrm{H}$ ) waarmee $85 \%$ van de onderzochte stations gekenmerkt kon worden. Binnen de gemeenschappen A, B en $\mathrm{G}$ is verder onderscheid gemaakt tussen 8, 5 en 6 gemeenschapsvarianten respectievelijk.

Tabel 17. Eigenschappen van de infauna clusters met verdeling over Oosterschelde en Westerschelde monsters en indeling tot 17 gemeenschappen (A t.m. Q) waaronder de vier dominante gemeenschappen $A$, B, G en H met verder onderscheid van 19 gemeenschapsvarianten binnen gemeenschappen A (8), B (5) en $\mathrm{G}(6)$. (n stat: aantal locaties, $\mathrm{n} \mathrm{sp}$ : aantal soorten, $\mathrm{n} / \mathrm{m}^{2}$ : aantal individuen per $\mathrm{m}^{2}$.

\begin{tabular}{|c|c|c|c|c|c|c|c|}
\hline & $\mathrm{n}$ stat & $\% \mathrm{OS}$ & $\mathrm{nsp}$ & $\mathrm{n} / \mathrm{m} 2$ & $\% \mathrm{WS}$ & $\mathrm{nsp}$ & $\mathrm{n} / \mathrm{m} 2$ \\
\hline $\mathrm{A} 1$ & 7 & 100 & 9,9 & 4333,8 & 0 & 0 & 0 \\
\hline A2 & 15 & 100 & 11,5 & 4878,7 & 0 & 0 & 0 \\
\hline $\mathrm{A} 3$ & 3 & 100 & 10,0 & 1121,7 & 0 & 0 & 0 \\
\hline $\mathrm{A} 4$ & 2 & 100 & 13,0 & 8036,2 & 0 & 0 & 0 \\
\hline A5 & 4 & 100 & 10,3 & 8651,5 & 0 & 0 & 0 \\
\hline $\mathrm{A} 6$ & 12 & 100 & 9,8 & 2883,8 & 0 & 0 & 0 \\
\hline A7 & 10 & 100 & 7,8 & 2124,6 & 0 & 0 & 0 \\
\hline A8 & 33 & 70 & 15,8 & 4579,3 & 30 & 10,5 & 2898,1 \\
\hline B1 & 48 & 100 & 24,1 & 11928,8 & 0 & 0 & 0 \\
\hline B2 & 14 & 93 & 18,1 & 7673,1 & 7 & 13,0 & 4570,6 \\
\hline B3 & 9 & 100 & 33,9 & 12450,6 & 0 & 0 & 0 \\
\hline B4 & 22 & 100 & 24,5 & 48669,0 & 0 & 0 & 0 \\
\hline B5 & 2 & 0 & 0 & 0 & 100 & 15,5 & 15997,1 \\
\hline C & 4 & 75 & 11,7 & 904,1 & 25 & 13,0 & 7282,8 \\
\hline $\mathrm{D}$ & 5 & 80 & 7,3 & 869,6 & 20 & 8,0 & 703,2 \\
\hline $\mathrm{E}$ & 2 & 100 & 7,0 & 577,6 & 0 & 0 & 0 \\
\hline $\mathrm{F}$ & 1 & 100 & 20,0 & 3164,3 & 0 & 0 & 0 \\
\hline G1 & 7 & 14 & 9,0 & 3616,3 & 86 & 13,5 & 7584,2 \\
\hline G2 & 19 & 0 & 0 & 0 & 100 & 5,1 & 3597,8 \\
\hline G3 & 3 & 67 & 5,0 & 1079,9 & 33 & 6,0 & 502,3 \\
\hline G4 & 8 & 100 & 5,4 & 577,6 & 0 & 0 & 0,0 \\
\hline G5 & 4 & 0 & 0 & 0 & 100 & 6,8 & 1142,7 \\
\hline G6 & 4 & 0 & 0 & 0 & 100 & 2,5 & 200,9 \\
\hline $\mathrm{H}$ & 9 & 100 & 6,4 & 898,5 & 0 & 0 & 0 \\
\hline I & 6 & 50 & 8,7 & 786,9 & 50 & 5,7 & 619,5 \\
\hline $\mathrm{J}$ & 9 & 100 & 3,4 & 1199,9 & 0 & 0 & 0 \\
\hline $\mathrm{K}$ & 2 & 50 & 4,0 & 200,9 & 50 & 2,0 & 150,7 \\
\hline $\mathrm{L}$ & 1 & 100 & 5,0 & 552,5 & 0 & 0 & 0 \\
\hline $\mathrm{M}$ & 1 & 100 & 3,0 & 301,4 & 0 & 0 & 0 \\
\hline $\mathrm{N}$ & 1 & 0 & 0 & 0 & 100 & 11,0 & 2109,5 \\
\hline $\mathrm{O}$ & 1 & 100 & 1,0 & 50,2 & 0 & 0 & 0 \\
\hline $\mathrm{P}$ & 1 & 100 & 1,0 & 50,2 & 0 & 0 & 0 \\
\hline $\mathrm{Q}$ & 1 & 100 & 1,0 & 50,2 & 0 & 0 & 0 \\
\hline leeg & 5 & 60 & 0 & 0 & 40 & 0 & 0 \\
\hline
\end{tabular}

Gemeenschap A is hoofdzakelijk beperkt tot de Oosterschelde (ca $8 \mathrm{~m}$ diep), en is gedomineerd door oligochaeten, de polychaeten Aphelochaeta marioni, Scoloplos armiger, Mediomastus fragilis, Streblospio shrubsolii, Capitella capitata en Pseudopolydora pulchra en de witte dunschaal Abra alba.

Gemeenschap B komt in dezelfde typen sedimenten voor als gemeenschap A maar wel op grotere diepte (ca $15 \mathrm{~m}$ ). Deze gemeenschap is gedomineerd door oligochaeten, de polychaeten Aphelochaeta marioni, Mediomastus fragilis, Scoloplos armiger, Pseudopolydora pulchra, Notomastus latericeus, Capitella capitata, Lanice conchilega en Cossura longocirrata, de mollusken Abra alba en Crepidula fornicata, anemonen en spookkreeftjes.

Gemeenschap G komt zowel in de Ooster- als Westerschelde voor en is gedomineerd door de polychaeten Aphelochaeta marioni en Heteromastus filiformis, en oligochaeten.

Gemeenschap $\mathbf{H}$ is beperkt tot de Oosterschelde (vooral het oostelijk deel) op (fijn- )zandige bodems en is gedomineerd door tweekleppigen, waaronder de Filipijnse tapijtschelp Ruditapes philippinarum en de polychaete Nephtys hombergii. 
Gemeenschap $\mathbf{K}$ is gekenmerkt door lage dichtheden en de afwezigheid van dominante soorten.

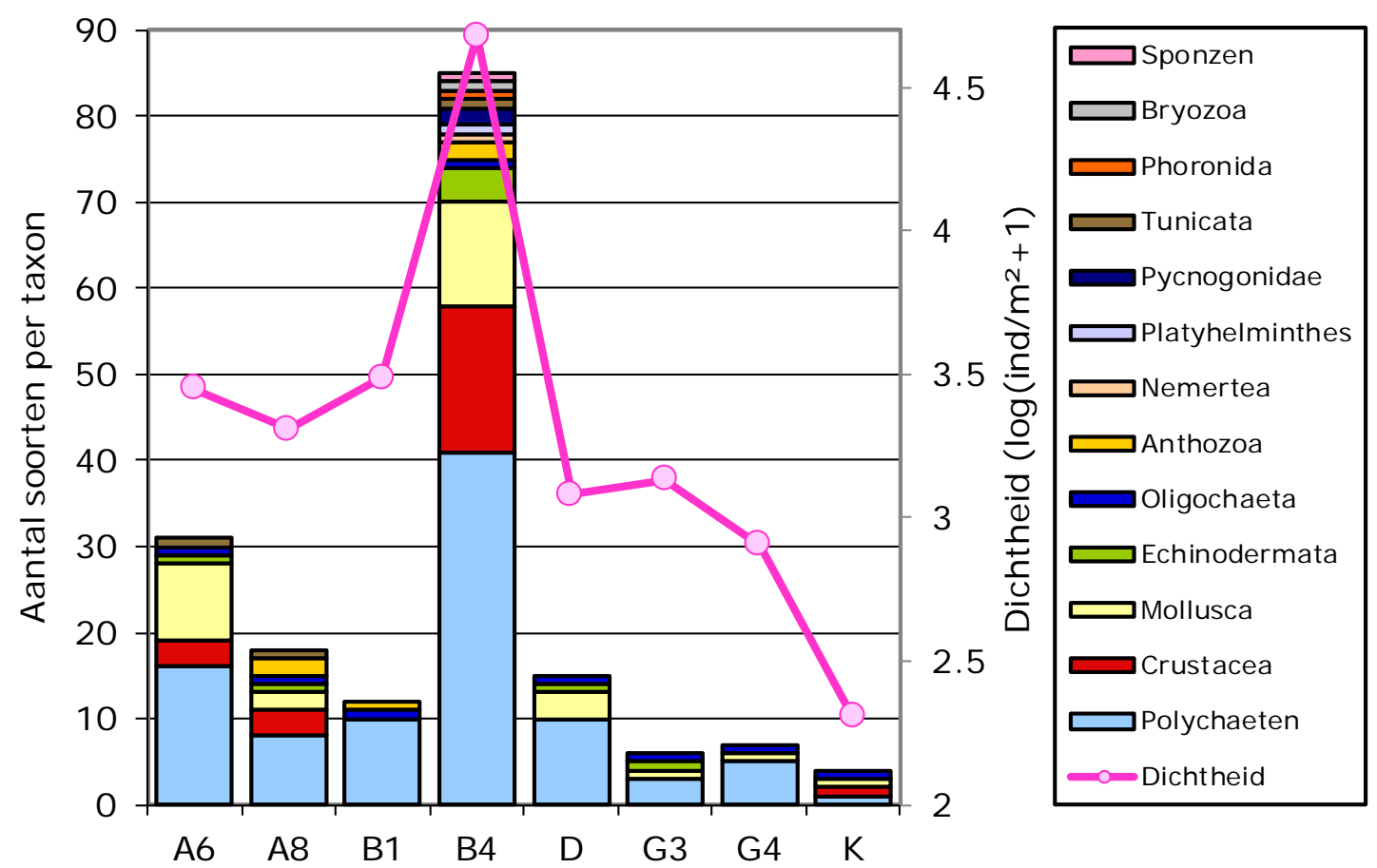

Figuur 11. Aantal soorten met onderscheid tussen taxa en totale dichtheid voor dominante gemeenschapsvarianten zoals aangetroffen in de huidige studie.

Gemeenschap B is de rijkste gemeenschap m.b.t. soortenrijkdom (gem=24 per monster) en dichtheid ( gem $=19.912 \mathrm{ind} / \mathrm{m}^{2}$ ). Dit valt vooral toe te schrijven aan de B4 variant met gemiddeld 24 soorten per station en meer dan $45.000 \mathrm{ind} / \mathrm{m}^{2}$ (Figuur 11). Die hoge dichtheden zijn vooral te danken aan oligochaeten die goed zijn voor gemiddeld $85 \%$ van de totale dichtheid. In totaal clusterden 18 stations tot variant B4. Deze stations betreffen vier stations die met steekbuizen bemonsterd zijn, en 14 met de Van Veen happer. Het gebruik van een Van Veen Happer kan in vergelijking met de steekbuismethode leiden tot een kunstmatige verhoging van het aantal soorten (zie Bijlage $\mathbf{3}$ ).

Gemeenschap $\mathrm{H}$ beperkt zich tot het oostelijk deel van de Oosterschelde. Deze gemeenschap is (op gemeenschap $\mathrm{K} \mathrm{na}$ ) de armste van alle gemeenschappen (gem $\mathrm{S}=6$, gem $\mathrm{D}=899 \mathrm{ind} / \mathrm{m}^{2}$ ).

Gemeenschap $\mathrm{G}$ is even soortenarm als gemeenschap $\mathrm{H}$ met gemiddeld 6 soorten per monster, maar het is wel rijker in dichtheid (gem $\mathrm{D}=2.892 \mathrm{ind} / \mathrm{m}^{2}$ ). Met gemiddeld 12 soorten per monster en 4.044 ind $/ \mathrm{m}^{2}$ ligt gemeenschap A m.b.t. de kwaliteit van de infauna tussen gemeenschap B en $\mathrm{G}$ in.

De verdeling van de gemeenschappen over de monsterlocaties sinds 2009 zijn weergegeven in Bijlage 10. Voor de huidige rapportage is ervoor gekozen om de weergave van de gemeenschappen te beperken tot de monsterlocaties waarvoor een vergelijking mogelijk is t.o.v. de monstercampagne van 2016, zoals dit tevens is gedaan voor soortenrijkdom, dichtheid en aanwezigheid van typische (N2000) soorten. 
Tabel 18. Gemeenschapsvarianten waargenomen op locaties bemonsterd m.b.v. steekbuizen in 2016 en in eerdere jaren (ter vergelijking). De tabelcellen zijn gesplitst volgens de diepte $(\mathrm{m})$ waar de bemonstering plaats vindt (v.I.n.r.:|0-5|5-10|>10|). Op sommige locaties kon er door de afwezigheid van voldoende sediment geen monster genomen worden (-). De rode dubbellijnen staan voor de bestortingen. T.g.v. de leesbaarheid zijn de tabelcellen gekleurd naar de gemeenschappen, in volgorde van soortenrijk naar soortenarm: \begin{tabular}{|l|l|l|l|l|l|l|}
\hline B & A & C & D & G & J & P \\
\hline
\end{tabular}

\begin{tabular}{|c|c|c|c|c|c|c|c|c|c|c|c|c|c|c|c|c|c|}
\hline Locaties & \multicolumn{2}{|c|}{2009} & \multicolumn{3}{|c|}{2010} & \multicolumn{3}{|c|}{2011} & \multicolumn{3}{|c|}{2013} & \multicolumn{3}{|c|}{2014} & \multicolumn{3}{|c|}{2016} \\
\hline Burghsluis & & & ర) & $\neg$ & 是 & & & & & & & & & & ' & ' & 0 \\
\hline Schelphoek-midden & & & & & & $\approx$ & ' & $\approx$ & & & & \& & 足 & $\$$ & ' & 1 & मे \\
\hline Schelphoek-west & 兵 & $\stackrel{\infty}{<}$ & & & & $\neg$ & u & $\stackrel{\infty}{<}$ & & & & \& & \& & $\neg$ & ষ & 这 & ष \\
\hline Schelphoek-west II & & & 군 & $\stackrel{\infty}{<}$ & $\stackrel{\infty}{<}$ & & & & & & & D & $\stackrel{\infty}{<}$ & $\stackrel{\infty}{<}$ & 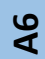 & 电 & $\stackrel{\circ}{<}$ \\
\hline Zierikzee & & & & & & $\neg$ & a & ষ্ণ & e & ' & $\Sigma$ & & & & $\stackrel{0}{<}$ & 电 & लै \\
\hline
\end{tabular}

Tabel 19. Gemeenschapsvarianten waargenomen op locaties bemonsterd m.b.v. Van Veen happer in 2016 op bestorte locaties bij Schelphoek oost, vergeleken met een nabij gelegen referentie gebied. De rode dubbellijnen ligt tussen de groepen van locaties die vergeleken kunnen worden

\begin{tabular}{|l|c|}
\hline Locatie & $\begin{array}{c}\text { Gemeenschaps- } \\
\text { variant }\end{array}$ \\
\hline Schelphoek oost 1 & B4 \\
\hline Schelphoek oost 3 & B4 \\
\hline Schelphoek oost 4 & B4 \\
\hline Schelphoek oost 5 & B4 \\
\hline Schelphoek oost 6 & D \\
\hline \hline Schelphoek referentie 1 & B4 \\
\hline Schelphoek referentie 2 & B4 \\
\hline Schelphoek referentie 3 & B4 \\
\hline
\end{tabular}

Op basis van de informatie in Tabel $\mathbf{1 8}$ kunnen de volgende observaties worden gemaakt:

- Op basis van de gemeenschapsanalyse komt geen eenduidige ontwikkeling in de infauna karakteristieken naar voren naar verloop van tijd na een bestorting of in de vergelijking tussen een eerder bestorte locatie en een nabij gelegen referentie.

- Zoals opgemerkt m.b.t. de dichtheden lijken de bestortingen geen langdurig effect te hebben op de infauna mits voldoende sediment is neergevallen na de ingreep. Vooral op de ondiepe stations zoals bijvoorbeeld in Burghsluis (2016) en Schelphoek $(2011,2016)$ zorgt een schaarste aan zacht substraat voor arme bodemgemeenschappen. 


\subsubsection{Sedimentsamenstelling en sediment dikte}

De samenstelling van de bodemsedimenten, zoals geanalyseerd in 2016, is weergegeven in Figuur 12 , Figuur 13 en Figuur 14.

\begin{tabular}{|c|c|c|c|c|c|c|c|c|c|c|c|}
\hline OS-2016 & Burgh-w & Sch-wII & Sch-wII & Sch-wII & Sch-w & Sch-m & Sch-o & & & Sch-R & Zie \\
\hline $0-5$ & 65,4 & 65,4 & 76,7 & 76,5 & 84,7 & 22,4 & & & & 42,4 & 80,0 \\
\hline 5.1-10 & 25,7 & 73,9 & 92,5 & 83,9 & 46,8 & 44,5 & & & & 22,9 & 77,5 \\
\hline \multirow[t]{2}{*}{$>10.1$} & 12,6 & 57,3 & 39,9 & 58,9 & 21,1 & 37,7 & & & & 28,4 & 67,4 \\
\hline & & 48,6 & & 83,3 & & & & & & & \\
\hline & & & & & & & & & & & \\
\hline \multirow[t]{5}{*}{ van Veen } & 33,3 & & & & 34,3 & & & & & 17,8 & \\
\hline & 37,0 & & & & 26,9 & & 48,0 & 42,1 & 38,2 & 27,6 & \\
\hline & 22,7 & & & & 34,5 & 47,9 & 40,9 & 39,6 & 45,2 & 14,4 & \\
\hline & & & & & & & & & & & \\
\hline & & & & & & & & & & & \\
\hline
\end{tabular}

Figuur 12. Sedimenttype en $\%$ fracties $<0.09 \mathrm{~mm}$, blauw type $\mathrm{V}$, groen type $\mathrm{VI}$, bruin type $\mathrm{V}$ (dis) en rood type VIII (zie Tabel 3 voor de definitie van de codes).

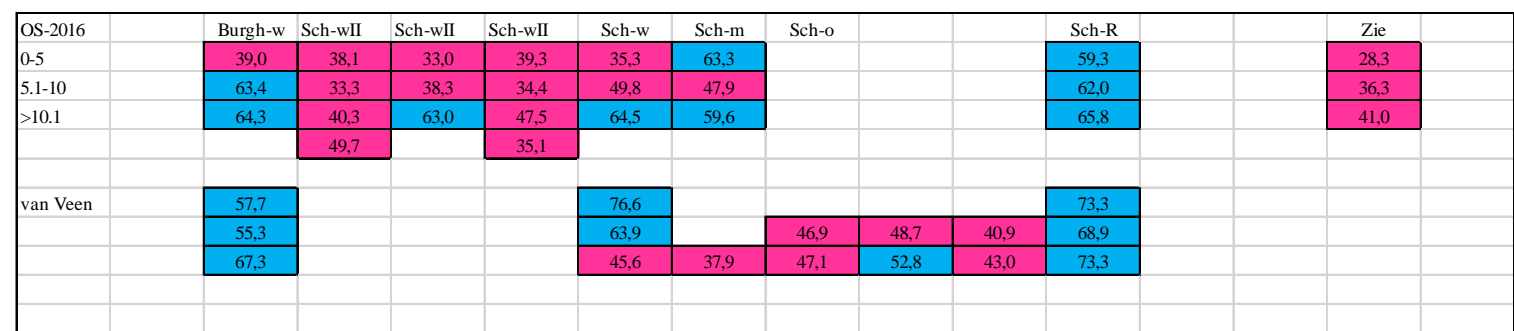

Figuur 13. Percentage droge stof in de bodemsedimenten, rood $<50 \%$ en blauw $>50 \%$.

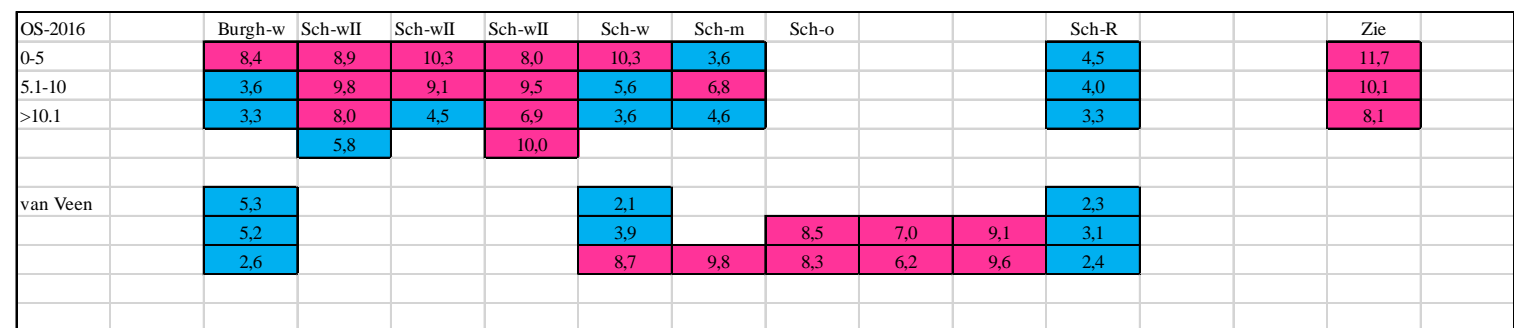

Figuur 14. Percentage organische stof in de bodemsedimenten, rood $>6 \%$ en blauw $<6 \%$.

Op de locatie Burghsluis-west, slechts twee jaar na de bestorting heeft zich over het gehele talud een pakket sediment afgezet. Tot ongeveer 10 meter diepte is deze laag tussen 10 en $40 \mathrm{~cm}$ dik en deze is dunner op grotere diepte. De bijdrage van de fijne fractie $(<0,09 \mathrm{~mm})$ neemt af met de diepte tussen $0(65 \%)$ en ca $15 \mathrm{~m}(13 \%)$ en weer iets toe tussen 20 en 30m (ca 30\%). Op 35 meter bestaat het sediment (ca $5 \mathrm{~cm}$ dik) vooral uit zand (0.3-0.15 mm).

Op de locatie Schelphoek-west II, ook twee jaar na de bemonstering, is de sedimentlaag, tussen de riffen, minder dik dan op de locatie Burghsluis-west, en de sedimenten zijn, vooral ondiep, van fijnere samenstelling. Zoals eerder gerapporteerd i.h.k.v. het RAAKPRO onderzoek is de sedimentdikte sneller toegenomen na de bestorting van 2014 aan de oostelijke kant van het gebied: tot $29 \mathrm{~cm}$ in het transect oost-midden en slechts $8 \mathrm{~cm}$ in het westelijk transect in 2016. Daarenboven blijkt het sediment zich lokaal op te hopen (Tangelder et al., 2017). De meest omvangrijke ophopingen (tussen 10 en $30 \mathrm{~cm}$ ) bevinden zich aan de oostelijke kant van het gebied met name in de ondiepe zone tussen 2,5 en 7,5 meter - NAP rondom de riffen. Daar blijkt de aanwezigheid van de riffen met name in de ondiepe zone, de sedimentatie te versterken door ophoping van sediment rondom de riffen (Tangelder et al., 2017).

Op de locatie Schelphoek-west heeft zich sinds de bestorting van 2009 een pakket sediment gevormd op het talud van gemiddeld $32.3 \mathrm{~cm}$ dikte. Vooral ondiep, tot 9 meter diepte, is dit pakket dik en bestaat uit slib of zand met slib. Dieper neemt de dikte van het sediment af en neemt de bijdrage van de zandfracties toe. Ook in de Van Veen happen was de sedimentdikte op 20-30 m gering, maar op 35 meter is wel een laag van $18 \mathrm{~cm}$ gevonden. Het sediment op $35 \mathrm{~m}$ is fijn van samenstelling en heeft een hoger percentage organische stof dan op 20-30 m. 
Op de locatie Schelphoek-midden, waar de staalslakken met breuksteen afgedekt zijn, komt zeven jaar na de bestorting (2009) bijna geen sediment voor: gemiddeld slechts $0.3 \mathrm{~cm}$ over het talud. In het ondiepere deel, waar breuksteen is afgegleden en de staalslakken blootliggen is er wel wat sediment aanwezig. Met de Van Veen happer was het niet mogelijk om een monster op $32 \mathrm{~m}$ diepte te nemen, en op $45.7 \mathrm{~m}$ kon alleen een schraapmonster worden genomen. Dit monster was fijn van samenstelling (type VIII) en had een hoog percentage organische stof.

Op de locatie Schelphoek-oost is alleen de bodem met een ondergrond van staalslakken (bestorting van 2009) op grotere diepte bemonsterd met de Van Veen happer. Op de zes locaties konden drie schraapmonsters worden genomen en drie monsters met een steekdiepte van $6 \mathrm{~cm}$ of meer. Op twee stations is het type $\mathrm{V}$ (dis) gevonden, op de overige vier wordt het sediment gedomineerd door de fracties kleiner dan $0.09 \mathrm{~mm}$. Het percentage organische stof was hoog op alle stations.

Op de referentie locatie Schelphoek-oost is de onverstoorde bodem bemonsterd. Op het talud ligt gemiddeld $20 \mathrm{~cm}$ aan sediment maar ook natuurlijke oesterriffen. De steekdiepte was beperkt doordat in het sediment een oude steenbestorting werd bereikt, of er gehapt werd op oesterriffen. Op grote diepte varieerde de steekdiepte met de Van Veen happer van 8 tot $14 \mathrm{~cm}$. Op het talud is het ondiepste station op 4.8 meter diepte, gedomineerd door fracties kleiner dan $0.09 \mathrm{~mm}$. Op grotere diepten is dit de fijne zandfractie van 0.15-0.09 mm. Het sediment in de Van Veen happer bestond uit zandfracties (type V en VI). In alle monsters is een hoog percentage droge stof gevonden, en een laag percentage organische stof.

Op de locatie Zierikzee is alleen de sedimentdikte op het talud bepaald. Gemiddeld ligt er, twee jaar na de bestorting, $6 \mathrm{~cm}$ aan sediment op het talud. Het zeegrind is echter golvend gestort waardoor, zoals dit is waargenomen tussen de ecoriffen op de BFN locaties (Tangelder et al., 2017), de sedimentdikten relatief hoog is (tot maximaal $20 \mathrm{~cm}$ ) in de golfdalen. Het sediment is gedomineerd door fracties kleiner dan $0.09 \mathrm{~mm}$, met een laag percentage droge stof en een hoog percentage organische stof.

De omvang en samenstelling van de sedimentafzetting op de bestortingen blijken zeer variabel te zijn op de verschillende locaties en dieptes. Waar op locatie Burghsluis-west na twee jaar al een laag van 10 tot $40 \mathrm{~cm}$ zich heeft kunnen ontwikkelen ligt er, zeven jaar na de bestorting, slechts een laag van $0.3 \mathrm{~cm}$ op de locatie Schelphoek-midden. De oorzaken voor deze variatie zal gezocht moeten worden in verschillen in lokale omstandigheden (hydrodynamica), waardoor geen eenduidige tendens uit die gegevens te halen valt. Wel blijkt dat de aanwezigheid van obstakels zoals ecoriffen (Schelphoekwest II) of grindgolven (Zierikzee) een bevorderende rol speelt bij de afzetting van sediment.

\subsubsection{Relaties tussen gemeenschappen en omgevingsfactoren}

De combinaties tussen omgevingsfactoren en gemeenschappen, op basis van de gegevens verzameld tussen 2009 en 2016, zijn weergegeven in Tabel 20.

In de gemeenschappen A, B en G komen zowel varianten voor in gestabiliseerde bodems (blauw), als in recent gevormde bodems, waarin nog geen of een lager percentage zandfracties aanwezig zijn (rood). In hoofdgroep $\mathrm{H}$, vooral aanwezig op de oostelijke locaties, waaronder Gorishoek en Wemeldinge-oost, zijn de sedimenten fijn-zandig tot zandig, en is de gemeenschap soortenarm, maar heeft karakteristieke tweekleppige soorten. 
Tabel 20. Gemiddelde waarden van de omgevingsfactoren in combinatie met de gemeenschapsvarianten op basis van de gegevens verzameld tussen 2009 en 2016 (blauw is percentage droge stof $>50 \%$ en organische stof $<6 \%$, rood is percentage droge stof $<50 \%$ en organische stof $>6 \%$ ).

\begin{tabular}{|c|c|c|c|c|c|c|c|c|c|c|c|}
\hline Gem & $\mathrm{n} s \mathrm{p}$ & $\mathrm{n} / \mathrm{m} 2$ & nstat & diepte & $\%$ droge stof & $\%$ org. st of & fracties $<0.09 \mathrm{~mm}$ & $\mathrm{v}$ & vI & $\mathrm{V}$ (dis) & VIII \\
\hline A4 & 13,0 & 8036,2 & 2 & 15,0 & 71,5 & 2,1 & 27,4 & - & 50,0 & 50,0 & - \\
\hline A 1 & 9,9 & 4333,8 & 7 & 8,7 & 69,3 & 2,6 & 23,2 & 75,0 & - & 25,0 & - \\
\hline $\mathrm{A} 3$ & 10,0 & 1121,7 & 3 & 6,6 & 66,9 & 2,5 & 29,5 & 66,7 & 33,3 & - & - \\
\hline A 8 & 15,8 & 4579,3 & 23 & 10,4 & 63,5 & 3,8 & 27,1 & 47,1 & 23,5 & 5,9 & 23,5 \\
\hline A 5 & 10,3 & 8651,5 & 4 & 5,7 & 53,9 & 6,2 & 36,1 & 50,0 & - & 25,0 & 25,0 \\
\hline$A_{2}$ & 11,5 & 4878,7 & 15 & 7,7 & 49,9 & 6,4 & 45,0 & 7,7 & 46,2 & 7,7 & 38,5 \\
\hline A 7 & 7,8 & 2124,6 & 10 & 5,0 & 44,5 & 7,8 & 60,2 & - & 20,0 & - & 80,0 \\
\hline$A 6$ & 9,8 & 2883,8 & 12 & 7,3 & 39,1 & 8,7 & 68,4 & - & - & 8,3 & 91,7 \\
\hline B3 & 339 & 12450,6 & 9 & 13,9 & 71,2 & 2,3 & 12,7 & 22,3 & - & 77,8 & - \\
\hline B4 & 24,5 & 48669,0 & 22 & 26,3 & 58,7 & 5,1 & 32,9 & 18,2 & 13,6 & 27,3 & 40,9 \\
\hline $\mathrm{B} 1$ & 24,1 & 11928,8 & 48 & 11,1 & 56,2 & 5,4 & 32,1 & 9,5 & 2,4 & 66,7 & 21,4 \\
\hline $\mathrm{B} 2$ & 18,1 & 7673,1 & 13 & 9,8 & 48,1 & 69 & 45,3 & 23,1 & - & 38,5 & 38,5 \\
\hline $\mathrm{C}$ & 11,7 & 904,1 & 3 & 10,0 & 68,7 & 3,0 & 18,4 & 66,7 & - & 33,3 & - \\
\hline E & 7,0 & 577,6 & 2 & 9,7 & 56,0 & 5,4 & 42,0 & - & - & 50,0 & 50,0 \\
\hline D & 7,3 & 869,6 & 4 & 12,4 & 52,6 & 6,4 & 38,9 & - & 50,0 & - & 50,0 \\
\hline F & 20 & 3164,3 & 1 & 12,0 & & & & & & & \\
\hline G4 & 5,4 & 577,6 & 8 & 6,7 & 56,6 & 5,4 & 36,5 & 50,0 & - & 12,5 & 37,5 \\
\hline$G_{3}$ & 5,0 & 1079,9 & 2 & 8,5 & 40,5 & 8,5 & 72,2 & - & - & - & 100,0 \\
\hline $\mathrm{Gl}$ & 9 & 3616,3 & 1 & 5,0 & & & & & & & \\
\hline $\mathrm{H}$ & 6,4 & 898,5 & 9 & 9,4 & 619 & 3,7 & 29,4 & 2,2 & 66,7 & - & 11,1 \\
\hline I & 8,7 & 786,9 & 3 & 5,1 & 68,5 & 3,1 & 17,2 & 66,7 & - & 33,3 & - \\
\hline $\mathrm{J}$ & 3,4 & 1199,9 & 9 & 6,7 & 45,5 & 7,6 & 58,6 & 12,5 & 12,5 & 37,5 & 37,5 \\
\hline leeg & 0 & 0,0 & 0 & 6,4 & 44,1 & 7,6 & 56,1 & - & 33,3 & - & 66,7 \\
\hline $\mathrm{K}$ & 4 & 200,9 & 1 & 4,7 & 34,4 & 9,5 & 83,9 & - & - & - & 100,0 \\
\hline $\mathrm{M}$ & 3 & 301,4 & 1 & 15,5 & 31,0 & 11,3 & 73,0 & - & - & - & 100,0 \\
\hline $\mathrm{p}$ & 1 & 50,2 & 1 & 7,5 & 30,8 & 11,0 & 87,6 & - & - & - & 100,0 \\
\hline L & 5 & 552,5 & 1 & 15,0 & & & & & & & \\
\hline 0 & 1 & 50,2 & 1 & 3,0 & & & & & & & \\
\hline$Q$ & 1 & 50,2 & 1 & 9,0 & & & & & & & \\
\hline
\end{tabular}




\section{Conclusies en aanbevelingen}

De huidige rapportage geeft de resultaten van de bodemdieren monitoring VOV-OS 2016 weer in relatie tot eerdere jaren en tussen gebieden waar al dan niet bestortingen plaats gevonden hebben, met als doel om antwoorden te geven op de volgende vragen:

1. Hoe snel treedt sedimentatie op de verschillende locaties na de bestortingen van 2009 en 2014

in vergelijking met de referentielocatie en wat is de kwantiteit (sedimentdikte) en de kwaliteit (korrelgrootte en slibgehalte) van dit sediment?

2. Heeft kolonisatie van zacht substraat plaats gevonden na de bestortingen van 2009 en 2014 en welke soorten zijn daar voornamelijk aanwezig/dominant in vergelijking met de situatie vóór de bestortingen en in referentielocatie? Welke van die soorten zijn ook kenmerkende Natura 2000 soorten van het habitattype 1160 in de Oosterschelde?

De bevindingen $m$.b.t. deze vragen worden hieronder weergegeven voor elke locatie:

\section{Burghsluis-west}

1. Sedimentatie: tijdens de twee jaar na de bestorting heeft zich een pakket sediment afgezet met een dikte tussen 10 en $40 \mathrm{~cm}$ dik tot ongeveer 10 meter diepte en dunner wordend op grotere diepte (ca $5 \mathrm{~cm}$ op $35 \mathrm{~m}$ ). Van de kust tot $15 \mathrm{~m}$ neemt de bijdrage van de fijne fractie $(<0,09 \mathrm{~mm})$ in het sediment af van $65 \%$ tot $13 \%$. Tussen 20 en $30 \mathrm{~m}$ is het sediment weer slibrijker (ca $30 \%$ ) en op de diepste punt van het transect, dicht bij de geul, bestaat het sediment vooral uit zand (0.3-0.15 mm). 2. Kolonisatie: twee jaar na de bestorting zijn er evenveel soorten gevonden bij Burghsluis (8) dan vier jaar ervoor (7), terwijl de gemiddelde individuele dichtheden een ordegrootte kleiner zijn in 2016 (804) dan in 2010 (9945). Dit is voor een deel te verklaren door de afwezigheid van infauna op de twee ondiepste monsterlocaties. Ook de bodemgemeenschap op de diepste monsterlocatie in 2016 (D) was armer dan die in 2010 (A1). De kenmerkende N2000 soort voor habitat 1160 Echinocardium cordatum die aanwezig was in 2010, is niet terug gevonden in 2016.

\section{Schelphoek-west II}

1. Sedimentatie: tijdens de twee jaar na de bestorting van 2014 is de sedimentdikte sneller toegenomen aan de oostelijke kant van het gebied: tot $29 \mathrm{~cm}$ in transect oost-midden en slechts $8 \mathrm{~cm}$ in transect west in 2016. Bovendien blijkt de aanwezigheid van de riffen, met name in de ondiepe zone, de sedimentatie te versterken door ophoping van sediment rondom de riffen (Tangelder et al., 2017). Het sediment op locatie Schelphoek-west II is fijner dan bij Burghsluis-west met bijdrage van de fijne fractie $(<0,09 \mathrm{~mm})$ in het sediment tussen 40 en $93 \%$.

2. Kolonisatie: net zoals bij Burghsluis zijn er evenveel soorten of zelf meer soorten gevonden in 2016 (13) twee jaar na de bestorting in vergelijking tot voorafgaande monsterjaren 2013 (12) en 2010 (11). Op Schelphoek-west II (midden-oost) nemen de individuele dichtheden wel toe, van 1741 in 2010 naar 3298 in 2013 tot $5877 \mathrm{ind} / \mathrm{m}^{2}$ in 2016. Met betrekking tot de gemeenschappen valt geen noemenswaardige verandering te melden door de jaren heen. De kenmerkende N2000 soort voor habitat 1160, Nephtys hombergii, aanwezig in 2010 en 2014, is niet aangetroffen in 2016, en de andere N2000 soort, Lanice conchilega, is alleen aangetroffen in 2010.

\section{Schelphoek-west}

1. Sedimentatie: zeven jaar na de bestorting van 2009 ligt een pakket sediment op het talud van gemiddeld $32.3 \mathrm{~cm}$ dikte. Dieper neemt de dikte van het sediment af. Op 35 meter is wel een laag van $18 \mathrm{~cm}$ gevonden. Het sediment bestaat vooral uit de fijne fractie in het ondiepe ( $85 \%<0,09 \mathrm{~mm}$ ) en wordt snel grover met de diepte tot $21 \%$ onder de 10 meter om weer slibrijker (ca $30 \%$ ) te worden op 20-30 m.

2. Kolonisatie: het aantal soorten is iets hoger in 2016 (9) dan in 2014 (6), maar lager dan voor de bestorting (16). Een dergelijke patroon komt echter niet terug op basis van de individuele dichtheden (4370 in 2016 en 3466 in 2009). De gemeenschap in 2016 wijkt niet noemenswaardig af van die voor de bestorting. De enige N2000 soort gevonden op deze locatie, Nephtys hombergii, is in alle monsterjaren aangetroffen. 


\section{Schelphoek-midden}

1. Sedimentatie: zeven jaar na de bestorting van 2009 ligt er nog bijna geen sediment (ca $0.3 \mathrm{~cm}$ ) op de met breukstenen afgedekte staalslakken. lets dieper is er wel wat sediment aanwezig, maar veel minder dan op de andere locaties. De bijdrage van de fijne fractie in het ondiepe (tot $5 \mathrm{~m}$ ) is duidelijke lager $(22 \%<0,09)$ dan op alle andere locaties en neemt toe (tot $48 \%$ ) met de diepte. 2. Kolonisatie: In de monsterjaren na de bestorting bereikte het aantal soorten de hoogste niveau voor deze studie (19 soorten in 2011 en 24 in 2014); in 2016 zijn er 9 soorten aangetroffen. De individuele dichtheden zijn ook het hoogste in 2014 en dalen in 2016 naar een niveau dat hoger is dan in 2011. De bodemgemeenschap zoals aangetroffen in 2016 was ook aanwezig in 2014. In 2016 is voor de eerst keer de N2000 soort Mytilus edulis aangetroffen op deze locatie.

\section{Zierikzee}

1. Sedimentatie: twee jaar na de bestorting van 2014 ligt $6 \mathrm{~cm}$ aan sediment op het talud, dat is ongeveer even veel als op het westelijke transect in Schelphoek-west II. Tussen de grindribben hoopt het sediment versneld op tot pakketten van $20 \mathrm{~cm}$ in dikte. De bijdrage van de fijne fractie $(<0.09$ $\mathrm{mm}$ ) is redelijk hoog (vergelijkbaar met Schelphoek-west II) tussen $67 \%$ en $80 \%$.

2. Kolonisatie: twee jaar na de kolonisatie zijn er evenveel soorten (8) aangetroffen op de locatie Zierikzee als in 2013, ook waren de individuele dichtheden op ongeveer hetzelfde niveau (3214 vs 2729) en verschilden de gemeenschappen niet drastisch van elkaar voor en na de bestorting. De kenmerkende N2000 soort voor habitat 1160, Nephtys hombergii, is aangetroffen zowel in de jaren voor als na de bestorting. Een andere N2000 soort, Cerastoderma edule, is alleen aangetroffen in 2011.

\section{Schelphoek-referentie (oost) vs Schelphoek oost (staalslakken 2009)}

1. Sedimentatie: op de referentielocatie varieerde op grote diepte de steekdiepte met de Van Veen happer van 8 tot $14 \mathrm{~cm}$ (de aanwezigheid van stenen of schelpen in het sediment verhinderde wel regelmatig de bemonstering) en deze was ca $6 \mathrm{~cm}$ in de bestorte locatie. De bijdrage aan fijne fractie $(<0.09 \mathrm{~mm}$ ) was duidelijk lager op de referentielocatie ( 14 tot $28 \%$ ) dan op de bestorte locatie (38 en $48 \%)$.

2. Kolonisatie: het aantal soorten en de individuele dichtheden zijn relatief hoog op de referentielocatie en vergelijkbaar in omvang met de waarnemingen op drie van de vijf monsters in de bestorte locaties. De lagere niveaus in soortendiversiteit en individuele dichtheid op twee van de vijf monsters op de bestorte locatie zijn zeer waarschijnlijk te wijten aan afwijkende lokale omstandigheden. Op één monster na op de bestorte locatie was er ook geen verschil tussen de gemeenschappen aangetroffen op de referentie en de bestorte locatie. Beide N2000 soorten, Carcinus maenas en Mytilus edulis, zijn aangetroffen op de bestorte en de referentielocatie, terwijl Lanice conchilega alleen aanwezig was op de referentielocatie.

Op basis van de huidige waarnemingen kunnen de volgende antwoorden gegeven worden op de hoofdvragen:

1. Hoe snel treedt sedimentatie op de verschillende locaties na de bestortingen van 2009 en 2014 in vergelijking met de referentielocatie en wat is de kwantiteit (sedimentdikte) en de kwaliteit (korrelgrootte en slibgehalte) van dit sediment?

Met betrekking tot de sedimentatiesnelheid, waar op sommige locaties zoals Schelphoek-oost, Schelphoek-west II en Zierikzee, al twee jaar na een bestorting voldoende sediment is opgehoopt voor de ontwikkeling van bodemdierengemeenschappen, verloopt op andere locaties zoals Schelphoekmidden het afzetten van sediment zeer traag. De sedimentafzettingen blijken over het algemeen vrij slibrijk te zijn.

De omvang en samenstelling van de sedimentafzetting op de bestortingen blijken zeer variabel te zijn op de verschillende locaties en dieptes waardoor geen eenduidige tendens uit die gegevens te halen valt. Rekening gehouden met het belang van de bodemkarakteristieken voor de vestiging van bodemdieren is een beter begrip van deze processen en vereiste voor de correcte interpretatie m.b.t. de effecten van de ingreep en eventuele bijsturing ervan.

2. Heeft kolonisatie van zacht substraat plaats gevonden na de bestortingen van 2009 en 2014 en welke soorten zijn daar voornamelijk aanwezig/dominant in vergelijking met de situatie vóór de 
bestortingen en in referentielocatie? Welke van die soorten zijn ook kenmerkende Natura 2000 soorten van het habitattype 1160 in de Oosterschelde?

Op basis van de huidige waarnemingen kan geconcludeerd worden dat, evenals bij de sedimentatieprocessen, de kolonisatie van het sediment sterke verschillen vertonen tussen de onderzochte locaties. Waar op Schelphoek-oost, Schelphoek-west II en Zierikzee, zich bodemdiergemeenschappen ontwikkelen die zeer vergelijkbaar zijn met de gemeenschappen die aanwezig waren voor de bestorting, verloopt de kolonisatie van de slibrijke sedimentlaag op andere locaties, zoals Burghsluis, duidelijk achter.

De resultaten laten geen stelselmatige verschuiving zien in de taxonomische samenstelling van de bodemdiergemeenschap. Het is dus niet mogelijk om, op die tijdschaal, een taxonomische groep aan te wijzen die selectief bevorderd wordt door het beschikbaar komen van een nieuwe sedimentafzetting.

Door de relatieve lage dichtheden waarmee de meeste kenmerkende N2000 soorten in de monsters voorkomen betreffen waarnemingen in de monitoring louter toevaltreffers. Daardoor valt er ook over de afwezigheid van die soorten in de monsters van een locatie weinig zinvols te concluderen met betrekking tot die locatie.

Ook vinden er ontwikkelingen in de bodemdiergemeenschappen plaats, zoals een explosieve toename in individuele dichtheid (vooral Oligochaeta) op Schelphoek-midden en Zierikzee respectievelijk vijf en zeven jaar na de bestorting. Dergelijke waarnemingen kunnen de interpretatie van de veranderingen i.r.t. de ingrepen bemoeilijken.

De huidige bevindingen benadrukken de moeilijkheid om tendensen en/of verschillen kwantitatief te detecteren. Dit lage onderscheidend vermogen heeft mogelijk te maken met de volgende aspecten van de huidige monitoring:

\section{Hoge onregelmatigheid van de monitoringsfrequentie}

Omdat niet alle locaties tijdens elke monsterperiode bezocht zijn is het niet mogelijk om de categorieën "jaar" en "locatie" als onafhankelijke factoren in een kwantitatieve analyse mee te nemen. Daardoor blijven de vergelijkingen die worden gemaakt afhankelijk van onbepaalde interacties tussen de factoren jaar en locatie.

2. Gebruik van verschillende bemonsteringstechnieken

Door de geringere bemonsteringsoppervlakte worden meer 'zeldzame' soorten gemist met de 6 steekbuizen dan met de Van Veen happer. Tegelijkertijd worden meer diep levende infauna verzameld met de steekbuizen in vergelijking tot de Van Veen happer waar relatief meer epifauna soorten worden bemonsterd. Daardoor kunnen steekbuizen en Van Veen monsters, ook komen die uit hetzelfde gebied, niet direct vergeleken worden op basis van de bodemdiergemeenschappen maar slechts met betrekking tot dichtheden en dominante soorten.

3. Afwezigheid van gerepliceerde bemonsteringen

Elke individuele waarnemingen bevat een afwijking t.o.v. de gemiddelde van de populatie waaruit die getrokken is. Door meerdere monsters te nemen op een locatie (replica's) kan een beter beeld worden verkregen van de variatie in bodemgemeenschappen op de locatie. Bij gebrek aan een gerepliceerde bemonstering binnen een bepaald (zo homogeen mogelijk) habitat blijft het niet mogelijk om tot een schatting te komen voor deze individuele variatie. 


\section{$6 \quad$ Kwaliteitsborging}

Wageningen Marine Research beschikt over een ISO 9001:2008 gecertificeerd kwaliteitsmanagementsysteem (certificaatnummer: 187378-2015-AQ-NLD-RVA). Dit certificaat is geldig tot 15 september 2018. De organisatie is gecertificeerd sinds 27 februari 2001. De certificering is uitgevoerd door DNV Certification B.V. 


\section{$7 \quad$ Literatuur}

In huidige rapportage:

Anderson, M.J., Gorley, R.N. and Clarke, K.R. (2008) PERMANOVA for PRIMER: Guide to Software and Statistical Methods. PRIMER-E, Plymouth.

Clarke, K.R. and Gorley, R.N. (2006) PRIMER v6: User Manual/Tutorial (Plymouth Routines in Multivariate Ecological Research). PRIMER-E, Plymouth.

Escaravage, V., Herman, P. M. J., Merckx, B., Wlodarska-Kowalczuk, M., Amouroux, J. M., Degraer, S., Willems, W. (2009). Distribution patterns of macrofaunal species diversity in subtidal soft sediments: biodiversity-productivity relationships from the MacroBen database. Marine Ecology Progress Series, 382, 253-264.

Kaandorp, J.A., 1986. Rocky substrate communities of the inffalittoral fringe of the Boulonnais, NW France: a quantitative survey. Mar. Biol, 92: 255-265.

Kovach W (1999) MVSP-A MultiVariate Statistical Package for Windows, ver. 3.1 Kovach Computing Services. Pentraeth, Wales, Great Britain.

Tangelder, M., van Oijen, T., de Kluijver, M.\& Ysebaert T. (2017). Ontwikkeling epifauna, infauna en kreeften (T0, T1, T2) op een ecologisch aantrekkelijke vooroeverbestorting (Schelphoek, Oosterschelde) Monitoring Building for Nature proefvak Schelphoek. Wageningen Marine Research Wageningen UR (University \& Research centre), Wageningen Marine Research rapport C039/17.

\section{Voorafgaande rapportages:}

Tangelder, M., Brummelhuis, E.B.M. de Kluijver M. \& Van den Heuvel-Greve, M.J (2014). Data rapport: Het effect van vooroeververdediging op bodemorganismen in de Oosterschelde: 2013. I MARES Wageningen UR, rapport C119/14

Tangelder, M, De Kluijver, M.J., Brummelhuis, E.B.M., Van den Heuvel-Greve, M.J . (2015) Data rapport: Effect van vooroeververdediging op bodemorganismen in Oosterschelde en Westerschelde in 2014. I MARES Wageningen UR, rapport C116/15.

Tangelder, M, De Kluijver, M.J., Craeymeersch, J., E.B.M. Brummelhuis, Van den Heuvel-Greve, M.J. (2017) Data rapport: Effect van vooroeververdediging op bodemorganismen in de Oosterschelde in 2017. I MARES Wageningen UR, rapport C013/17.

Tangelder, M., Schellekens, T., De Kluijver, M. en van den Heuvel-Greve, M (2014). Monitoring vooroeververdediging 2013. IMARES Wageningen UR, rapport C102/14.

Tangelder, M., M.J. Van den Heuvel-Greve, S.T. Glorius, H. Jansen (2015) Monitoring vooroeververdediging Oosterschelde en Westerschelde in 2014. IMARES Wageningen UR, rapport C102/15.

Van den Heuvel-Greve, M.J. (2010). T0 monitoring vooroeververdediging Oosterschelde; cluster 1 2009. IMARES Wageningen UR, rapport C137/09.

Van den Heuvel-Greve, M., A. van den Brink, S. Glorius, C. Schipper, M. de Kluijver, M. Dubbeldam (2011). Monitoring vooroeververdediging Oosterschelde 2010: T1 Cluster 1/T0 Cluster 2. I MARES Wageningen UR, rapport C029/11.

Van den Heuvel-Greve, M., A. van den Brink, S. Glorius, C. Schipper, A. Gittenberger, M.J . de Kluijver, M. Dubbeldam (2012). Monitoring vooroeververdediging Oosterschelde en Westerschelde 2011: T2 Cluster 2. IMARES Wageningen UR, rapport C081/12.

Van den Heuvel-Greve, M., A. van den Brink, S. Glorius, M.J. de Kluijver, M. Dubbeldam (2013). Monitoring vooroeververdediging Oosterschelde en Westerschelde 2012: T3 Cluster 1. IMARES Wageningen UR, rapport C102/13.

Van den Heuvel-Greve, M.; M. Tangelder; T. Ysebaert; M de Kluijver (2016) Notitie Kolonisatie van bodemgemeenschappen van zacht substraat in de Oosterschelde en Westerschelde na vooroeververdediging. IMARES Wageningen UR. p. 31 


\section{$8 \quad$ Verantwoording}

Rapport C089/17

Projectnummer: 4313100048

Dit rapport is met grote zorgvuldigheid tot stand gekomen. De wetenschappelijke kwaliteit is intern getoetst door een collega-onderzoeker en het verantwoordelijk lid van het managementteam van Wageningen Marine Research

$\begin{array}{ll}\text { Akkoord: } & \text { Tom Ysebaert } \\ & \text { Onderzoeker }\end{array}$

Handtekening:

Datum:

10 november 2017

Akkoord: $\quad$ Jakob Asjes

MT lid integratie

Handtekening:

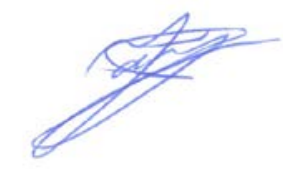

Datum:

10 november 2017 
9 Bijlagen 
Bijlage 1. Beoogd ontwerp van de eco-toplaag in de drie studiegebieden

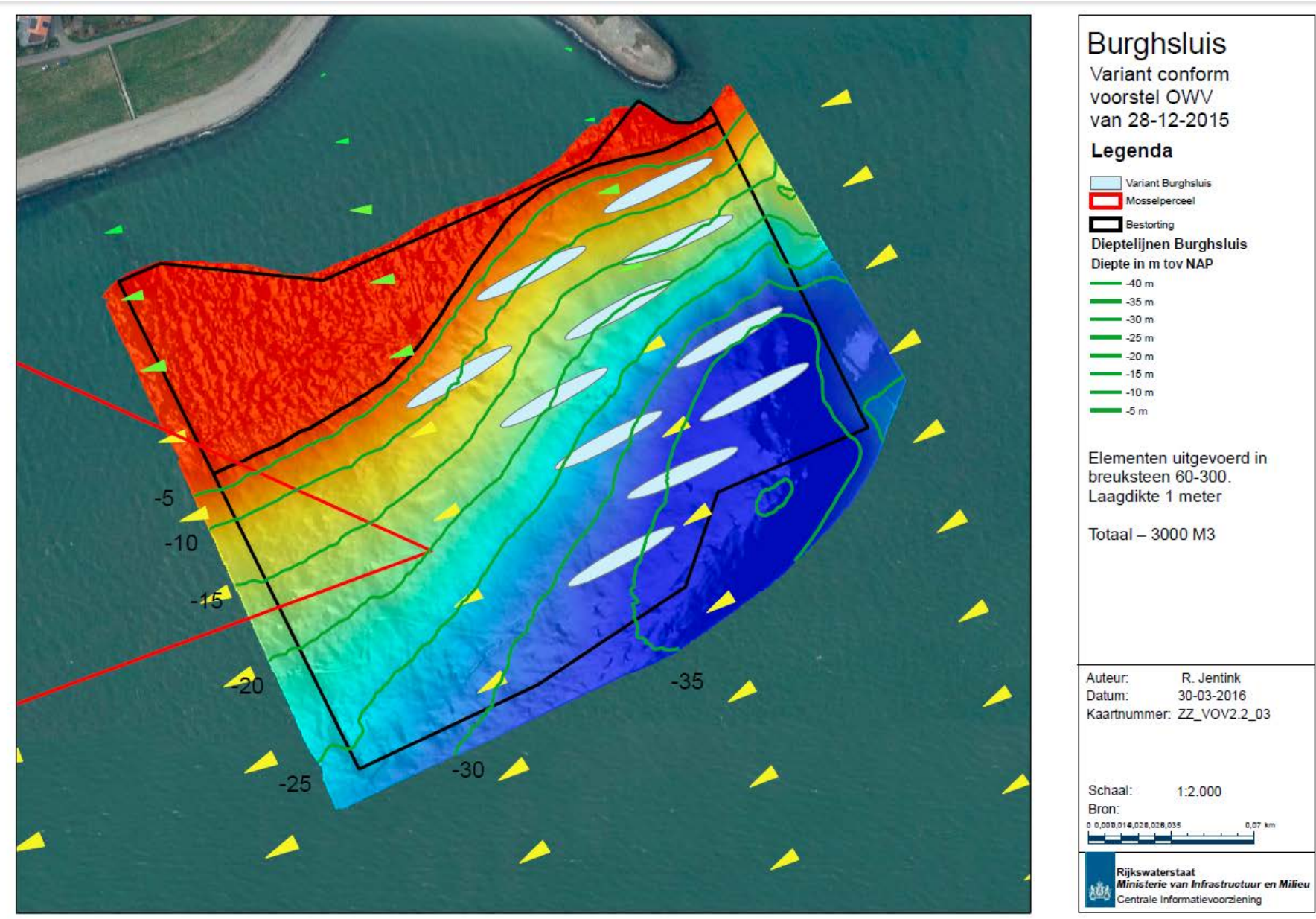




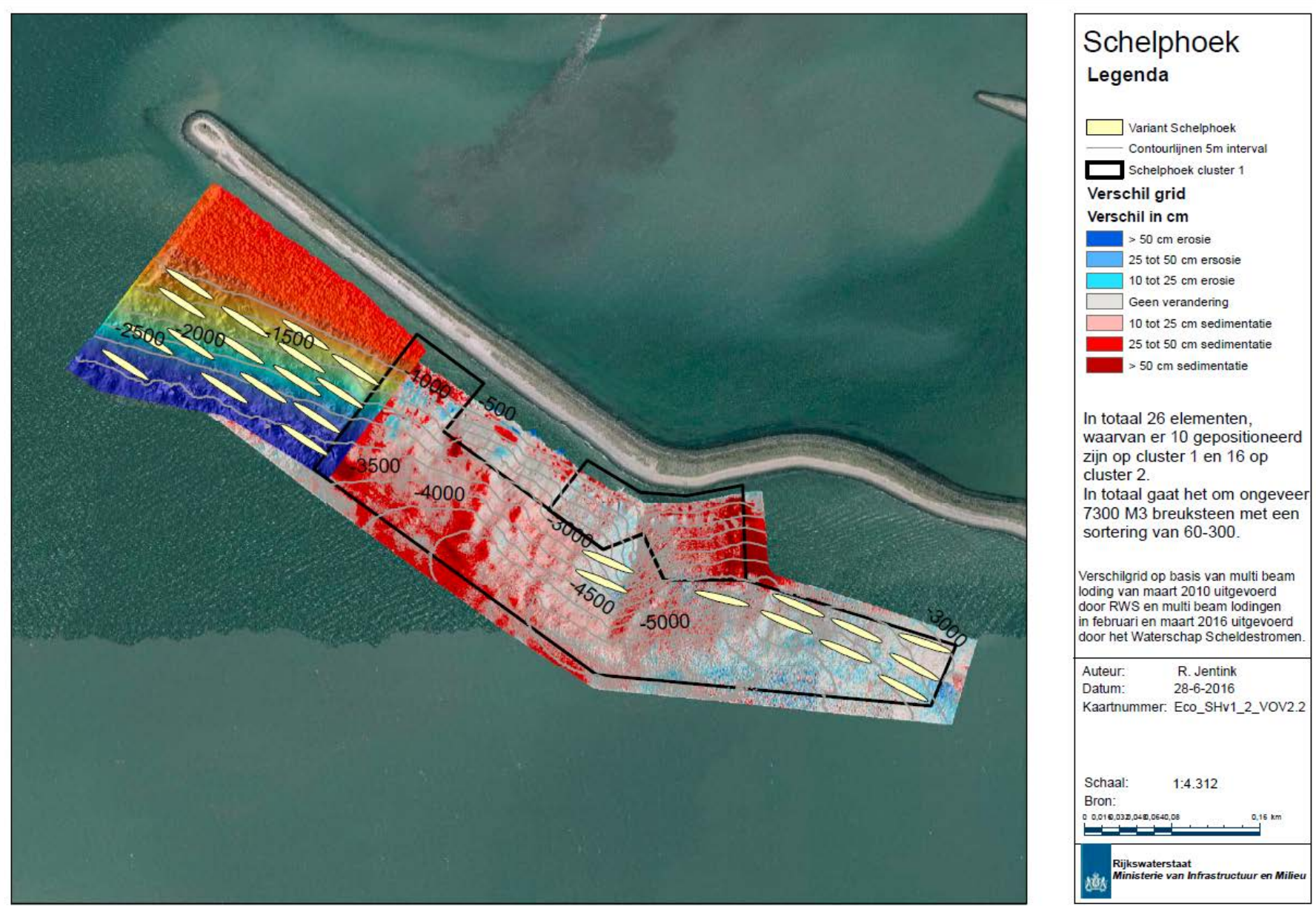

* Het ontwerp links op de kaart betreft Schelphoek Cluster 2.2 (zeegrind/zandsteen/breuksteen, bestort in 2014) en het ontwerp rechts op de kaart betreft Schelphoek Cluster 1 (staalslakken en breuksteen, bestort in 2009) 


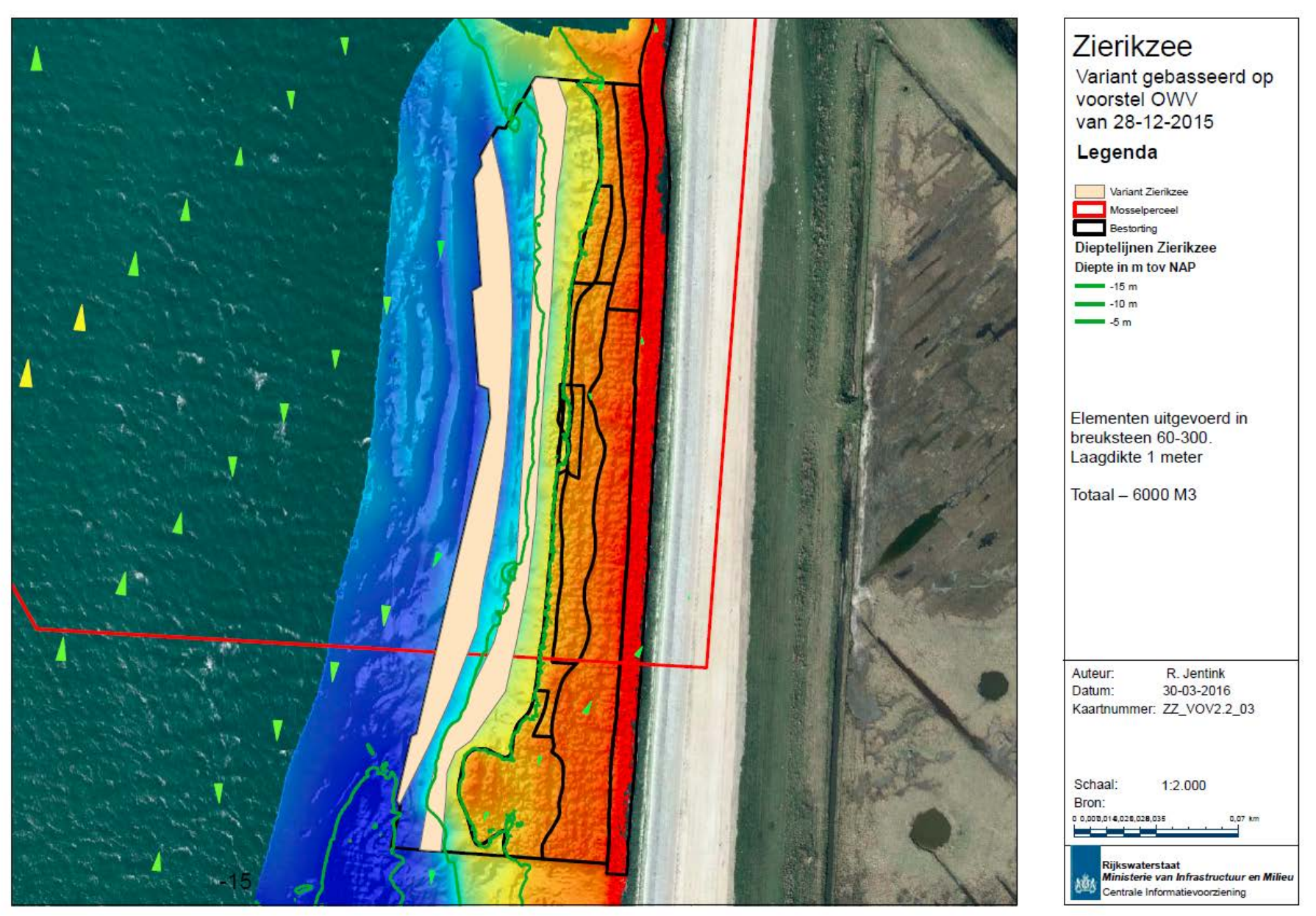


Bijlage 2. Oorspronkelijk ontwerp van de ecoriffen op locatie Schelphoek-westl I, Building for Nature (zie Tangelder et al. 2017 voor meer informatie; uiteindelijke uitvoering verschillend van oorspronkelijke opzet).

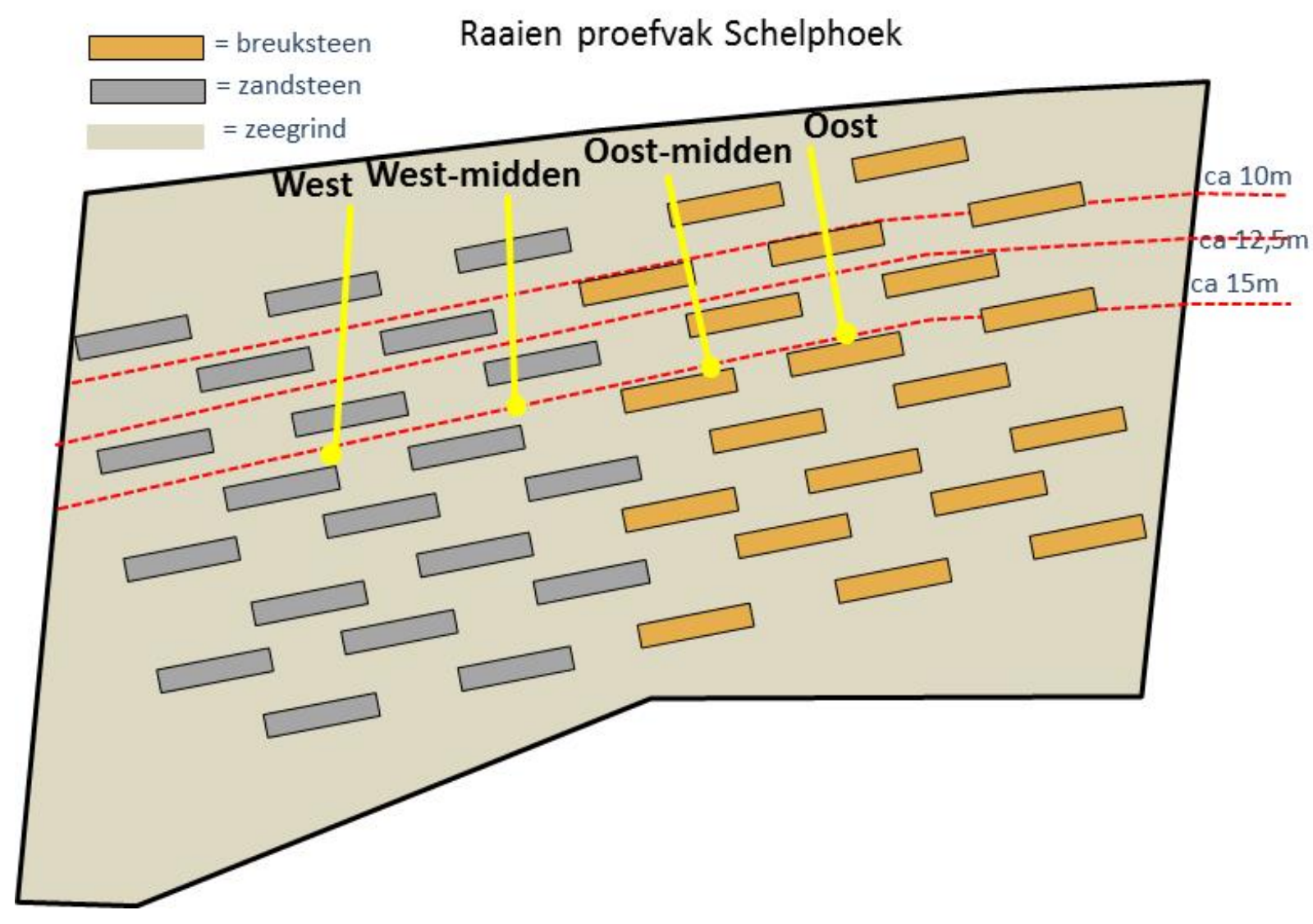




\section{Bijlage 3. Effecten van de monstertuigen op de waarnemingen en de mogelijke gevolgen voor de vergelijkingen tussen monsters verkregen d.m.v. verschillende monstertechnieken.}

De twee gebruikte methodes verschillen vooral m.b.t. het monsteroppervlak: 0,02 $\mathrm{m}^{2}$ voor de steekbuizen en 0,1 $\mathrm{m}^{2}$ voor de van Veen happer. Bovendien steekt de Van Veen minder diep het sediment in dan de steekbuizen. Dit kan een effect hebben op de waargenomen infauna soortenrijkdom en dichtheid.

Het gemiddeld aantal soorten per monster is hoger in de monsters verzameld met de Van Veen happer $(26,2 \pm 4,5)$ dan waar gebruik is gemaakt van de steekbuizen $(10,2 \pm 1,5)$. Dit verschil zou toegeschreven kunnen worden aan het verschil in bemonsterd oppervlak m.b.v. de steekbuizen $(0,02$ $\left.\mathrm{m}^{2}\right)$ in vergelijking tot de Van Veen happer $\left(0,10 \mathrm{~m}^{2}\right)$. Uit de analyse in Escaravage et al. (2009) bleek inderdaad dat verandering in soortenrijkdom (ds) als functie van de relatieve verandering in bemonsterd oppervlak $(\mathrm{dA})$ benaderd konden worden door de volgende formule: $d S \approx \mathrm{dA}^{\wedge} 0,44$.

Dit betekent een verdubbeling van het aantal soorten in de monsters als gevolg van de vijfverhouding van het monsteroppervlak tussen de steekbuizen en de Van Veen happer wat goed overeenkomt met de huidige waarnemingen.

Ook met betrekking tot de dichtheid liggen de waarnemingen verzameld met de Van Veen (gemiddeld een ordegrootte) hoger $(50732 \pm 22774)$ dan voor de steekbuizen (7456 \pm 5132$)$. Door het grotere oppervlak zijn er meer zeldzame soorten te verwachten in de Van Veen dan in de steekbuizen maar de effecten ervan op de dichtheden is verwaarloosbaar aangezien zeldzame soorten vooral in lage dichtheden voorkomen. Het verschil in bemonstering efficiëntie tussen de Van Veen happer en de steekbuizen geldt inderdaad vooral voor soorten met een dichtheid lager dan 200 ind. per $\mathrm{m}^{2}$ waarvoor de individuele trefkans sneller afneemt in de steekbuizen dan in de Van Veen happer (Figuur 15A).

De gemiddelde dichtheid (uitgedrukt in $\mathrm{N}$ per $\mathrm{m}^{2}$ ) van de soorten getroffen in de Van Veen happer is altijd hoger in de van Veen dan in de steekbuizen (Figuur 15B) wat niet toe te schrijven kan zijn aan het groter bemonsteringsoppervlak van de monstertuig.
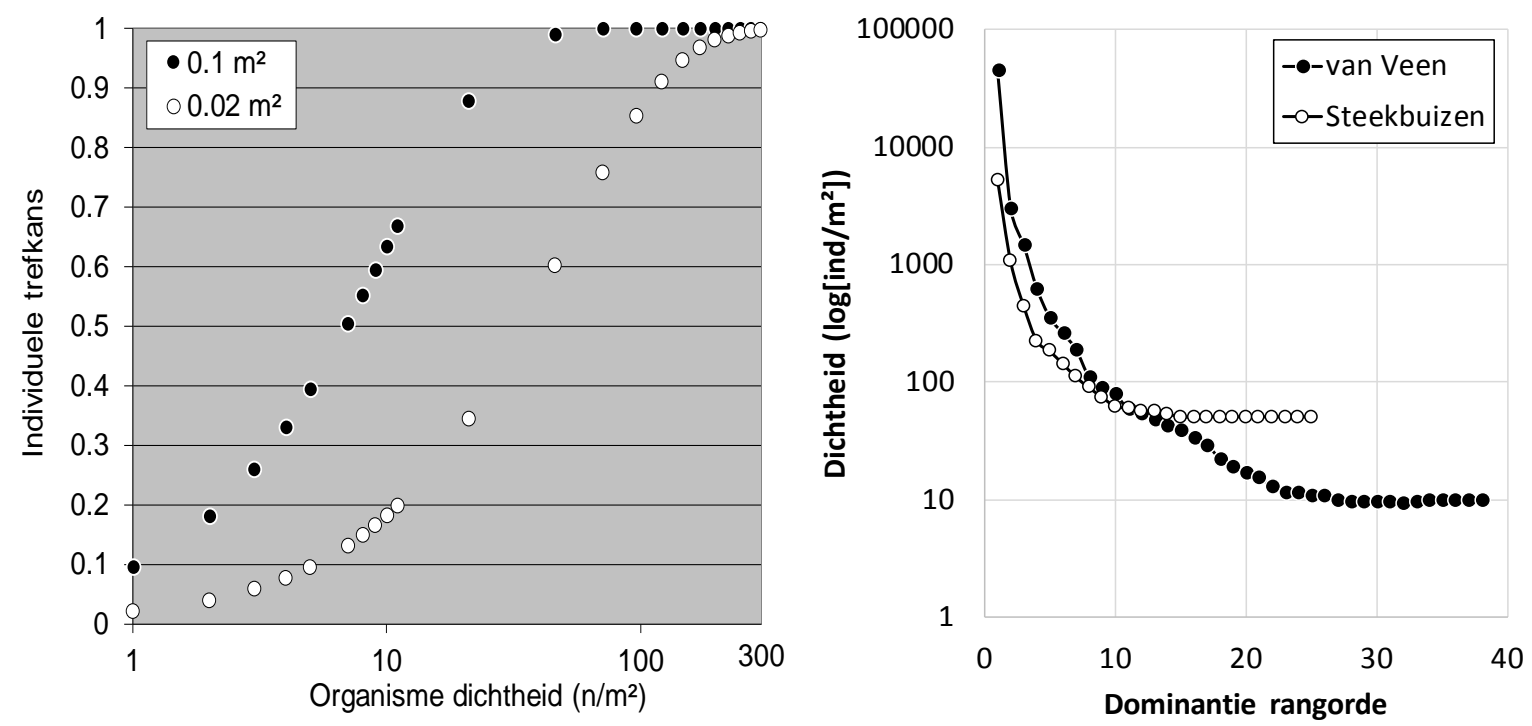

A

Figuur 15. A-Individuele trefkans als functie van de dichtheid d.m.v. monstertuigen van $0,1 \mathrm{~m}^{2}$ (Van Veen happer) en $0,02 \mathrm{~m}^{2}$ (steekbuizen). B-Gemiddelde dichtheid van soorten gesorteerd op basis van dominantie bemonsterd m.b.v. de Van Veen happer versus m.b.v. de steekbuizen.

De huidige analyse wijst erop dat de verschillen in het aantal soorten zoals waargenomen tussen de steekbuizen en de Van Veen happer mogelijk te verklaren zijn door de verschillen tussen de twee monstertuigen. Dit geldt niet voor de hogere dichtheden zoals waargenomen met de Van Veen happer die zeer vermoedelijk representatief zijn voor de veldsituatie.

Als aanvulling op deze resultaten op basis van soortenrijkdom en dichtheid is door Stichting Zeeschelde een vergelijking uitgevoerd tussen monsters verzameld met steekbuizen en de Van Veen happer binnen dezelfde gemeenschapsvariant B4 (Tabel 21). 
Tabel 21. Soortensamenstelling van gemeenschapsvariant B4, bemonsterd met de Van Veen happer (vv) en steekbuizen (sb).

\begin{tabular}{|c|c|c|c|c|c|c|c|}
\hline & & B4-vv & B4-sb & vervolg & & & \\
\hline Oligochaeta & Oli & 47517,2 & 16775,7 & & & & \\
\hline Abra alba & Mol & 2559,6 & 6203,0 & & & B4-vv & B4-sb \\
\hline Mediomastus fragilis & Po & $\underline{1727,8}$ & 891,5 & Owenia fusiformis & Po & 11,4 & 150,7 \\
\hline Actiniaria & An & $\underline{206,4}$ & $\underline{816,2}$ & Aora typica & $\mathrm{Cr}$ & 0,7 & $\underline{50,2}$ \\
\hline Pholoe baltica & Po & 188,6 & 150,7 & Anoplodactylus petiolatus & Pyc & 0,7 & $\underline{12,6}$ \\
\hline Capitella capitata & Po & 49,6 & 263,7 & Bodotria scorpioides & $\mathrm{Cr}$ & 0,7 & $\underline{12,6}$ \\
\hline Sthenelais boa & Po & $\overline{74,3}$ & $\underline{238,6}$ & Macoma balthica & Mol & 0,0 & $\underline{12,6}$ \\
\hline Kurtiella bidentata & Mol & $\underline{77,9}$ & $\underline{213,5}$ & Pectinaria koreni & Po & 1,4 & $\underline{12,6}$ \\
\hline Pseudopolydora pulchra & Po & $\underline{53,6}$ & $\underline{188,3}$ & Ophiuroidea & Ech & 0,7 & $\underline{12,6}$ \\
\hline Melita obtusata & $\mathrm{Cr}$ & $\underline{151,4}$ & 37,7 & Phoronida & $\mathrm{Ph}$ & 0,0 & $\underline{12,6}$ \\
\hline Notomastus latericeus & Po & 42,1 & 37,7 & Pycnogonida & Pyc & 0,0 & 12,6 \\
\hline Corophiidae & $\mathrm{Cr}$ & $\underline{22,9}$ & $\overline{37,7}$ & & & & \\
\hline Monocorophium acherusicur & $\mathrm{Cr}$ & $\underline{15,7}$ & $\underline{37,7}$ & dichtheid $\mathrm{n} / \mathrm{m} 2$ & & 54240,4 & 26331,3 \\
\hline Venerupis corrugata & Mol & 28,6 & $\underline{12,6}$ & & & & \\
\hline Mya arenaria & Mol & 24,3 & $\overline{12,6}$ & Index Log base 2 & & 1,040 & 1,771 \\
\hline Caprellidae & $\mathrm{Cr}$ & $\overline{5,0}$ & $\underline{25,1}$ & evenness & & 0,220 & 0,452 \\
\hline Aonides oxycephala & Po & $\underline{10,7}$ & $\underline{12,6}$ & gemiddeld aantal soorten & & 27,3 & 14,5 \\
\hline Glycera (spec.) & Po & 9,3 & $\underline{12,6}$ & & & & \\
\hline Aoridae & $\mathrm{Cr}$ & $\underline{8,6}$ & $\underline{12,6}$ & & & & \\
\hline Nereis longissima & Po & $\frac{7,9}{19}$ & $\underline{12,6}$ & & & & \\
\hline Nephtys hombergii & Po & $\overline{7,1}$ & $\overline{12,6}$ & & & & \\
\hline Ophiothrix fragilis & Ech & 382,1 & 12,6 & & & & \\
\hline Lysianassa ceratina & $\mathrm{Cr}$ & 277,9 & 0,0 & & & & \\
\hline Mytilus edulis & Mol & 237,1 & 12,6 & & & & \\
\hline Aphelochaeta marioni & Po & 218,1 & 12,6 & & & & \\
\hline Nemertea & $\mathrm{Ne}$ & $\underline{92,9}$ & 0,0 & & & & \\
\hline Streblospio shrubsolii & Po & $\underline{26,8}$ & 0,0 & & & & \\
\hline Platyhelminthes & Pt & $\underline{23,6}$ & 0,0 & & & & \\
\hline Crepidula fornicata & Mol & 20,7 & 0,0 & & & & \\
\hline Subadyte pellucida & Po & $\overline{16,4}$ & 0,0 & & & & \\
\hline Eteone (spec.) & Po & $\underline{16,4}$ & 0,0 & & & & \\
\hline Pholoe inornata & Po & 15,0 & 0,0 & & & & \\
\hline Ophiura ophiura & Ech & $\underline{12,9}$ & 0,0 & & & & \\
\hline Scoloplos armiger & Po & 6,4 & 0,0 & & & & \\
\hline Buccinum undatum & Mol & $\underline{5,7}$ & 0,0 & & & & \\
\hline Cerianthus Iloydii & An & 5,7 & 0,0 & & & & \\
\hline Lepidonotus squamatus & Po & $\underline{5,0}$ & 0,0 & & & & \\
\hline Pisidia longicornis & $\mathrm{Cr}$ & $\underline{5,0}$ & 0,0 & & & & \\
\hline Prionospio steenstrupi & Po & 4,3 & 0,0 & & & & \\
\hline Polynoidae & Po & $\overline{4,3}$ & 0,0 & & & & \\
\hline Asterias rubens & Ech & 3,6 & 0,0 & & & & \\
\hline Kefersteinia cirrata & Po & $\underline{3,6}$ & 0,0 & & & & \\
\hline Lanice conchilega & Po & $\overline{3,6}$ & 0,0 & & & & \\
\hline Harmothoe (spec.) & Po & 3,6 & 0,0 & & & & \\
\hline Carcinus maenas & $\mathrm{Cr}$ & $\underline{2,9}$ & 0,0 & & & & \\
\hline Spisula subtruncata & Mol & $\underline{2,9}$ & 0,0 & & & & \\
\hline Microdeutopus (spec.) & $\mathrm{Cr}$ & $\underline{2,9}$ & 0,0 & & & & \\
\hline Polydora (spec.) & Po & $\frac{2,9}{2,9}$ & 0,0 & & & & \\
\hline Cossura longocirrata & Po & $\underline{2,1}$ & 0,0 & & & & \\
\hline Eumida sanguinea & Po & 2,1 & 0,0 & & & & \\
\hline Flabelligera affinis & Po & $\underline{2,1}$ & 0,0 & & & & \\
\hline Sabellaria spinulosa & Po & $\overline{2,1}$ & 0,0 & & & & \\
\hline Eumida (spec.) & Po & $\underline{2,1}$ & 0,0 & & & & \\
\hline Harmothoe impar & Po & $\underline{1,4}$ & 0,0 & & & & \\
\hline Microdeutopus anomalus & $\mathrm{Cr}$ & $\underline{1,4}$ & 0,0 & & & & \\
\hline Ostrea edulis & Mol & 1,4 & 0,0 & & & & \\
\hline Syllidia armata & Po & $\overline{1,4}$ & 0,0 & & & & \\
\hline Autolytus (spec.) & Po & 1,4 & 0,0 & & & & \\
\hline BRYOZOA & $\mathrm{Br}$ & 1,4 & 0,0 & & & & \\
\hline Eunoe nodosa & Po & 1,4 & 0,0 & & & & \\
\hline Hesionidae & Po & 1,4 & 0,0 & & & & \\
\hline Malmgreniella (spec.) & Po & 1,4 & 0,0 & & & & \\
\hline Liocarcinus holsatus & $\mathrm{Cr}$ & $\underline{0,7}$ & 0,0 & & & & \\
\hline Monocorophium insidiosum & $\mathrm{Cr}$ & 0,7 & 0,0 & & & & \\
\hline Neoamphitrite figulus & Po & $\underline{0,7}$ & 0,0 & & & & \\
\hline Pagurus bernhardus & $\mathrm{Cr}$ & $\underline{0,7}$ & 0,0 & & & & \\
\hline Petricola pholadiformis & Mol & $\underline{0,7}$ & 0,0 & & & & \\
\hline Scalibregma inflatum & Po & $\underline{0,7}$ & 0,0 & & & & \\
\hline Sphaerodorum gracilis & Po & $\underline{0,7}$ & 0,0 & & & & \\
\hline Styela clava & Tu & $\underline{0,7}$ & 0,0 & & & & \\
\hline Syllis gracillis & Po & 0,7 & 0,0 & & & & \\
\hline Cheirocratus (spec.) & $\mathrm{Cr}$ & $\underline{0,7}$ & 0,0 & & & & \\
\hline Decapoda & $\mathrm{Cr}$ & $\underline{0,7}$ & 0,0 & & & & \\
\hline Gastropoda & Mol & $\underline{0,7}$ & 0,0 & & & & \\
\hline Nereis (spec.) & Po & $\underline{0,7}$ & 0,0 & & & & \\
\hline Polycirrus (spec.) & Po & $\underline{0,7}$ & 0,0 & & & & \\
\hline Sycon & Sp & $\overline{0,7}$ & 0,0 & & & & \\
\hline
\end{tabular}

Het gemiddelde aantal soorten per station en de gevonden dichtheden zijn ongeveer een factor twee keer hoger bij het gebruik van de Van Veen happer dan met de steekbuizen.

24.4\% van de soorten komen in beide methoden voor, $65.1 \%$ alleen in de monsters van de Van Veen en $10,5 \%$ van de soorten alleen in de steekbuis-monsters.

Zoals aangetoond d.m.v. de vorige berekening kan het grotere bemonsterde oppervlak van de Van Veen het hogere aantal gevonden soorten verklaren maar niet de verdubbeling van de dichtheden zoals waargenomen tussen de van Veen- en de steekbuizen-monsters.

De dominante soorten uit de Van Veen happer laten zien dat er schraapmonsters van harde substraten zijn. De brokkelsterren en mosselbroed zijn oppervlakte soorten en Styela clava, Crepidula fornicata en Asterias rubens zijn zeker met harde substraten verbonden. 
Bijlage 4. Typische soorten gebruikt als kwaliteitselement in de profielbeschrijving van habitat 1160

( $\mathrm{Ca}=$ constante soort met indicatie voor goede abiotische toestand;

$\mathrm{Cab}=$ constante soort met indicatie voor goede abiotische toestand en goede biotische structuur).

\begin{tabular}{|l|l|l|l|}
\hline Nederlandse naam & Wetenschappelijke naam & Soortgroep & Categorie2 \\
\hline Zeeanjelier & Metridium senile & Bloemdieren & Cab \\
\hline Wadpier & Arenicola marina & Borstelwormen & \\
\hline Schelpkokerworm & Lanice conchilega & Borstelwormen & $\mathrm{Ca}$ \\
\hline Zandzager & Nephtys hombergii & Borstelwormen & $\mathrm{Ca}$ \\
\hline Zeeduizendpoot & Hediste diversicolor & Borstelwormen & $\mathrm{Ca}$ \\
\hline Gewone strandkrab & Carcinus maenas & Kreeftachtigen & $\mathrm{Cab}$ \\
\hline Buldozerkreeftje & Urothoe poseidonis & Kreeftachtigen & $\mathrm{Ca}$ \\
\hline Hartegel & Echinocardium cordatum & Stekelhuidigen & $\mathrm{Ca}$ \\
\hline Kokkel & Cerastoderma edule & Weekdieren & $\mathrm{Ca}$ \\
\hline Mossel & Mytilus edulis & Weekdieren & $\mathrm{Ca}$ \\
\hline
\end{tabular}




\section{Bijlage 5. Resultaten van de sediment analyses uitgevoerd door RWS op de monsters uit de huidige studie (korrelgrootte metingen)}

\begin{tabular}{|c|c|c|c|c|c|c|c|c|c|c|c|c|c|c|c|c|c|c|c|c|}
\hline ies & $\begin{array}{c}\text { Monster- } \\
\text { codes }\end{array}$ & $\begin{array}{l}\widehat{১} \\
\text { ১े } \\
\text { 당 }\end{array}$ & $\begin{array}{l}\bar{\Xi} \\
0 \\
0 \\
\frac{1}{0} \\
\frac{0}{0}\end{array}$ & $\begin{array}{l}\bar{\varrho} \\
m \\
\underline{n} \\
\underline{0} \\
\underline{0}\end{array}$ & $\begin{array}{l}\widehat{\varrho} \\
\text { m} \\
0 \\
\underline{0} \\
\underline{0}\end{array}$ & 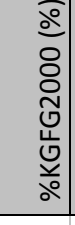 & $\begin{array}{l}\widehat{\xi} \\
\underline{\Xi} \\
0 \\
-1 \\
0\end{array}$ & 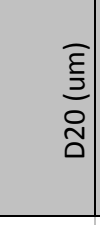 & $\begin{array}{l}\bar{\xi} \\
\underline{\Xi} \\
\circ \\
\tilde{m}\end{array}$ & $\begin{array}{l}\bar{\xi} \\
\bar{\Xi} \\
o \\
\vdots\end{array}$ & $\begin{array}{l}\bar{\xi} \\
\underline{\Xi} \\
\text { م⿱ } \\
0\end{array}$ & $\begin{array}{l}\bar{\xi} \\
\underline{\Xi} \\
o \\
o\end{array}$ & 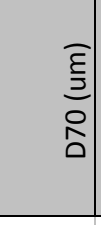 & $\begin{array}{l}\bar{\xi} \\
\bar{\Xi} \\
\circ \\
\infty \\
0\end{array}$ & 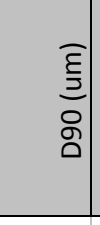 & $\begin{array}{l}\bar{\xi} \\
\underline{\Sigma} \\
\tilde{n} \\
0 \\
\Sigma\end{array}$ & $\begin{array}{l}\overrightarrow{0} \\
\underline{\underline{n}}\end{array}$ & 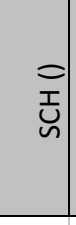 & $\begin{array}{l}\overline{\bar{E}} \\
\bar{\Xi} \\
\bar{v} \\
\overline{\bar{u}}\end{array}$ & 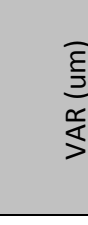 \\
\hline Burghsluis & inf243 & 67.2 & 12.9 & 3.5 & 5.2 & 0.1 & 76.2 & 96.4 & 12.8 & 128.7 & 145.2 & 163.5 & 185.1 & 213.0 & 55.3 & 150.4 & 0.4 & 0.7 & 25 & 72.0 \\
\hline Burghsluis & f244 & 56.5 & 18.2 & 12.0 & 17.8 & 0.1 & 46.2 & 64.3 & 78.9 & 92.6 & 106.8 & 122.5 & 140.9 & 64.7 & 01.1 & 116.8 & 0.5 & 0.8 & 0 & 61.5 \\
\hline Burghsluis & $n f 245$ & 49.6 & .1 & 8.8 & 13.3 & 0.1 & 52.7 & 72.7 & 88.1 & 02.6 & 117.4 & 133.7 & 52.7 & 77.2 & 214.5 & 126.8 & 0.4 & 0.7 & 0 & 64.1 \\
\hline Burghsluis 3 & vv1 & 54.0 & 19.4 & 6.5 & 9.4 & 0.1 & 62.2 & 85.0 & 102.6 & 119.3 & 136.5 & 155.6 & 178.1 & 207.1 & 251.8 & 145.7 & 0.5 & 0.7 & 0 & 75.4 \\
\hline Burghsluis 2 & vv2 & 65.1 & 14.5 & 4.5 & 6.0 & 0.1 & 78.0 & 105.0 & 126.4 & 146.8 & 168.2 & 192.0 & 220.3 & 257.1 & 314.2 & 177.9 & 0.7 & 0.8 & 0 & 95.0 \\
\hline Burghsluis 1 & vv3 & 77.1 & 8.4 & 2.5 & 3.4 & 0.1 & 92.5 & 118.2 & 139.7 & 160.7 & 182.6 & 207.0 & 235.9 & 273.0 & 329.4 & 191.3 & 0.4 & 0.8 & 31 & 94.4 \\
\hline Schelphoek-midden & $\inf 24$ & 43.8 & 14.5 & 8.4 & 11.6 & 0.1 & 54.8 & 80.0 & 98.5 & 115.7 & 133.4 & 153.1 & 176.5 & 07.6 & 258.5 & 143.2 & 37.5 & 5.5 & 172 & 180.3 \\
\hline Schelphoek-midden & $\operatorname{sed} 250$ & 38.6 & 25.5 & 12.4 & 16.9 & 0.1 & 42.4 & 66.2 & 83.6 & 99.2 & 115.0 & 132.0 & 151.8 & 177.0 & 215.0 & 129.4 & 0.2 & 0.7 & 0 & 66.6 \\
\hline Schelphoek-midden & sed251 & 44.8 & 5.2 & 1.5 & 3.2 & 0.1 & 81.3 & 101.1 & 118.5 & 135.8 & 154.5 & 175.9 & 202.2 & 238.4 & 302.2 & 152.6 & 29.6 & 5.0 & 1205 & 196.3 \\
\hline Schelphoekmidden 1 & vv8 & 26.5 & 35.0 & 19.7 & 26.3 & 0.1 & 34.9 & 50.7 & 65.9 & 81.2 & 97.1 & 114.6 & 135.2 & 161.8 & 202.8 & 116.1 & 0.7 & 0.9 & 0 & 67.0 \\
\hline Schelphoek-oost-ref & $\inf 246$ & 70.4 & 11.7 & 4.1 & 6.2 & 0.1 & 73.2 & 92.4 & 107.9 & 122.6 & 137.9 & 154.7 & 174.3 & 199.3 & 236.7 & 143.9 & 0.2 & 0.6 & 25 & 65.1 \\
\hline Schelphoek-oost-ref & $\operatorname{inf247}$ & 66.2 & 12.5 & 5.2 & 9.1 & 0.1 & 62.5 & 79.9 & 94.1 & 107.6 & 121.7 & 137.2 & 155.4 & 178.7 & 213.9 & 127.6 & 0.3 & 0.6 & 22 & 60.5 \\
\hline Schelphoek-oost-ref & $\inf 248$ & 54.9 & 18.4 & 9.1 & 14.2 & 0.1 & 52.0 & 70.3 & 84.7 & 98.3 & 112.3 & 127.6 & 145.6 & 168.5 & 203.0 & 121.2 & 0.2 & 0.6 & 0 & 59.5 \\
\hline Schelphoek oost 5 & vv10 & 38.9 & 27.2 & 13.4 & 18.7 & 0.1 & 42.1 & 62.6 & 79.4 & 95.0 & 111.0 & 128.6 & 149.3 & 176.0 & 217.2 & 125.0 & 0.6 & 0.8 & 0 & 69.1 \\
\hline Schelphoek oost 3 & vv11 & 51.5 & 18.2 & 10.1 & 14.8 & 0.1 & 49.4 & 69.8 & 85.5 & 100.3 & 115.4 & 132.0 & 151.6 & 176.8 & 215.4 & 125.7 & 0.4 & 0.7 & 0 & 65.7 \\
\hline Schelphoek oost 6 & vv12 & 54.3 & 17.6 & 8.6 & 11.7 & 0.1 & 51.0 & 80.1 & 103.9 & 127.6 & 153.9 & 186.4 & 232.8 & 321.4 & 701.1 & 148.2 & 6.5 & 2.6 & 1018 & 331.9 \\
\hline Schelphoek oost 1 & vv13 & 42.5 & 23.2 & 12.1 & 16.6 & 0.1 & 43.2 & 66.8 & 84.8 & 101.2 & 117.8 & 135.8 & 156.8 & 183.7 & 224.6 & 133.3 & 0.2 & 0.7 & 0 & 70.2 \\
\hline Schelphoek oost & vv14 & 32.7 & 21.1 & 5.9 & 9.7 & 0.1 & 61.6 & 81.1 & 97.3 & 112.8 & 129.0 & 146.9 & 168.1 & 195.5 & 237.3 & 137.4 & 0.5 & 0.8 & 0 & 70.1 \\
\hline Schelphoek referentie 3 & vv15 & 79.4 & 7.7 & 1.5 & 1.5 & 0.1 & 107.2 & 126.2 & 142.0 & 157.1 & 172.5 & 189.3 & 208.9 & 233.6 & 270.7 & 174.6 & 0.5 & 0.6 & 25 & 66.2 \\
\hline Schelphoek referentie 2 & vv16 & 71.5 & 8.0 & 1.7 & 3.2 & 0.1 & 82.1 & 100.2 & 115.8 & 131.0 & 146.9 & 164.6 & 185.6 & 212.7 & 254.2 & 149.3 & 0.6 & 0.8 & 22 & 69.2 \\
\hline Schelphoek referentie 1 & vv17 & 72.1 & 9.4 & 2.1 & 3.0 & 0.1 & 100.0 & 137.3 & 171.7 & 207.0 & 245.3 & 288.8 & 341.0 & 409.4 & 516.5 & 276.7 & 1.2 & 1.1 & 0 & 169.9 \\
\hline Schelphoek oost 4 & vv9 & 35.9 & 28.0 & 18.2 & 24.0 & 0.1 & 34.4 & 52.9 & 69.7 & 85.5 & 101.6 & 119.0 & 139.3 & 165.3 & 205.1 & 120.1 & 0.5 & 0.8 & 0 & 67.0 \\
\hline
\end{tabular}


Bijlage 5 (vervolg). Resultaten van de sediment analyses uitgevoerd door RWS op de monsters uit de huidige studie (korrelgrootte metingen)

\begin{tabular}{|c|c|c|c|c|c|c|c|c|c|c|c|c|c|c|c|c|c|c|c|c|}
\hline Locaties & $\begin{array}{c}\text { Monster- } \\
\text { codes }\end{array}$ & $\begin{array}{l}\text { ১} \\
\text { ৩) } \\
\text { ㅇ }\end{array}$ & 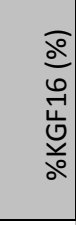 & $\begin{array}{l}\widehat{o} \\
\frac{0}{n} \\
\underline{y} \\
\frac{0}{2}\end{array}$ & $\begin{array}{l}\widehat{\widehat{o}} \\
\hat{n} \\
\underline{0} \\
\underline{0}\end{array}$ & 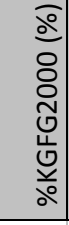 & $\begin{array}{l}\bar{\xi} \\
\underline{\Xi} \\
0 \\
0 \\
0\end{array}$ & 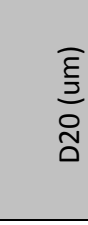 & $\begin{array}{l}\bar{\xi} \\
\underline{\Xi} \\
0 \\
\underline{n}\end{array}$ & 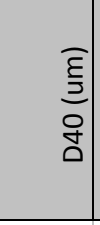 & 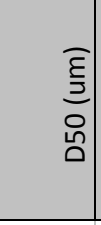 & 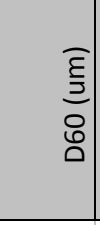 & $\begin{array}{c}\bar{\xi} \\
\underline{\Xi} \\
\circ \\
\stackrel{0}{0}\end{array}$ & $\begin{array}{l}\bar{\xi} \\
\underline{\Xi} \\
0 \\
0 \\
0\end{array}$ & $\begin{array}{l}\bar{\xi} \\
\text { 음 } \\
\circ \\
\circ\end{array}$ & $\begin{array}{l}\bar{\xi} \\
\bar{\Xi} \\
\widetilde{0} \\
\bar{\Sigma}\end{array}$ & $\begin{array}{l}= \\
\tilde{E} \\
\underline{E}\end{array}$ & $\begin{array}{l}= \\
\text { 工⿱ } \\
\text { n }\end{array}$ & $\begin{array}{l}\overline{\underline{E}} \\
\underline{\Xi} \\
\frac{\mathrm{v}}{\mathrm{u}} \\
\end{array}$ & $\begin{array}{l}\vec{\xi} \\
\underline{5} \\
\frac{q}{5} \\
>\end{array}$ \\
\hline SCHLPHK-WII BFN mid-oost & $\inf 234$ & 51.3 & 22.8 & 8.0 & 11.2 & 0.1 & 56.0 & 79.5 & 96.4 & 112.0 & 127.8 & 145.2 & 165.5 & 191.4 & 230.8 & 138.2 & 0.2 & 0.6 & 0 & 68.6 \\
\hline SCHLPHK-WII BFN mid-oost & $\inf 235$ & 27.9 & 27.4 & 26.4 & 34.9 & 0.1 & 30.6 & 43.0 & 54.6 & 66.4 & 78.9 & 92.8 & 109.2 & 130.3 & 162.8 & 92.4 & 0.8 & 0.9 & 0 & 53.0 \\
\hline SCHLPHK-WII BFN mid-oost & $\inf 236$ & 27.9 & 32.9 & 30.0 & 39.3 & 0.1 & 28.5 & 39.8 & 50.2 & 60.7 & 72.0 & 84.8 & 99.9 & 119.6 & 150.0 & 82.6 & 0.7 & 0.9 & 0 & 48.9 \\
\hline Schelphoek-west & $\operatorname{inf237}$ & 55.6 & 16.4 & 6.4 & 9.0 & 0.1 & 64.6 & 99.2 & 133.6 & 170.2 & 210.4 & 255.8 & 309.5 & 378.5 & 484.1 & 275.1 & 0.8 & 1.0 & 0 & 167.8 \\
\hline Schelphoek-west & $\inf 238$ & 62.0 & 15.3 & 6.6 & 9.4 & 0.1 & 60.9 & 85.3 & 103.9 & 121.5 & 139.7 & 159.8 & 183.7 & 214.8 & 263.0 & 149.7 & 0.7 & 0.8 & 0 & 81.0 \\
\hline Schelphoek-west & $\inf 239$ & 26.4 & 34.9 & 26.7 & 35.4 & 0.1 & 30.8 & 42.9 & 54.3 & 65.9 & 78.2 & 92.0 & 108.5 & 129.8 & 162.8 & 90.3 & 0.9 & 1.0 & 0 & 53.3 \\
\hline Schelphoek-west 3 & vv4 & 69.1 & 8.2 & 1.3 & 2.6 & 0.1 & 86.1 & 108.2 & 128.7 & 150.7 & 176.5 & 209.9 & 259.2 & 348.4 & 553.0 & 149.7 & 9.3 & 2.8 & 21 & 252.2 \\
\hline Schelphoek-west 2 & vv5 & 65.4 & 12.3 & 3.1 & 4.8 & 0.1 & 78.0 & 99.9 & 118.8 & 137.8 & 158.6 & 183.3 & 215.6 & 264.8 & 377.9 & 150.7 & 17.5 & 3.7 & 25 & 220.4 \\
\hline Schelphoek west 1 & vv6 & 40.9 & 27.5 & 13.8 & 18.9 & 0.1 & 40.2 & 61.9 & 78.9 & 94.4 & 110.0 & 127.0 & 146.7 & 172.0 & 210.6 & 124.8 & 0.4 & 0.7 & 0 & 66.4 \\
\hline Zierikzee & $\inf 240$ & 38.9 & 27.2 & 27.0 & 36.5 & 0.1 & 30.2 & 42.5 & 53.3 & 63.8 & 74.8 & 87.1 & 101.8 & 120.8 & 150.5 & 84.1 & 90.3 & 6.6 & 0 & 65.6 \\
\hline Zierikzee & inf241 & 27.0 & 34.8 & 38.1 & 49.0 & 0.1 & 26.5 & 35.5 & 43.7 & 52.1 & 61.2 & 71.5 & 84.1 & 100.7 & 127.0 & 65.8 & 208.0 & 11.4 & 0 & 70.5 \\
\hline Zierikzee & $\inf 242$ & 18.2 & 40.3 & 42.0 & 53.5 & 0.1 & 26.2 & 34.4 & 41.7 & 49.2 & 57.4 & 66.7 & 78.0 & 93.0 & 116.8 & 60.0 & 1.2 & 1.0 & 0 & 37.3 \\
\hline
\end{tabular}


Bijlage 6. Resultaten van de sediment analyses uitgevoerd door RWS op de monsters uit de huidige studie (chemische metingen).

\begin{tabular}{|c|c|c|c|c|c|}
\hline Locaties & $\begin{array}{c}\text { Monster- } \\
\text { codes }\end{array}$ & $\frac{\bar{a}}{\overline{0}}$ & 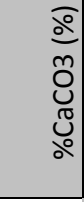 & $\frac{\widehat{o}}{u}$ & $\frac{\stackrel{0}{0}}{\sum_{2}^{n}}$ \\
\hline Burghsluis & $\inf 243$ & 0.7 & 19.5 & 2.4 & 0.4 \\
\hline Burghsluis & $\inf 244$ & 0.9 & 24.8 & 3.0 & 0.5 \\
\hline Burghsluis & $\inf 245$ & 1.4 & 33.6 & 3.7 & 0.7 \\
\hline Burghsluis 3 & vv1 & 1.3 & 25.9 & 3.4 & 0.7 \\
\hline Burghsluis 2 & vv2 & 0.9 & 19.8 & 2.5 & 0.6 \\
\hline Burghsluis 1 & vv3 & 0.6 & 14.0 & 1.8 & 0.5 \\
\hline Schelphoek-midden & $\inf 249$ & 1.2 & 37.7 & 4.8 & 1.0 \\
\hline Schelphoek-midden & sed250 & 1.4 & & 4.5 & 1.1 \\
\hline Schelphoek-midden & $\operatorname{sed} 251$ & 0.6 & 49.6 & 4.2 & 0.5 \\
\hline Schelphoekmidden 1 & vv8 & 2.2 & 36.9 & 4.8 & 1.6 \\
\hline Schelphoek-oost-ref & $\operatorname{inf246}$ & 0.8 & 17.6 & 2.2 & 0.2 \\
\hline Schelphoek-oost-ref & $\operatorname{inf247}$ & 0.7 & 21.1 & 2.5 & 0.2 \\
\hline Schelphoek-oost-ref & $\inf 248$ & 0.0 & 26.4 & 3.3 & 0.3 \\
\hline Schelphoek oost 5 & vv10 & 1.6 & 32.7 & 4.0 & 1.3 \\
\hline Schelphoek oost 3 & vv11 & 1.5 & 29.2 & 3.6 & 1.1 \\
\hline Schelphoek oost 6 & vv12 & 1.6 & 28.1 & 3.7 & 0.1 \\
\hline Schelphoek oost 1 & vv13 & 1.5 & 33.0 & 4.3 & 1.3 \\
\hline Schelphoek oost & vv14 & 1.4 & 45.3 & 4.2 & 0.9 \\
\hline Schelphoek referentie 3 & vv15 & 0.1 & 12.6 & 1.5 & 0.2 \\
\hline Schelphoek referentie 2 & vv16 & 0.5 & 20.4 & 2.1 & 0.1 \\
\hline Schelphoek referentie 1 & vv17 & 0.6 & 17.7 & 1.7 & 0.8 \\
\hline Schelphoek oost 4 & vv9 & 2.0 & 34.9 & 4.4 & 1.2 \\
\hline SCHLPHK-WII BFN mid-oost & $\operatorname{inf234}$ & 1.4 & 25.1 & 3.5 & 0.8 \\
\hline SCHLPHK-WII BFN mid-oost & $\operatorname{inf235}$ & 1.7 & 44.0 & 4.5 & 0.8 \\
\hline SCHLPHK-WII BFN mid-oost & $\inf 236$ & 2.1 & 38.3 & 4.8 & 1.0 \\
\hline Schelphoek-west & inf237 & 1.0 & 27.2 & 3.5 & 0.7 \\
\hline Schelphoek-west & $\inf 238$ & 0.8 & 22.5 & 2.7 & 0.2 \\
\hline Schelphoek-west & inf239 & 1.9 & 37.8 & 4.7 & 1.0 \\
\hline Schelphoek-west 3 & vv4 & 0.5 & 22.2 & 2.2 & 0.5 \\
\hline Schelphoek-west 2 & vv5 & 0.8 & 21.6 & 2.7 & 0.6 \\
\hline Schelphoek west 1 & vv6 & 1.7 & 30.6 & 4.0 & 1.0 \\
\hline Zierikzee & $\inf 240$ & 1.6 & 33.2 & 4.2 & 0.8 \\
\hline Zierikzee & inf241 & 1.9 & 37.4 & 4.8 & 0.7 \\
\hline Zierikzee & $\operatorname{inf242}$ & 2.4 & 40.5 & 5.2 & 0.9 \\
\hline
\end{tabular}




\section{Bijlage 7. Vergelijkende studie tussen de sediment analyses van Stichting Zeeschelp (Fractie $<90 \mu \mathrm{m}$ en \% organische stof) en en de standaard sedimentaire analyses (D50 $\mu \mathrm{m}$ en \% OC) uitgevoerd bij de analytische lab van RWS.}

De waarden die gebruikt zijn voor deze analyse zijn beschikbaar in Bijlage 11 (Stichting Zeeschelp) en in Bijlage $\mathbf{5}$ en Bijlage $\mathbf{6}$ (RWS analyses) van de huidige rapportage.

\section{Fractie $<0.09 \mathrm{~mm}$}

De percentage (o.b.v. volumes) van de sedimentaire fractie met korrelgroottes kleiner dan $90 \mu \mathrm{m}$ is gebruikt door Stichting Zeeschelp (zeef methode) in de huidige rapportage voor een typologie van het sediment. Deze meetwaarden laten (Figuur 16) een negatieve lineaire relatie zien $\left(R^{2}=0.62\right)$ met de mediane bepaald door RWS (Malvern, laser diffractie). Door middel van die relatie kunnen de 'RWS' mediane korrelgroottes voorspeld worden met een gemiddelde relatieve fout van slechts $16 \%$.

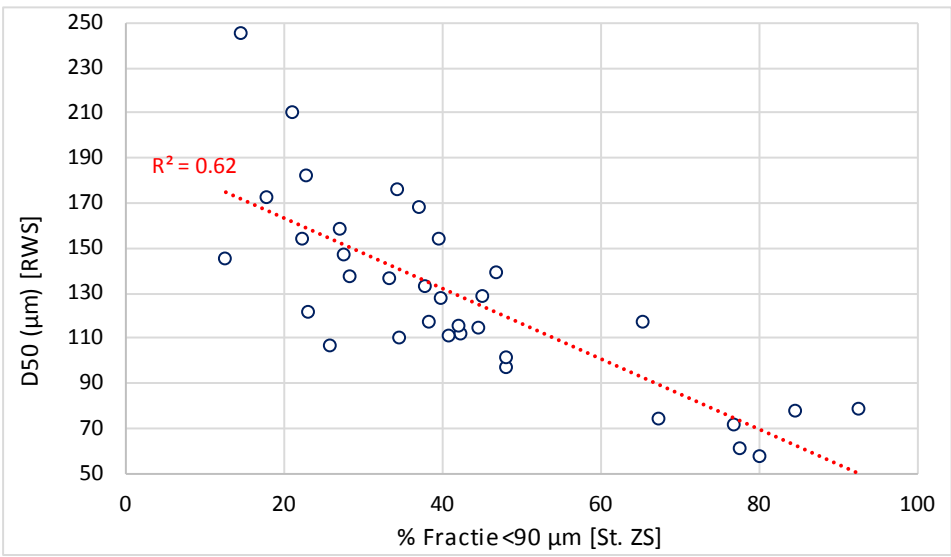

Figuur 16.- Mediane waarde van de sedimentaire Korrelgrootte zoals bepaald door het analytisch lab van RWS als functie van de percentage (o.b.v. volumes) aan sedimentaire deeltjes met korrelgroottes kleiner dan $90 \mu \mathrm{m}$ zoals bepaald door Stichting Zee Schelp.

\section{$\%$ organische stof}

De percentage aan organische stof in het sediment is bepaald door Stichting Zeeschelp op basis van het gewichtsverlies van sediment monsters na verrassing $\left(525^{\circ} \mathrm{C}, 5 \mathrm{u}\right)$. Deze meetwaarden zijn ca 4 keer hoger dan die van het analytische lab van RWS (Figuur 17). Dit verschil is te verklaren door de verbranding van organische stoffen tijdens de verassing bij de methode Stichting Zeeschelp en die niet gevoelig zijn (refractaire) voor de 'mildere' chemische oxidatie die wordt toegepast in de methode van het RWS lab. Desondanks laten de waarden verkregen d.m.v. verassing een positieve lineaire relatie zien $\left(R^{2}=0.84\right)$ met de lab-analyses van RWS (Figuur 17). Door middel van die relatie kunnen de 'RWS' waarden van organisch koolstof voorspeld worden met een gemiddelde relatieve fout van slechts $15 \%$.

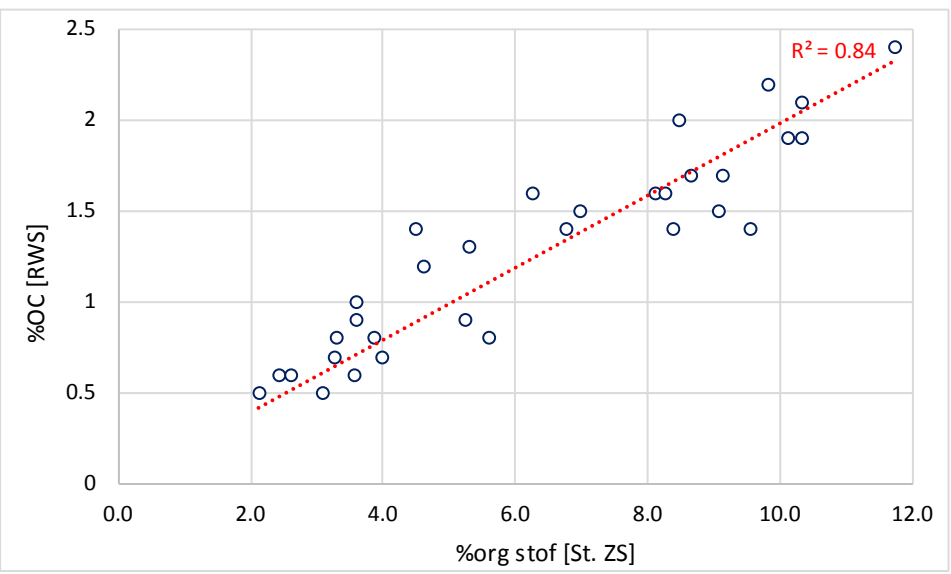

Figuur 17.-Organisch koolstof inhoud zoals bepaald door het analytisch lab van RWS (chemische analyse) als functie van de organisch koolstof inhoud zoals bepaald door Stichting Zee Schelp (verassing).

Uit deze analyse blijkt een overeenstemming tussen de korrelgrootte en organische koolstof bepalingen zoals uitgevoerd door Stichting Zeeschelp en door het RWS laboratorium. Op basis 
hiervan is de verwachting dat het gebruik van de meetgegevens aangeleverd door Stichting

Zeeschelp of van RWS tot vergelijkbare resultaten/conclusies leiden voor de huidige studie. 
Bijlage 8. Infauna dichtheden waargenomen in 2016.

De locaties bij Monsternummer (no) is te vinden in Tabel 4. (Met staat voor methode, $\mathrm{S}=$ Steekbuis, $\mathrm{V}=$ van Veen).

\begin{tabular}{|c|c|c|c|c|}
\hline Met & Jaar & Monsterno & Soortnaam & $\mathrm{N} / \mathrm{m}^{2}$ \\
\hline$S$ & 2016 & BfN 10 & Abra alba & 854 \\
\hline$S$ & 2016 & BfN 10 & Capitella capitata & 50 \\
\hline$S$ & 2016 & BfN 10 & Cossura longocirrata & 50 \\
\hline $\mathrm{S}$ & 2016 & BfN 10 & Eteone species & 50 \\
\hline$S$ & 2016 & BfN 10 & Nephtys hombergii & 50 \\
\hline$S$ & 2016 & BfN 10 & Notomastus latericeus & 50 \\
\hline$S$ & 2016 & BfN 10 & OLIGOCHAETA & 201 \\
\hline$S$ & 2016 & BfN 10 & Pseudopolydora pulchra & 502 \\
\hline$S$ & 2016 & BfN 10 & Spio & 100 \\
\hline$S$ & 2016 & BfN 10 & Spisula subtruncata & 100 \\
\hline$S$ & 2016 & BfN 10 & Streblospio shrubsolii & 50 \\
\hline$S$ & 2016 & BfN 11 & Abra alba & 50 \\
\hline$S$ & 2016 & BfN 11 & Capitella capitata & 301 \\
\hline$S$ & 2016 & BfN 11 & OLIGOCHAETA & 100 \\
\hline$S$ & 2016 & BfN 11 & OSTRACODA & 50 \\
\hline $\mathrm{S}$ & 2016 & BfN 11 & Pseudopolydora pulchra & 452 \\
\hline $\mathrm{S}$ & 2016 & BfN 11 & Streblospio shrubsolii & 100 \\
\hline$S$ & 2016 & BfN 4 & Abra alba & 50 \\
\hline $\mathrm{S}$ & 2016 & $\mathrm{BfN} 4$ & Ascidicea species & 50 \\
\hline$S$ & 2016 & BfN 4 & Bivalvia undetermined & 100 \\
\hline$S$ & 2016 & $\mathrm{BfN} 4$ & Nephtys hombergii & 151 \\
\hline $\mathrm{S}$ & 2016 & $\mathrm{BfN} 4$ & OLIGOCHAETA & 151 \\
\hline$S$ & 2016 & $\mathrm{BfN} 4$ & Pseudopolydora pulchra & 452 \\
\hline $\mathrm{S}$ & 2016 & $\mathrm{BfN} 4$ & Spisula subtruncata & 50 \\
\hline$S$ & 2016 & BfN 4 & Streblospio shrubsolii & 100 \\
\hline $\mathrm{S}$ & 2016 & BfN 5 & Abra alba & 50 \\
\hline$S$ & 2016 & BfN 5 & Aphelochaeta marioni & 100 \\
\hline$S$ & 2016 & BfN 5 & Cossura longocirrata & 301 \\
\hline$S$ & 2016 & BfN 5 & Mediomastus fragilis & 100 \\
\hline $\mathrm{S}$ & 2016 & BfN 5 & Microphthalmus spec. & 50 \\
\hline$S$ & 2016 & BfN 5 & Nephtys hombergii & 100 \\
\hline $\mathrm{S}$ & 2016 & BfN 5 & Notomastus latericeus & 50 \\
\hline$S$ & 2016 & BfN 5 & OLIGOCHAETA & 452 \\
\hline$S$ & 2016 & BfN 5 & Pseudopolydora pulchra & 502 \\
\hline $\mathrm{S}$ & 2016 & BfN 5 & Streblospio shrubsolii & 251 \\
\hline $\mathrm{S}$ & 2016 & BfN 6 & Abra alba & 1858 \\
\hline$S$ & 2016 & BfN 6 & Ampelisca brevicornis & 50 \\
\hline$S$ & 2016 & BfN 6 & Capitella capitata & 50 \\
\hline$S$ & 2016 & BfN 6 & Eteone species & 50 \\
\hline$S$ & 2016 & BfN 6 & Kurtiella bidentata & 703 \\
\hline$S$ & 2016 & BfN 6 & Macoma balthica & 100 \\
\hline$S$ & 2016 & BfN 6 & Mediomastus fragilis & 5073 \\
\hline$S$ & 2016 & BfN 6 & Nassarius spec. & 50 \\
\hline $\mathrm{S}$ & 2016 & BfN 6 & Nephtys hombergii & 50 \\
\hline$S$ & 2016 & BfN 6 & Notomastus latericeus & 50 \\
\hline$S$ & 2016 & BfN 6 & OLIGOCHAETA & 3014 \\
\hline$S$ & 2016 & BfN 6 & Ophiuroidea & 50 \\
\hline$S$ & 2016 & BfN 6 & Pholoe baltica & 201 \\
\hline $\mathrm{S}$ & 2016 & BfN 6 & Pseudopolydora pulchra & 603 \\
\hline$S$ & 2016 & BfN 6 & Scoloplos (Scoloplos) armiger & 50 \\
\hline $\mathrm{S}$ & 2016 & BfN 6 & Streblospio shrubsolii & 352 \\
\hline$S$ & 2016 & BfN 7 & Abra alba & 50 \\
\hline $\mathrm{S}$ & 2016 & BfN 7 & Aphelochaeta marioni & 201 \\
\hline $\mathrm{S}$ & 2016 & BfN 7 & Capitella capitata & 251 \\
\hline$S$ & 2016 & BfN 7 & Corophiidae & 50 \\
\hline$S$ & 2016 & BfN 7 & Cossura longocirrata & 100 \\
\hline$S$ & 2016 & BfN 7 & Mediomastus fragilis & 352 \\
\hline $\mathrm{S}$ & 2016 & BfN 7 & Nephtys hombergii & 50 \\
\hline $\mathrm{S}$ & 2016 & BfN 7 & OLIGOCHAETA & 603 \\
\hline$S$ & 2016 & BfN 7 & Pseudopolydora pulchra & 703 \\
\hline $\mathrm{S}$ & 2016 & BfN 7 & Spisula subtruncata & 50 \\
\hline$S$ & 2016 & BfN 7 & Streblospio shrubsolii & 703 \\
\hline $\mathrm{S}$ & 2016 & $\mathrm{BfN} 8$ & Abra alba & 1758 \\
\hline$S$ & 2016 & BfN 8 & Actiniaria & 151 \\
\hline$S$ & 2016 & BfN 8 & Ampelisca brevicornis & 50 \\
\hline$S$ & 2016 & $\mathrm{BfN} 8$ & Aora typica & 50 \\
\hline$S$ & 2016 & BfN 8 & Aphelochaeta marioni & 100 \\
\hline$S$ & 2016 & BfN 8 & Ascidicea species & 50 \\
\hline$S$ & 2016 & BfN 8 & Cossura longocirrata & 100 \\
\hline$S$ & 2016 & BfN 8 & Eteone species & 50 \\
\hline $\mathrm{S}$ & 2016 & BfN 8 & Mediomastus fragilis & 50 \\
\hline$S$ & 2016 & BfN 8 & Nephtys hombergii & 201 \\
\hline$S$ & 2016 & BfN 8 & Ophiuroidea & 50 \\
\hline$S$ & 2016 & BfN 8 & Pseudopolydora pulchra & 100 \\
\hline$S$ & 2016 & $\mathrm{BfN} 8$ & Sthenelais boa & 50 \\
\hline$S$ & 2016 & BfN 9 & Corophiidae & 50 \\
\hline
\end{tabular}

\begin{tabular}{|c|c|c|c|c|}
\hline Met & Jaar & Monsterno & Soortnaam & $\mathrm{N} / \mathrm{m}^{2}$ \\
\hline$S$ & 2016 & BfN 9 & Nassarius spec. & 50 \\
\hline$S$ & 2016 & BfN 9 & OLIGOCHAETA & 50 \\
\hline$S$ & 2016 & BfN 9 & Pseudopolydora pulchra & 50 \\
\hline$S$ & 2016 & INF234 & Abludomelita obtusata & 151 \\
\hline$S$ & 2016 & INF234 & Abra alba & 5927 \\
\hline $\mathrm{S}$ & 2016 & INF234 & Actiniaria & 2511 \\
\hline $\mathrm{S}$ & 2016 & INF234 & Anoplodactylus petiolatus & 50 \\
\hline $\mathrm{S}$ & 2016 & INF234 & Aora typica & 201 \\
\hline$S$ & 2016 & INF234 & Aoridae spec. & 50 \\
\hline$S$ & 2016 & INF234 & Caprellidae & 50 \\
\hline$S$ & 2016 & INF234 & Corophiidae & 50 \\
\hline$S$ & 2016 & INF234 & Eunereis longissima & 50 \\
\hline$S$ & 2016 & INF234 & Kurtiella bidentata & 804 \\
\hline$S$ & 2016 & INF234 & Lagis koreni & 50 \\
\hline$S$ & 2016 & INF234 & Mediomastus fragilis & 603 \\
\hline $\mathrm{S}$ & 2016 & INF234 & Monocorophium acherusicum & 50 \\
\hline$S$ & 2016 & INF234 & Mya arenaria & 50 \\
\hline$S$ & 2016 & INF234 & Nephtys hombergii & 50 \\
\hline$S$ & 2016 & INF234 & Notomastus latericeus & 50 \\
\hline$S$ & 2016 & INF234 & OLIGOCHAETA & 3566 \\
\hline$S$ & 2016 & INF234 & Ophiuroidea & 50 \\
\hline$S$ & 2016 & INF234 & Owenia fusiformis & 603 \\
\hline$S$ & 2016 & INF234 & Pholoe baltica & 151 \\
\hline$S$ & 2016 & INF234 & Pseudopolydora pulchra & 352 \\
\hline$S$ & 2016 & INF234 & Pycnogodia species & 50 \\
\hline $\mathrm{S}$ & 2016 & INF234 & Sthenelais boa & 301 \\
\hline$S$ & 2016 & INF235 & Abra alba & 100 \\
\hline$S$ & 2016 & INF235 & Aonides oxycephala & 50 \\
\hline$S$ & 2016 & INF235 & Cossura longocirrata & 100 \\
\hline$S$ & 2016 & INF235 & Mediomastus fragilis & 100 \\
\hline$S$ & 2016 & INF235 & Nassarius spec. & 50 \\
\hline$S$ & 2016 & INF235 & OLIGOCHAETA & 100 \\
\hline$S$ & 2016 & INF235 & Ophiuroidea & 50 \\
\hline$S$ & 2016 & INF235 & Pseudopolydora pulchra & 352 \\
\hline$S$ & 2016 & INF235 & Spisula subtruncata & 100 \\
\hline$S$ & 2016 & INF235 & Streblospio shrubsolii & 50 \\
\hline$S$ & 2016 & INF236 & Acanthocardia & 50 \\
\hline$S$ & 2016 & INF236 & Capitella capitata & 251 \\
\hline$S$ & 2016 & INF236 & Nassarius spec. & 50 \\
\hline$S$ & 2016 & INF236 & OLIGOCHAETA & 251 \\
\hline$S$ & 2016 & INF236 & Pseudopolydora pulchra & 100 \\
\hline$S$ & 2016 & INF236 & Streblospio shrubsolii & 50 \\
\hline$S$ & 2016 & INF236 & Venerupis corrugata & 50 \\
\hline$S$ & 2016 & INF237 & Abra alba & 2461 \\
\hline$S$ & 2016 & INF237 & Actiniaria & 301 \\
\hline $\mathrm{S}$ & 2016 & INF237 & Aonides oxycephala & 50 \\
\hline $\mathrm{S}$ & 2016 & INF237 & Bodotria scorpioides & 50 \\
\hline$S$ & 2016 & INF237 & Glycera spec. & 50 \\
\hline$S$ & 2016 & INF237 & Macoma balthica & 50 \\
\hline$S$ & 2016 & INF237 & Mediomastus fragilis & 1557 \\
\hline$S$ & 2016 & INF237 & Monocorophium acherusicum & 50 \\
\hline$S$ & 2016 & INF237 & Notomastus latericeus & 100 \\
\hline$S$ & 2016 & INF237 & OLIGOCHAETA & 6278 \\
\hline$S$ & 2016 & INF237 & Pholoe baltica & 301 \\
\hline$S$ & 2016 & INF237 & Phoronida spec. & 50 \\
\hline$S$ & 2016 & INF237 & Pseudopolydora pulchra & 201 \\
\hline $\mathrm{S}$ & 2016 & INF237 & Sthenelais boa & 100 \\
\hline$S$ & 2016 & INF238 & Abra alba & 201 \\
\hline$S$ & 2016 & INF238 & Glycera spec. & 50 \\
\hline $\mathrm{S}$ & 2016 & INF238 & Mediomastus fragilis & 50 \\
\hline $\mathrm{S}$ & 2016 & INF238 & OLIGOCHAETA & 151 \\
\hline$S$ & 2016 & INF238 & Pseudopolydora pulchra & 100 \\
\hline$S$ & 2016 & INF238 & Spisula subtruncata & 151 \\
\hline$S$ & 2016 & INF239 & Aphelochaeta marioni & 50 \\
\hline $\mathrm{S}$ & 2016 & INF239 & Capitella capitata & 301 \\
\hline$S$ & 2016 & INF239 & Glycera spec. & 50 \\
\hline$S$ & 2016 & INF239 & Nephtys hombergii & 50 \\
\hline$S$ & 2016 & INF239 & OLIGOCHAETA & 251 \\
\hline$S$ & 2016 & INF239 & Spisula subtruncata & 50 \\
\hline$S$ & 2016 & INF239 & Sthenelais boa & 50 \\
\hline $\mathrm{S}$ & 2016 & INF240 & Cossura longocirrata & 452 \\
\hline $\mathrm{S}$ & 2016 & INF240 & Macoma balthica & 50 \\
\hline$S$ & 2016 & INF240 & Nephtys hombergii & 50 \\
\hline$S$ & 2016 & INF240 & OLIGOCHAETA & 50 \\
\hline $\mathrm{S}$ & 2016 & INF240 & Ophiuroidea & 201 \\
\hline$S$ & 2016 & INF240 & Streblospio shrubsolii & 552 \\
\hline
\end{tabular}




\begin{tabular}{|c|c|c|c|c|}
\hline Met & Jaar & Monsterno & Soortnaam & $\mathrm{N} / \mathrm{m}^{2}$ \\
\hline $\mathrm{S}$ & 2016 & INF241 & Abra alba & 100 \\
\hline $\mathrm{S}$ & 2016 & INF241 & Cossura longocirrata & 151 \\
\hline $\mathrm{S}$ & 2016 & INF241 & Ensis spec. & 50 \\
\hline $\mathrm{S}$ & 2016 & INF241 & Nephtys hombergii & 151 \\
\hline $\mathrm{S}$ & 2016 & INF241 & OLIGOCHAETA & 301 \\
\hline $\mathrm{S}$ & 2016 & INF241 & \begin{tabular}{|l|} 
Pseudopolydora pulchra \\
\end{tabular} & 301 \\
\hline $\mathrm{s}$ & 2016 & INF241 & Streblospio shrubsolii & 1256 \\
\hline $\mathrm{S}$ & 2016 & INF241 & Syllidae & 50 \\
\hline $\mathrm{S}$ & 2016 & INF242 & Abra alba & 151 \\
\hline $\mathrm{S}$ & 2016 & INF242 & Acanthocardia & 50 \\
\hline $\mathrm{s}$ & 2016 & INF242 & Aphelochaeta marioni & 100 \\
\hline $\mathrm{S}$ & 2016 & INF242 & Capitella capitata & 50 \\
\hline $\mathrm{S}$ & 2016 & INF242 & Cossura longocirrata & 50 \\
\hline $\mathrm{S}$ & 2016 & INF242 & Macoma balthica & 100 \\
\hline $\mathrm{S}$ & 2016 & INF242 & OLIGOCHAETA & 100 \\
\hline $\mathrm{S}$ & 2016 & INF242 & Pseudopolydora pulchra & 3767 \\
\hline $\mathrm{S}$ & 2016 & INF242 & Streblospio shrubsolii & 100 \\
\hline $\mathrm{S}$ & 2016 & INF243 & Abra alba & 100 \\
\hline $\mathrm{S}$ & 2016 & INF243 & Aphelochaeta marioni & 50 \\
\hline $\mathrm{S}$ & 2016 & INF243 & Ensis spec. & 100 \\
\hline $\mathrm{S}$ & 2016 & INF243 & Lagis koreni & 50 \\
\hline $\mathrm{S}$ & 2016 & INF243 & Nephtys hombergii & 100 \\
\hline $\mathrm{s}$ & 2016 & INF243 & OLIGOCHAETA & 301 \\
\hline $\mathrm{S}$ & 2016 & INF243 & Pholoe baltica & 50 \\
\hline $\mathrm{S}$ & 2016 & INF243 & Spiophanes bombyx & 50 \\
\hline $\mathrm{S}$ & 2016 & INF246 & Abra alba & 12305 \\
\hline $\mathrm{S}$ & 2016 & INF246 & \begin{tabular}{|l|} 
Actiniaria \\
\end{tabular} & 301 \\
\hline $\mathrm{S}$ & 2016 & INF246 & Aphelochaeta marioni & 50 \\
\hline $\mathrm{S}$ & 2016 & INF246 & Corophiidae & 100 \\
\hline $\mathrm{S}$ & 2016 & INF246 & Kurtiella bidentata & 50 \\
\hline $\mathrm{S}$ & 2016 & INF246 & Mediomastus fragilis & 1205 \\
\hline $\mathrm{S}$ & 2016 & INF246 & Monocorophium acherusicum & 50 \\
\hline $\mathrm{S}$ & 2016 & INF246 & OLIGOCHAETA & 7886 \\
\hline $\mathrm{S}$ & 2016 & INF246 & Pholoe baltica & 151 \\
\hline $\mathrm{S}$ & 2016 & INF246 & Pseudopolydora pulchra & 201 \\
\hline $\mathrm{S}$ & 2016 & INF246 & Sthenelais boa & 301 \\
\hline $\mathrm{S}$ & 2016 & INF246 & Venerupis corrugata & 50 \\
\hline $\mathrm{S}$ & 2016 & INF247 & Actiniaria & 100 \\
\hline $\mathrm{S}$ & 2016 & INF247 & Aphelochaeta marioni & 151 \\
\hline $\mathrm{S}$ & 2016 & INF247 & Cossura longocirrata & 50 \\
\hline $\mathrm{S}$ & 2016 & INF247 & Eteone species & 50 \\
\hline $\mathrm{S}$ & 2016 & INF247 & Eunereis longissima & 50 \\
\hline $\mathrm{S}$ & 2016 & INF247 & Mediomastus fragilis & 201 \\
\hline $\mathrm{S}$ & 2016 & INF247 & \begin{tabular}{|l} 
Notomastus latericeus \\
\end{tabular} & 100 \\
\hline $\mathrm{S}$ & 2016 & INF247 & OLIGOCHAETA & 1909 \\
\hline $\mathrm{S}$ & 2016 & INF247 & Pseudopolydora pulchra & 100 \\
\hline $\mathrm{S}$ & 2016 & INF247 & Scoloplos (Scoloplos) armiger & 251 \\
\hline $\mathrm{S}$ & 2016 & INF247 & Sthenelais boa & 50 \\
\hline $\mathrm{S}$ & 2016 & INF247 & Streblospio shrubsolii & 50 \\
\hline$S$ & 2016 & INF248 & Actiniaria & 100 \\
\hline $\mathrm{S}$ & 2016 & INF248 & Aphelochaeta marioni & 201 \\
\hline $\mathrm{S}$ & 2016 & INF248 & Cerianthus lloydii & 100 \\
\hline $\mathrm{S}$ & 2016 & INF248 & Mediomastus fragilis & 201 \\
\hline$S$ & 2016 & INF248 & Microdeutopus anomalus & 50 \\
\hline $\mathrm{S}$ & 2016 & INF248 & Nephtys hombergii & 50 \\
\hline $\mathrm{S}$ & 2016 & INF248 & OLIGOCHAETA & 402 \\
\hline$S$ & 2016 & INF248 & Pseudopolydora pulchra & 100 \\
\hline $\mathrm{S}$ & 2016 & INF248 & Scoloplos (Scoloplos) armiger & 50 \\
\hline $\mathrm{S}$ & 2016 & INF248 & Venerupis corrugata & 50 \\
\hline $\mathrm{S}$ & 2016 & INF249 & Abra alba & 4119 \\
\hline $\mathrm{S}$ & 2016 & INF249 & Actiniaria & 151 \\
\hline$S$ & 2016 & INF249 & Capitella capitata & 1055 \\
\hline $\mathrm{S}$ & 2016 & INF249 & Caprellidae & 50 \\
\hline $\mathrm{s}$ & 2016 & INF249 & Mediomastus fragilis & 201 \\
\hline $\mathrm{S}$ & 2016 & INF249 & Mytilus edulis & 50 \\
\hline $\mathrm{s}$ & 2016 & INF249 & OLIGOCHAETA & 49373 \\
\hline $\mathrm{S}$ & 2016 & INF249 & Ophiotrix fragilis & 50 \\
\hline$S$ & 2016 & INF249 & Sthenelais boa & 251 \\
\hline $\mathrm{V}$ & 2016 & VV1 & Abludomelita obtusata & 40 \\
\hline $\mathrm{V}$ & 2016 & VV1 & Abra alba & 6204 \\
\hline $\mathrm{V}$ & 2016 & VV1 & Aoridae spec. & 10 \\
\hline $\mathrm{V}$ & 2016 & VV1 & \begin{tabular}{|l} 
Aphelochaeta marioni \\
\end{tabular} & 250 \\
\hline $\mathrm{V}$ & 2016 & VV1 & Capitella capitata & 10 \\
\hline $\mathrm{V}$ & 2016 & VV1 & Cossura longocirrata & 10 \\
\hline $\mathrm{V}$ & 2016 & VV1 & Crepidula fornicata & 10 \\
\hline $\mathrm{V}$ & 2016 & VV1 & \begin{tabular}{|l} 
Eteone species \\
\end{tabular} & 10 \\
\hline $\mathrm{V}$ & 2016 & VV1 & Eunereis longissima & 40 \\
\hline $\mathrm{V}$ & 2016 & VV1 & \begin{tabular}{|l} 
Glycera spec. \\
\end{tabular} & 10 \\
\hline $\mathrm{V}$ & 2016 & VV1 & Glycera tridactyla & 20 \\
\hline $\mathrm{V}$ & 2016 & VV1 & Kurtiella bidentata & 30 \\
\hline $\mathrm{V}$ & 2016 & VV1 & Lanice conchilega & 30 \\
\hline
\end{tabular}

\begin{tabular}{|c|c|c|c|c|}
\hline Met & Jaar & Monsterno & Soortnaam & $\mathrm{N} / \mathrm{m}^{2}$ \\
\hline $\mathrm{V}$ & 2016 & VV1 & Lysianassa ceratina & 10 \\
\hline $\mathrm{V}$ & 2016 & VV1 & Mediomastus fragilis & 1600 \\
\hline $\mathrm{V}$ & 2016 & VV1 & Monocorophium insidiosum & 10 \\
\hline $\mathrm{V}$ & 2016 & VV1 & Nephtys hombergii & 90 \\
\hline $\mathrm{V}$ & 2016 & VV1 & Notomastus latericeus & 20 \\
\hline $\mathrm{V}$ & 2016 & VV1 & OLIGOCHAETA & 1070 \\
\hline $\mathrm{V}$ & 2016 & VV1 & Ophiotrix fragilis & 260 \\
\hline $\mathrm{V}$ & 2016 & VV1 & Owenia fusiformis & 20 \\
\hline $\mathrm{V}$ & 2016 & VV1 & Pholoe baltica & 410 \\
\hline $\mathrm{V}$ & 2016 & VV1 & Polydora spec. & 10 \\
\hline $\mathrm{V}$ & 2016 & VV1 & Polynoidae & 10 \\
\hline $\mathrm{V}$ & 2016 & VV1 & Scoloplos (Scoloplos) armiger & 50 \\
\hline $\mathrm{V}$ & 2016 & VV1 & Spisula subtruncata & 40 \\
\hline $\mathrm{V}$ & 2016 & VV1 & Sthenelais boa & 30 \\
\hline $\mathrm{V}$ & 2016 & VV1 & Sycon & 10 \\
\hline $\mathrm{V}$ & 2016 & VV10 & Abludomelita obtusata & 150 \\
\hline $\mathrm{V}$ & 2016 & VV10 & Abra alba & 510 \\
\hline $\mathrm{V}$ & 2016 & VV10 & Actiniaria & 110 \\
\hline $\mathrm{V}$ & 2016 & VV10 & Aonides oxycephala & 10 \\
\hline $\mathrm{V}$ & 2016 & VV10 & Aphelochaeta marioni & 280 \\
\hline $\mathrm{V}$ & 2016 & VV10 & Asterias rubens & 20 \\
\hline $\mathrm{V}$ & 2016 & VV10 & Buccinum undatum & 20 \\
\hline $\mathrm{V}$ & 2016 & VV10 & Capitella capitata & 100 \\
\hline $\mathrm{V}$ & 2016 & VV10 & Carcinus maenas & 10 \\
\hline $\mathrm{V}$ & 2016 & VV10 & Corophiidae & 30 \\
\hline $\mathrm{V}$ & 2016 & VV10 & Crepidula fornicata & 40 \\
\hline $\mathrm{V}$ & 2016 & VV10 & Eteone species & 30 \\
\hline $\mathrm{V}$ & 2016 & VV10 & Eumida sanguinea & 20 \\
\hline $\mathrm{V}$ & 2016 & VV10 & Flabelligera affinis & 30 \\
\hline $\mathrm{V}$ & 2016 & VV10 & Harmothoe & 20 \\
\hline $\mathrm{V}$ & 2016 & VV10 & Kefersteinia cirrata & 10 \\
\hline $\mathrm{V}$ & 2016 & VV10 & Kurtiella bidentata & 10 \\
\hline $\mathrm{V}$ & 2016 & VV10 & Lepidonotus squamatus & 40 \\
\hline $\mathrm{V}$ & 2016 & VV10 & Lysianassa ceratina & 3240 \\
\hline $\mathrm{V}$ & 2016 & VV10 & Mediomastus fragilis & 700 \\
\hline $\mathrm{V}$ & 2016 & VV10 & Mytilus edulis & 2230 \\
\hline $\mathrm{V}$ & 2016 & VV10 & Nemertinae species & 70 \\
\hline $\mathrm{V}$ & 2016 & VV10 & Neoamphitrite figulus & 10 \\
\hline $\mathrm{V}$ & 2016 & VV10 & OLIGOCHAETA & 42300 \\
\hline $\mathrm{V}$ & 2016 & VV10 & Ophiotrix fragilis & 1360 \\
\hline $\mathrm{V}$ & 2016 & VV10 & Pholoe baltica & 60 \\
\hline $\mathrm{V}$ & 2016 & VV10 & Pholoe inornata & 30 \\
\hline $\mathrm{V}$ & 2016 & VV10 & Pisidia longicornis & 50 \\
\hline $\mathrm{V}$ & 2016 & VV10 & Sabellaria spinulosa & 10 \\
\hline $\mathrm{V}$ & 2016 & VV10 & Sthenelais boa & 70 \\
\hline $\mathrm{V}$ & 2016 & VV10 & Subadyte pellucida & 50 \\
\hline $\mathrm{V}$ & 2016 & VV10 & Syllis gracilis & 10 \\
\hline $\mathrm{V}$ & 2016 & VV10 & Venerupis corrugata & 40 \\
\hline $\mathrm{V}$ & 2016 & VV11 & Abludomelita obtusata & 40 \\
\hline $\mathrm{V}$ & 2016 & VV11 & Abra alba & 1570 \\
\hline $\mathrm{V}$ & 2016 & VV11 & Actiniaria & 50 \\
\hline $\mathrm{V}$ & 2016 & VV11 & Aphelochaeta marioni & 445 \\
\hline $\mathrm{V}$ & 2016 & VV11 & Buccinum undatum & 20 \\
\hline $\mathrm{V}$ & 2016 & VV11 & Capitella capitata & 375 \\
\hline $\mathrm{V}$ & 2016 & VV11 & Corophiidae & 20 \\
\hline $\mathrm{V}$ & 2016 & VV11 & Crepidula fornicata & 100 \\
\hline $\mathrm{V}$ & 2016 & VV11 & Eteone species & 20 \\
\hline $\mathrm{V}$ & 2016 & VV11 & Eumida sanguinea & 10 \\
\hline $\mathrm{V}$ & 2016 & VV11 & Eunoe nodosa & 10 \\
\hline $\mathrm{V}$ & 2016 & VV11 & Harmothoe impar & 10 \\
\hline $\mathrm{V}$ & 2016 & VV11 & Kefersteinia cirrata & 10 \\
\hline $\mathrm{V}$ & 2016 & VV11 & Kurtiella bidentata & 20 \\
\hline $\mathrm{V}$ & 2016 & VV11 & Lagis koreni & 10 \\
\hline $\mathrm{V}$ & 2016 & VV11 & Mediomastus fragilis & 2485 \\
\hline $\mathrm{V}$ & 2016 & VV11 & Monocorophium acherusicum & 20 \\
\hline $\mathrm{V}$ & 2016 & VV11 & Mya arenaria & 10 \\
\hline $\mathrm{V}$ & 2016 & VV11 & Nemertinae species & 50 \\
\hline $\mathrm{V}$ & 2016 & VV11 & Nereis spec. & 10 \\
\hline $\mathrm{V}$ & 2016 & VV11 & OLIGOCHAETA & 139160 \\
\hline $\mathrm{V}$ & 2016 & VV11 & Ophiotrix fragilis & 300 \\
\hline $\mathrm{V}$ & 2016 & VV11 & Ostrea edulis & 10 \\
\hline $\mathrm{V}$ & 2016 & VV11 & Pholoe baltica & 170 \\
\hline $\mathrm{V}$ & 2016 & VV11 & Pholoe inornata & 20 \\
\hline $\mathrm{V}$ & 2016 & VV11 & Pisidia longicornis & 10 \\
\hline $\mathrm{V}$ & 2016 & VV11 & Platyhelminthes spec. & 10 \\
\hline $\mathrm{V}$ & 2016 & VV11 & Sthenelais boa & 90 \\
\hline $\mathrm{V}$ & 2016 & VV11 & Streblospio shrubsolii & 355 \\
\hline $\mathrm{V}$ & 2016 & VV11 & Styela clava & 10 \\
\hline $\mathrm{V}$ & 2016 & VV11 & Subadyte pellucida & 50 \\
\hline $\mathrm{V}$ & 2016 & VV11 & Venerupis corrugata & 10 \\
\hline $\mathrm{V}$ & 2016 & VV12 & Abludomelita obtusata & 10 \\
\hline
\end{tabular}




\begin{tabular}{|c|c|c|c|c|}
\hline Met & Jaar & Monsterno & Soortnaam & $\mathrm{N} / \mathrm{m}^{2}$ \\
\hline $\mathrm{V}$ & 2016 & VV12 & Abra alba & 1310 \\
\hline V & 2016 & VV12 & Actiniaria & 120 \\
\hline $\mathrm{V}$ & 2016 & VV12 & Aonides oxycephala & 10 \\
\hline $\mathrm{V}$ & 2016 & VV12 & Aoridae spec. & 10 \\
\hline $\mathrm{V}$ & 2016 & VV12 & Aphelochaeta marioni & 100 \\
\hline $\mathrm{V}$ & 2016 & VV12 & Capitella capitata & 10 \\
\hline $\mathrm{V}$ & 2016 & VV12 & Carcinus maenas & 10 \\
\hline $\mathrm{V}$ & 2016 & VV12 & Corophiidae & 30 \\
\hline $\mathrm{V}$ & 2016 & VV12 & Eteone species & 10 \\
\hline $\mathrm{V}$ & 2016 & VV12 & Eumida species & 10 \\
\hline $\mathrm{V}$ & 2016 & VV12 & GASTROPODA & 10 \\
\hline $\mathrm{V}$ & 2016 & VV12 & Hesionidae & 10 \\
\hline $\mathrm{V}$ & 2016 & VV12 & Kurtiella bidentata & 20 \\
\hline $\mathrm{V}$ & 2016 & VV12 & Lepidonotus squamatus & 30 \\
\hline $\mathrm{V}$ & 2016 & VV12 & Lysianassa ceratina & 500 \\
\hline $\mathrm{V}$ & 2016 & VV12 & Mediomastus fragilis & 1050 \\
\hline $\mathrm{V}$ & 2016 & VV12 & \begin{tabular}{|l} 
Monocorophium acherusicum \\
\end{tabular} & 20 \\
\hline $\mathrm{V}$ & 2016 & VV12 & Mya arenaria & 30 \\
\hline $\mathrm{V}$ & 2016 & VV12 & Mytilus edulis & 960 \\
\hline $\mathrm{V}$ & 2016 & VV12 & Nemertinae species & 30 \\
\hline V & 2016 & VV12 & OLIGOCHAETA & 50400 \\
\hline $\mathrm{V}$ & 2016 & VV12 & \begin{tabular}{|l|} 
Ophiotrix fragilis \\
\end{tabular} & 290 \\
\hline $\mathrm{V}$ & 2016 & VV12 & Pholoe baltica & 170 \\
\hline $\mathrm{V}$ & 2016 & VV12 & Pholoe inornata & 40 \\
\hline $\mathrm{V}$ & 2016 & VV12 & Platyhelminthes spec. & 290 \\
\hline V & 2016 & VV12 & Sabellaria spinulosa & 10 \\
\hline $\mathrm{V}$ & 2016 & VV12 & Sphaerodorum gracilis & 10 \\
\hline $\mathrm{V}$ & 2016 & VV12 & Sthenelais boa & 40 \\
\hline V & 2016 & VV12 & Subadyte pellucida & 20 \\
\hline $\mathrm{V}$ & 2016 & VV12 & Venerupis corrugata & 70 \\
\hline V & 2016 & VV13 & Abludomelita obtusata & 50 \\
\hline V & 2016 & VV13 & Abra alba & 1910 \\
\hline $\mathrm{V}$ & 2016 & VV13 & Actiniaria & 40 \\
\hline $\mathrm{V}$ & 2016 & VV13 & Aphelochaeta marioni & 530 \\
\hline $\mathrm{V}$ & 2016 & VV13 & Asterias rubens & 10 \\
\hline V & 2016 & VV13 & Buccinum undatum & 20 \\
\hline V & 2016 & VV13 & Carcinus maenas & 10 \\
\hline $\mathrm{V}$ & 2016 & VV13 & Eteone species & 30 \\
\hline V & 2016 & VV13 & Harmothoe & 10 \\
\hline $\mathrm{V}$ & 2016 & VV13 & Kefersteinia cirrata & 10 \\
\hline V & 2016 & VV13 & Mediomastus fragilis & 1670 \\
\hline V & 2016 & VV13 & Monocorophium acherusicum & 10 \\
\hline V & 2016 & VV13 & Mya arenaria & 10 \\
\hline $\mathrm{V}$ & 2016 & VV13 & Nemertinae species & 10 \\
\hline $\mathrm{V}$ & 2016 & VV13 & OLIGOCHAETA & 49720 \\
\hline V & 2016 & VV13 & Ophiotrix fragilis & 420 \\
\hline V & 2016 & VV13 & Ophiura ophiura & 10 \\
\hline $\mathrm{V}$ & 2016 & VV13 & Ophiuroidea & 10 \\
\hline $\mathrm{V}$ & 2016 & VV13 & Pholoe baltica & 170 \\
\hline V & 2016 & VV13 & Pholoe inornata & 10 \\
\hline $\mathrm{V}$ & 2016 & VV13 & Pseudopolydora pulchra & 450 \\
\hline V & 2016 & VV13 & Sthenelais boa & 20 \\
\hline $\mathrm{V}$ & 2016 & VV13 & Subadyte pellucida & 10 \\
\hline $\mathrm{V}$ & 2016 & VV13 & Venerupis corrugata & 40 \\
\hline $\mathrm{V}$ & 2016 & VV15 & Abludomelita obtusata & 120 \\
\hline $\mathrm{V}$ & 2016 & VV15 & Abra alba & 5760 \\
\hline V & 2016 & VV15 & Actiniaria & 369 \\
\hline $\mathrm{V}$ & 2016 & VV15 & Aonides oxycephala & 10 \\
\hline $\mathrm{V}$ & 2016 & VV15 & Aphelochaeta marioni & 668 \\
\hline V & 2016 & VV15 & Caprellidae & 10 \\
\hline V & 2016 & VV15 & Cerianthus lloydii & 20 \\
\hline $\mathrm{V}$ & 2016 & VV15 & Corophiidae & 110 \\
\hline $\mathrm{V}$ & 2016 & VV15 & Crepidula fornicata & 20 \\
\hline $\mathrm{V}$ & 2016 & VV15 & Decapoda species & 10 \\
\hline $\mathrm{V}$ & 2016 & VV15 & Eteone species & 40 \\
\hline V & 2016 & VV15 & Eumida species & 20 \\
\hline V & 2016 & VV15 & Eunereis longissima & 10 \\
\hline V & 2016 & VV15 & Eunoe nodosa & 10 \\
\hline V & 2016 & VV15 & Harmothoe & 10 \\
\hline $\mathrm{V}$ & 2016 & VV15 & Hesionidae & 10 \\
\hline V & 2016 & VV15 & Kefersteinia cirrata & 10 \\
\hline V & 2016 & VV15 & Kurtiella bidentata & 20 \\
\hline V & 2016 & VV15 & Lanice conchilega & 10 \\
\hline V & 2016 & VV15 & Lysianassa ceratina & 110 \\
\hline $\mathrm{V}$ & 2016 & VV15 & Mediomastus fragilis & 1734 \\
\hline $\mathrm{V}$ & 2016 & VV15 & \begin{tabular}{|l|} 
Microdeutopus anomalus \\
\end{tabular} & 20 \\
\hline $\mathrm{V}$ & 2016 & VV15 & Microdeutopus spec. & 40 \\
\hline V & 2016 & VV15 & Monocorophium acherusicum & 80 \\
\hline $\mathrm{V}$ & 2016 & VV15 & Mytilus edulis & 20 \\
\hline $\mathrm{V}$ & 2016 & VV15 & Notomastus latericeus & 20 \\
\hline $\mathrm{V}$ & 2016 & VV15 & OLIGOCHAETA & 41616 \\
\hline
\end{tabular}

\begin{tabular}{|c|c|c|c|c|}
\hline Met & Jaar & Monsterno & Soortnaam & $\mathrm{N} / \mathrm{m}^{2}$ \\
\hline $\mathrm{V}$ & 2016 & VV15 & Ophiotrix fragilis & 270 \\
\hline $\mathrm{V}$ & 2016 & VV15 & Ostrea edulis & 10 \\
\hline $\mathrm{V}$ & 2016 & VV15 & Owenia fusiformis & 20 \\
\hline $\mathrm{V}$ & 2016 & VV15 & Pholoe baltica & 300 \\
\hline $\mathrm{V}$ & 2016 & VV15 & Pholoe inornata & 20 \\
\hline $\mathrm{V}$ & 2016 & VV15 & Platyhelminthes spec. & 10 \\
\hline $\mathrm{V}$ & 2016 & VV15 & Polycirrus spec. & 10 \\
\hline $\mathrm{V}$ & 2016 & VV15 & Pseudopolydora pulchra & 70 \\
\hline $\mathrm{V}$ & 2016 & VV15 & Scoloplos (Scoloplos) armiger & 10 \\
\hline $\mathrm{V}$ & 2016 & VV15 & Sthenelais boa & 90 \\
\hline V & 2016 & VV15 & Subadyte pellucida & 10 \\
\hline $\mathrm{V}$ & 2016 & VV16 & Abludomelita obtusata & 160 \\
\hline $\mathrm{V}$ & 2016 & VV16 & Abra alba & 3910 \\
\hline $\mathrm{V}$ & 2016 & VV16 & Actiniaria & 310 \\
\hline $\mathrm{V}$ & 2016 & VV16 & Aonides oxycephala & 10 \\
\hline $\mathrm{V}$ & 2016 & VV16 & Aphelochaeta marioni & 60 \\
\hline $\mathrm{V}$ & 2016 & VV16 & Buccinum undatum & 20 \\
\hline $\mathrm{V}$ & 2016 & VV16 & Capitella capitata & 10 \\
\hline $\mathrm{V}$ & 2016 & VV16 & Caprellidae & 30 \\
\hline $\mathrm{V}$ & 2016 & VV16 & Cerianthus Iloydii & 10 \\
\hline $\mathrm{V}$ & 2016 & VV16 & Corophiidae & 40 \\
\hline $\mathrm{V}$ & 2016 & VV16 & Crepidula fornicata & 80 \\
\hline $\mathrm{V}$ & 2016 & VV16 & Eunereis longissima & 30 \\
\hline $\mathrm{V}$ & 2016 & VV16 & Harmothoe impar & 10 \\
\hline $\mathrm{V}$ & 2016 & VV16 & Kefersteinia cirrata & 10 \\
\hline $\mathrm{V}$ & 2016 & VV16 & Kurtiella bidentata & 360 \\
\hline $\mathrm{V}$ & 2016 & VV16 & Mediomastus fragilis & 2070 \\
\hline $\mathrm{V}$ & 2016 & VV16 & Monocorophium acherusicum & 80 \\
\hline $\mathrm{V}$ & 2016 & VV16 & Mya arenaria & 60 \\
\hline $\mathrm{V}$ & 2016 & VV16 & Mytilus edulis & 30 \\
\hline $\mathrm{V}$ & 2016 & VV16 & Nemertinae species & 10 \\
\hline $\mathrm{V}$ & 2016 & VV16 & Notomastus latericeus & 10 \\
\hline $\mathrm{V}$ & 2016 & VV16 & OLIGOCHAETA & 144900 \\
\hline $\mathrm{V}$ & 2016 & VV16 & Ophiotrix fragilis & 770 \\
\hline $\mathrm{V}$ & 2016 & VV16 & Ophiura ophiura & 20 \\
\hline $\mathrm{V}$ & 2016 & VV16 & Pagurus bernhardus & 10 \\
\hline $\mathrm{V}$ & 2016 & VV16 & Petricolaria pholadiformis & 10 \\
\hline $\mathrm{V}$ & 2016 & VV16 & Pholoe baltica & 240 \\
\hline $\mathrm{V}$ & 2016 & VV16 & Pholoe inornata & 10 \\
\hline $\mathrm{V}$ & 2016 & VV16 & Platyhelminthes spec. & 20 \\
\hline $\mathrm{V}$ & 2016 & VV16 & Sthenelais boa & 100 \\
\hline $\mathrm{V}$ & 2016 & VV16 & Subadyte pellucida & 80 \\
\hline $\mathrm{V}$ & 2016 & VV16 & Syllidia armata & 10 \\
\hline $\mathrm{V}$ & 2016 & VV16 & Venerupis corrugata & 90 \\
\hline $\mathrm{V}$ & 2016 & VV17 & Abludomelita obtusata & 260 \\
\hline $\mathrm{V}$ & 2016 & VV17 & Abra alba & 2810 \\
\hline $\mathrm{V}$ & 2016 & VV17 & Actiniaria & 420 \\
\hline $\mathrm{V}$ & 2016 & VV17 & Aphelochaeta marioni & 20 \\
\hline $\mathrm{V}$ & 2016 & VV17 & Bryozoa & 10 \\
\hline $\mathrm{V}$ & 2016 & VV17 & Capitella capitata & 10 \\
\hline $\mathrm{V}$ & 2016 & VV17 & Caprellidae & 20 \\
\hline $\mathrm{V}$ & 2016 & VV17 & Carcinus maenas & 10 \\
\hline $\mathrm{V}$ & 2016 & VV17 & Corophiidae & 10 \\
\hline $\mathrm{V}$ & 2016 & VV17 & Eteone species & 10 \\
\hline $\mathrm{V}$ & 2016 & VV17 & Eunereis longissima & 10 \\
\hline $\mathrm{V}$ & 2016 & VV17 & Glycera tridactyla & 30 \\
\hline $\mathrm{V}$ & 2016 & VV17 & Harmothoe & 10 \\
\hline $\mathrm{V}$ & 2016 & VV17 & Kurtiella bidentata & 110 \\
\hline $\mathrm{V}$ & 2016 & VV17 & Liocarcinus holsatus & 10 \\
\hline $\mathrm{V}$ & 2016 & VV17 & Mediomastus fragilis & 1000 \\
\hline $\mathrm{V}$ & 2016 & VV17 & Mya arenaria & 100 \\
\hline $\mathrm{V}$ & 2016 & VV17 & Nemertinae species & 30 \\
\hline $\mathrm{V}$ & 2016 & VV17 & Notomastus latericeus & 30 \\
\hline $\mathrm{V}$ & 2016 & VV17 & OLIGOCHAETA & 53265 \\
\hline V & 2016 & VV17 & Ophiotrix fragilis & 330 \\
\hline $\mathrm{V}$ & 2016 & VV17 & Ophiura ophiura & 10 \\
\hline $\mathrm{V}$ & 2016 & VV17 & Pholoe baltica & 370 \\
\hline $\mathrm{V}$ & 2016 & VV17 & Pholoe inornata & 30 \\
\hline $\mathrm{V}$ & 2016 & VV17 & Pseudopolydora pulchra & 10 \\
\hline $\mathrm{V}$ & 2016 & VV17 & Scalibregma inflatum & 10 \\
\hline $\mathrm{V}$ & 2016 & VV17 & Sthenelais boa & 90 \\
\hline $\mathrm{V}$ & 2016 & VV17 & Streblospio shrubsolii & 10 \\
\hline $\mathrm{V}$ & 2016 & VV17 & Subadyte pellucida & 10 \\
\hline $\mathrm{V}$ & 2016 & VV17 & Venerupis corrugata & 30 \\
\hline $\mathrm{V}$ & 2016 & VV2 & Abludomelita obtusata & 180 \\
\hline $\mathrm{V}$ & 2016 & VV2 & Abra alba & 2440 \\
\hline $\mathrm{V}$ & 2016 & VV2 & Actiniaria & 160 \\
\hline $\mathrm{V}$ & 2016 & VV2 & Aonides oxycephala & 100 \\
\hline $\mathrm{V}$ & 2016 & VV2 & Aphelochaeta marioni & 60 \\
\hline $\mathrm{V}$ & 2016 & VV2 & Capitella capitata & 150 \\
\hline $\mathrm{V}$ & 2016 & VV2 & Cerianthus Iloydii & 20 \\
\hline
\end{tabular}




\begin{tabular}{|c|c|c|c|c|}
\hline Met & Jaar & Monsterno & Soortnaam & $\mathrm{N} / \mathrm{m}^{2}$ \\
\hline $\mathrm{V}$ & 2016 & VV2 & Corophiidae & 10 \\
\hline $\mathrm{V}$ & 2016 & VV2 & Cossura longocirrata & 10 \\
\hline $\mathrm{V}$ & 2016 & VV2 & Crepidula fornicata & 40 \\
\hline $\mathrm{V}$ & 2016 & VV2 & Eteone species & 20 \\
\hline $\mathrm{V}$ & 2016 & VV2 & Kurtiella bidentata & 30 \\
\hline $\mathrm{V}$ & 2016 & VV2 & Lagis koreni & 10 \\
\hline $\mathrm{V}$ & 2016 & VV2 & Malmgreniella species & 20 \\
\hline $\mathrm{V}$ & 2016 & VV2 & Mediomastus fragilis & 4500 \\
\hline V & 2016 & VV2 & Nemertinae species & 790 \\
\hline $\mathrm{V}$ & 2016 & VV2 & Nephtys hombergii & 10 \\
\hline $\mathrm{V}$ & 2016 & VV2 & Notomastus latericeus & 240 \\
\hline V & 2016 & VV2 & OLIGOCHAETA & 11850 \\
\hline $\mathrm{V}$ & 2016 & VV2 & Ophiotrix fragilis & 330 \\
\hline $\mathrm{V}$ & 2016 & VV2 & Ophiura ophiura & 40 \\
\hline $\mathrm{V}$ & 2016 & VV2 & Owenia fusiformis & 10 \\
\hline $\mathrm{V}$ & 2016 & VV2 & Pholoe baltica & 180 \\
\hline $\mathrm{V}$ & 2016 & VV2 & Prionospio steenstrupi & 60 \\
\hline $\mathrm{V}$ & 2016 & VV2 & Pseudopolydora pulchra & 50 \\
\hline $\mathrm{V}$ & 2016 & VV2 & Sthenelais boa & 110 \\
\hline $\mathrm{V}$ & 2016 & VV3 & Abludomelita obtusata & 10 \\
\hline $\mathrm{V}$ & 2016 & VV3 & Abra alba & 5520 \\
\hline V & 2016 & VV3 & Actiniaria & 60 \\
\hline $\mathrm{V}$ & 2016 & VV3 & Aphelochaeta marioni & 110 \\
\hline $\mathrm{V}$ & 2016 & VV3 & Asterias rubens & 20 \\
\hline $\mathrm{V}$ & 2016 & VV3 & Cerianthus lloydii & 10 \\
\hline $\mathrm{V}$ & 2016 & VV3 & Cossura longocirrata & 10 \\
\hline V & 2016 & VV3 & Eteone species & 50 \\
\hline $\mathrm{V}$ & 2016 & VV3 & Glycera tridactyla & 10 \\
\hline $\mathrm{V}$ & 2016 & VV3 & Kurtiella bidentata & 60 \\
\hline $\mathrm{V}$ & 2016 & VV3 & Lanice conchilega & 10 \\
\hline $\mathrm{V}$ & 2016 & VV3 & Lysianassa ceratina & 10 \\
\hline V & 2016 & VV3 & Mediomastus fragilis & 1910 \\
\hline $\mathrm{V}$ & 2016 & VV3 & Mya arenaria & 50 \\
\hline $\mathrm{V}$ & 2016 & VV3 & Nemertinae species & 220 \\
\hline V & 2016 & VV3 & Notomastus latericeus & 50 \\
\hline $\mathrm{V}$ & 2016 & VV3 & OLIGOCHAETA & 5060 \\
\hline $\mathrm{V}$ & 2016 & VV3 & Ophiotrix fragilis & 830 \\
\hline $\mathrm{V}$ & 2016 & VV3 & Ophiura ophiura & 40 \\
\hline $\mathrm{V}$ & 2016 & VV3 & Pholoe baltica & 50 \\
\hline $\mathrm{V}$ & 2016 & VV3 & Polydora spec. & 30 \\
\hline $\mathrm{V}$ & 2016 & VV3 & Polynoidae & 40 \\
\hline $\mathrm{V}$ & 2016 & VV3 & Pseudopolydora pulchra & 40 \\
\hline $\mathrm{V}$ & 2016 & VV3 & Scoloplos (Scoloplos) armiger & 30 \\
\hline $\mathrm{V}$ & 2016 & VV3 & Sthenelais boa & 80 \\
\hline V & 2016 & VV4 & Abludomelita obtusata & 10 \\
\hline $\mathrm{V}$ & 2016 & VV4 & Abra alba & 180 \\
\hline $\mathrm{V}$ & 2016 & VV4 & Actiniaria & 60 \\
\hline $\mathrm{V}$ & 2016 & VV4 & Aphelochaeta marioni & 10 \\
\hline $\mathrm{V}$ & 2016 & VV4 & Capitella capitata & 20 \\
\hline $\mathrm{V}$ & 2016 & VV4 & Kurtiella bidentata & 50 \\
\hline $\mathrm{V}$ & 2016 & VV4 & Mediomastus fragilis & 870 \\
\hline V & 2016 & VV4 & Mya arenaria & 10 \\
\hline $\mathrm{V}$ & 2016 & VV4 & OLIGOCHAETA & 17000 \\
\hline $\mathrm{V}$ & 2016 & VV4 & Ophiotrix fragilis & 30 \\
\hline $\mathrm{V}$ & 2016 & VV4 & Owenia fusiformis & 30 \\
\hline $\mathrm{V}$ & 2016 & VV4 & Pholoe baltica & 30 \\
\hline $\mathrm{V}$ & 2016 & VV4 & Sthenelais boa & 30 \\
\hline $\mathrm{V}$ & 2016 & VV5 & Abludomelita obtusata & 730 \\
\hline $\mathrm{V}$ & 2016 & VV5 & Abra alba & 1270 \\
\hline $\mathrm{V}$ & 2016 & VV5 & Actiniaria & 560 \\
\hline $\mathrm{V}$ & 2016 & VV5 & Anoplodactylus petiolatus & 10 \\
\hline $\mathrm{V}$ & 2016 & VV5 & Aonides oxycephala & 10 \\
\hline V & 2016 & VV5 & Aora typica & 10 \\
\hline $\mathrm{V}$ & 2016 & VV5 & Aoridae spec. & 100 \\
\hline V & 2016 & VV5 & Aphelochaeta marioni & 40 \\
\hline $\mathrm{V}$ & 2016 & VV5 & Bodotria scorpioides & 10 \\
\hline $\mathrm{V}$ & 2016 & VV5 & Bryozoa & 10 \\
\hline $\mathrm{V}$ & 2016 & VV5 & Capitella capitata & 10 \\
\hline $\mathrm{V}$ & 2016 & VV5 & Caprellidae & 10 \\
\hline $\mathrm{V}$ & 2016 & VV5 & Cerianthus lloydii & 10 \\
\hline $\mathrm{V}$ & 2016 & VV5 & Cheirocratus & 10 \\
\hline V & 2016 & VV5 & Corophiidae & 60 \\
\hline
\end{tabular}

\begin{tabular}{|c|c|c|c|c|}
\hline Met & Jaar & Monsterno & Soortnaam & $\mathrm{N} / \mathrm{m}^{2}$ \\
\hline $\mathrm{V}$ & 2016 & VV5 & Eteone species & 10 \\
\hline $\mathrm{V}$ & 2016 & VV5 & Eunereis longissima & 10 \\
\hline V & 2016 & VV5 & Glycera tridactyla & 20 \\
\hline $\mathrm{V}$ & 2016 & VV5 & Kurtiella bidentata & 320 \\
\hline $\mathrm{V}$ & 2016 & VV5 & Mediomastus fragilis & 2000 \\
\hline $\mathrm{V}$ & 2016 & VV5 & Monocorophium acherusicum & 10 \\
\hline $\mathrm{V}$ & 2016 & VV5 & Mya arenaria & 70 \\
\hline $\mathrm{V}$ & 2016 & VV5 & Myrianida & 20 \\
\hline $\mathrm{V}$ & 2016 & VV5 & Nemertinae species & 20 \\
\hline $\mathrm{V}$ & 2016 & VV5 & Notomastus latericeus & 80 \\
\hline V & 2016 & VV5 & OLIGOCHAETA & 35000 \\
\hline $\mathrm{V}$ & 2016 & VV5 & Ophiotrix fragilis & 50 \\
\hline $\mathrm{V}$ & 2016 & VV5 & Ophiura ophiura & 50 \\
\hline $\mathrm{V}$ & 2016 & VV5 & Owenia fusiformis & 10 \\
\hline $\mathrm{V}$ & 2016 & VV5 & Pholoe baltica & 250 \\
\hline V & 2016 & VV5 & Pholoe inornata & 50 \\
\hline $\mathrm{V}$ & 2016 & VV5 & Polynoidae & 10 \\
\hline $\mathrm{V}$ & 2016 & VV5 & Pseudopolydora pulchra & 70 \\
\hline $\mathrm{V}$ & 2016 & VV5 & Sabellaria spinulosa & 10 \\
\hline $\mathrm{V}$ & 2016 & VV5 & Sthenelais boa & 120 \\
\hline $\mathrm{V}$ & 2016 & VV5 & Syllidia armata & 10 \\
\hline $\mathrm{V}$ & 2016 & VV5 & Venerupis corrugata & 20 \\
\hline $\mathrm{V}$ & 2016 & VV6 & Abludomelita obtusata & 350 \\
\hline $\mathrm{V}$ & 2016 & VV6 & Abra alba & 2180 \\
\hline $\mathrm{V}$ & 2016 & VV6 & Actiniaria & 570 \\
\hline $\mathrm{V}$ & 2016 & VV6 & Aphelochaeta marioni & 480 \\
\hline $\mathrm{V}$ & 2016 & VV6 & Cerianthus lloydii & 10 \\
\hline V & 2016 & VV6 & Corophiidae & 10 \\
\hline V & 2016 & VV6 & Eunereis longissima & 10 \\
\hline $\mathrm{V}$ & 2016 & VV6 & Glycera tridactyla & 40 \\
\hline $\mathrm{V}$ & 2016 & VV6 & Kurtiella bidentata & 60 \\
\hline $\mathrm{V}$ & 2016 & VV6 & Mediomastus fragilis & 2460 \\
\hline V & 2016 & VV6 & Nemertinae species & 70 \\
\hline $\mathrm{V}$ & 2016 & VV6 & Notomastus latericeus & 140 \\
\hline $\mathrm{V}$ & 2016 & VV6 & OLIGOCHAETA & 57400 \\
\hline $\mathrm{V}$ & 2016 & VV6 & Ophiotrix fragilis & 20 \\
\hline $\mathrm{V}$ & 2016 & VV6 & Ophiura ophiura & 10 \\
\hline $\mathrm{V}$ & 2016 & VV6 & Owenia fusiformis & 70 \\
\hline $\mathrm{V}$ & 2016 & VV6 & Pholoe baltica & 230 \\
\hline $\mathrm{V}$ & 2016 & VV6 & Pseudopolydora pulchra & 50 \\
\hline $\mathrm{V}$ & 2016 & VV6 & Sthenelais boa & 170 \\
\hline V & 2016 & VV6 & Streblospio shrubsolii & 10 \\
\hline V & 2016 & VV6 & Venerupis corrugata & 60 \\
\hline $\mathrm{V}$ & 2016 & VV8 & Abludomelita obtusata & 10 \\
\hline $\mathrm{V}$ & 2016 & VV8 & Abra alba & 260 \\
\hline $\mathrm{V}$ & 2016 & VV8 & Actiniaria & 60 \\
\hline $\mathrm{V}$ & 2016 & VV8 & Lysianassa ceratina & 20 \\
\hline $\mathrm{V}$ & 2016 & VV8 & Mediomastus fragilis & 140 \\
\hline $\mathrm{V}$ & 2016 & VV8 & Mytilus edulis & 80 \\
\hline $\mathrm{V}$ & 2016 & VV8 & OLIGOCHAETA & 16500 \\
\hline $\mathrm{V}$ & 2016 & VV8 & Ophiotrix fragilis & 90 \\
\hline $\mathrm{V}$ & 2016 & VV8 & Pholoe baltica & 10 \\
\hline $\mathrm{V}$ & 2016 & VV8 & Pisidia longicornis & 10 \\
\hline $\mathrm{V}$ & 2016 & VV8 & Pseudopolydora pulchra & 10 \\
\hline $\mathrm{V}$ & 2016 & VV8 & Venerupis corrugata & 40 \\
\hline $\mathrm{V}$ & 2016 & VV9 & Abra alba & 80 \\
\hline $\mathrm{V}$ & 2016 & VV9 & Flabelligera affinis & 10 \\
\hline $\mathrm{V}$ & 2016 & VV9 & Mediomastus fragilis & 80 \\
\hline $\mathrm{V}$ & 2016 & VV9 & Nassarius spec. & 10 \\
\hline V & 2016 & VV9 & OLIGOCHAETA & 1380 \\
\hline $\mathrm{V}$ & 2016 & VV9 & Ophiotrix fragilis & 20 \\
\hline $\mathrm{V}$ & 2016 & VV9 & Pholoe inornata & 10 \\
\hline $\mathrm{V}$ & 2016 & VV9 & Polychaeta & 10 \\
\hline V & 2016 & VV9 & Sthenelais boa & 10 \\
\hline $\mathrm{V}$ & 2016 & VV9 & Subadyte pellucida & 10 \\
\hline
\end{tabular}


Bijlage 9. Geordende tabel van de zachtsubstraat varianten van de

levensgemeenschappen in de Oosterschelde in 2016.

Vet gedrukte dichtheden $(\mathrm{N} / \mathrm{m} 2)$ geven een presentie van de soort in $>66.7 \%$ van de stations van een cluster, onderstreepte waarden geven per soort een voorkomen van minimaal $90 \%$ van de totale kwantiteit binnen de onderzochte stations. Afkortingen: An-Anthozoa, Br-Bryozoa, $\mathrm{Cr}$ Crustacea, Ech-Echinodermata, Mol-Mollusca, Ne-Nemertea, Oli-Oligochaetea, Ph-Phoronida, Pla-Platyhelminthes, Po-Polychaeta, Pyc-Pycnogonidae, Sp-Sponzen en Tu-Tunicaten.

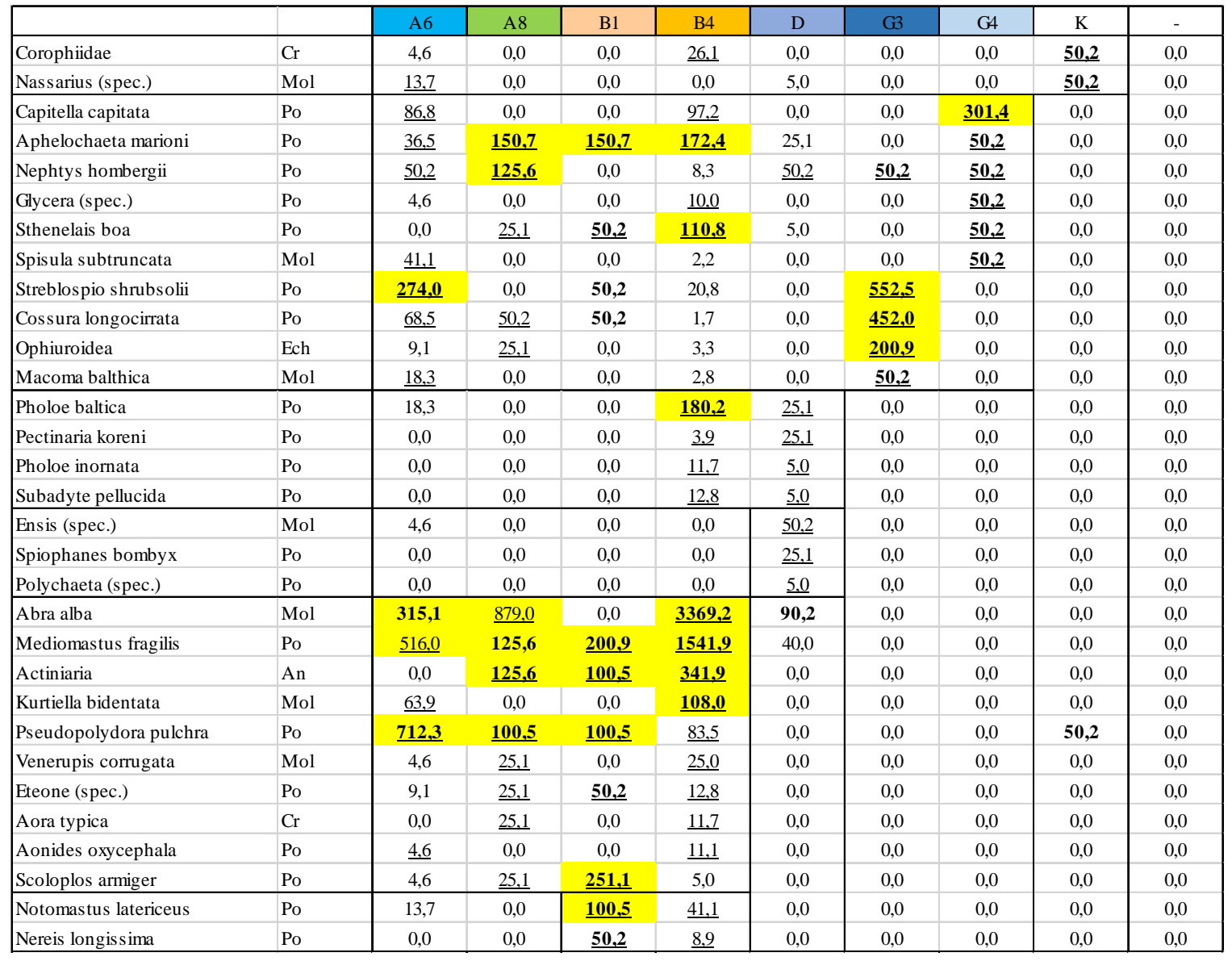




\begin{tabular}{|c|c|c|c|c|c|c|c|c|c|c|}
\hline & & A6 & A8 & $\mathrm{B} 1$ & B4 & $\mathrm{D}$ & G3 & G4 & $\mathrm{K}$ & - \\
\hline Oligochaeta & Oli & 493,1 & 200,9 & 1908,6 & $\underline{40685,8}$ & 840,7 & 50,2 & 251,1 & 50,2 & 0,0 \\
\hline Ophiothrix fragilis & Ech & 0,0 & 0,0 & 0,0 & $\underline{300,0}$ & 10,0 & 0,0 & 0,0 & 0,0 & 0,0 \\
\hline Lysianassa ceratina & $\mathrm{Cr}$ & 0,0 & 0,0 & 0,0 & $\underline{216,1}$ & 0,0 & 0,0 & 0,0 & 0,0 & 0,0 \\
\hline Mytilus edulis & Mol & 0,0 & 0,0 & 0,0 & $\underline{187,2}$ & 0,0 & 0,0 & 0,0 & 0,0 & 0,0 \\
\hline Melita obtusata & $\mathrm{Cr}$ & 0,0 & 0,0 & 0,0 & $\underline{126,1}$ & 0,0 & 0,0 & 0,0 & 0,0 & 0,0 \\
\hline Nemertea & $\mathrm{Ne}$ & 0,0 & 0,0 & 0,0 & $\underline{72,2}$ & 0,0 & 0,0 & 0,0 & 0,0 & 0,0 \\
\hline Owenia fusiformis & Po & 0,0 & 0,0 & 0,0 & $\underline{42,4}$ & 0,0 & 0,0 & 0,0 & 0,0 & 0,0 \\
\hline Mya arenaria & Mol & 0,0 & 0,0 & 0,0 & $\underline{21,7}$ & 0,0 & 0,0 & 0,0 & 0,0 & 0,0 \\
\hline Monocorophium acherusicum & $\mathrm{Cr}$ & 0,0 & 0,0 & 0,0 & $\underline{20,6}$ & 0,0 & 0,0 & 0,0 & 0,0 & 0,0 \\
\hline Platyhelminthes & Pt & 0,0 & 0,0 & 0,0 & $\underline{18,3}$ & 0,0 & 0,0 & 0,0 & 0,0 & 0,0 \\
\hline Crepidula fornicata & Mol & 0,0 & 0,0 & 0,0 & $\underline{16,1}$ & 0,0 & 0,0 & 0,0 & 0,0 & 0,0 \\
\hline Ophiura ophiura & Ech & 0,0 & 0,0 & 0,0 & $\underline{10,0}$ & 0,0 & 0,0 & 0,0 & 0,0 & 0,0 \\
\hline Aoridae & $\mathrm{Cr}$ & 0,0 & 0,0 & 0,0 & $\underline{9,5}$ & 0,0 & 0,0 & 0,0 & 0,0 & 0,0 \\
\hline Caprellidae & $\mathrm{Cr}$ & 0,0 & 0,0 & 0,0 & $\underline{9,5}$ & 0,0 & 0,0 & 0,0 & 0,0 & 0,0 \\
\hline Buccinum undatum & Mol & 0,0 & 0,0 & 0,0 & $\underline{4,4}$ & 0,0 & 0,0 & 0,0 & 0,0 & 0,0 \\
\hline Lepidonotus squamatus & Po & 0,0 & 0,0 & 0,0 & $\underline{3,9}$ & 0,0 & 0,0 & 0,0 & 0,0 & 0,0 \\
\hline Pisidia longicornis & $\mathrm{Cr}$ & 0,0 & 0,0 & 0,0 & $\underline{3,9}$ & 0,0 & 0,0 & 0,0 & 0,0 & 0,0 \\
\hline Anoplodactylus petiolatus & Pyc & 0,0 & 0,0 & 0,0 & $\underline{3,3}$ & 0,0 & 0,0 & 0,0 & 0,0 & 0,0 \\
\hline Bodotria scorpioides & $\mathrm{Cr}$ & 0,0 & 0,0 & 0,0 & $\underline{3,3}$ & 0,0 & 0,0 & 0,0 & 0,0 & 0,0 \\
\hline Polynoidae & Po & 0,0 & 0,0 & 0,0 & $\underline{3,3}$ & 0,0 & 0,0 & 0,0 & 0,0 & 0,0 \\
\hline Prionospio steenstrupi & Po & 0,0 & 0,0 & 0,0 & $\underline{3,3}$ & 0,0 & 0,0 & 0,0 & 0,0 & 0,0 \\
\hline Asterias rubens & Ech & 0,0 & 0,0 & 0,0 & $\underline{2,8}$ & 0,0 & 0,0 & 0,0 & 0,0 & 0,0 \\
\hline Kefersteinia cirrata & Po & 0,0 & 0,0 & 0,0 & $\underline{2,8}$ & 0,0 & 0,0 & 0,0 & 0,0 & 0,0 \\
\hline Lanice conchilega & Po & 0,0 & 0,0 & 0,0 & $\underline{2,8}$ & 0,0 & 0,0 & 0,0 & 0,0 & 0,0 \\
\hline Harmothoe (spec.) & Po & 0,0 & 0,0 & 0,0 & $\underline{2,8}$ & 0,0 & 0,0 & 0,0 & 0,0 & 0,0 \\
\hline Phoronida & $\mathrm{Ph}$ & 0,0 & 0,0 & 0,0 & $\underline{2,8}$ & 0,0 & 0,0 & 0,0 & 0,0 & 0,0 \\
\hline Pycnogonida & Рyc & 0,0 & 0,0 & 0,0 & $\underline{2,8}$ & 0,0 & 0,0 & 0,0 & 0,0 & 0,0 \\
\hline Carcinus maenas & $\mathrm{Cr}$ & 0,0 & 0,0 & 0,0 & $\underline{2,2}$ & 0,0 & 0,0 & 0,0 & 0,0 & 0,0 \\
\hline Microdeutopus (spec.) & $\mathrm{Cr}$ & 0,0 & 0,0 & 0,0 & $\underline{2,2}$ & 0,0 & 0,0 & 0,0 & 0,0 & 0,0 \\
\hline Polydora (spec.) & Po & 0,0 & 0,0 & 0,0 & $\underline{2,2}$ & 0,0 & 0,0 & 0,0 & 0,0 & 0,0 \\
\hline Eumida sanguinea & Po & 0,0 & 0,0 & 0,0 & $\underline{1,7}$ & 0,0 & 0,0 & 0,0 & 0,0 & 0,0 \\
\hline Sabellaria spinulosa & Po & 0,0 & 0,0 & 0,0 & $\underline{1,7}$ & 0,0 & 0,0 & 0,0 & 0,0 & 0,0 \\
\hline Eumida (spec.) & Po & 0,0 & 0,0 & 0,0 & $\underline{1,7}$ & 0,0 & 0,0 & 0,0 & 0,0 & 0,0 \\
\hline Eunoe nodosa & Po & 0,0 & 0,0 & 0,0 & $\underline{1,1}$ & 0,0 & 0,0 & 0,0 & 0,0 & 0,0 \\
\hline Harmothoe impar & Po & 0,0 & 0,0 & 0,0 & $\underline{1,1}$ & 0,0 & 0,0 & 0,0 & 0,0 & 0,0 \\
\hline Ostrea edulis & Mol & 0,0 & 0,0 & 0,0 & $\underline{1,1}$ & 0,0 & 0,0 & 0,0 & 0,0 & 0,0 \\
\hline Syllidia armata & Po & 0,0 & 0,0 & 0,0 & $\underline{1,1}$ & 0,0 & 0,0 & 0,0 & 0,0 & 0,0 \\
\hline Autolytus (spec.) & Po & 0,0 & 0,0 & 0,0 & $\underline{1,1}$ & 0,0 & 0,0 & 0,0 & 0,0 & 0,0 \\
\hline Malmgreniella (spec.) & Po & 0,0 & 0,0 & 0,0 & $\underline{1,1}$ & 0,0 & 0,0 & 0,0 & 0,0 & 0,0 \\
\hline BRYOZOA & $\mathrm{Br}$ & 0,0 & 0,0 & 0,0 & $\underline{1,1}$ & 0,0 & 0,0 & 0,0 & 0,0 & 0,0 \\
\hline Hesionidae & Po & 0,0 & 0,0 & 0,0 & $\underline{1,1}$ & 0,0 & 0,0 & 0,0 & 0,0 & 0,0 \\
\hline Neoamphitrite figulus & Po & 0,0 & 0,0 & 0,0 & $\underline{0,6}$ & 0,0 & 0,0 & 0,0 & 0,0 & 0,0 \\
\hline Nereis (spec.) & Po & 0,0 & 0,0 & 0,0 & $\underline{0,6}$ & 0,0 & 0,0 & 0,0 & 0,0 & 0,0 \\
\hline Monocorophium insidiosum & $\mathrm{Cr}$ & 0,0 & 0,0 & 0,0 & $\underline{0,6}$ & 0,0 & 0,0 & 0,0 & 0,0 & 0,0 \\
\hline Pagurus bernhardus & $\mathrm{Cr}$ & 0,0 & 0,0 & 0,0 & $\underline{0,6}$ & 0,0 & 0,0 & 0,0 & 0,0 & 0,0 \\
\hline Petricola pholadiformis & Mol & 0,0 & 0,0 & 0,0 & $\underline{0,6}$ & 0,0 & 0,0 & 0,0 & 0,0 & 0,0 \\
\hline Scalibregma inflatum & Po & 0,0 & 0,0 & 0,0 & $\underline{0,6}$ & 0,0 & 0,0 & 0,0 & 0,0 & 0,0 \\
\hline Styela clava & $\mathrm{Tu}$ & 0,0 & 0,0 & 0,0 & $\underline{0,6}$ & 0,0 & 0,0 & 0,0 & 0,0 & 0,0 \\
\hline Syllis gracillis & Po & 0,0 & 0,0 & 0,0 & $\underline{0,6}$ & 0,0 & 0,0 & 0,0 & 0,0 & 0,0 \\
\hline Liocarcinus holsatus & $\mathrm{Cr}$ & 0,0 & 0,0 & 0,0 & $\underline{0,6}$ & 0,0 & 0,0 & 0,0 & 0,0 & 0,0 \\
\hline Sphaerodorum gracilis & Po & 0,0 & 0,0 & 0,0 & $\underline{0,6}$ & 0,0 & 0,0 & 0,0 & 0,0 & 0,0 \\
\hline Sycon & Sp & 0,0 & 0,0 & 0,0 & $\underline{0,6}$ & 0,0 & 0,0 & 0,0 & 0,0 & 0,0 \\
\hline Cheirocratus (spec.) & $\mathrm{Cr}$ & 0,0 & 0,0 & 0,0 & $\underline{0,6}$ & 0,0 & 0,0 & 0,0 & 0,0 & 0,0 \\
\hline Decapoda & $\mathrm{Cr}$ & 0,0 & 0,0 & 0,0 & $\underline{0,6}$ & 0,0 & 0,0 & 0,0 & 0,0 & 0,0 \\
\hline Gastropoda & Mol & 0,0 & 0,0 & 0,0 & $\underline{0,6}$ & 0,0 & 0,0 & 0,0 & 0,0 & 0,0 \\
\hline Polycirrus (spec.) & Po & 0,0 & 0,0 & 0,0 & $\underline{0,6}$ & 0,0 & 0,0 & 0,0 & 0,0 & 0,0 \\
\hline Ampelisca brevicornis & $\mathrm{Cr}$ & $\underline{4,6}$ & $\underline{25,1}$ & 0,0 & 0,0 & 0,0 & 0,0 & 0,0 & 0,0 & 0,0 \\
\hline Ascidiacea & $\mathrm{Tu}$ & $\underline{4,6}$ & $\underline{25,1}$ & 0,0 & 0,0 & 0,0 & 0,0 & 0,0 & 0,0 & 0,0 \\
\hline Cerianthus lloydii & An & 0,0 & $\underline{50,2}$ & 0,0 & 4,4 & 0,0 & 0,0 & 0,0 & 0,0 & 0,0 \\
\hline Microdeutopus anomalus & $\mathrm{Cr}$ & 0,0 & $\underline{25,1}$ & 0,0 & 1,1 & 0,0 & 0,0 & 0,0 & 0,0 & 0,0 \\
\hline Acanthocardia & Mol & $\underline{9,1}$ & 0,0 & 0,0 & 0,0 & 0,0 & 0,0 & 0,0 & 0,0 & 0,0 \\
\hline Bivalve (spec.) & Mol & $\underline{9,1}$ & 0,0 & 0,0 & 0,0 & 0,0 & 0,0 & 0,0 & 0,0 & 0,0 \\
\hline Spio (spec.) & Po & $\underline{9,1}$ & 0,0 & 0,0 & 0,0 & 0,0 & 0,0 & 0,0 & 0,0 & 0,0 \\
\hline Microphthalmus & Po & $\underline{4,6}$ & 0,0 & 0,0 & 0,0 & 0,0 & 0,0 & 0,0 & 0,0 & 0,0 \\
\hline OSTRACODA & $\mathrm{Cr}$ & 4,6 & 0,0 & 0,0 & 0,0 & 0,0 & 0,0 & 0,0 & 0,0 & 0,0 \\
\hline Syllidae & Po & $\underline{4,6}$ & 0,0 & 0,0 & 0,0 & 0,0 & 0,0 & 0,0 & 0,0 & 0,0 \\
\hline dichtheid n/m2 & & 2817,3 & 2034,2 & 3063,8 & 48038,4 & 1211,8 & 1356,1 & 803,6 & 200,9 & 0,0 \\
\hline Index Log base 2 & & 2,404 & 2,551 & 2,161 & 1,203 & 1,815 & 1,991 & 2,303 & 2,000 & $* * * *$ \\
\hline Evenness & & 0,769 & 0,735 & 0,603 & 0,271 & 0,590 & 0,770 & 0,820 & 1,000 & $* * * *$ \\
\hline ids & & 9,3 &, 5 & 12 & 24,4 & 9,0 & 6,0 & 7,0 & 4,0 & 0,0 \\
\hline
\end{tabular}


Bijlage 10. Schematische verdeling van de clusters over de locaties in de

Oosterschelde.

Voor 2016 ('OS 2016' onderaan) zijn de monsters van de Van Veen happer aangeduid (rode omlijsting). De rest van de monsters betreffen monsters die genomen zijn m.b.v. steekbuizen.

\begin{tabular}{|c|c|c|c|c|c|c|c|c|c|}
\hline OS-2009 & & & Sch-w & Sch-o & Lok-a & Lok-b & Zeel-w & Zeel-m & Zeel-o \\
\hline $0-5$ & & & A1 & A7 & A7 & A7 & B1 & & $\mathrm{A} 2$ \\
\hline 5.1-10 & & & $\mathrm{A} 8$ & $\mathrm{~A} 8$ & A7 & A7 & B1 & & $\mathrm{A} 2$ \\
\hline$>10.1$ & & & B1 & $\mathrm{A} 8$ & B1 & B1 & B1 & & A8 \\
\hline & & & & & & & & & \\
\hline OS-2010 & \multicolumn{2}{|c|}{ Burgh-w Sch-wII } & & Sch-o & & & & & Zeel-o \\
\hline $0-5$ & G1 & $\mathrm{A} 1$ & & $\mathrm{O}$ & & & & & \\
\hline $5.1-10$ & $\mathrm{~J}$ & $\mathrm{~A} 8$ & & $\mathrm{Q}$ & & & & & \\
\hline$>10.1$ & $\mathrm{~A} 1$ & $\mathrm{~A} 8$ & & $\mathrm{~L}$ & & & & & $\mathrm{~F}$ \\
\hline
\end{tabular}

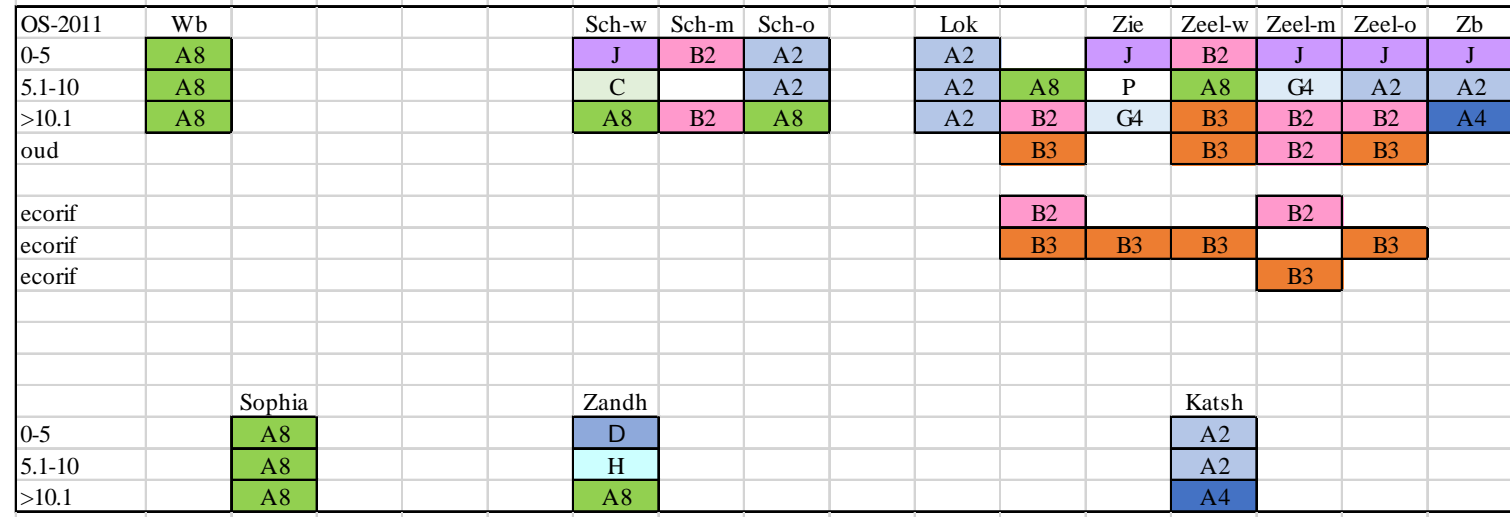

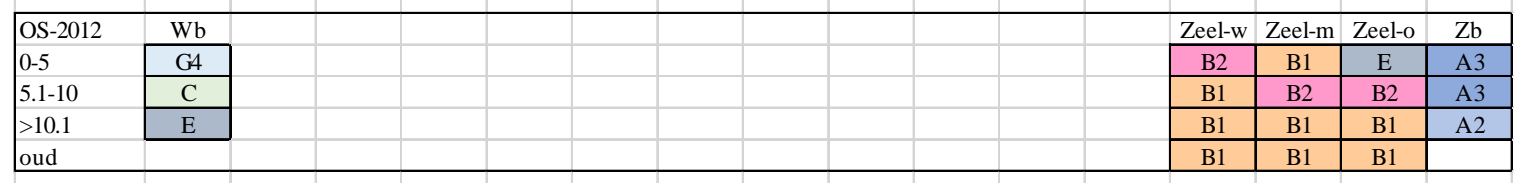

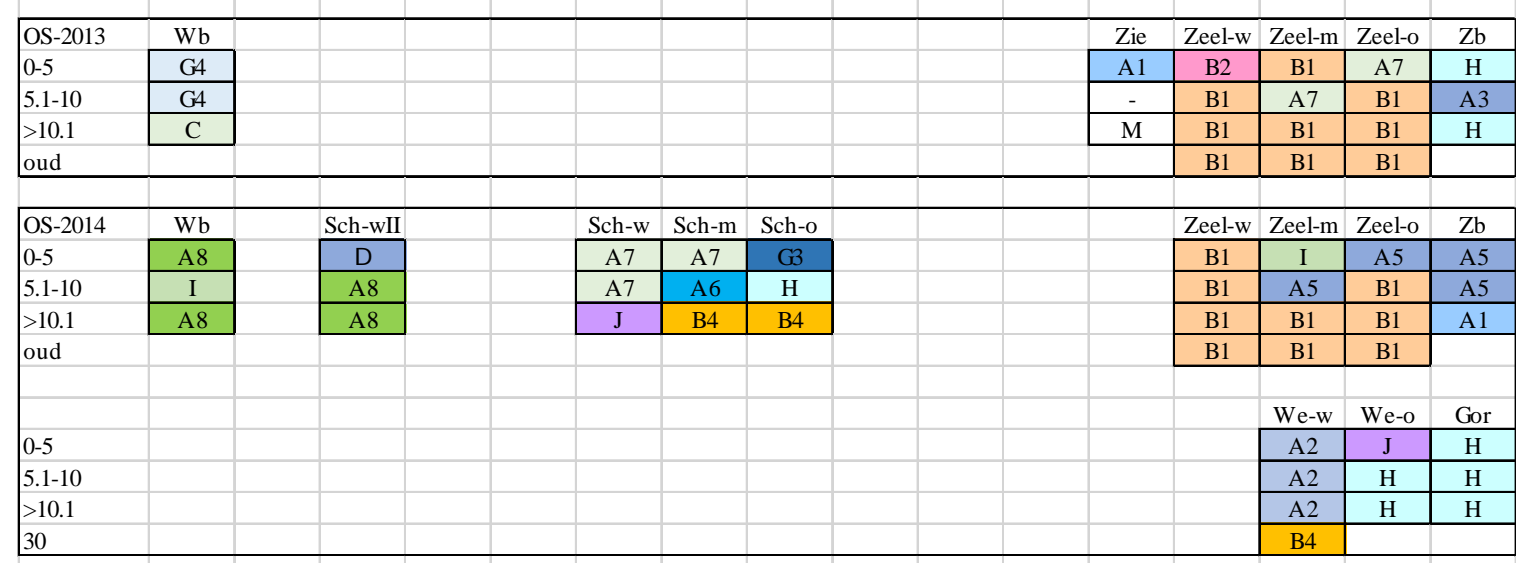

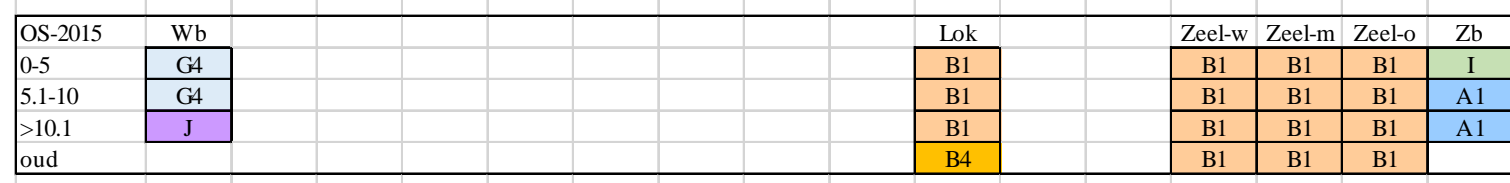

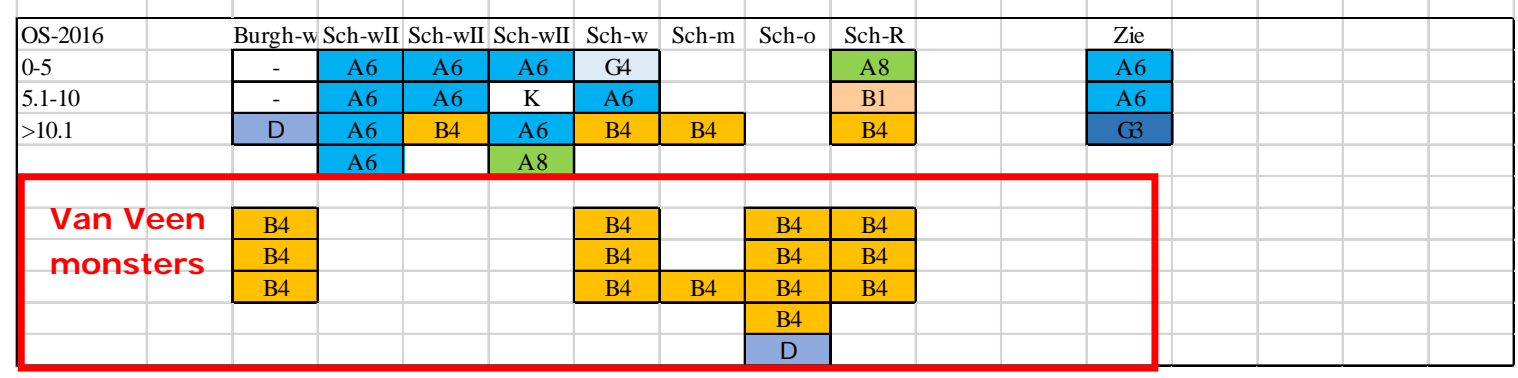


Bijlage 11. I nfauna 2009-2016, Mario de Kluijver (2016), Stichting Zeeschelp 


\section{I nfauna 2009-2016}

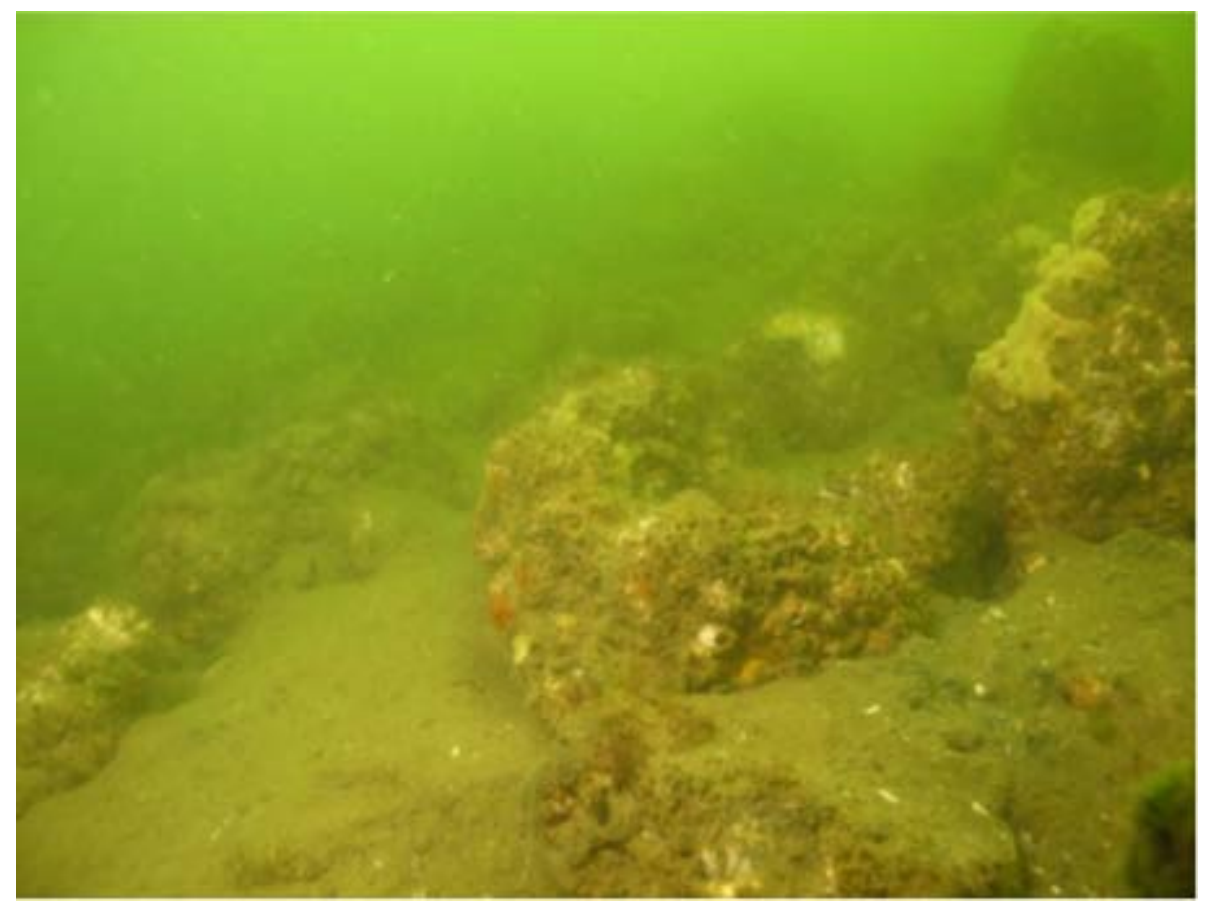

stichting

Zeeschelp 


\title{
Infauna, 2009-2016
}

In opdracht van: Imares

Auteur: M.J . de Kluijver

Conceptrapport, 9 maart 2016

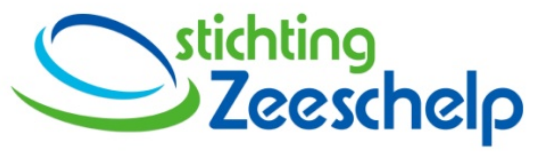

Marien Onderzoek en Aquacultuur

\author{
Jacobahaven 1 \\ 4493 ML Kamperland
}

Tel: 0113-376296

Fax: 0113-376297

info@zeeschelp.nl

www.zeeschelp.nl

Foto voorpagina: Nieuw zacht substraat op de locatie Zeelandbrug. 


\section{Inhoud}

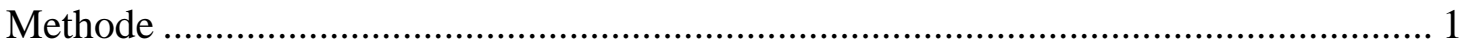

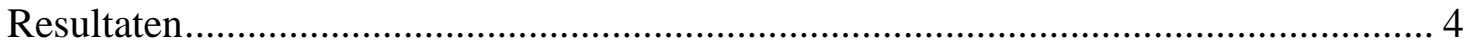

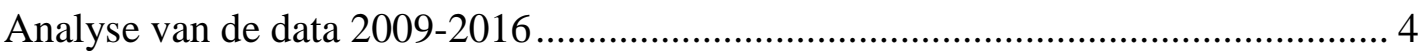

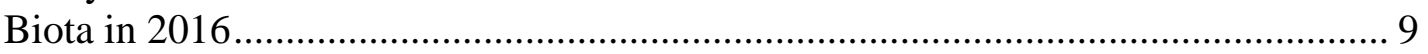

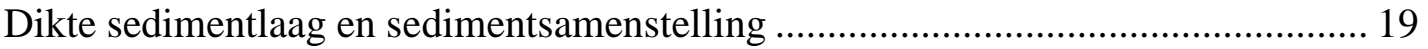

Relatie tussen de varianten en de abiotische parameters ....................................... 22

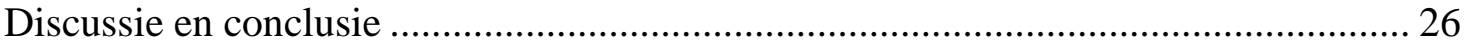

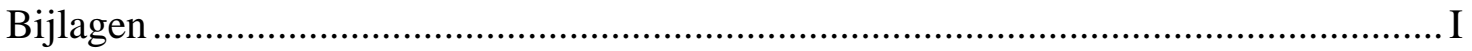

Bijlage 1 - stationsgegevens............................................................................ II

Bijlage 2 - sedimentkarakteristieken........................................................................ VI

Bijlage 3 - dikte sedimentlaag............................................................................ VII 



\section{Methode}

De biota van de zachte substraten, het macrobenthos, is bemonsterd met behulp van steekbuizen in drie diepte strata: 0-5 m, 5-10 m en >10 m -NAP. Per monster zijn 6 steekbuizen (6.5 cm doorsnede) genomen tot circa $30 \mathrm{~cm}$ in de waterbodem. De monsters zijn over $1 \mathrm{~mm}$ gezeefd en gefixeerd met borax gebufferde formaline (4\%). In 2016 zijn ook stations dieper dan 20 meter -NAP bemonsterd met een Van Veen happer. Bij de huidige analyse is aangenomen dat de happer een effectief vermogen heeft van $0.1 \mathrm{~m}^{2}$.

Om te beoordelen of er veranderingen op gemeenschapsniveau binnen de in- en epifauna in en op de zachte substraten zijn opgetreden is een clusteranalyse met de data van de $\mathrm{T}_{0}$ $\mathrm{T}_{6}$-inventarisatie uitgevoerd (275 stations uit de Ooster- en Westerschelde met 209 soorten, dit inclusief 11 stations van het programma 'Building for Nature' in 2014 en 2016). De analyse is uitgevoerd met het programma MVSP (Kovach, 1999). De clusteranalyse is uitgevoerd met logaritmisch getransformeerde data, met de 'BrayCurtis' coëfficiënt in combinatie met de 'Average-linkage' methode.

Vervolgens is een inverse analyse uitgevoerd zoals beschreven in Kaandorp (1986). De inverse analyse maakt een onderscheid mogelijk tussen dominante soorten $\left(\mathrm{n}>100 \mathrm{~m}^{2}\right)$, karakteristieke soorten voor een cluster en soorten beperkt tot een cluster.

Tijdens de bemonstering is ook de samenstelling van de bodemsedimenten bepaald en is de saliniteit gemeten.

De sedimentkarakteristieken van de bovenste centimeter van de sedimentlaag zijn bepaald door monsters te zeven over 7 gekalibreerde zeven (2.8-0.053 mm). De karakteristieken zijn uitgedrukt als de procentuele bijdrage van de drooggewichten van de verschillende fracties. Omdat de verdeling van de fracties niet altijd normaal verdeeld bleek te zijn, is op basis van de dominante fracties een typologie voor de bodemsedimenten opgesteld (Tabel 1). Wanneer, door een recente verstoring, de sedimenten een tweetoppige verdeling vertonen, wordt dit sediment aangeduid als een verstoord (dis) grover type.

Tabel 1. Typologie voor de bodemsedimenten.

\begin{tabular}{|l|c|c|c|c|c|c|c|c|}
\hline Type sediment & I & II & II & IV & V & VI & VII & VIII \\
\hline Dominante fractie in mm & $>2.8$ & $2-8-1.4$ & $1.4-0.6$ & $0.6-0.3$ & $0.3-0.15$ & $0.15-0.09$ & $0.09-0.05$ & $<0.05$ \\
\hline Benaming & \multicolumn{2}{|c|}{ schelprest } & zeer & grof zand & fijn zand & zeer & ultra & slib \\
\hline & & & grof zand & & & fijn zand & fijn zand & \\
\hline
\end{tabular}

In 2009 en 2010 zijn de sedimenten op de nabij gelegen stations voor de hardsubtraat bemonstering gebruikt, in 2011-2016 zijn de monsters op exact dezelfde locaties als de infauna monsters genomen.

Naast de sedimentkarakteristieken zijn in 2011-16 ook de percentages organische en droge stof bepaald. Deze percentages zijn bepaald van de bovenste $6 \mathrm{~cm}$ van het bodemsediment, door de monsters te drogen bij $70{ }^{\circ} \mathrm{C}$ en vijf uur te verassen bij $525{ }^{\circ} \mathrm{C}$. In 2016 zijn op de stations van de vooroeververdediging ook sedimentmonsters verzameld die door Rijkswaterstaat zullen worden geanalyseerd op de 
deeltjesgrootteverdeling van de minerale fractie 16-2000 $\mu$ m door middel van laserdiffractie (Analysevoorschrift A1.063).

Op 6 raaien (Burghsluis, Schelphoek-West II-midden-oost, Schelphoek-west, Schelphoek-midden, Schelphoek-oost-Referentie en Zierikzee) is de dikte van de sedimentlaag bepaald. Voor het project 'Building for Nature' is de dikte bepaald op drie andere locaties: Schelphoek-West II-west, Schelphoek-West II-west-midden en Schelphoek-West II-oost. De dikte van de sedimentlaag is bepaald door vanaf $15 \mathrm{~m}$-NAP tot $3 \mathrm{~m}$-NAP een kwadrant van 50x50 cm om te klappen en in het hart de dikte te meten. 



\section{Resultaten}

Analyse van de data 2009-2016

In de periode 2009-2016 zijn in de Oosterschelde en de Westerschelde het macrobenthos op 275 stations onderzocht. De stationsgegevens en abiotische factoren zijn in Bijlage 1 gegeven. De onderzochte locaties in de Oosterschelde zijn gegeven in Figuur 1, die in de Westerschelde in Bijlage 2.

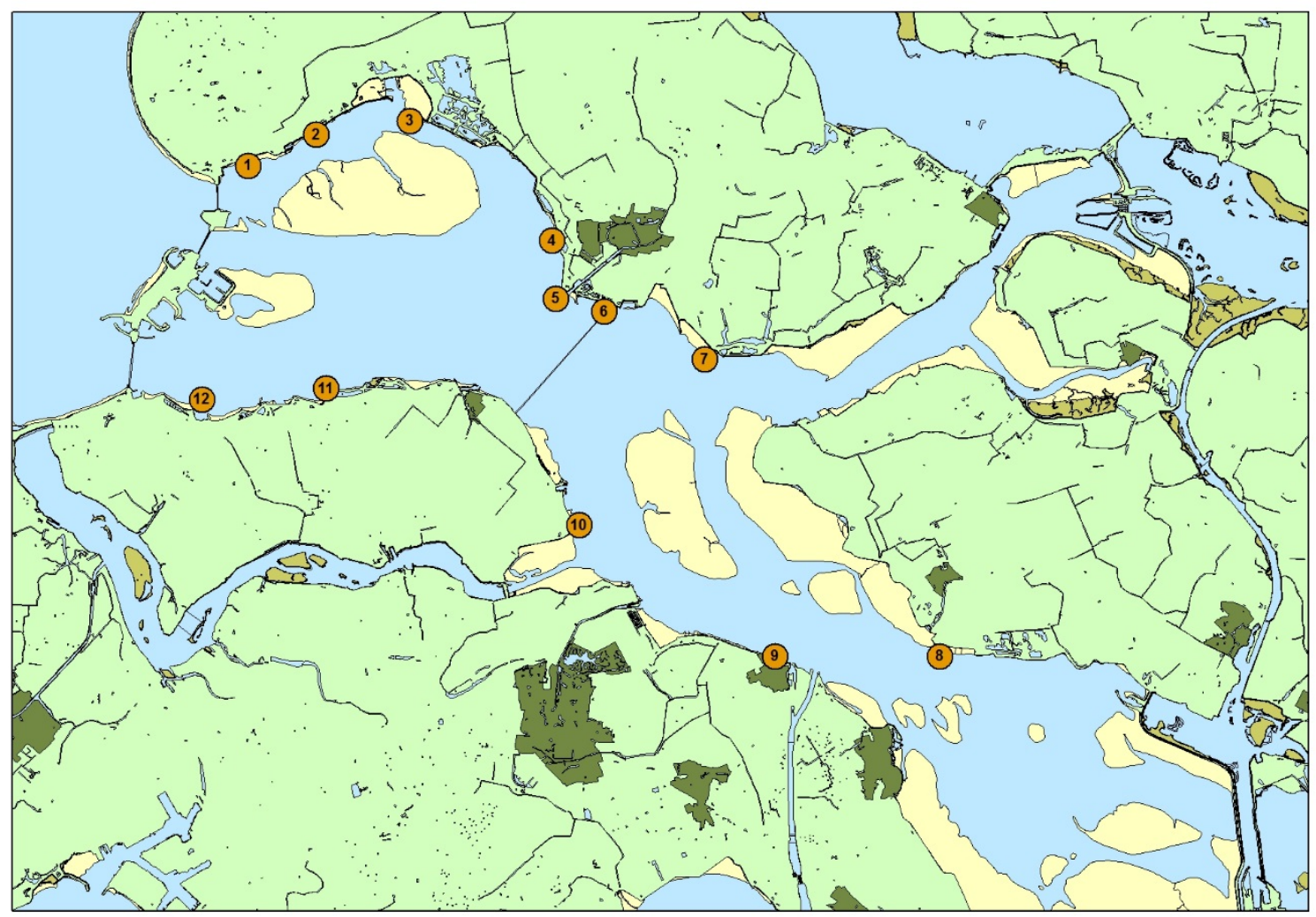

Figuur 1. De onderzochte locaties in de Oosterschelde, 1-Westbout, 2-Burghsluis, 3-Schelphoek (westII, west, midden, oost en oost-Referentie), 4-Lokkersnol (a en b), 5-Zierikzee, 6-Zeelandbrug (west, midden en oost), 7-Zuidbout, 8-Gorishoek, 9-Wemeldinge (west en oost), 10-Katshoek, 11-Zandhoek en 12Sophiahaven.

Het dendrogram van de clusteranalyse is in Figuur 2 gegeven. 


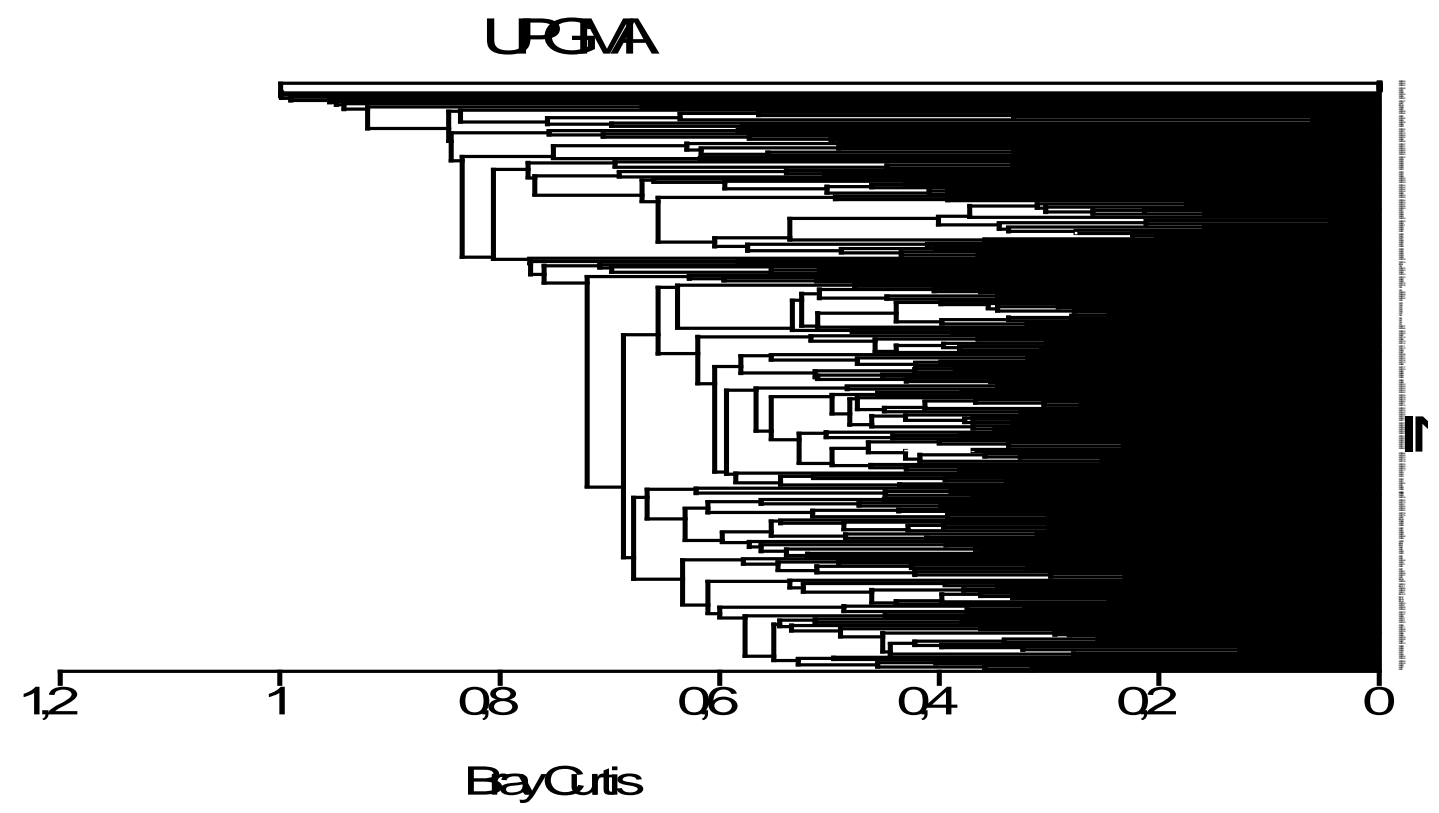

Figuur 2. Dendrogram van de clustering van de zachtsubstraat data van de Ooster- en Westerschelde uit de periode 2009-2016.

In totaal zijn er 33 clusters gevonden, waarvan er 28 in de Oosterschelde en 13 in de Westerschelde voorkwamen. Twintig clusters waren beperkt tot de Oosterschelde en 5 tot de Westerschelde (Tabel 2). Op 5 stations was geen macrobenthos aanwezig.

Deze 33 clusters kunnen worden gezien als 4 gemeenschappen, met varianten (A, B, G en $\mathrm{H}$ ) en een groot aantal verarmde varianten en pioniersgemeenschappen. Van de onderzochte stations behoren $85 \%$ tot de vier hoofdgemeenschappen.

Gemeenschap A werd gedomineerd door oligochaeten, de polychaeten Aphelochaeta marioni, Scoloplos armiger, Mediomastus fragilis, Streblospio shrubsolii, Capitella capitata en Pseudopolydora pulchra en de witte dunschaal Abra alba. Gemiddeld kwamen er 11.7 soorten per station voor met een dichtheid van 4043.9 individuen per $\mathrm{m}^{2}$.

Gemeenschap B werd gedomineerd door oligochaeten, de polychaeten Aphelochaeta marioni, Mediomastus fragilis, Scoloplos armiger, Pseudopolydora pulchra, Notomastus latericeus, Capitella capitata, Lanice conchilega en Cossura longocirrata, de mollusken Abra alba en Crepidula fornicata, anemonen en spookkreeftjes. Gemiddeld kwamen er 24.0 soorten per station voor met een dichtheid van 19912.3 individuen per $\mathrm{m}^{2}$.

Gemeenschap $\mathrm{G}$ werd gedomineerd door de polychaeten Aphelochaeta marioni en Heteromastus filiformis en oligochaeten. Gemiddeld kwamen er 6.3 soorten per station voor met een dichtheid van 2891.9 individuen per $\mathrm{m}^{2}$.

Gemeenschap H werd gedomineerd door tweekleppigen, waaronder De Philipijnse tapijtschelp Ruditapes philippinarum en de polychaet Nephtys hombergii. Gemiddeld kwamen er 6.4 soorten per station voor met een dichtheid van 898.5 individuen per $\mathrm{m}^{2}$. 
Tabel 2. Verdeling van de clusters over de Ooster- en Westerschelde.

\begin{tabular}{|c|c|c|c|c|c|c|c|}
\hline & n stat & $\%$ OS & $\mathrm{nsp}$ & $\mathrm{n} / \mathrm{m} 2$ & $\% \mathrm{WS}$ & $\mathrm{nsp}$ & $\mathrm{n} / \mathrm{m} 2$ \\
\hline A1 & 7 & 100 & 9,9 & 4333,8 & 0 & 0 & 0 \\
\hline A2 & 15 & 100 & 11,5 & 4878,7 & 0 & 0 & 0 \\
\hline A3 & 3 & 100 & 10,0 & 1121,7 & 0 & 0 & 0 \\
\hline A4 & 2 & 100 & 13,0 & 8036,2 & 0 & 0 & 0 \\
\hline A5 & 4 & 100 & 10,3 & 8651,5 & 0 & 0 & 0 \\
\hline A6 & 12 & 100 & 9,8 & 2883,8 & 0 & 0 & 0 \\
\hline A7 & 10 & 100 & 7,8 & 2124,6 & 0 & 0 & 0 \\
\hline A8 & 33 & 70 & 15,8 & 4579,3 & 30 & 10,5 & 2898,1 \\
\hline B1 & 48 & 100 & 24,1 & 11928,8 & 0 & 0 & 0 \\
\hline B2 & 14 & 93 & 18,1 & 7673,1 & 7 & 13,0 & 4570,6 \\
\hline B3 & 9 & 100 & 33,9 & 12450,6 & 0 & 0 & 0 \\
\hline B4 & 22 & 100 & 24,5 & 48669,0 & 0 & 0 & 0 \\
\hline B5 & 2 & 0 & 0 & 0 & 100 & 15,5 & 15997,1 \\
\hline C & 4 & 75 & 11,7 & 904,1 & 25 & 13,0 & 7282,8 \\
\hline $\mathrm{D}$ & 5 & 80 & 7,3 & 869,6 & 20 & 8,0 & 703,2 \\
\hline $\mathrm{E}$ & 2 & 100 & 7,0 & 577,6 & 0 & 0 & 0 \\
\hline $\mathrm{F}$ & 1 & 100 & 20,0 & 3164,3 & 0 & 0 & 0 \\
\hline G1 & 7 & 14 & 9,0 & 3616,3 & 86 & 13,5 & 7584,2 \\
\hline G2 & 19 & 0 & 0 & 0 & 100 & 5,1 & 3597,8 \\
\hline G3 & 3 & 67 & 5,0 & 1079,9 & 33 & 6,0 & 502,3 \\
\hline G4 & 8 & 100 & 5,4 & 577,6 & 0 & 0 & 0,0 \\
\hline G5 & 4 & 0 & 0 & 0 & 100 & 6,8 & 1142,7 \\
\hline G6 & 4 & 0 & 0 & 0 & 100 & 2,5 & 200,9 \\
\hline $\mathrm{H}$ & 9 & 100 & 6,4 & 898,5 & 0 & 0 & 0 \\
\hline I & 6 & 50 & 8,7 & 786,9 & 50 & 5,7 & 619,5 \\
\hline $\mathrm{J}$ & 9 & 100 & 3,4 & 1199,9 & 0 & 0 & 0 \\
\hline $\mathrm{K}$ & 2 & 50 & 4,0 & 200,9 & 50 & 2,0 & 150,7 \\
\hline $\mathrm{L}$ & 1 & 100 & 5,0 & 552,5 & 0 & 0 & 0 \\
\hline $\mathrm{M}$ & 1 & 100 & 3,0 & 301,4 & 0 & 0 & 0 \\
\hline $\mathrm{N}$ & 1 & 0 & 0 & 0 & 100 & 11,0 & 2109,5 \\
\hline $\mathrm{O}$ & 1 & 100 & 1,0 & 50,2 & 0 & 0 & 0 \\
\hline $\mathrm{P}$ & 1 & 100 & 1,0 & 50,2 & 0 & 0 & 0 \\
\hline $\mathrm{Q}$ & 1 & 100 & 1,0 & 50,2 & 0 & 0 & 0 \\
\hline leeg & 5 & 60 & 0 & 0 & 40 & 0 & 0 \\
\hline
\end{tabular}

Gemeenschap A was hoofdzakelijk beperkt tot de Oosterschelde, alleen variant A8 kwam ook in de Westerschelde voor op de westelijke locaties Ritthem en Paulinapolder. Gemeenschap B kwam in dezelfde typen sedimenten als gemeenschap A. Ook deze gemeenschap kwam hoofdzakelijk in de Oosterschelde voor en was in de Westerschelde beperkt tot de westelijke locatie Ritthem. De gemeenschap kwam op grotere diepte voor dan gemeenschap A.

Gemeenschap G kwam zowel in de Ooster- als Westerschelde voor. De varianten in de Westerschelde kwamen ten oosten van Ritthem voor, de varianten in de Oosterschelde kwamen vooral op minder grote diepten voor. De varianten die in beide bekkens voorkwamen (G1 en G3) waren minder soortenrijk in de Oosterschelde dan in de Westerschelde.

Gemeenschap $\mathrm{H}$ was beperkt tot de Oosterschelde en werd vooral gevonden in (fijn)zandige bodems. De gemeenschap werd vooral in het oostelijke deel gevonde. 
Tabel 3. Abiotische factoren van de gemeenschappen.

\begin{tabular}{|l|c|c|c|c|c|c|c|c|}
\hline Gem. & diepte & \% droge stof & \% org. stof & fracties $<0.09 \mathrm{~mm}$ & V & VI & V(dis) & VIII \\
\hline A & 8,3 & 57,1 & 5,1 & 38,2 & 27,1 & 18,6 & 17,1 & 37,1 \\
\hline B & 14,7 & 57,7 & 5,1 & 31,6 & 14,6 & 4,5 & 55,1 & 25,8 \\
\hline G & 8,4 & 58,5 & 4,7 & 45,1 & 21,2 & 3 & 15,2 & 60,6 \\
\hline H & 9,4 & 61,9 & 3,7 & 29,3 & 22,2 & 66,7 & 0,0 & 11,1 \\
\hline
\end{tabular}

De schematische verdeling van de clusters over de locaties in de Oosterschelde is gegeven in Figuur 3, die over de Westerschelde in Bijlage 3. 


\begin{tabular}{|c|c|c|c|c|c|c|c|c|c|c|c|c|c|}
\hline OS-2009 & & & & Sch-w & & Sch-o & Lok-a & Lok-b & & Zeel-w & Zeel-m & Zeel-o & \\
\hline $0-5$ & & & & $\mathrm{~A} 1$ & & A7 & A7 & A7 & & B1 & & $\mathrm{A} 2$ & \\
\hline $5.1-10$ & & & & A8 & & A8 & A7 & A7 & & B1 & & A2 & \\
\hline$>10.1$ & & & & B1 & & A8 & B1 & B1 & & B1 & & A8 & \\
\hline & & & & & & & & & & & & & \\
\hline OS-2010 & \multicolumn{3}{|c|}{ Burgh-w Sch-wII } & & & Sch-o & & & & & & Zeel-o & \\
\hline $0-5$ & & G1 & $\mathrm{A} 1$ & & & $\mathrm{O}$ & & & & & & & \\
\hline $5.1-10$ & & $\mathrm{~J}$ & $\mathrm{~A} 8$ & & & $\mathrm{Q}$ & & & & & & & \\
\hline$>10.1$ & & $\mathrm{~A} 1$ & $\mathrm{~A} 8$ & & & $\mathrm{~L}$ & & & & & & $\bar{F}$ & \\
\hline OS-2011 & $\mathrm{Wb}$ & & & Sch-w & Sch-m & Sch-o & Lok & & Zie & Zeel-w & Zeel-m & Zeel-o & $\mathrm{Zb}$ \\
\hline $0-5$ & A8 & & & $\mathrm{J}$ & B2 & $\mathrm{A} 2$ & A2 & & $\mathrm{J}$ & B2 & $\mathrm{J}$ & $\mathrm{J}$ & $\mathrm{J}$ \\
\hline $5.1-10$ & A8 & & & $\mathrm{C}$ & & $\mathrm{A} 2$ & $\mathrm{~A} 2$ & $\mathrm{~A} 8$ & $\mathrm{P}$ & A8 & G4 & $\mathrm{A} 2$ & A2 \\
\hline$>10.1$ & $\mathrm{~A} 8$ & & & $\mathrm{~A} 8$ & B2 & $\mathrm{A} 8$ & $\mathrm{~A} 2$ & B2 & G4 & B3 & B2 & B2 & $\mathrm{A} 4$ \\
\hline oud & & & & & & & & B3 & & B3 & $\mathrm{B} 2$ & B3 & \\
\hline & & & & & & & & & & & & & \\
\hline ecorif & & & & & & & & B2 & & & B2 & & \\
\hline ecorif & & & & & & & & B3 & B3 & B3 & & B3 & \\
\hline ecorif & & & & & & & & & & & B3 & & \\
\hline & & & & & & & & & & & & & \\
\hline & & & & & & & & & & & & & \\
\hline & & & & & & & & & & & & & \\
\hline & & Sophia & & Zandh & & & & & & Katsh & & & \\
\hline $0-5$ & & A8 & & $\mathrm{D}$ & & & & & & $\mathrm{A} 2$ & & & \\
\hline 5.1-10 & & A8 & & $\mathrm{H}$ & & & & & & A2 & & & \\
\hline$>10.1$ & & A8 & & A8 & & & & & & $\mathrm{A} 4$ & & & \\
\hline
\end{tabular}

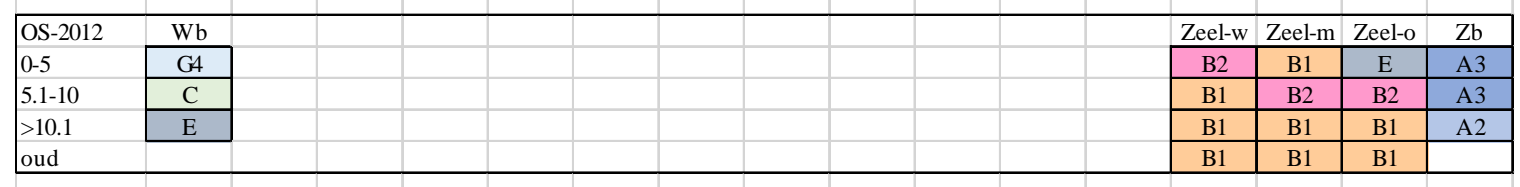

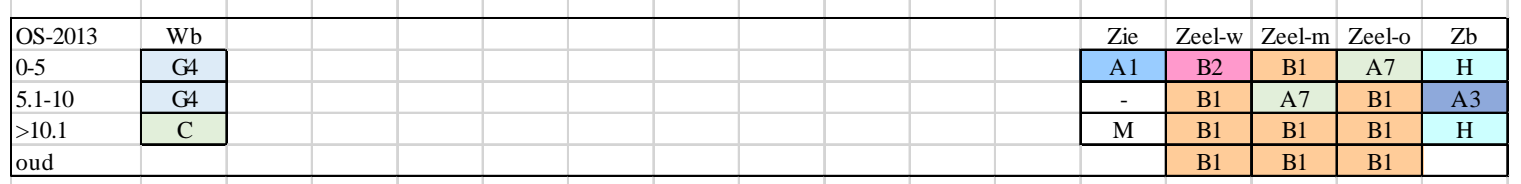

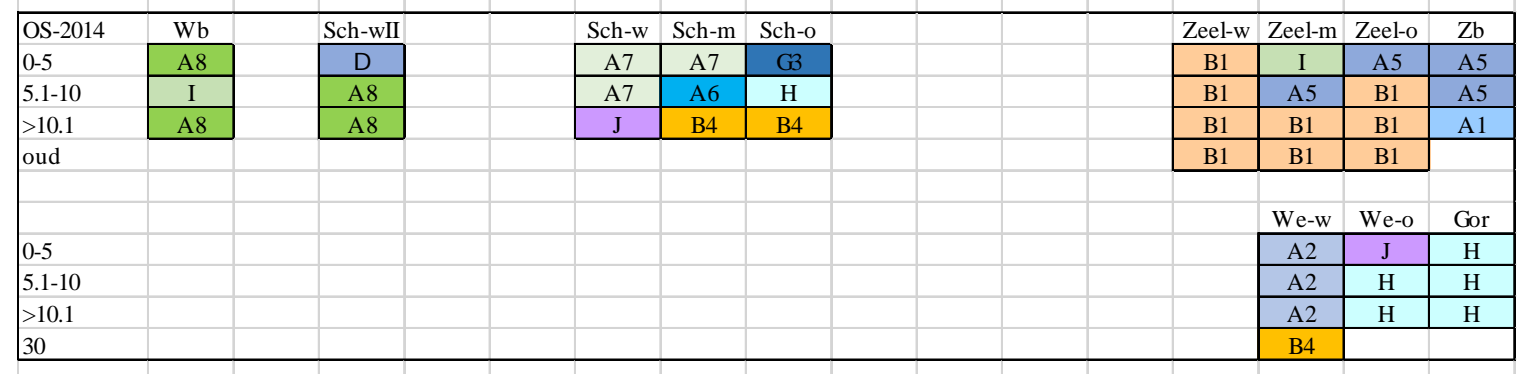

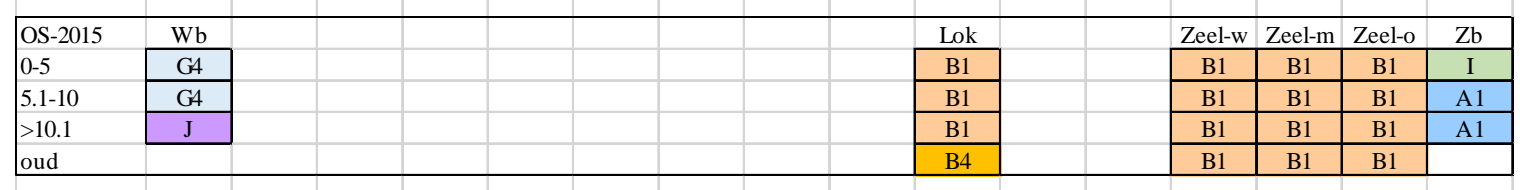

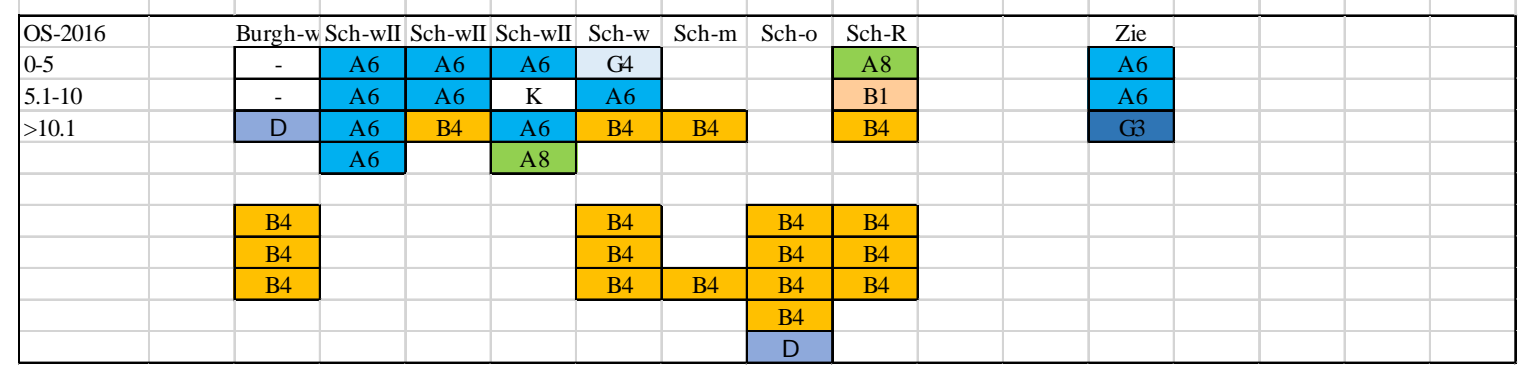

Figuur 3. Schematische verdeling van de clusters over de locaties in de Oosterschelde. 
In Figuur 3 is duidelijk te zien dat de bemonsterde locaties in 2016 niet overlappen met de bemonsterde locaties in 2015, en dat de meest algemene varianten (A6 en B4) hoofdzakelijk in 2016 gevonden zijn. Hierom is een verdere analyse uitgevoerd met alleen de data uit 2016.

In Figuur 4 is de ligging van de stations meer in detail weergegeven. Hierin is ook duidelijk te zien welke stations met steekbuizen bemonsterd zijn, en welke met de Van Veen happer.

\begin{tabular}{|c|c|c|c|c|c|c|c|c|c|c|c|}
\hline OS-2016 & Burgh-w & Sch-wII & Sch-wII & Sch-wII & Sch-w & Sch-m & Sch-o & & & Sch-R & Zie \\
\hline $0-5$ & - & A6 & A6 & A6 & G4 & & & & & A8 & A6 \\
\hline 5.1-10 & - & A6 & $\mathrm{A} 6$ & $\mathrm{~K}$ & A6 & & & & & B1 & $\mathrm{A} 6$ \\
\hline \multirow[t]{2}{*}{$>10.1$} & $\mathrm{D}$ & A6 & B4 & $\mathrm{A} 6$ & B4 & B4 & & & & B4 & G3 \\
\hline & & $\mathrm{A} 6$ & & $\mathrm{~A} 8$ & & & & & & & \\
\hline & & & & & & & & & & & \\
\hline \multirow[t]{5}{*}{ van Veen } & B4 & & & & B4 & & & & & B4 & \\
\hline & B4 & & & & B4 & & $\mathrm{D}$ & B4 & B4 & B4 & \\
\hline & B4 & & & & B4 & B4 & B4 & B4 & & B4 & \\
\hline & & & & & & & & & & & \\
\hline & & & & & & & & & & & \\
\hline
\end{tabular}

Figuur 4. Ligging van de in 2016 bemonsterde stations.

De stations hebben een verschillende ondergrond waarop nieuw zacht substraat is gesedimenteerd.

Op de locaties Schelphoek-west, midden en oost zijn in 2009 de vooroevers versterkt met staalslakken. Op de locatie Schelphoek-midden zijn de staalslakken met breuksteen afgedekt. Op de locatie Schelphoek-Referentie is de oude bodem bemonsterd, waar geen bestorting heeft plaats gevonden.

Op de locaties Burghsluis-west, Schelphoek-west II en Zierikzee zijn in 2014 de vooroevers versterkt met zeegrind. Op de locatie Schelphoek-west II zijn riffen van breuk- en zandsteen op het grind aangelegd.

Op vier stations was de sedimentlaag onvoldoende dik om de infauna te bemonsteren: op 3.5, 7.5 en 32 meter, tussen de breuksteen, op locatie Schelphoek-midden en op de locatie Schelphoek-oost op 35 meter diepte op staalslakken.

In totaal werden op de stations 8 varianten gevonden, op twee stations was in het sediment geen infauna aanwezig.

De geordende tabel voor de stations uit 2016 is gegeven in Tabel 4. 
Tabel 4. Geordende tabel van de zachtsubstraat varianten van de levensgemeenschappen in de Oosterschelde in 2016. Vet gedrukte dichtheden geven een presentie van de soort in 66.7\% van de stations van een cluster, onderstreepte waarden geven per soort een voorkomen van minimaal $90 \%$ van de totale kwantiteit binnen de onderzochte stations. Afkortingen: An-Anthozoa, Br-Bryozoa, Cr-Crustacea, EchEchinodermata, Mol-Mollusca, Ne-Nemertea, Oli-Oligochaetea, Ph-Phoronida, Pla-Platyhelminthes, PoPolychaeta, Pyc-Pycnogonidae, Sp-Sponzen en Tu-Tunicaten.

\begin{tabular}{|c|c|c|c|c|c|c|c|c|c|c|}
\hline & & A6 & A8 & B1 & B4 & $\mathrm{D}$ & G3 & G4 & $\mathrm{K}$ & - \\
\hline Corophiidae & $\mathrm{Cr}$ & 4,6 & 0,0 & 0,0 & $\underline{26,1}$ & 0,0 & 0,0 & 0,0 & $\underline{50,2}$ & 0,0 \\
\hline Nassarius (spec.) & Mol & $\underline{13,7}$ & 0,0 & 0,0 & 0,0 & 5,0 & 0,0 & 0,0 & $\underline{50,2}$ & 0,0 \\
\hline Capitella capitata & Po & $\underline{86,8}$ & 0,0 & 0,0 & $\underline{97,2}$ & 0,0 & 0,0 & $\underline{301,4}$ & 0,0 & 0,0 \\
\hline Aphelochaeta marioni & Po & $\underline{36,5}$ & $\underline{150,7}$ & $\underline{150,7}$ & $\underline{172,4}$ & 25,1 & 0,0 & $\underline{50,2}$ & 0,0 & 0,0 \\
\hline Nephtys hombergii & Po & $\underline{50,2}$ & $\underline{125,6}$ & 0,0 & 8,3 & $\underline{50,2}$ & $\underline{\mathbf{5 0 , 2}}$ & $\underline{\mathbf{5 0 , 2}}$ & 0,0 & 0,0 \\
\hline Glycera (spec.) & Po & 4,6 & 0,0 & 0,0 & $\underline{10,0}$ & 0,0 & 0,0 & $\underline{50,2}$ & 0,0 & 0,0 \\
\hline Sthenelais boa & Po & 0,0 & $\underline{25,1}$ & $\underline{50,2}$ & $\underline{110,8}$ & 5,0 & 0,0 & $\underline{50,2}$ & 0,0 & 0,0 \\
\hline Spisula subtruncata & Mol & $\underline{41,1}$ & 0,0 & 0,0 & 2,2 & 0,0 & 0,0 & $\underline{50,2}$ & 0,0 & 0,0 \\
\hline Streblospio shrubsolii & Po & $\underline{274,0}$ & 0,0 & 50,2 & 20,8 & 0,0 & $\underline{552,5}$ & 0,0 & 0,0 & 0,0 \\
\hline Cossura longocirrata & Po & $\underline{68,5}$ & $\underline{50,2}$ & 50,2 & 1,7 & 0,0 & $\underline{452,0}$ & 0,0 & 0,0 & 0,0 \\
\hline Ophiuroidea & Ech & 9,1 & $\underline{25,1}$ & 0,0 & 3,3 & 0,0 & $\underline{200,9}$ & 0,0 & 0,0 & 0,0 \\
\hline Macoma balthica & Mol & $\underline{18,3}$ & 0,0 & 0,0 & 2,8 & 0,0 & $\underline{\mathbf{5 0 , 2}}$ & 0,0 & 0,0 & 0,0 \\
\hline Pholoe baltica & Po & 18,3 & 0,0 & 0,0 & $\underline{180,2}$ & $\underline{25,1}$ & 0,0 & 0,0 & 0,0 & 0,0 \\
\hline Pectinaria koreni & Po & 0,0 & 0,0 & 0,0 & $\underline{3,9}$ & $\underline{25,1}$ & 0,0 & 0,0 & 0,0 & 0,0 \\
\hline Pholoe inornata & Po & 0,0 & 0,0 & 0,0 & $\underline{11,7}$ & $\underline{5,0}$ & 0,0 & 0,0 & 0,0 & 0,0 \\
\hline Subadyte pellucida & Po & 0,0 & 0,0 & 0,0 & $\underline{12,8}$ & $\underline{5,0}$ & 0,0 & 0,0 & 0,0 & 0,0 \\
\hline Ensis (spec.) & Mol & 4,6 & 0,0 & 0,0 & 0,0 & $\underline{50,2}$ & 0,0 & 0,0 & 0,0 & 0,0 \\
\hline Spiophanes bombyx & Po & 0,0 & 0,0 & 0,0 & 0,0 & $\underline{25,1}$ & 0,0 & 0,0 & 0,0 & 0,0 \\
\hline Polychaeta (spec.) & Po & 0,0 & 0,0 & 0,0 & 0,0 & $\underline{5,0}$ & 0,0 & 0,0 & 0,0 & 0,0 \\
\hline Abra alba & Mol & 315,1 & $\underline{879,0}$ & 0,0 & $\underline{3369,2}$ & $\mathbf{9 0 , 2}$ & 0,0 & 0,0 & 0,0 & 0,0 \\
\hline Mediomastus fragilis & Po & $\underline{516,0}$ & 125,6 & $\underline{200,9}$ & $\underline{1541,9}$ & 40,0 & 0,0 & 0,0 & 0,0 & 0,0 \\
\hline Actiniaria & An & 0,0 & $\underline{125,6}$ & $\underline{100,5}$ & $\underline{341,9}$ & 0,0 & 0,0 & 0,0 & 0,0 & 0,0 \\
\hline Kurtiella bidentata & Mol & $\underline{63,9}$ & 0,0 & 0,0 & $\underline{108,0}$ & 0,0 & 0,0 & 0,0 & 0,0 & 0,0 \\
\hline Pseudopolydora pulchra & Po & $\underline{712,3}$ & $\underline{100,5}$ & $\underline{100,5}$ & $\underline{83,5}$ & 0,0 & 0,0 & 0,0 & 50,2 & 0,0 \\
\hline Venerupis corrugata & Mol & 4,6 & $\underline{25,1}$ & 0,0 & $\underline{25,0}$ & 0,0 & 0,0 & 0,0 & 0,0 & 0,0 \\
\hline Eteone (spec.) & Po & 9,1 & $\underline{25,1}$ & $\underline{50,2}$ & $\underline{12,8}$ & 0,0 & 0,0 & 0,0 & 0,0 & 0,0 \\
\hline Aora typica & $\mathrm{Cr}$ & 0,0 & $\underline{25,1}$ & 0,0 & $\underline{11,7}$ & 0,0 & 0,0 & 0,0 & 0,0 & 0,0 \\
\hline Aonides oxycephala & Po & $\underline{4,6}$ & 0,0 & 0,0 & $\underline{11,1}$ & 0,0 & 0,0 & 0,0 & 0,0 & 0,0 \\
\hline Scoloplos armiger & Po & 4,6 & $\underline{25,1}$ & $\underline{251,1}$ & 5,0 & 0,0 & 0,0 & 0,0 & 0,0 & 0,0 \\
\hline Notomastus latericeus & Po & 13,7 & 0,0 & $\underline{100,5}$ & $\underline{41,1}$ & 0,0 & 0,0 & 0,0 & 0,0 & 0,0 \\
\hline Nereis longissima & Po & 0,0 & 0,0 & $\underline{50,2}$ & $\underline{8,9}$ & 0,0 & 0,0 & 0,0 & 0,0 & 0,0 \\
\hline
\end{tabular}


Tabel 4 (vervolg).

\begin{tabular}{|c|c|c|c|c|c|c|c|c|c|c|}
\hline & & $\mathrm{A} 6$ & $\mathrm{~A} 8$ & B1 & B4 & $\mathrm{D}$ & $\mathrm{G} 3$ & G4 & $\mathrm{K}$ & - \\
\hline Oligochaeta & Oli & 493,1 & 200,9 & 1908,6 & $\underline{40685,8}$ & $\mathbf{8 4 0 , 7}$ & 50,2 & 251,1 & 50,2 & 0,0 \\
\hline Ophiothrix fragilis & Ech & 0,0 & 0,0 & 0,0 & $\underline{300,0}$ & 10,0 & 0,0 & 0,0 & 0,0 & 0,0 \\
\hline Lysianassa ceratina & $\mathrm{Cr}$ & 0,0 & 0,0 & 0,0 & $\underline{216,1}$ & 0,0 & 0,0 & 0,0 & 0,0 & 0,0 \\
\hline Mytilus edulis & Mol & 0,0 & 0,0 & 0,0 & $\underline{187,2}$ & 0,0 & 0,0 & 0,0 & 0,0 & 0,0 \\
\hline Melita obtusata & $\mathrm{Cr}$ & 0,0 & 0,0 & 0,0 & $\underline{126,1}$ & 0,0 & 0,0 & 0,0 & 0,0 & 0,0 \\
\hline Nemertea & $\mathrm{Ne}$ & 0,0 & 0,0 & 0,0 & $\underline{72,2}$ & 0,0 & 0,0 & 0,0 & 0,0 & 0,0 \\
\hline Owenia fusiformis & Po & 0,0 & 0,0 & 0,0 & $\underline{42,4}$ & 0,0 & 0,0 & 0,0 & 0,0 & 0,0 \\
\hline Mya arenaria & Mol & 0,0 & 0,0 & 0,0 & $\underline{21,7}$ & 0,0 & 0,0 & 0,0 & 0,0 & 0,0 \\
\hline Monocorophium acherusicum & $\mathrm{Cr}$ & 0,0 & 0,0 & 0,0 & $\underline{20,6}$ & 0,0 & 0,0 & 0,0 & 0,0 & 0,0 \\
\hline Platyhelminthes & $\mathrm{Pt}$ & 0,0 & 0,0 & 0,0 & $\underline{18,3}$ & 0,0 & 0,0 & 0,0 & 0,0 & 0,0 \\
\hline Crepidula fornicata & Mol & 0,0 & 0,0 & 0,0 & $\underline{16,1}$ & 0,0 & 0,0 & 0,0 & 0,0 & 0,0 \\
\hline Ophiura ophiura & Ech & 0,0 & 0,0 & 0,0 & $\underline{10,0}$ & 0,0 & 0,0 & 0,0 & 0,0 & 0,0 \\
\hline Aoridae & $\mathrm{Cr}$ & 0,0 & 0,0 & 0,0 & $\underline{9,5}$ & 0,0 & 0,0 & 0,0 & 0,0 & 0,0 \\
\hline Caprellidae & $\mathrm{Cr}$ & 0,0 & 0,0 & 0,0 & $\underline{9,5}$ & 0,0 & 0,0 & 0,0 & 0,0 & 0,0 \\
\hline Buccinum undatum & Mol & 0,0 & 0,0 & 0,0 & $\underline{4,4}$ & 0,0 & 0,0 & 0,0 & 0,0 & 0,0 \\
\hline Lepidonotus squamatus & Po & 0,0 & 0,0 & 0,0 & $\underline{3,9}$ & 0,0 & 0,0 & 0,0 & 0,0 & 0,0 \\
\hline Pisidia longicornis & $\mathrm{Cr}$ & 0,0 & 0,0 & 0,0 & $\underline{3,9}$ & 0,0 & 0,0 & 0,0 & 0,0 & 0,0 \\
\hline Anoplodactylus petiolatus & Рус & 0,0 & 0,0 & 0,0 & $\underline{3,3}$ & 0,0 & 0,0 & 0,0 & 0,0 & 0,0 \\
\hline Bodotria scorpioides & $\mathrm{Cr}$ & 0,0 & 0,0 & 0,0 & $\underline{3,3}$ & 0,0 & 0,0 & 0,0 & 0,0 & 0,0 \\
\hline Polynoidae & Po & 0,0 & 0,0 & 0,0 & $\underline{3.3}$ & 0,0 & 0,0 & 0,0 & 0,0 & 0,0 \\
\hline Prionospio steenstrupi & Po & 0,0 & 0,0 & 0,0 & $\underline{3,3}$ & 0,0 & 0,0 & 0,0 & 0,0 & 0,0 \\
\hline Asterias rubens & Ech & 0,0 & 0,0 & 0,0 & $\underline{2,8}$ & 0,0 & 0,0 & 0,0 & 0,0 & 0,0 \\
\hline Kefersteinia cirrata & Po & 0,0 & 0,0 & 0,0 & $\underline{2,8}$ & 0,0 & 0,0 & 0,0 & 0,0 & 0,0 \\
\hline Lanice conchilega & Po & 0,0 & 0,0 & 0,0 & $\underline{2,8}$ & 0,0 & 0,0 & 0,0 & 0,0 & 0,0 \\
\hline Harmothoe (spec.) & Po & 0,0 & 0,0 & 0,0 & $\underline{2,8}$ & 0,0 & 0,0 & 0,0 & 0,0 & 0,0 \\
\hline Phoronida & $\mathrm{Ph}$ & 0,0 & 0,0 & 0,0 & $\underline{2,8}$ & 0,0 & 0,0 & 0,0 & 0,0 & 0,0 \\
\hline Pycnogonida & Рус & 0,0 & 0,0 & 0,0 & $\underline{2,8}$ & 0,0 & 0,0 & 0,0 & 0,0 & 0,0 \\
\hline Carcinus maenas & $\mathrm{Cr}$ & 0,0 & 0,0 & 0,0 & $\underline{2,2}$ & 0,0 & 0,0 & 0,0 & 0,0 & 0,0 \\
\hline Microdeutopus (spec.) & $\mathrm{Cr}$ & 0,0 & 0,0 & 0,0 & $\underline{2,2}$ & 0,0 & 0,0 & 0,0 & 0,0 & 0,0 \\
\hline Polydora (spec.) & Po & 0,0 & 0,0 & 0,0 & $\underline{2,2}$ & 0,0 & 0,0 & 0,0 & 0,0 & 0,0 \\
\hline Eumida sanguinea & Po & 0,0 & 0,0 & 0,0 & $\underline{1,7}$ & 0,0 & 0,0 & 0,0 & 0,0 & 0,0 \\
\hline Sabellaria spinulosa & Po & 0,0 & 0,0 & 0,0 & $\underline{1,7}$ & 0,0 & 0,0 & 0,0 & 0,0 & 0,0 \\
\hline Eumida (spec.) & Po & 0,0 & 0,0 & 0,0 & $\underline{1,7}$ & 0,0 & 0,0 & 0,0 & 0,0 & 0,0 \\
\hline Eunoe nodosa & Po & 0,0 & 0,0 & 0,0 & $\underline{1,1}$ & 0,0 & 0,0 & 0,0 & 0,0 & 0,0 \\
\hline Harmothoe impar & Po & 0,0 & 0,0 & 0,0 & $\underline{1,1}$ & 0,0 & 0,0 & 0,0 & 0,0 & 0,0 \\
\hline Ostrea edulis & Mol & 0,0 & 0,0 & 0,0 & $\underline{1,1}$ & 0,0 & 0,0 & 0,0 & 0,0 & 0,0 \\
\hline Syllidia armata & Po & 0,0 & 0,0 & 0,0 & $\underline{1,1}$ & 0,0 & 0,0 & 0,0 & 0,0 & 0,0 \\
\hline Autolytus (spec.) & Po & 0,0 & 0,0 & 0,0 & $\underline{1,1}$ & 0,0 & 0,0 & 0,0 & 0,0 & 0,0 \\
\hline Malmgreniella (spec.) & Po & 0,0 & 0,0 & 0,0 & $\underline{1,1}$ & 0,0 & 0,0 & 0,0 & 0,0 & 0,0 \\
\hline BRYOZOA & $\mathrm{Br}$ & 0,0 & 0,0 & 0,0 & $\underline{1,1}$ & 0,0 & 0,0 & 0,0 & 0,0 & 0,0 \\
\hline Hesionidae & Po & 0,0 & 0,0 & 0,0 & $\underline{1,1}$ & 0,0 & 0,0 & 0,0 & 0,0 & 0,0 \\
\hline Neoamphitrite figulus & Po & 0,0 & 0,0 & 0,0 & $\underline{0,6}$ & 0,0 & 0,0 & 0,0 & 0,0 & 0,0 \\
\hline Nereis (spec.) & Po & 0,0 & 0,0 & 0,0 & $\underline{0,6}$ & 0,0 & 0,0 & 0,0 & 0,0 & 0,0 \\
\hline Monocorophium insidiosum & $\mathrm{Cr}$ & 0,0 & 0,0 & 0,0 & $\underline{0,6}$ & 0,0 & 0,0 & 0,0 & 0,0 & 0,0 \\
\hline Pagurus bernhardus & $\mathrm{Cr}$ & 0,0 & 0,0 & 0,0 & $\underline{0.6}$ & 0,0 & 0,0 & 0,0 & 0,0 & 0,0 \\
\hline Petricola pholadiformis & Mol & 0,0 & 0,0 & 0,0 & $\underline{0,6}$ & 0,0 & 0,0 & 0,0 & 0,0 & 0,0 \\
\hline Scalibregma inflatum & Po & 0,0 & 0,0 & 0,0 & $\underline{0,6}$ & 0,0 & 0,0 & 0,0 & 0,0 & 0,0 \\
\hline Styela clava & $\mathrm{Tu}$ & 0,0 & 0,0 & 0,0 & $\underline{0,6}$ & 0,0 & 0,0 & 0,0 & 0,0 & 0,0 \\
\hline Syllis gracillis & Po & 0,0 & 0,0 & 0,0 & $\underline{0.6}$ & 0,0 & 0,0 & 0,0 & 0,0 & 0,0 \\
\hline Liocarcinus holsatus & $\mathrm{Cr}$ & 0,0 & 0,0 & 0,0 & $\underline{0,6}$ & 0,0 & 0,0 & 0,0 & 0,0 & 0,0 \\
\hline Sphaerodorum gracilis & Po & 0,0 & 0,0 & 0,0 & $\underline{0,6}$ & 0,0 & 0,0 & 0,0 & 0,0 & 0,0 \\
\hline Sycon & $\mathrm{Sp}$ & 0,0 & 0,0 & 0,0 & $\underline{0,6}$ & 0,0 & 0,0 & 0,0 & 0,0 & 0,0 \\
\hline Cheirocratus (spec.) & $\mathrm{Cr}$ & 0,0 & 0,0 & 0,0 & $\underline{0,6}$ & 0,0 & 0,0 & 0,0 & 0,0 & 0,0 \\
\hline Decapoda & $\mathrm{Cr}$ & 0,0 & 0,0 & 0,0 & $\underline{0,6}$ & 0,0 & 0,0 & 0,0 & 0,0 & 0,0 \\
\hline Gastropoda & Mol & 0,0 & 0,0 & 0,0 & $\underline{0,6}$ & 0,0 & 0,0 & 0,0 & 0,0 & 0,0 \\
\hline Polycirrus (spec.) & Po & 0,0 & 0,0 & 0,0 & $\underline{0,6}$ & 0,0 & 0,0 & 0,0 & 0,0 & 0,0 \\
\hline Ampelisca brevicornis & $\mathrm{Cr}$ & 4,6 & 25,1 & 0,0 & 0,0 & 0,0 & 0,0 & 0,0 & 0,0 & 0,0 \\
\hline Ascidiacea & $\mathrm{Tu}$ & $\underline{4,6}$ & $\underline{25,1}$ & 0,0 & 0,0 & 0,0 & 0,0 & 0,0 & 0,0 & 0,0 \\
\hline Cerianthus lloydii & An & 0,0 & $\underline{50,2}$ & 0,0 & 4,4 & 0,0 & 0,0 & 0,0 & 0,0 & 0,0 \\
\hline Microdeutopus anomalus & $\mathrm{Cr}$ & 0,0 & $\underline{25,1}$ & 0,0 & 1,1 & 0,0 & 0,0 & 0,0 & 0,0 & 0,0 \\
\hline Acanthocardia & Mol & $\underline{9,1}$ & 0,0 & 0,0 & 0,0 & 0,0 & 0,0 & 0,0 & 0,0 & 0,0 \\
\hline Bivalve (spec.) & Mol & $\underline{9,1}$ & 0,0 & 0,0 & 0,0 & 0,0 & 0,0 & 0,0 & 0,0 & 0,0 \\
\hline Spio (spec.) & Po & $\underline{9,1}$ & 0,0 & 0,0 & 0,0 & 0,0 & 0,0 & 0,0 & 0,0 & 0,0 \\
\hline Microphthalmus & Po & $\underline{4,6}$ & 0,0 & 0,0 & 0,0 & 0,0 & 0,0 & 0,0 & 0,0 & 0,0 \\
\hline OSTRACODA & $\mathrm{Cr}$ & $\underline{4,6}$ & 0,0 & 0,0 & 0,0 & 0,0 & 0,0 & 0,0 & 0,0 & 0,0 \\
\hline Syllidae & Po & $\underline{4,6}$ & 0,0 & 0,0 & 0,0 & 0,0 & 0,0 & 0,0 & 0,0 & 0,0 \\
\hline dichtheid n/m2 & & 2817,3 & 2034,2 & 3063,8 & 48038,4 & 1211,8 & 1356,1 & 803,6 & 200,9 & 0,0 \\
\hline Index Log base 2 & & 2,404 & 2,551 & 2,161 & 1,203 & 1,815 & 1,991 & 2,303 & 2,000 & $* * * *$ \\
\hline Evenness & & 0,769 & 0,735 & 0,603 & 0,271 & 0,590 & 0,770 & 0,820 & 1,000 & $* * * *$ \\
\hline gemiddeld aantal soorten & & 9,3 & 11,5 & 12,0 & 24,4 & 9,0 & 6,0 & 7,0 & 4,0 & 0,0 \\
\hline
\end{tabular}


Het aantal soorten per station is in Figuur 5 weergegeven, de totale dichtheid $\left(\mathrm{n} / \mathrm{m}^{2}\right)$ in Figuur 6.

\begin{tabular}{|c|c|c|c|c|c|c|c|c|c|c|c|}
\hline OS-2016 & Burgh-w & Sch-wII & Sch-wII & Sch-wII & Sch-w & Sch-m & Sch-o & & & Sch-R & Zie \\
\hline $0-5$ & 0 & 10 & 7 & 11 & 7 & & & & & 10 & 9 \\
\hline $5.1-10$ & 0 & 6 & 10 & 4 & 6 & & & & & 12 & 8 \\
\hline \multirow[t]{2}{*}{$>10.1$} & 8 & 8 & 23 & 16 & 14 & 9 & & & & 12 & 6 \\
\hline & & 11 & & 13 & & & & & & & \\
\hline & & & & & & & & & & & \\
\hline \multirow[t]{5}{*}{ van Veen } & 27 & & & & 13 & & & & & 38 & \\
\hline & 26 & & & & 37 & & 10 & 32 & 24 & 33 & \\
\hline & 25 & & & & 21 & 12 & 33 & 31 & & 30 & \\
\hline & & & & & & & & & & & \\
\hline & & & & & & & & & & & \\
\hline
\end{tabular}

Figuur 5. Het aantal soorten op de stations in 2016.

\begin{tabular}{|c|c|c|c|c|c|c|c|c|c|c|c|}
\hline OS-2016 & Burgh-w & Sch-wII & Sch-wII & Sch-wII & Sch-w & Sch-m & Sch-o & & & Sch-R & Zie \\
\hline $0-5$ & 0 & 1959 & 804 & 3114 & 804 & & & & & 1306 & 4470 \\
\hline $5.1-10$ & 0 & 1055 & 1055 & 201 & 703 & & & & & 3064 & 2361 \\
\hline \multirow[t]{2}{*}{$>10.1$} & 804 & 1105 & 15771 & 12305 & 11602 & 55299 & & & & 22652 & 1356 \\
\hline & & 2059 & & 2762 & & & & & & & \\
\hline & & & & & & & & & & & \\
\hline \multirow[t]{5}{*}{ van Veen } & 10314 & & & & 18330 & & & & & 51697 & \\
\hline & 21420 & & & & 41060 & & 1620 & 145480 & 55180 & 153570 & \\
\hline & 14310 & & & & 64400 & 17230 & 51670 & 55630 & & 59075 & \\
\hline & & & & & & & & & & & \\
\hline & & & & & & & & & & & \\
\hline
\end{tabular}

Figuur 6. De totale dichtheid $\left(\mathrm{n} / \mathrm{m}^{2}\right)$ op de stations in 2016.

Burghsluis-west

Op de locatie Burghsluis-west was ondiep geen infauna in het sediment aanwezig. Op 11.0 meter diepte werd variant D gevonden, en op 19.9, 29.0 en 34.8 meter variant B4.

Variant D werd alleen gedomineerd door oligochaeten. Er waren geen soorten karakteristiek voor deze variant, maar 3 soorten, waaronder de polychaet Spiophanes bombyx, waren ertoe beperkt. Gemiddeld kwamen er 9.0 soorten per station voor, met een dichtheid van 1211.8 individuen per $\mathrm{m}^{2}$.

Variant B4 werd gekarakteriseerd door oligochaeten, de vlokreeftjes Lysianassa ceratina en Melita obtusata, jonge mosselen (Mytilus edulis) en de brokkelster Ophiothrix fragilis. Verder waren de tweekleppige Abra alba en Kurtiella bidentata, de polychaeten Mediomastus fragilis, Pholoe baltica, Aphelochaeta marioni en Sthenelais boa en anemonen dominant binnen deze variant aanwezig. Verder waren 51 soorten tot de variant beperkt. Gemiddeld kwamen er 24.4 soorten per station voor, met een dichtheid van 48038.4 individuen per $\mathrm{m}^{2}$.

In 2010 is de locatie Burghsluis-west in de ongestoorde situatie onderzocht en destijds waren de varianten G1 (5 meter diepte met 8 soorten), J (10 meter diepte met 4 soorten) en A1 (15 meter diepte met 7 soorten) aanwezig.

\section{$\underline{\text { Schelphoek-west II }}$}

Op de locatie Schelphoek-west II zijn vier raaien tussen de ecoriffen onderzocht.

Op de raai west was onvoldoende sediment aanwezig om de infauna te bemonsteren. 
Op de raai west-midden was voldoende sediment aanwezig op 3.5-4.5 en 7.5 meter. In

deze sedimenten zijn vier stations bemonsterd. Op alle stations was variant A6 aanwezig.

Variant A6 werd gedomineerd door de polychaeten Pseudopolydora pulchra, Mediomastus fragilis en Streblospio shrubsolii, oligochaeten en de witte dunschaal Abra alba. Er waren geen soorten karakteristiek voor deze variant, maar 6 soorten waren ertoe beperkt. Gemiddeld kwamen er 9.3 soorten per station voor, met een dichtheid van 2817.3 individuen per $\mathrm{m}^{2}$.

Op de raai midden-oost is de infauna op 3 diepten onderzocht. Op 4.7 en 8.5 meter diepte werden ook hier de variant A6 gevonden, op 15.5 meter diepte was de soortenrijke variant B4 aanwezig.

Op de raai oost was voldoende sediment aanwezig op 4.7 en 13.4-14.2 meter diepte. In de sedimenten zijn vier stations bemonsterd. Op de ondiepe stations werden de varianten A6 en K gevonden, op de diepere stations de varianten A6 en A8.

In variant K kwamen geen dominante of karakteristieke soorten voor en geen enkele soort was tot de variant beperkt. Op het station kwamen 4 soorten voor, met een dichtheid van 200.9 individuen per $\mathrm{m}^{2}$. Deze soortenarme variant is verder alleen in de Westerschelde op de locatie Hoedekenskerke-zuid gevonden.

Variant A8 werd gedomineerd door de witte dunschaal Abra alba, oligochaeten, de polychaeten Aphelochaeta marioni, Nephtys hombergii, Mediomastus fragilis en Pseudopolydora pulchra en anemonen. Er waren geen soorten karakteristiek voor deze variant, maar 2 soorten waren ertoe beperkt. Gemiddeld kwamen er 11.5 soorten per station voor, met een dichtheid van 2034.2 individuen per $\mathrm{m}^{2}$.

In 2010 en 2014 is de locatie Schelphoek-west II in de ongestoorde situatie onderzocht. In 2010 waren de varianten A1 (3 meter diepte met 8 soorten) en A8 (7.5 en 15 meter diepte met 14 en 11 soorten) aanwezig, in 2014 de varianten D (3.5 meter diepte met 6 soorten) en A8 (10 en 15 meter diepte met 13 en 17 soorten).

Schelphoek-west

Op de locatie Burghsluis-west was op 4.0 meter diepte variant G4 aanwezig. Op 7.5 meter diepte werd variant A6 gevonden, en op 15.5, 22.6, 29.7 en 34.4 meter diepte variant B4.

Variant G4 werd alleen gedomineerd door de polychaet Capitella capitata en oligochaeten. Er waren geen soorten karakteristiek voor, of beperkt tot deze variant. Op het station kwamen 7 soorten voor, met een dichtheid van 803.6 individuen per $\mathrm{m}^{2}$.

In 2009 is de locatie Schelphoek in de ongestoorde situatie onderzocht. Op het talud waren de varianten A1 (3 meter diepte met 7 soorten), A8 (7.5 meter diepte met 23 soorten) en B1 (15 meter diepte met 18 soorten) aanwezig. Na de versteviging van de vooroever in 2009, was er in 2010 nog onvoldoende sediment aanwezig om de infauna te bemonsteren. 
In 2011 waren in het nieuwe sediment de varianten $\mathrm{J}$ (3 meter diepte met 1 soort), C (7.5 meter diepte met 14 soorten) en A8 (10.5 meter diepte met 16 soorten) aanwezig. In 2014 is de locatie opnieuw bemonsterd en waren de varianten A7 (4 meter diepte met 5 soorten en 7.9 meter diepte met 8 soorten) en $\mathrm{J}$ (13.8 meter diepte met 5 soorten) aanwezig.

Schelphoek-midden

Op de locatie Schelphoek-midden was alleen voldoende sediment aanwezig om de infauna te bemonsteren op 15.9 en 45.7 meter diepte. Op beide stations werd de soortenrijke variant B4 gevonden.

Op de locatie Schelphoek-midden was in 2008 een noodstort met staalslakken uitgevoerd, waardoor de ongestoorde situatie niet is onderzocht. In 2009 is de locatie opnieuw verstevigd en zijn de staalslakken met breuksteen afgedekt. In 2010 was er nog onvoldoende sediment aanwezig om de infauna te bemonsteren.

In 2011 was er alleen voldoende sediment aanwezig op 3.5 en 14.8 meter diepte. Op beide diepten was variant B2 aanwezig met ondiep 11 soorten en 19 soorten op het diepere station.

In 2014 is de locatie opnieuw bemonsterd en waren de varianten A7 (3.5 meter diepte met 5 soorten), A6 (7.5 meter diepte met 15 soorten) en B4 (15.0 meter diepte met 24 soorten) aanwezig.

Schelphoek-oost

Op de locatie Schelphoek-oost zijn alleen stations op grotere diepte bemonsterd met de Van Veen happer. Op deze diepte is in 2009 de bodem versterkt met staalslakken. De bemonstering is uitgevoerd in 3 raaien. Op de oostelijke raai kon op 35 meter diepte geen sediment worden bemonsterd. Op de overige 5 stations werden de varianten D (gemiddeld 9.0 soorten) en B4 (gemiddeld 24.4 soorten) gevonden.

\section{Schelphoek-oost-Referentie}

De locatie Schelphoek-oost-Referentie ligt ten oosten van het stortvak van 2009 en de bodem bestaat uit de ongestoorde bodem. In 2016 was op 4.8 meter diepte variant A8 aanwezig, op 7.5 meter variant B1 en op 15.0, 21.9, 28.8 en 30.6 meter diepte de soortenrijke variant B4.

Variant B1 werd gedomineerd door oligochaeten, de polychaeten Scoloplos armiger, Mediomastus fragilis, Aphelochaeta marioni, Pseudopolydora pulchra en Notomastus latericeus en anemonen. Er waren geen soorten karakteristiek voor, of beperkt tot deze variant. Op het station kwamen 12 soorten voor, met een dichtheid van 3063.8 individuen per $\mathrm{m}^{2}$.

\section{Zierikzee}

Op de locatie Zierikzee zijn in 2016 alleen de stations op het talud bemonsterd. Op 6.0 en 11.4 meter diepte was variant A6 aanwezig, op 13.5 meter diepte variant G3. 
Variant G3 werd gedomineerd door de polychaeten Streblospio shrubsolii en Cossura longocirrata en slangsterren. Er waren geen soorten karakteristiek voor, of beperkt tot deze variant. Op het station kwamen 6 soorten voor, met een dichtheid van 1356.1 individuen per $\mathrm{m}^{2}$.

In 2011 en 2013 was de onverstoorde situatie op deze locatie onderzocht.

In 2011 waren de varianten $\mathrm{J}$ (4.0 meter diepte met 1 soort), $\mathrm{P}$ (7.5 meter diepte met 1 soort) en G4 (15.0 meter diepte met 4 soorten) aanwezig, in 2013, A1 (4.4 meter diepte met 12 soorten) en $\mathrm{M}$ (15.5 meter diepte met 3 soorten). Op het station op 7.6 meter diepte was geen infauna aanwezig

In de Figuur 7 is het aantallen soorten per taxa in de varianten in 2016 weergegeven.

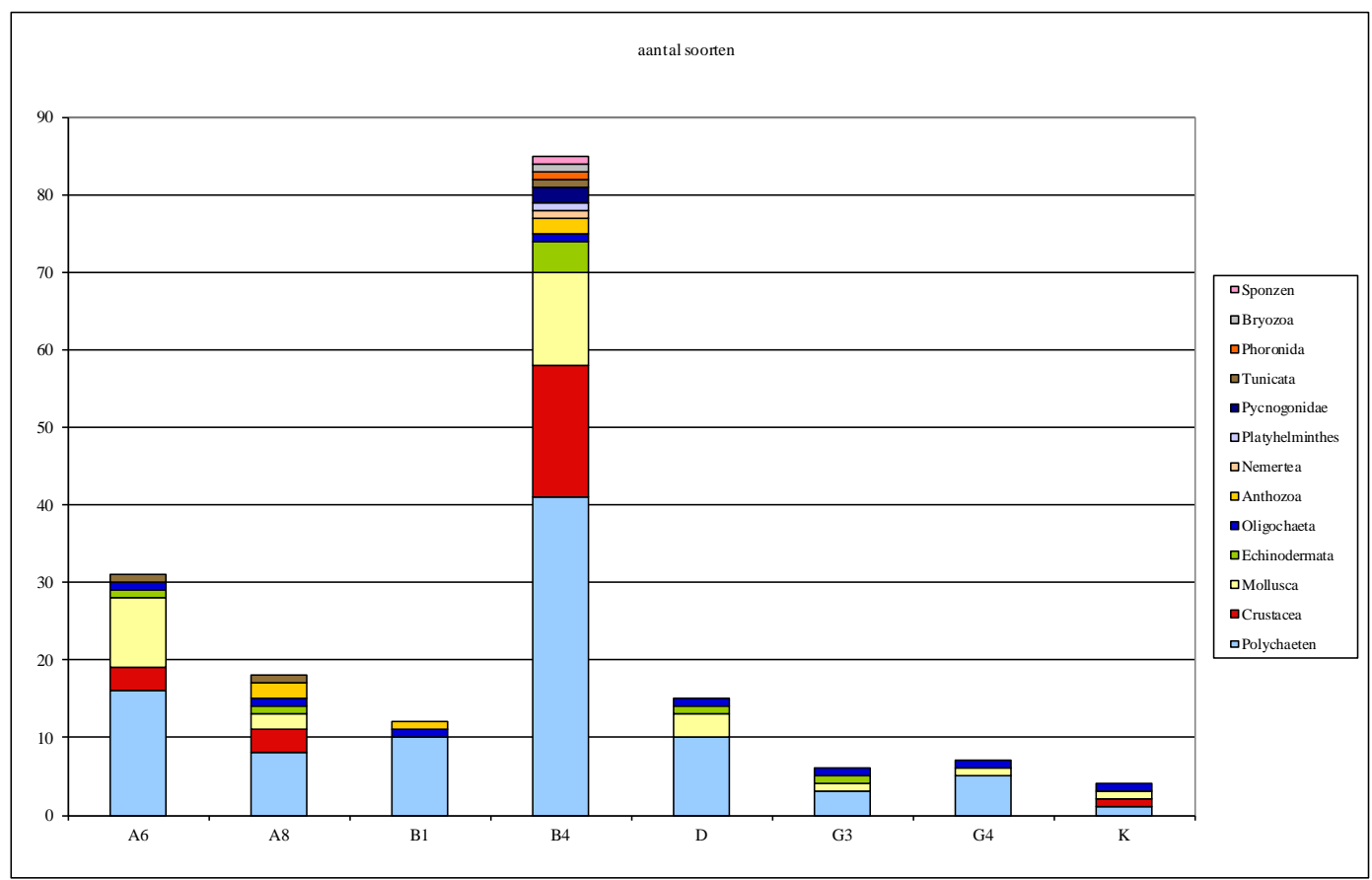

Figuur 7. Aantal soorten per taxa binnen de varianten in 2016.

Het aantal soorten binnen variant B4 is duidelijk het hoogste, dit betreft vooral soorten van de taxa Polychaeta, Crustacea, Mollusca en Echinodermata. Dit is mede veroorzaakt door het groot aantal stations dat tot deze variant clusterden, maar de variant is werkelijk meer soortenrijk. Gemiddeld kwamen er per station 24.4 soorten voor, terwijl dit in de overige varianten 4.0 tot 12.0 waren. Ook was de dichtheid van de soorten binnen deze variant het hoogste: $48038.4 \mathrm{n} / \mathrm{m}^{2}$, tegen 200,9 tot $3063.8 \mathrm{n} / \mathrm{m}^{2}$ in de andere varianten. Deze hoge dichtheid is hoofdzakelijk door oligochaeten veroorzaakt (Figuur 8), maar ook de dichtheden van de Polychaeta en Mollusa zijn duidelijk hoger. 


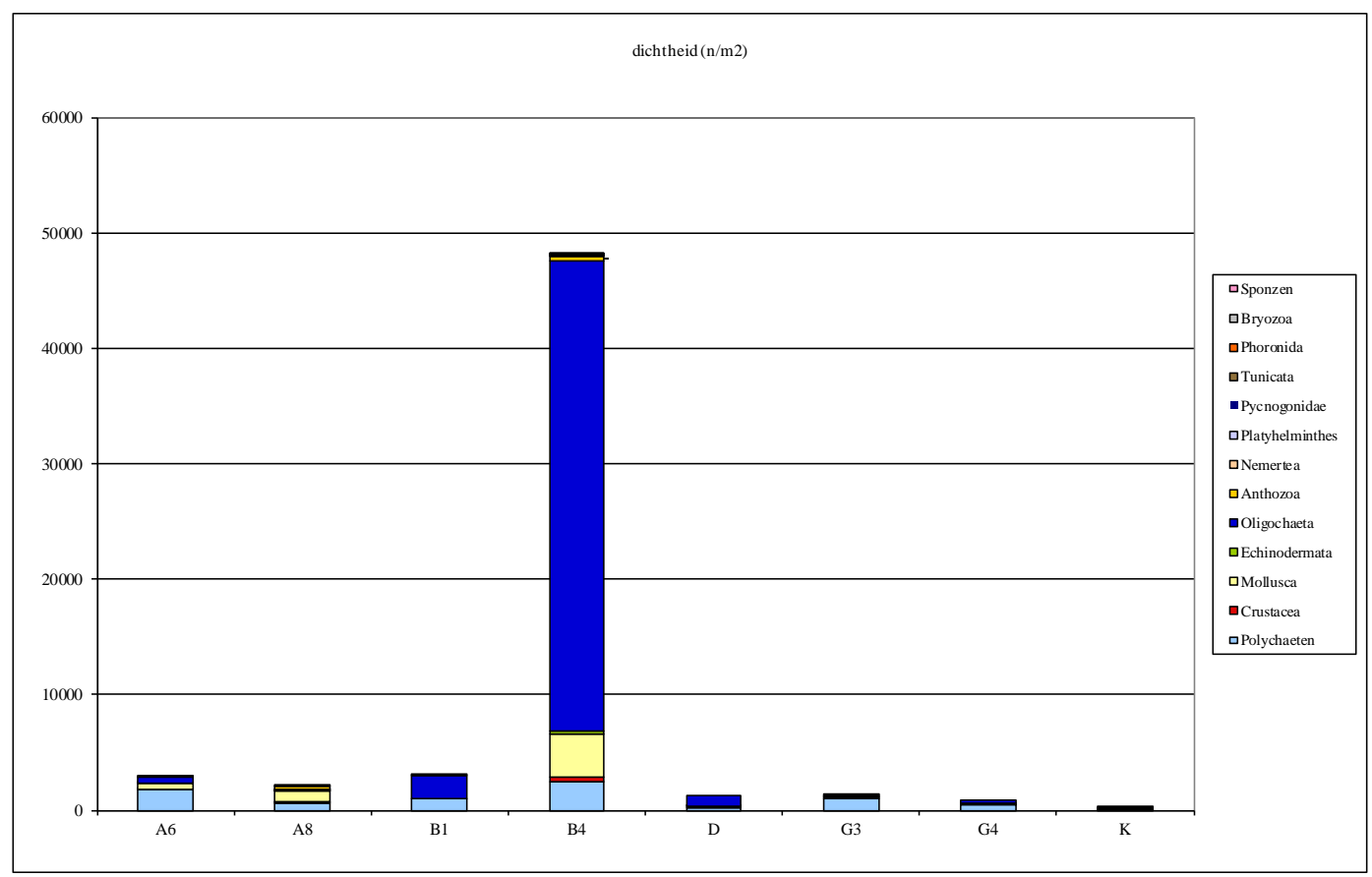

Figuur 8. Dichtheden $\left(\mathrm{n} / \mathrm{m}^{2}\right)$ per taxa binnen de varianten in 2016.

In totaal clusterden 18 stations tot variant B4. Hiervan zijn vier stations met steekbuizen bemonsterd, en 14 met de Van Veen happer. Om het effect van de monstermethode te bepalen zijn de soorten binnen de variant per monstermethode vergeleken (Tabel 5). 
Tabel 5. Soortensamenstelling van variant B4, bemonsterd met de Van Veenhapper (vv) en steekbuizen (sb). Voor een verklaring en de afkortingen zie Tabel 4.

\begin{tabular}{|c|c|c|c|c|c|c|c|}
\hline & & B4-vv & B4-sb & vervolg & & & \\
\hline Oligochaeta & Oli & 47517,2 & 16775,7 & & & & \\
\hline Abra alba & Mol & 2559,6 & 6203,0 & & & B4-vv & B4-sb \\
\hline Mediomastus fragilis & Po & $\overline{1727,8}$ & 891,5 & Owenia fusiformis & Po & 11,4 & 150,7 \\
\hline Actiniaria & An & 206,4 & 816,2 & Aora typica & $\mathrm{Cr}$ & 0,7 & 50,2 \\
\hline Pholoe baltica & Po & 188,6 & 150,7 & Anoplodactylus petiolatus & Pyc & 0,7 & $\overline{12,6}$ \\
\hline Capitella capitata & Po & 49,6 & 263,7 & Bodotria scorpioides & $\mathrm{Cr}$ & 0,7 & $\overline{12,6}$ \\
\hline Sthenelais boa & Po & $\overline{74,3}$ & $\underline{238,6}$ & Macoma balthica & Mol & 0,0 & $\overline{12,6}$ \\
\hline Kurtiella bidentata & Mol & $\overline{77,9}$ & $\overline{213,5}$ & Pectinaria koreni & Po & 1,4 & $\overline{12,6}$ \\
\hline Pseudopolydora pulchra & Po & $\overline{53,6}$ & $\underline{188,3}$ & Ophiuroidea & Ech & 0,7 & $\overline{12,6}$ \\
\hline Melita obtusata & $\mathrm{Cr}$ & $\overline{151,4}$ & 37,7 & Phoronida & $\mathrm{Ph}$ & 0,0 & $\overline{12,6}$ \\
\hline Notomastus latericeus & Po & $\overline{42,1}$ & $\overline{37,7}$ & Pycnogonida & Pyc & 0,0 & $\overline{12,6}$ \\
\hline Corophiidae & $\mathrm{Cr}$ & $\overline{22,9}$ & $\overline{37,7}$ & & & & \\
\hline Monocorophium acherusicur & $\mathrm{rCr}$ & $\overline{15,7}$ & $\overline{37,7}$ & dichtheid $\mathrm{n} / \mathrm{m} 2$ & & 54240,4 & 26331,3 \\
\hline Venerupis corrugata & Mol & $\overline{28,6}$ & $\overline{12,6}$ & & & & \\
\hline Mya arenaria & Mol & $\overline{24,3}$ & $\overline{12,6}$ & Index Log base 2 & & 1,040 & 1,771 \\
\hline Caprellidae & $\mathrm{Cr}$ & $\overline{5,0}$ & $\overline{25,1}$ & evenness & & 0,220 & 0,452 \\
\hline Aonides oxycephala & Po & $\underline{10,7}$ & $\overline{12,6}$ & gemiddeld aantal soorten & & 27,3 & 14,5 \\
\hline Glycera (spec.) & Po & $\overline{9,3}$ & $\overline{12,6}$ & & & & \\
\hline Aoridae & $\mathrm{Cr}$ & 8,6 & $\overline{\underline{12,6}}$ & & & & \\
\hline Nereis longissima & Po & $\overline{7,9}$ & $\underline{12,6}$ & & & & \\
\hline Nephtys hombergii & Po & $\overline{7,1}$ & $\overline{12,6}$ & & & & \\
\hline Ophiothrix fragilis & Ech & 382,1 & 12,6 & & & & \\
\hline Lysianassa ceratina & $\mathrm{Cr}$ & $\overline{277,9}$ & 0,0 & & & & \\
\hline Mytilus edulis & Mol & $\underline{237,1}$ & 12,6 & & & & \\
\hline Aphelochaeta marioni & Po & $\overline{218,1}$ & 12,6 & & & & \\
\hline Nemertea & $\mathrm{Ne}$ & 92,9 & 0,0 & & & & \\
\hline Streblospio shrubsolii & Po & $\underline{26,8}$ & 0,0 & & & & \\
\hline Platyhelminthes & $\mathrm{Pt}$ & $\underline{23,6}$ & 0,0 & & & & \\
\hline Crepidula fornicata & Mol & $\overline{20,7}$ & 0,0 & & & & \\
\hline Subadyte pellucida & Po & $\underline{16,4}$ & 0,0 & & & & \\
\hline Eteone (spec.) & Po & $\overline{16,4}$ & 0,0 & & & & \\
\hline Pholoe inornata & Po & $\underline{15,0}$ & 0,0 & & & & \\
\hline Ophiura ophiura & Ech & $\underline{12,9}$ & 0,0 & & & & \\
\hline Scoloplos armiger & Po & 6,4 & 0,0 & & & & \\
\hline Buccinum undatum & Mol & $\overline{5,7}$ & 0,0 & & & & \\
\hline Cerianthus Iloydii & An & $\overline{5,7}$ & 0,0 & & & & \\
\hline Lepidonotus squamatus & Po & $\overline{5,0}$ & 0,0 & & & & \\
\hline Pisidia longicornis & $\mathrm{Cr}$ & $\overline{5,0}$ & 0,0 & & & & \\
\hline Prionospio steenstrupi & Po & 4,3 & 0,0 & & & & \\
\hline Polynoidae & Po & $\overline{4,3}$ & 0,0 & & & & \\
\hline Asterias rubens & Ech & 3,6 & 0,0 & & & & \\
\hline Kefersteinia cirrata & Po & $\overline{3,6}$ & 0,0 & & & & \\
\hline Lanice conchilega & Po & 3,6 & 0,0 & & & & \\
\hline Harmothoe (spec.) & Po & $\frac{\pi}{3,6}$ & 0,0 & & & & \\
\hline Carcinus maenas & $\mathrm{Cr}$ & $\underline{2,9}$ & 0,0 & & & & \\
\hline Spisula subtruncata & Mol & 2,9 & 0,0 & & & & \\
\hline Microdeutopus (spec.) & $\mathrm{Cr}$ & 2,9 & 0,0 & & & & \\
\hline Polydora (spec.) & Po & $\overline{2,9}$ & 0,0 & & & & \\
\hline Cossura longocirrata & Po & $\overline{2,1}$ & 0,0 & & & & \\
\hline Eumida sanguinea & Po & $\overline{2,1}$ & 0,0 & & & & \\
\hline Flabelligera affinis & Po & 2,1 & 0,0 & & & & \\
\hline Sabellaria spinulosa & Po & $\overline{2,1}$ & 0,0 & & & & \\
\hline Eumida (spec.) & Po & $\overline{2,1}$ & 0,0 & & & & \\
\hline Harmothoe impar & Po & $\overline{1,4}$ & 0,0 & & & & \\
\hline Microdeutopus anomalus & $\mathrm{Cr}$ & 1,4 & 0,0 & & & & \\
\hline Ostrea edulis & Mol & $\overline{1,4}$ & 0,0 & & & & \\
\hline Syllidia armata & Po & $\underline{1,4}$ & 0,0 & & & & \\
\hline Autolytus (spec.) & Po & $\frac{17}{1,4}$ & 0,0 & & & & \\
\hline BRYOZOA & $\mathrm{Br}$ & $\overline{1,4}$ & 0,0 & & & & \\
\hline Eunoe nodosa & Po & $\overline{1,4}$ & 0,0 & & & & \\
\hline Hesionidae & Po & $\overline{1,4}$ & 0,0 & & & & \\
\hline Malmgreniella (spec.) & Po & 1,4 & 0,0 & & & & \\
\hline Liocarcinus holsatus & $\mathrm{Cr}$ & $\overline{0,7}$ & 0,0 & & & & \\
\hline Monocorophium insidiosum & $\mathrm{Cr}$ & 0,7 & 0,0 & & & & \\
\hline Neoamphitrite figulus & Po & $\overline{0,7}$ & 0,0 & & & & \\
\hline Pagurus bernhardus & $\mathrm{Cr}$ & $\overline{0,7}$ & 0,0 & & & & \\
\hline Petricola pholadiformis & Mol & $\overline{0,7}$ & 0,0 & & & & \\
\hline Scalibregma inflatum & Po & $\underline{0,7}$ & 0,0 & & & & \\
\hline Sphaerodorum gracilis & Po & $\overline{0,7}$ & 0,0 & & & & \\
\hline Styela clava & $\mathrm{Tu}$ & 0,7 & 0,0 & & & & \\
\hline Syllis gracillis & Po & $\overline{0,7}$ & 0,0 & & & & \\
\hline Cheirocratus (spec.) & $\mathrm{Cr}$ & $\underline{0,7}$ & 0,0 & & & & \\
\hline Decapoda & $\mathrm{Cr}$ & 0,7 & 0,0 & & & & \\
\hline Gastropoda & $\mathrm{Mol}$ & $\underline{0,7}$ & 0,0 & & & & \\
\hline Nereis (spec.) & Po & $\underline{0,7}$ & 0,0 & & & & \\
\hline Polycirrus (spec.) & Po & $\overline{0,7}$ & 0,0 & & & & \\
\hline Sycon & $\mathrm{Sp}$ & 0,7 & 0,0 & & & & \\
\hline
\end{tabular}


De tabel laat duidelijk zien dat de gebruikte methode de resultaten wel beïnvloedt, maar niet bepalend is. Het gemiddeld aantal soorten per station en de gevonden dichtheden zijn ongeveer een factor twee keer hoger bij het gebruik van de Van Veen happer in vergelijking met de bemonstering door middel van steekbuizen. Van de soorten kwam 24.4\% in beide methoden voor, 65.1\% in alleen de Van Veen monsters en 10,5\% van de soorten waren beperkt tot de steekbuis-monsters. Dat het aantal gevonden soorten in de Van Veen happer kan verklaard worden door ket grotere bemonsterde oppervlak, $0.1 \mathrm{~m}^{2}$ bij de Van Veen happer tegenover $0.02 \mathrm{~m}^{2}$ bij de steekbuizen, maar de verdubbeling van de dichtheid van de individuen kan hierdoor niet verklaard worden.

Maar het aantal soorten en hun dichtheden in zowel de Van Veen happer als de steekbuizen is nog altijd hoger dan in de overige varianten die in 2016 gevonden zijn.

De meest gebruikte methoden voor het bemonsteren van de zachte onderwater bodem kennen een groot aantal verschillen voor een kwantitatieve bemonstering en analyse. Bij het gebruik van steekbuizen staat het bemonsterde oppervlak vast, en kan onder water bepaald worden of de steekdiepte voldoende is. Bij gebruik van boxcores is het bemonsterde oppervlak vast, maar ligt de steekdiepte vast op minimaal $15 \mathrm{~cm}$. Bij de Van Veen happer is het bemonsterde oppervlak vastgesteld op de geopende happer. Diepte van de penetratie is echter afhankelijk van het type ondergrond. Bij de bemonstering in 2016 zijn verschillende bodems bemonsterd: onverstoorde bodems, ouder gestort materiaal met staalslakken en breuksteen en recent gestort zeegrind. De steekdiepte kan, niet altijd, omdat het ook schraapmonsters betreft, worden achterhaald.

De dominante soorten uit de Van Veen happer laten wel zien dat er schraapmonsters van harde substraten zijn. De brokkelsterren en mosselbroed zijn oppervlakte soorten en Styela clava, Crepidula fornicata en Asterias rubens zijn zeker met de harde substraten verbonden. 


\section{Dikte sedimentlaag en sedimentsamenstelling}

De dikte van de sedimentlaag tot 15 meter -NAP is gegeven in Bijlage 5. In Tabel 6 is de gemiddelde dikte op het talud vanaf het breuksteen in de golfzone tot 15 meter -NAP gegeven, en de dikte in de Van Veen happer.

Tabel 6. Gemiddelde sediment dikte op het talud in cm, en de dikten in de Van Veen monsters. Schraapmonsters zijn duidelijk verstoorde monsters, waarbij de ondergrond is afgeschraapt.

\begin{tabular}{|l|c|c|c|c|}
\hline & talud & \multicolumn{2}{|c|}{ Van Veen, toenemende diepte } \\
\hline Burghsluis & 15,7 & 16 & 12 & 5 \\
\hline Sch-west II-west & 3,3 & & & \\
\hline Sch-west II-west-midden & 4,7 & & & \\
\hline Sch-west II-midden-oost & 7,7 & & & \\
\hline Sch-west II-oost & 4,1 & & & 18 \\
\hline Schelphoek-west & 32,3 & 5 & 6 & schraap \\
\hline Schelphoek-midden & 0,3 & & - & 6 \\
\hline Schelphoek-oost-1 & & & schraap & 7 \\
\hline Schelphoek-oost-2 & & & 14 & schraap \\
\hline Schelphoek-oost-3 & & & 3 & 13 \\
\hline Schelphoek-Ref & 20,0 & 8 & 14 & \\
\hline Zierikzee & 6,0 & & & \\
\hline
\end{tabular}

De samenstelling van de bodemsedimenten is weergegeven in de Figuren 8, 9 en 10.

\begin{tabular}{|c|c|c|c|c|c|c|c|c|c|c|c|}
\hline OS-2016 & Burgh-w & Sch-wII & Sch-wII & Sch-wII & Sch-w & Sch-m & Sch-o & & & Sch-R & Zie \\
\hline $0-5$ & 65,4 & 65,4 & 76,7 & 76,5 & 84,7 & 22,4 & & & & 42,4 & 80,0 \\
\hline $5.1-10$ & 25,7 & 73,9 & 92,5 & 83,9 & 46,8 & 44,5 & & & & 22,9 & 77,5 \\
\hline \multirow[t]{2}{*}{$>10.1$} & 12,6 & 57,3 & 39,9 & 58,9 & 21,1 & 37,7 & & & & 28,4 & 67,4 \\
\hline & & 48,6 & & 83,3 & & & & & & & \\
\hline & & & & & & & & & & & \\
\hline \multirow[t]{5}{*}{ van Veen } & 33,3 & & & & 34,3 & & & & & 17,8 & \\
\hline & 37,0 & & & & 26,9 & & 48,0 & 42,1 & 38,2 & 27,6 & \\
\hline & 22,7 & & & & 34,5 & 47,9 & 40,9 & 39,6 & 45,2 & 14,4 & \\
\hline & & & & & & & & & & & \\
\hline & & & & & & & & & & & \\
\hline
\end{tabular}

Figuur 8. Sedimenttype en \% fracties $<0.09 \mathrm{~mm}$, blauw type V, groen type VI, bruin type V(dis) en rood type VIII (Voor een verklaring zie Tabel 1).

\begin{tabular}{|c|c|c|c|c|c|c|c|c|c|c|c|}
\hline OS-2016 & Burgh-w & Sch-wII & Sch-wII & Sch-wII & Sch-w & Sch-m & Sch-o & & & Sch-R & Zie \\
\hline $0-5$ & 39,0 & 38,1 & 33,0 & 39,3 & 35,3 & 63,3 & & & & 59,3 & 28,3 \\
\hline 5.1-10 & 63,4 & 33,3 & 38,3 & 34,4 & 49,8 & 47,9 & & & & 62,0 & 36,3 \\
\hline \multirow[t]{2}{*}{$>10.1$} & 64,3 & 40,3 & 63,0 & 47,5 & 64,5 & 59,6 & & & & 65,8 & 41,0 \\
\hline & & 49,7 & & 35,1 & & & & & & & \\
\hline & & & & & & & & & & & \\
\hline \multirow[t]{5}{*}{ van Veen } & 57,7 & & & & 76,6 & & & & & 73,3 & \\
\hline & 55,3 & & & & 63,9 & & 46,9 & 48,7 & 40,9 & 68,9 & \\
\hline & 67,3 & & & & 45,6 & 37,9 & 47,1 & 52,8 & 43,0 & 73,3 & \\
\hline & & & & & & & & & & & \\
\hline & & & & & & & & & & & \\
\hline
\end{tabular}

Figuur 9. Percentage droge stof in de bodemsedimenten, rood $<50 \%$ en blauw $>50 \%$. 


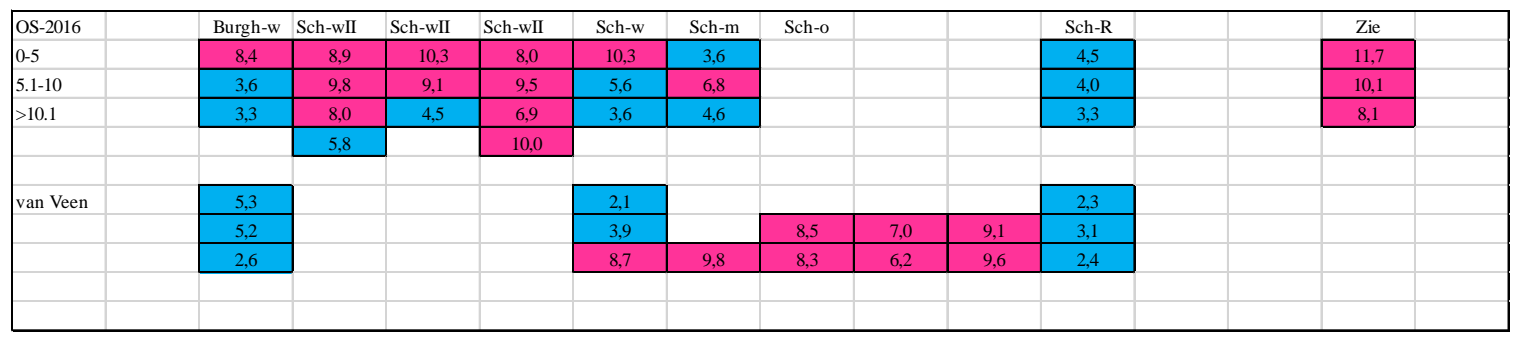

Figuur 10. Percentage organische stof in de bodemsedimenten, rood $>6 \%$ en blauw $<6 \%$.

Op de locatie Burghsluis-west had zich over het gehele talud een pakket sediment afgezet. Tot ongeveer 10 meter diepte was deze laag tussen de 10 en $40 \mathrm{~cm}$ dik, maar werd op grotere diepte dunner. Gemiddeld over het talud was de sedimentlaag $15.7 \mathrm{~cm}$ dik. Ondiep bestond het sediment vooral uit fijne fracties, maar dieper namen de fijne zandfracties (0.15-0.09 mm) toe, waardoor het percentage droge stof steeg, en het percentage organische stof afnam. Op 20 en 30 meter was de sedimentlaag meer dan 10 $\mathrm{cm}$ dik en namen de fijne fracties iets toe, maar op 35 meter bestond het materiaal vooral uit zand (0.3-0.15 mm) en was de sedimentlaag $5 \mathrm{~cm}$ dik.

Tussen de riffen op de locatie Schelphoek-west II was de sedimentlaag minder dik dan op de locatie Burghsluis-west, maar de sedimenten waren, vooral ondiep, van fijnere samenstelling. Op de raaien west en oost was de sedimentdikte minder dik (gemiddeld 3.3 en $4.1 \mathrm{~cm}$ over het talud) dan op de binnenste raaien (gemiddeld 4.7 en $7.7 \mathrm{~cm}$ ). In 2015 is de dikte van de sedimentlaag ook bepaald en toen werd op de buitenste raaien een pakket van 1.7 en $3.2 \mathrm{~cm}$ gevonden, en 5.0 en $6.1 \mathrm{~cm}$ op de binnenste raaien.

Op de locatie Schelphoek-west heeft zich sinds 2009 een pakket sediment gevormd op het talud van gemiddeld $32.3 \mathrm{~cm}$ dikte. Vooral ondiep, tot 9 meter diepte, was dit pakket dik en bestond uit fijne fracties of uit zand met slib. Dieper werd dit pakket dunner en namen de zandfracties toe. Ook in de Van Veen happen was de sedimentdikte op 20-30 m gering, maar op 35 meter werd een laag van $18 \mathrm{~cm}$ gevonden. Het sediment op $35 \mathrm{~m}$ diepte was fijn van samenstelling en had een hoger percentage organische stof dan de monsters op 20-30 meter.

Op de locatie Schelphoek-midden, waar de staalslakken met breuksteen afgedekt zijn, kwam bijna geen sediment voor (gemiddeld $0.3 \mathrm{~cm}$ over het talud). Het sediment was ondiep aanwezig, waar het breuksteen is afgegleden en de staalslakken blootliggen. Met de Van Veen happer was het niet mogelijk een monster van 32 meter diepte te nemen, en op 45.7 meter kon alleen een schraapmonster worden genomen. Dit monster was fijn van samenstelling (type VIII) en had een hoog percentage organische stof.

Op de locatie Schelphoek-oost is alleen de bodem met een ondergrond van staalslakken op grotere diepte bemonsterd met de Van Veen happer. Op de 6 locaties konden 3 schraapmonsters worden genomen en 3 monsters met een steekdiepte van $6 \mathrm{~cm}$ of meer. Op 2 stations werd het type V(dis) gevonden, op de overige 4 werd het sediment gedomineerd door de fracties kleiner dan $0.09 \mathrm{~mm}$. Het percentage organische stof was hoog in alle stations. 
Op de referentie locatie Schelphoek-oost is de onverstoorde, oude, bodem bemonsterd. Op het talud was gemiddeld $20.0 \mathrm{~cm}$ aanwezig. Het talud bestond uit een mix van sediment en plekken met natuurlijke oesterriffen. De steekdiepte werd beperkt doordat in het sediment een oude steenbestorting werd bereikt, of onder gesedimenteerde oesterriffen. Dit kon niet worden bepaald. Op grote diepte varieerde de steekdiepte met de Van Veen happer van 8 tot $14 \mathrm{~cm}$. Op het talud werd het ondiepste station op 4.8 meter diepte, gedomineerd door fracties kleiner dan $0.09 \mathrm{~mm}$. Op grotere diepten was dit de fijne zandfractie van 0.15-0.09 mm. Het sediment in de Van Veen happer bestond uit zandfracties (type V en VI). In alle monsters werd een hoog percentage droge stof gevonden, en een laag percentage organische stof.

Op de locatie Zierikzee is alleen de sedimentdikte op het talud bepaald. Gemiddeld kwam er $6 \mathrm{~cm}$ sediment op het talud voor. Het zeegrind is echter golvend gestort en de sedimentdikten was relatief hoog in de golfdalen (tot maximaal $20 \mathrm{~cm}$ ). Het sediment werd gedomineerd door fracties kleiner dan $0.09 \mathrm{~mm}$, met een laag percentage droge stof en een hoog percentage organische stof. 
Relatie tussen de varianten en de abiotische parameters

In de volgende figuren is de verdeling van de varianten over de abiotische factoren onderzocht. Allereerst is naar de soortenrijkdom in relatie tot de diepte gekeken (Figuur $11)$.

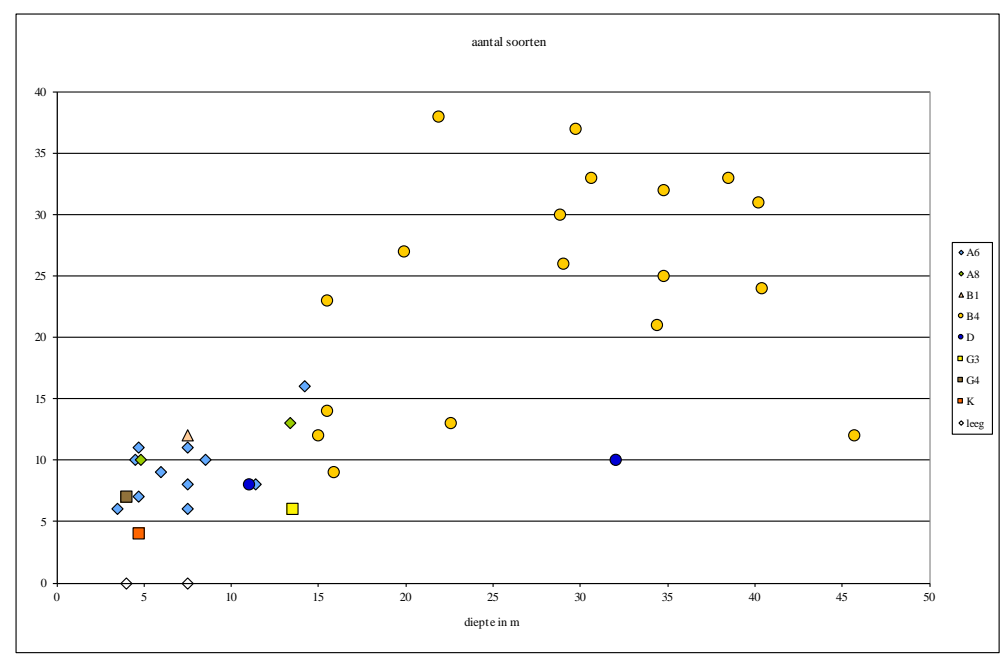

Figuur 11. Het aantal soorten per variant in relatie tot de diepte.

De meest soortenrijke stations zijn gevonden met de Van Veen happer op grotere diepte. Drie stations waren relatief soortenarm, het schraapmonster op de oostelijke raai (variant D) van Schelphoek-oost, het station op Schelphoek-midden en op Schelphoek-west (22.6 $\mathrm{m})$.

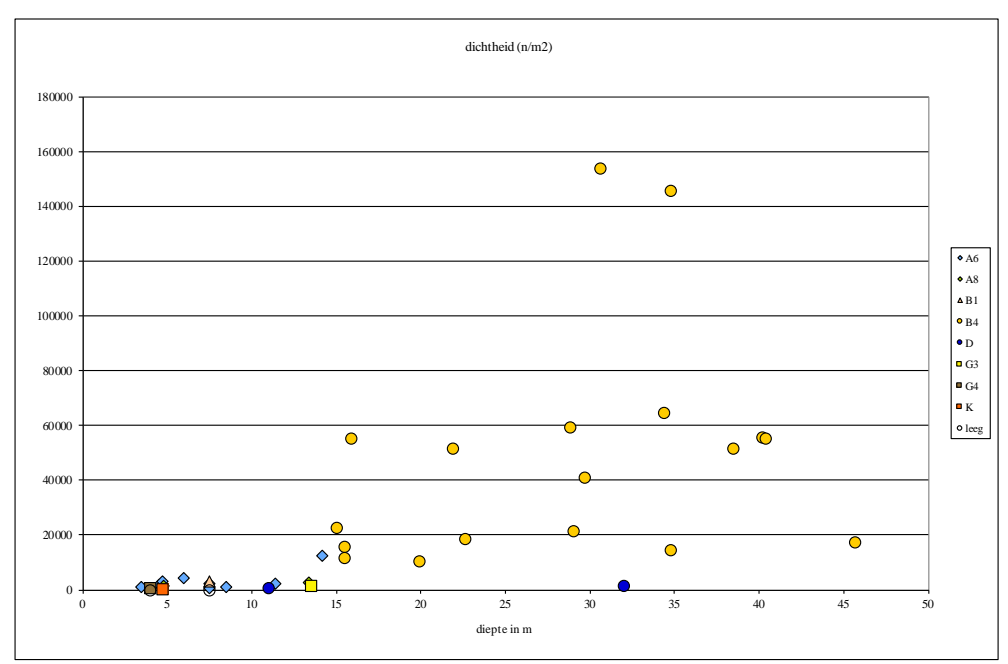

Figuur 12. De dichtheid van soorten per variant in relatie tot de diepte.

De grootste dichtheden werden ook gevonden op de stations die met de Van Veen happer bemonsterd zijn (Figuur 12). Twee stations vallen hierbij op door de hoge dichtheden van de soorten, het station op de midden raai van Schelphoek-oost en het Referentie station 
van de Schelphoek op 30.6 meter, maar op deze stations bestond de dichtheid voor 94 tot 96\% uit oligochaeten .

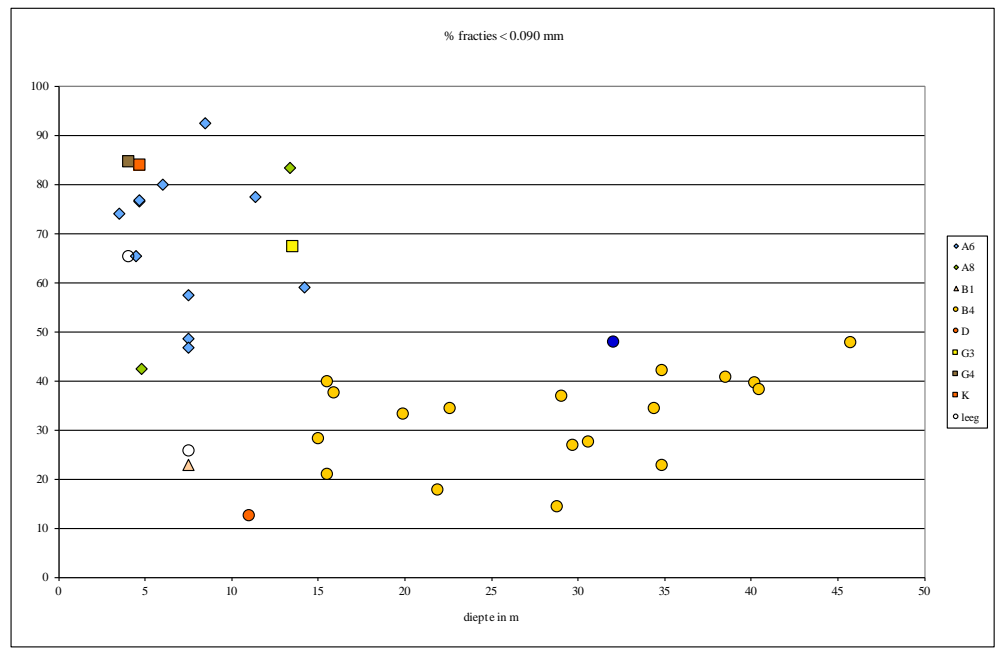

Figuur 13. De spreiding van de varianten in relatie tot de fracties $<0.09 \mathrm{~mm}$ over de diepte.

De samenstelling van de sedimenten op het talud is fijner dan op grotere diepte (Figuur 13). Alleen op de locaties Burghsluis en Schelphoek-west werden op het talud ook grovere sedimenten gevonden.

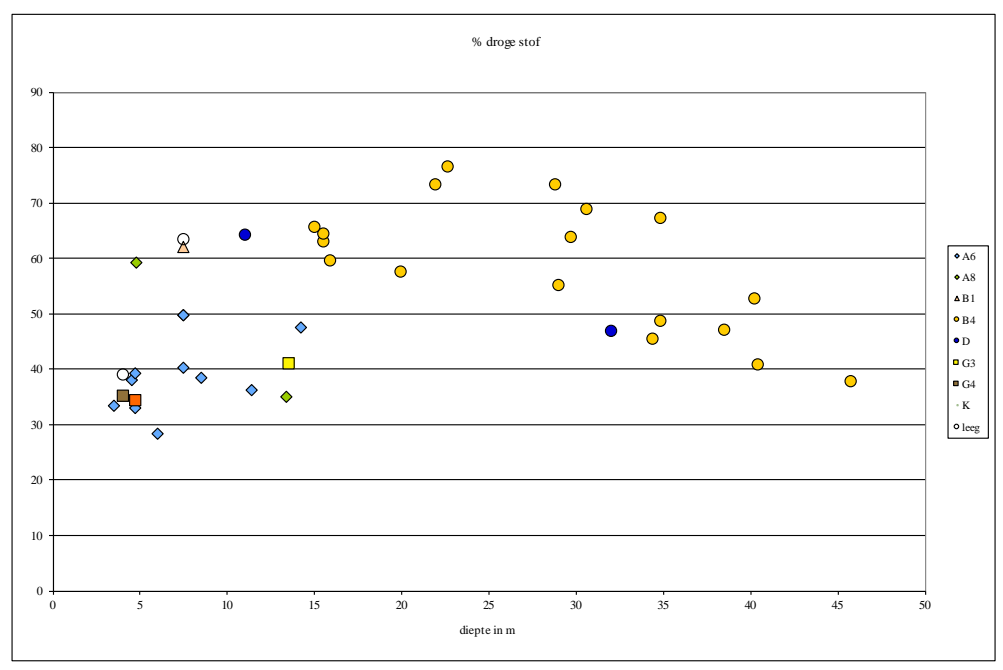

Figuur 14. De spreiding van de varianten in relatie tot het percentage droge stof over de diepte.

Het percentage droge stof was het hoogste tussen de 20 en 30 meter diepte (Figuur 14), en het percentage organische stof was op deze diepten het laagste (Figuur 15). 


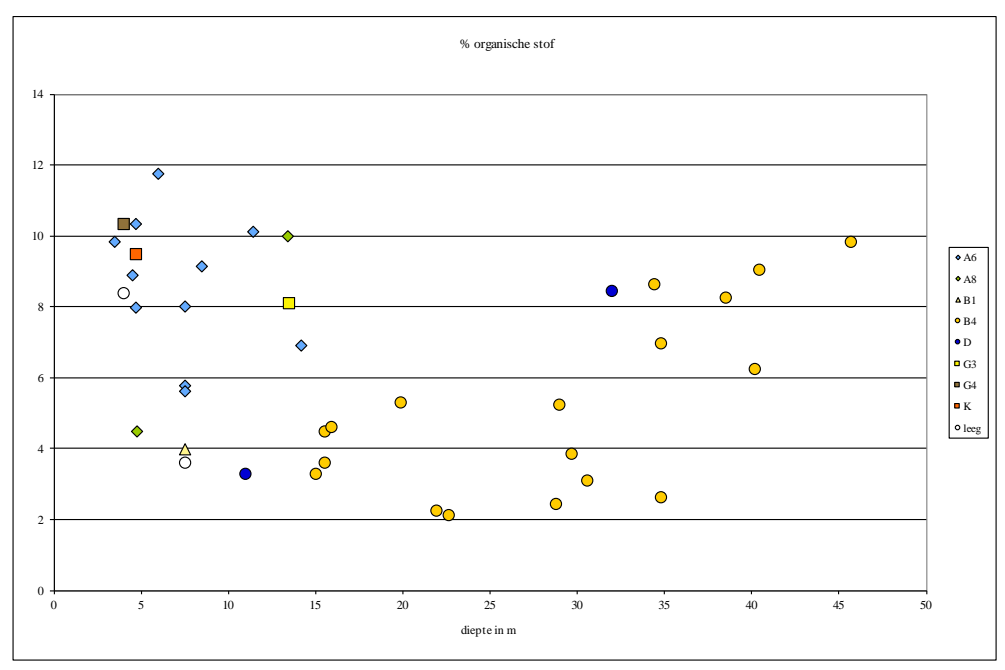

Figuur 15. De spreiding van de varianten in relatie tot het percentage organische stof over de diepte.

Deze factoren zijn per variant samengevat in Tabel 6.

Tabel 6. Abiotische factoren van de varianten in 2016.

\begin{tabular}{|l|c|c|c|c|c|c|c|c|}
\hline Gem. & diepte & \% droge stof & \% org. stof & fracties $<0.09 \mathrm{~mm}$ & V & VI & V(dis) & VIII \\
\hline A6 & 7,3 & 39,4 & 8,6 & 68,6 & - & - & 9,1 & 90,9 \\
\hline A8 & 9,1 & 47,2 & 7,2 & 62,8 & - & - & - & 100,0 \\
\hline B1 & 7,5 & 62,0 & 4,0 & 22,9 & - & 100,0 & - & - \\
B4 & 28,5 & 59,0 & 5,1 & 32,5 & 16,7 & 11,1 & 27,8 & 44,4 \\
\hline D & 21,5 & 55,6 & 5,9 & 30,3 & - & 50,0 & - & 50,0 \\
\hline G3 & 13,5 & 41,0 & 8,1 & 67,4 & - & - & - & 100,0 \\
\hline G4 & 4,0 & 35,3 & 10,3 & 84,7 & - & - & - & 100,0 \\
\hline K & 4,7 & 34,4 & 9,5 & 83,9 & - & - & - & 100,0 \\
\hline leeg & 5,8 & 51,2 & 6,0 & 45,6 & - & 50,0 & - & 50,0 \\
\hline
\end{tabular}

Uit de tabel blijkt duidelijk dat de varianten B1, B4 en D in grovere en minder organisch verrijkte bodems voorkomen dan de andere varianten. Dit komt niet overeen met het beeld van de gemeenschappen in de periode 2009-16 (zie Tabel 3). Dit lijkt in tegenstelling met elkaar, maar kennelijk komen de varianten van de gemeenschappen onder verschillende omstandigheden voor, waardoor de gemiddelden over de gemeenschappen gelijk zijn. Daarom zijn in Tabel 7 alle varianten met de beschikbare abiotische gegevens samengevat. 
Tabel 7. Abiotische factoren van de varianten in 2009-2016 (blauw is percentage droge stof $>50 \%$ en organische stof $<6 \%$, rood is percentage droge stof $<50 \%$ en organische stof $>6 \%$ ).

\begin{tabular}{|c|c|c|c|c|c|c|c|c|c|c|c|}
\hline Gem & $\mathrm{nsp}$ & $\mathrm{n} / \mathrm{m} 2$ & n stat & diepte & $\%$ droge stof & $\%$ org. stof & fracties $<0.09 \mathrm{~mm}$ & $\mathrm{~V}$ & $\mathrm{VI}$ & $\mathrm{V}(\mathrm{dis})$ & VIII \\
\hline $\mathrm{A} 4$ & 13,0 & 8036,2 & 2 & 15,0 & 71,5 & 2,1 & 27,4 & - & 50,0 & 50,0 & - \\
\hline $\mathrm{A} 1$ & 9,9 & 4333,8 & 7 & 8,7 & 69,3 & 2,6 & 23,2 & 75,0 & - & 25,0 & - \\
\hline $\mathrm{A} 3$ & 10,0 & 1121,7 & 3 & 6,6 & 66,9 & 2,5 & 29,5 & 66,7 & 33,3 & - & - \\
\hline A8 & 15,8 & 4579,3 & 23 & 10,4 & 63,5 & 3,8 & 27,1 & 47,1 & 23,5 & 5,9 & 23,5 \\
\hline $\mathrm{A} 5$ & 10,3 & 8651,5 & 4 & 5,7 & 53,9 & 6,2 & 36,1 & 50,0 & - & 25,0 & 25,0 \\
\hline $\mathrm{A} 2$ & 11,5 & 4878,7 & 15 & 7,7 & 49,9 & 6,4 & 45,0 & 7,7 & 46,2 & 7,7 & 38,5 \\
\hline A7 & 7,8 & 2124,6 & 10 & 5,0 & 44,5 & 7,8 & 60,2 & - & 20,0 & - & 80,0 \\
\hline $\mathrm{A} 6$ & 9,8 & 2883,8 & 12 & 7,3 & 39,1 & 8,7 & 68,4 & - & - & 8,3 & 91,7 \\
\hline B3 & 33,9 & 12450,6 & 9 & 13,9 & 71,2 & 2,3 & 12,7 & 22,3 & - & 77,8 & - \\
\hline B4 & 24,5 & 48669,0 & 22 & 26,3 & 58,7 & 5,1 & 32,9 & 18,2 & 13,6 & 27,3 & 40,9 \\
\hline B1 & 24,1 & 11928,8 & 48 & 11,1 & 56,2 & 5,4 & 32,1 & 9,5 & 2,4 & 66,7 & 21,4 \\
\hline B2 & 18,1 & 7673,1 & 13 & 9,8 & 48,1 & 6,9 & 45,3 & 23,1 & - & 38,5 & 38,5 \\
\hline C & 11,7 & 904,1 & 3 & 10,0 & 68,7 & 3,0 & 18,4 & 66,7 & - & 33,3 & - \\
\hline $\mathrm{E}$ & 7,0 & 577,6 & 2 & 9,7 & 56,0 & 5,4 & 42,0 & - & - & 50,0 & 50,0 \\
\hline $\mathrm{D}$ & 7,3 & 869,6 & 4 & 12,4 & 52,6 & 6,4 & 38,9 & - & 50,0 & - & 50,0 \\
\hline $\mathrm{F}$ & 20 & 3164,3 & 1 & 12,0 & & & & & & & \\
\hline G4 & 5,4 & 577,6 & 8 & 6,7 & 56,6 & $\overline{5,4}$ & 36,5 & 50,0 & - & 12,5 & 37,5 \\
\hline G3 & 5,0 & 1079,9 & 2 & 8,5 & 40,5 & 8,5 & 72,2 & - & - & - & 100,0 \\
\hline G1 & 9 & 3616,3 & 1 & 5,0 & & & & & & & \\
\hline $\mathrm{H}$ & 6,4 & 898,5 & 9 & 9,4 & 61,9 & 3,7 & 29,4 & 22,2 & 66,7 & - & 11,1 \\
\hline $\mathrm{I}$ & 8,7 & 786,9 & 3 & 5,1 & 68,5 & 3,1 & 17,2 & 66,7 & - & 33,3 & - \\
\hline $\mathrm{J}$ & 3,4 & 1199,9 & 9 & 6,7 & 45,5 & 7,6 & 58,6 & 12,5 & 12,5 & 37,5 & 37,5 \\
\hline leeg & 0 & 0,0 & 0 & 6,4 & 44,1 & 7,6 & 56,1 & - & 33,3 & - & 66,7 \\
\hline $\mathrm{K}$ & 4 & 200,9 & 1 & 4,7 & 34,4 & 9,5 & 83,9 & - & - & - & 100,0 \\
\hline $\mathrm{M}$ & 3 & 301,4 & 1 & 15,5 & 31,0 & 11,3 & 73,0 & - & - & - & 100,0 \\
\hline $\mathrm{P}$ & 1 & 50,2 & 1 & 7,5 & 30,8 & 11,0 & 87,6 & - & - & - & 100,0 \\
\hline $\mathrm{L}$ & 5 & 552,5 & 1 & 15,0 & & & & & & & \\
\hline $\mathrm{O}$ & 1 & 50,2 & 1 & 3,0 & & & & & & & \\
\hline $\mathrm{Q}$ & 1 & 50,2 & 1 & 9,0 & & & & & & & \\
\hline
\end{tabular}

In de hoofdgroepen A, B en G komen zowel varianten voor in gestabiliseerde bodems (blauw), als in recent gevormde bodems, waarin nog geen, of een verminderd percentage, zandfracties aanwezig zijn (rood). In hoofdgroep $\mathrm{H}$, vooral aanwezig op de oostelijke locaties, waaronder Gorishoek en Wemeldinge-oost, zijn de sedimenten fijn-zandig tot zandig, en is de gemeenschap soortenarm, maar heeft karakteristieke tweekleppige soorten. 


\section{Discussie en conclusie}

In 2016 is een specifieke habitat bemonsterd, die niet in 2015 is bemonsterd. Bovendien zijn twee verschillende monster methoden gebruikt. Door deze keuze zijn de dominante varianten (A6 en B4) uit 2017 niet te evalueren. Variant A6 is gevonden op het talud met niet gestabiliseerde bodems met steekbuizen, en variant B4 vooral op grotere diepten met de Van Veen happer.

Verschillen in resultaten tussen de beide methoden is duidelijk waar zowel stations van variant B4 zijn gevonden die met steekbuizen en de Van Veen happer zijn bemonsterd. De stations met de Van Veen happer hadden gemiddeld een tweemaal hoger soortenaantal en dichtheid.

Deze hele problematiek had gemakkelijk voorkomen kunnen worden door in 2016 enkele stations met zowel de Van Veen happer als met steekbuizen te bemonsteren, en door de stations uit 2015, met name op de Zeelandbrug, opnieuw in 2016 te bemonsteren. 




\section{Bijlagen}

1-Stationsgegevens en abiotische factoren.

3-Sedimentkarakteristieke infauna stations.

4-Dikte sedimentlaag. 


\section{Bijlage 1 - stationsgegevens}

\section{Stationsgegevens en abiotische factoren.}

\begin{tabular}{|c|c|c|c|c|c|c|c|c|c|c|c|c|}
\hline $\inf n$ & locatie & jaar & bekken & type & $\begin{array}{l}\text { diepte (NAP) } \\
\end{array}$ & anal diepte & \% droog & $\%$ organisch & type sed & $\%<90 \mu \mathrm{m}$ & sal & type bodem \\
\hline 1 & Schelp-west & 2009 & OS & T0 & 3 & $0-5$ & & & & & & ongestoorde bodem \\
\hline 2 & Schelp-west & 2009 & OS & T0 & 7,5 & $5-10$ & & & & & & ongestoorde bodem \\
\hline 3 & Schelp-west & 2009 & os & T0 & 15 & $>10$ & & & & & & ongestoorde bodem \\
\hline 4 & Schelp-oost & 2009 & os & T0 & 3 & $0-5$ & & & & & & ongestoorde bodem \\
\hline 5 & Schelp-oost & 2009 & os & T0 & 7 & $5-10$ & & & & & & ongestoorde bodem \\
\hline 6 & Schelp-oost & 2009 & os & T0 & 15 & $>10$ & & & & & & ongestoorde bodem \\
\hline 7 & Lok A & 2009 & OS & T0 & 3 & $0-5$ & & & & & & ongestoorde bodem \\
\hline 8 & Lok B & 2009 & os & T0 & 3 & $0-5$ & & & & & & ongestoorde bodem \\
\hline 9 & Lok A & 2009 & OS & T0 & 7 & $5-10$ & & & & & & ongestoorde bodem \\
\hline 10 & Lok B & 2009 & os & T0 & 7 & $5-10$ & & & & & & ongestoorde bodem \\
\hline 11 & Lok A & 2009 & OS & T0 & 15 & $>10$ & & & & & & ongestoorde bodem \\
\hline 12 & Lok B & 2009 & os & T0 & 15 & $>10$ & & & & & & ongestoorde bodem \\
\hline 13 & Zeel-west & 2009 & OS & T0 & 3 & $0-5$ & & & & & & ongestoorde bodem \\
\hline 14 & Zeel-west & 2009 & os & T0 & 7 & $5-10$ & & & & & & ongestoorde bodem \\
\hline 15 & Zeel-west & 2009 & OS & T0 & 15 & $>10$ & & & & & & ongestoorde bodem \\
\hline 16 & Zeel-oost & 2009 & os & T0 & 3 & $0-5$ & & & & & & ongestoorde bodem \\
\hline 17 & Zeel-oost & 2009 & OS & T0 & 7 & $5-10$ & & & & & & ongestoorde bodem \\
\hline 18 & Zeel-oost & 2009 & os & T0 & 15 & $>10$ & & & & & & ongestoorde bodem \\
\hline 19 & Burgh-w & 2010 & OS & $\mathrm{T} 0 / \mathrm{Ref}$ & 5 & $0-5$ & & & & & & ongestoorde bodem \\
\hline 20 & Burgh-w & 2010 & os & To/Ref & 10 & $5-10$ & & & & & & ongestoorde bodem \\
\hline 21 & Burgh-w & 2010 & OS & To/Ref & 15 & $>10$ & & & & & & ongestoorde bodem \\
\hline 22 & Sch-wII & 2010 & os & To/Ref & 3 & $0-5$ & & & & & & ongestoorde bodem \\
\hline 23 & Sch-wII & 2010 & os & To/Ref & 7,5 & $5-10$ & & & & & & ongestoorde bodem \\
\hline 24 & Sch-wII & 2010 & os & To/Ref & 15 & $>10$ & & & & & & ongestoorde bodem \\
\hline 25 & Schelp-oost & 2010 & OS & $\mathrm{T} 1$ & 3 & $0-5$ & & & & & & slib op staalslak \\
\hline 26 & Schelp-oost & 2010 & os & $\mathrm{T} 1$ & 9 & $5-10$ & & & & & & slib op staalslak \\
\hline 27 & Schelp-oost & 2010 & os & $\mathrm{T} 1$ & 15 & $>10$ & & & & & & slib op staalslak, tussen breuksteen \\
\hline 28 & Zeel-oost & 2010 & Os & $\mathrm{T} 1$ & 12 & $>10$ & & & & & & slib op staalslak \\
\hline 29 & Ritthem-west & 2010 & ws & $\mathrm{T} 1$ & 12 & $>10$ & & & & & & slib op staalslak \\
\hline 30 & Borselle & 2010 & WS & To & 3 & $0-5$ & & & & & & ongestoorde bodem \\
\hline 31 & Borselle & 2010 & WS & T0 & 7 & $5-10$ & & & & & & ongestoorde bodem \\
\hline 32 & Borselle & 2010 & ws & T0 & 15 & $>10$ & & & & & & ongestoorde bodem \\
\hline 33 & Ellewout-west & 2010 & ws & T0 & 5,5 & $0-5$ & & & & & & ongestoorde bodem \\
\hline 34 & Ellewout-west & 2010 & WS & T0 & 9,5 & $5-10$ & & & & & & ongestoorde bodem \\
\hline 35 & Ellewout-midden & 2010 & WS & T0 & 7,5 & $5-10$ & & & & & & ongestoorde bodem \\
\hline 36 & Ellewout-midden & 2010 & ws & T0 & 15 & $>10$ & & & & & & ongestoorde bodem \\
\hline 37 & Hoed-zuid & 2010 & ws & T0 & 3 & $0-5$ & & & & & & ongestoorde bodem \\
\hline 38 & Hoed-zuid & 2010 & ws & T0 & 7,5 & $5-10$ & & & & & & ongestoorde bodem \\
\hline 39 & Hoed-zuid & 2010 & ws & T0 & 15 & $>10$ & & & & & & ongestoorde bodem \\
\hline 40 & Hoed-haven & 2010 & WS & T0 & 15 & $>10$ & & & & & & ongestoorde bodem \\
\hline 41 & Hoed-noord & 2010 & ws & T0 & 2,5 & $0-5$ & & & & & & ongestoorde bodem \\
\hline 42 & Hoed-noord & 2010 & WS & T0 & 6,5 & $5-10$ & & & & & & ongestoorde bodem \\
\hline 43 & Hoed-noord & 2010 & ws & T0 & 10,5 & $>10$ & & & & & & ongestoorde bodem \\
\hline 44 & Lok A & 2011 & OS & $\mathrm{T} 2$ & 13,0 & $>10$ & 27,4 & 12,7 & VIII & 70,9 & 30,7 & slib op staalslak \\
\hline 45 & Lok A & 2011 & os & $\mathrm{T} 2$ & 8,0 & $5-10$ & 30,2 & 11,3 & VIII & 85,3 & 30,5 & slib op staalslak \\
\hline 46 & Lok A & 2011 & OS & $\mathrm{T} 2$ & 5,0 & $0-5$ & 29,7 & 10,6 & VIII & 83,5 & 30,5 & slib op staalslak \\
\hline 47 & Lok B & 2011 & os & Ref & 13,0 & oud & 62,8 & 3,6 & $V($ dis $)$ & 22,8 & 30,7 & oude bodem \\
\hline 48 & Lok B & 2011 & OS & $\mathrm{T} 2$ & 12,0 & $>10$ & 38,8 & 9,0 & VIII & 69,3 & 30,7 & slib op staalslak \\
\hline 49 & Lok B & 2011 & os & $\mathrm{T} 2$ & 8,0 & $5-10$ & 38,8 & 9,4 & VIII & 71,9 & 30,5 & slib op staalslak \\
\hline 50 & Zeel-west & 2011 & os & Ref & $\begin{array}{l}14,0 \\
14,0\end{array}$ & oud & 77,2 & 1,2 & $\mathrm{~V}(\mathrm{dis})$ & 14,8 & 30,4 & oude bodem \\
\hline 51 & Zeel-west & 2011 & os & $\mathrm{T} 2$ & 9,0 & $5-10$ & 48,3 & 6,3 & $\mathrm{~V}(\mathrm{dis})$ & 34,8 & 30,4 & slib op staalslak \\
\hline 52 & Zeel-west & 2011 & os & $\mathrm{T} 2$ & 12,0 & $>10$ & 55,7 & 5,1 & $\mathrm{~V}(\mathrm{dis})$ & 10,4 & 30,4 & slib op staals lak \\
\hline 53 & Zeel-west & 2011 & os & $\mathrm{T} 2$ & 6,0 & $0-5$ & 39,8 & 9,2 & VIII & 69,9 & 30,4 & slib op staalslak \\
\hline 54 & Ritthem-midden & 2011 & ws & $\mathrm{T} 2$ & 11,5 & $>10$ & 70,6 & 2,2 & $\mathrm{~V}(\mathrm{dis})$ & 14,1 & $\begin{array}{l}3,4 \\
29,7\end{array}$ & slib op staalslak \\
\hline 55 & Ritthem-midden & 2011 & ws & $\mathrm{T} 2$ & 7,5 & $5-10$ & 73,1 & 1,7 & $\mathrm{~V}(\mathrm{dis})$ & 6,9 & 29,9 & slib op staalslak \\
\hline 56 & Ritthem-west & 2011 & ws & $\mathrm{T} 2$ & 13,5 & $>10$ & 76,3 & 1,7 & $\mathrm{~V}(\mathrm{dis})$ & 14,8 & 30,1 & slib op staalslak \\
\hline 57 & Ritthem-west & 2011 & ws & $\mathrm{T} 2$ & 7,5 & $5-10$ & 76,4 & 1,7 & $\mathrm{~V}(\mathrm{dis})$ & 6,2 & 29,9 & slib op staalslak \\
\hline 58 & R-Ritthem & 2011 & ws & Ref & 13,5 & $>10$ & 79,4 & 0,8 & $\mathrm{v}$ & 2,1 & 30,1 & ongestoorde bodem \\
\hline 59 & R-Ritthem & 2011 & ws & Ref & 7,5 & $5-10$ & 69,7 & 2,6 & $\mathrm{v}$ & 3,9 & 29,9 & ongestoorde bodem \\
\hline 60 & R-Ritthem & 2011 & ws & Ref & 3,0 & $0-5$ & 79,7 & 1,0 & $\mathrm{v}$ & 1,7 & 29,8 & ongestoorde bodem \\
\hline 61 & Schelp-west & 2011 & OS & $\mathrm{T} 2$ & 10,5 & $>10$ & 45,2 & 7,3 & VIII & 49,2 & 30,7 & slib op staalslak \\
\hline 62 & Schelp-west & 2011 & os & $\mathrm{T} 2$ & 7,5 & $5-10$ & 50,6 & 6,6 & $V($ dis $)$ & 28,5 & 30,8 & slib op staalslak \\
\hline 63 & Schelp-west & 2011 & OS & $\mathrm{T} 2$ & 3,5 & $0-5$ & 29,5 & 10,4 & VIII & 90,2 & 30,8 & slib op staalslak, tussen breuksteen \\
\hline 64 & Schelp-midden & 2011 & os & $\mathrm{T} 2$ & 14,8 & $>10$ & 39,3 & 9,3 & VIII & 43,1 & 30,8 & slib op staalslak \\
\hline 65 & Schelp-midden & 2011 & OS & $\mathrm{T} 2$ & 3,5 & $0-5$ & 35,8 & 9,3 & VIII & 76,0 & 30,7 & slib op staalslak, tussen breuksteen \\
\hline 66 & Schelp-oost & 2011 & os & $\mathrm{T} 2$ & 15,8 & $>10$ & 53,0 & 5,2 & VI & 33,6 & 31,0 & slib op staalslak \\
\hline 67 & Schelp-oost & 2011 & os & $\mathrm{T} 2$ & 8,5 & $5-10$ & 44,5 & 6,6 & VIII & 73,7 & 31,0 & slib op staals lak \\
\hline 68 & Schelp-oost & 2011 & os & $\mathrm{T} 2$ & 4,5 & $0-5$ & 37,8 & 7,6 & VIII & 64,7 & 31,0 & slib op staalslak, tussen breuksteen \\
\hline 69 & Kabbelaarsbank & 2011 & WS & Ref & 13,5 & $>10$ & 48,4 & 6,8 & VIII & 53,0 & 22,4 & ongestoorde bodem \\
\hline 70 & Kabbelarsbank & 2011 & ws & Ref & 7,0 & $5-10$ & 57,4 & 5,2 & VIII & 70,9 & 22,4 & ongestoorde bodem \\
\hline 71 & Kabbelaarsbank & 2011 & ws & Ref & 3,5 & $0-5$ & 57,2 & 5,4 & $\mathrm{~V}(\mathrm{dis})$ & 56,5 & 22,4 & ongestoorde bodem \\
\hline 72 & Ossenisse & 2011 & ws & Ref & 14,3 & $>10$ & 80,8 & 0,7 & $\mathrm{~V}$ & 2,9 & 22,4 & ongestoorde bodem \\
\hline 73 & Ossenisse & 2011 & WS & Ref & $\begin{array}{l}14,0,1 \\
10,1\end{array}$ & $5-10$ & 76,3 & 1,1 & $\mathrm{v}$ & 4,0 & 22,4 & ongestoorde bodem \\
\hline 74 & Ossenisse & 2011 & Ws & Ref & 4,5 & $0-5$ & 69,0 & 2,7 & VI & 23,2 & 22,4 & ongestoorde bodem \\
\hline 75 & Ellewout-haven & 2011 & ws & Ref & 16,0 & $>10$ & 80,0 & 1,1 & $\mathrm{~V}(\mathrm{dis})$ & 5,3 & 27,0 & ongestoorde bodem \\
\hline
\end{tabular}




\section{Bijlage 1 (vervolg).}

\begin{tabular}{|c|c|c|c|c|c|c|c|c|c|c|c|c|}
\hline inf nr & locatie & jaar & bekken & type & diepte (NAP) & anal diepte & $\%$ droog & $\%$ organisch & type sed & $\%<90 \mu \mathrm{m}$ & sal & type bodem \\
\hline 76 & Ellewout-haven & 2011 & WS & Ref & 7,0 & $5-10$ & 55,5 & 6,5 & VIII & 56,1 & 26,8 & ongestoorde bodem \\
\hline 77 & Ellewout-haven & 2011 & ws & Ref & 3,5 & $0-5$ & 44,4 & 6,8 & VIII & 85,6 & 26,8 & ongestoorde bodem \\
\hline 78 & Paulinapolder & 2011 & ws & Ref & 15,0 & $>10$ & 69,9 & 2,8 & VIII & 36,9 & 27,0 & ongestoorde bodem \\
\hline 79 & Paulinapolder & 2011 & WS & Ref & 7,5 & $5-10$ & 69,4 & 2,9 & VIII & 34,4 & 26,5 & ongestoorde bodem \\
\hline 80 & Paulinapolder & 2011 & WS & Ref & 3,5 & $0-5$ & 70,2 & 2,8 & VIII & 43,3 & 26,7 & ongestoorde bodem \\
\hline 81 & Slijkplaat & 2011 & ws & Ref & 14,0 & $>10$ & 64,7 & 3,2 & $\mathrm{~V}(\mathrm{dis})$ & 21,3 & 29,2 & ongestoorde bodem \\
\hline 82 & Slijkplaat & 2011 & WS & Ref & 7,0 & $5-10$ & 53,2 & 5,1 & VIII & 58,2 & 29,3 & ongestoorde bodem \\
\hline 83 & Slijkplaat & 2011 & ws & Ref & 3,0 & $0-5$ & 63,2 & 4,0 & $V($ dis $)$ & 46,2 & 29,5 & ongestoorde bodem \\
\hline 84 & Zeel-oost & 2011 & OS & $\mathrm{T} 2$ & 14,5 & $>10$ & 48,7 & 6,7 & $V($ dis $)$ & 26,6 & 30,6 & slib op staalslak \\
\hline 85 & Zeel-oost & 2011 & os & $\mathrm{T} 2$ & 7,0 & $5-10$ & 37,0 & 10,5 & V(dis) & 60,0 & 30,6 & slib op staalslak \\
\hline 86 & Zeel-oost & 2011 & OS & $\mathrm{T} 2$ & 3,5 & $0-5$ & 30,1 & 12,1 & $\mathrm{~V}(\mathrm{dis})$ & 69,4 & 30,6 & slib op staals lak, tussen breuksteen \\
\hline 87 & Zeel-oost & 2011 & os & Ref & 17,0 & oud & 79,0 & 1,1 & $\mathrm{v}$ & 3,5 & 30,4 & oude bodem \\
\hline 88 & Zeel-midden & 2011 & os & Ref & 15,5 & oud & 71,7 & 2,1 & $\mathrm{~V}$ & 13,4 & 30,5 & oude bodem \\
\hline 89 & Zeel-midden & 2011 & os & $\mathrm{T} 2$ & 12,0 & $>10$ & 57,2 & 4,5 & $\mathrm{~V}(\mathrm{dis})$ & 23,1 & 30,5 & slib op staalslak \\
\hline 90 & Zeel-midden & 2011 & os & $\mathrm{T} 2$ & 7,0 & $5-10$ & 31,5 & 11,4 & VIII & 76,0 & 30,6 & slib op staalslak \\
\hline 91 & Zeel-midden & 2011 & os & $\mathrm{T} 2$ & 3,0 & $0-5$ & 34,8 & 9,9 & $\mathrm{~V}(\mathrm{dis})$ & 54,0 & 30,6 & slib op staalslak, tussen breuksteen \\
\hline 92 & Zandhoek & 2011 & os & Ref & 16,0 & $>10$ & 65,1 & 3,2 & VI & 37,0 & 30,8 & ongestoorde bodem \\
\hline 93 & Zandhoek & 2011 & os & Ref & 7,5 & $5-10$ & 53,2 & 5,3 & $\mathrm{VI}$ & 38,6 & 30,8 & ongestoorde bodem \\
\hline 94 & Zandhoek & 2011 & os & Ref & 3,0 & $0-5$ & $\begin{array}{l}34,2 \\
44,4\end{array}$ & 7,8 & VIII & 53,3 & 30,7 & ongestoorde bodem \\
\hline 95 & Zuidbout & 2011 & OS & Ref & 15,0 & $>10$ & 72,3 & 1,9 & $\mathrm{~V}(\mathrm{dis})$ & 36,8 & 30,4 & ongestoorde bodem \\
\hline 96 & Zuidbout & 2011 & os & Ref & 7,5 & 5-10 & 66,0 & 2,9 & VI & 20,0 & 30,3 & ongestoorde bodem \\
\hline 97 & Zuidbout & 2011 & os & Ref & 3,0 & $0-5$ & 77,8 & 1,0 & $\mathrm{v}$ & 3,2 & 30,3 & ongestoorde bodem \\
\hline 98 & Sophiahaven & 2011 & os & Ref & 15,0 & $>10$ & 77,4 & 1,4 & v & 7,3 & 31,5 & ongestoorde bodem \\
\hline 99 & Sophiahaven & 2011 & OS & Ref & 7,5 & 5-10 & 76,8 & 1,5 & $\mathrm{~V}$ & 8,4 & 31,5 & ongestoorde bodem \\
\hline 100 & Sophiahaven & 2011 & OS & Ref & 3,0 & $0-5$ & 73,8 & 1,8 & $\mathrm{~V}$ & 16,7 & 31,3 & ongestoorde bodem \\
\hline 101 & Westbout & 2011 & os & Ref & 15,0 & $>10$ & 76,1 & 1,4 & $\mathrm{v}$ & 4,0 & 31,5 & ongestoorde bodem \\
\hline 102 & Westbout & 2011 & os & Ref & 7,5 & $5-10$ & 79,3 & 0,8 & $\mathrm{v}$ & 3,0 & 31,7 & ongestoorde bodem \\
\hline 103 & Westbout & 2011 & OS & Ref & 3,0 & $0-5$ & 79,1 & 0,8 & $\mathrm{v}$ & 6,1 & 31,7 & ongestoorde bodem \\
\hline 104 & Zierikzee & 2011 & os & Ref & 15,0 & $>10$ & 40,9 & 8,7 & VIII & 75,7 & 30,7 & ongestoorde bodem \\
\hline 105 & Zierikzee & 2011 & os & Ref & 7,5 & 5-10 & 30,8 & 11,0 & VIII & 87,6 & 30,6 & ongestoorde bodem \\
\hline 106 & Zierikzee & 2011 & os & Ref & 4,0 & $0-5$ & 29,0 & 11,1 & VIII & 88,0 & 30,6 & ongestoorde bodem \\
\hline 107 & Katshoek & 2011 & OS & Ref & 15,0 & $>10$ & 70,6 & 2,2 & $\mathrm{VI}$ & 18,0 & 30,8 & ongestoorde bodem \\
\hline 108 & Katshoek & 2011 & os & Ref & 7,5 & $5-10$ & 69,8 & 2,4 & $\mathrm{v}$ & 15,7 & 30,8 & ongestoorde bodem \\
\hline 109 & Katshoek & 2011 & os & Ref & 3,0 & $0-5$ & 68,1 & 2,3 & $\mathrm{VI}$ & 15,5 & 30,7 & ongestoorde bodem \\
\hline 110 & eco-kr-noord & 2011 & os & ecorif & 11,4 & ecorif & 67,1 & 3,0 & $\mathrm{v}$ & 6,9 & 30,4 & slib op staalslak, tussen breuksteen \\
\hline 111 & eco-kr-oost & 2011 & os & ecorif & 13,3 & ecorif & 76,6 & 1,4 & $\mathrm{~V}(\mathrm{dis})$ & 13,6 & 30,3 & $\begin{array}{l}\text { slib op staalslak, tussen breuksteen } \\
\text { (a) }\end{array}$ \\
\hline 112 & eco-kr-zuid & 2011 & os & ecorif & 13,7 & ecorif & 77,0 & 1,3 & $V($ dis $)$ & 10,0 & 30,4 & oude bodem tussen breuksteen \\
\hline 113 & eco-kr-west & 2011 & OS & ecorif & 13,5 & ecorif & 65,5 & 3,5 & $\mathrm{~V}(\mathrm{dis})$ & 11,9 & 30,3 & slib op staals lak, tussen breuksteen \\
\hline 114 & eco-steenhoop & 2011 & os & ecorif & 14,3 & ecorif & 72,9 & 2,0 & $\mathrm{~V}(\mathrm{dis})$ & 13,2 & 30,3 & oude bodem tussen breuksteen \\
\hline 115 & eco-atol-buiten & 2011 & OS & ecorif & 14,0 & ecorif & 74,1 & 1,5 & $\mathrm{~V}$ & $\begin{array}{l}13,2 \\
13,7\end{array}$ & 30,4 & oude bodem tussen breuksteen \\
\hline 116 & eco-atol-binnen & 2011 & os & ecorif & 12,1 & ecorif & 50,5 & 6,0 & $\mathrm{~V}(\mathrm{dis})$ & 60,1 & 30,3 & slib op staalslak, tussen breuksteen \\
\hline 117 & Zeel-west & 2012 & OS & Ref & 14,2 & oud & 73,4 & 1,8 & $\mathrm{~V}(\mathrm{dis})$ & 9,8 & 31,3 & oude bodem \\
\hline 118 & Zeel-west & 2012 & os & $\mathrm{T} 3$ & 10,4 & $>10$ & 47,8 & 6,4 & $V($ dis $)$ & 22,3 & 31,3 & sediment op staalslak \\
\hline 119 & Zeel-west & 2012 & os & $\mathrm{T} 3$ & 9,6 & $5-10$ & 47,7 & 6,3 & VIII & 41,3 & 31,3 & sediment op staalslak \\
\hline 120 & Zeel-west & 2012 & os & $\mathrm{T} 3$ & 4,7 & $0-5$ & 38,2 & 9,4 & VIII & 64,4 & 31,3 & sediment tussen breuksteen op staalslak \\
\hline 121 & Zeel-oost & 2012 & os & Ref & 20,2 & oud & 79,8 & 1,1 & $\mathrm{v}$ & 5,4 & 31,3 & oude bodem \\
\hline 122 & Zeel-oost & 2012 & OS & $\mathrm{T} 3$ & 15,8 & $>10$ & 52,2 & 5,7 & $\mathrm{~V}$ & 15,4 & 31,3 & sediment op staalslak \\
\hline 123 & Zeel-oost & 2012 & os & $\mathrm{T} 3$ & 8,1 & $5-10$ & 66,7 & 2,9 & $\mathrm{v}$ & 13,6 & 31,3 & mogelijk oude bodem bestort met gebroken breul \\
\hline 124 & Zeel-oost & 2012 & OS & T3 & $\frac{0,1}{4,4}$ & $0-5$ & 37,6 & 9,9 & VIII & $\begin{array}{ll}1,0 \\
63,4\end{array}$ & 31,3 & sediment tussen breuksteen op staalslak \\
\hline 125 & Zeel-midden & 2012 & os & Ref & 16,4 & oud & 74,2 & 1,6 & $V($ dis $)$ & 8,6 & 31,6 & oude bodem \\
\hline 126 & Zeel-midden & 2012 & Os & $\mathrm{T} 3$ & 13,1 & $>10$ & 72,6 & 1,9 & $\mathrm{~V}(\mathrm{dis})$ & 17,5 & 31,6 & sediment op staalslak \\
\hline 127 & Zeel-midden & 2012 & os & $\mathrm{T} 3$ & 8,0 & $5-10$ & 35,6 & 9,2 & $V($ dis $)$ & 63,0 & 31,6 & sediment tussen breuksteen op staalslak \\
\hline 128 & Zeel-midden & 2012 & OS & $\mathrm{T} 3$ & 6,1 & $0-5$ & 38,5 & 8,2 & $\mathrm{~V}(\mathrm{dis})$ & 38,8 & 31,7 & sediment tussen breuksteen op staalslak \\
\hline 129 & Zuidbout & 2012 & os & Ref & 16,0 & $>10$ & 50,3 & 5,6 & $\mathrm{VI}$ & 31,3 & 32,1 & ongestoorde bodem \\
\hline 130 & Zuidbout & 2012 & OS & Ref & 7,8 & $5-10$ & 66,4 & 2,5 & $\mathrm{VI}$ & 31,8 & 32,2 & ongestoorde bodem \\
\hline 131 & Zuidbout & 2012 & os & Ref & 4,4 & $0-5$ & 65,7 & 2,9 & $\mathrm{v}$ & 25,1 & 32,2 & ongestoorde bodem \\
\hline 132 & Westbout & 2012 & OS & Ref & $\begin{array}{l}14,9 \\
149\end{array}$ & $>10$ & 74,4 & 1,7 & $\mathrm{~V}(\mathrm{dis})$ & 20,7 & 33,3 & ongestoorde bodem \\
\hline 133 & Westbout & 2012 & os & Ref & 7,5 & $5-10$ & 76,2 & 1,3 & $\mathrm{~V}$ & 9,3 & 33,2 & ongestoorde bodem \\
\hline 134 & Westbout & 2012 & os & Ref & 4,0 & $0-5$ & 63,2 & 3,3 & $\mathrm{~V}(\mathrm{dis})$ & 15,2 & 33,2 & ongestoorde bodem \\
\hline 135 & Zeel-west & 2013 & os & Ref & 12,2 & oud & 58,5 & 4,1 & V(dis) & 38,9 & 29,1 & oude bodem \\
\hline 136 & Zeel-west & 2013 & os & $\mathrm{T} 4$ & 10,6 & $>10$ & 43,7 & 7,7 & VIII & 51,6 & 29,1 & sediment op staalslak \\
\hline 137 & Zeel-west & 2013 & os & $\mathrm{T} 4$ & 7,0 & $5-10$ & 38,2 & 9,3 & VIII & 63,6 & 29,1 & sediment op staalslak \\
\hline 138 & Zeel-west & 2013 & os & T4 & 5,0 & $0-5$ & $\begin{array}{l}0,2 \\
35,4\end{array}$ & 9,7 & $\mathrm{~V}(\mathrm{dis})$ & 59,0 & 29,1 & sediment tussen breuksteen op staalslak \\
\hline 139 & Zeel-midden & 2013 & os & Ref & 16,1 & oud & 72,2 & 1,9 & V(dis) & 11,6 & 29,1 & oude bodem \\
\hline 140 & Zeel-midden & 2013 & OS & $\mathrm{T} 4$ & 10,8 & $>10$ & 53,1 & 5,6 & $\mathrm{~V}(\mathrm{dis})$ & $\begin{array}{l}3,0,5 \\
32,5\end{array}$ & 29,2 & sediment op staalslak \\
\hline 141 & Zeel-midden & 2013 & os & $\mathrm{T} 4$ & 7,5 & $5-10$ & 36,7 & 10,3 & VIII & 71,4 & 29,2 & sediment tussen breuksteen op staalslak \\
\hline $\begin{array}{l}141 \\
142\end{array}$ & Zeel-midden & 2013 & os & T4 & 5,3 & $0-5$ & 40,2 & $\begin{array}{l}8,5 \\
8,9\end{array}$ & $\mathrm{~V}(\mathrm{dis})$ & $\begin{array}{l}5,4,6 \\
52,5\end{array}$ & 29,3 & sediment tussen breuksteen op staalslak \\
\hline 143 & Zeel-oost & 2013 & os & Ref & 19,1 & oud & 68,8 & 2,7 & $\mathrm{~V}(\mathrm{dis})$ & 11,0 & 29,6 & oude bodem \\
\hline 144 & Zeel-oost & 2013 & os & $\mathrm{T} 4$ & 15,0 & $>10$ & 54,7 & 5,2 & V(dis) & 38,4 & 29,5 & sediment op staalslak \\
\hline 145 & Zeel-oost & 2013 & OS & $\mathrm{T} 4$ & 8,1 & 5-10 & 65,3 & 3,2 & $\mathrm{~V}(\mathrm{dis})$ & 30,9 & 29,5 & sediment op staalslak \\
\hline 146 & Zeel-oost & 2013 & os & $\mathrm{T} 4$ & 4,2 & $0-5$ & 37,9 & $\begin{array}{l}9,2 \\
9,5\end{array}$ & VIII & 74,4 & 29,6 & sediment tussen breuksteen op staalslak \\
\hline 147 & Zierikzee & 2013 & os & T0 & 15,5 & $>10$ & 31,0 & 11,3 & VIII & 73,0 & 29,3 & ongestoorde bodem \\
\hline 148 & Zierikzee & 2013 & os & T0 & 7,6 & $5-10$ & 30,0 & 10,9 & VIII & 77,2 & 29,3 & ongestoorde bodem \\
\hline 149 & Zierikzee & 2013 & os & T0 & 4,4 & $0-5$ & 57,2 & 5,3 & $\mathrm{~V}(\mathrm{dis})$ & 43,6 & 29,3 & ongestoorde bodem \\
\hline 150 & Zuidbout & 2013 & os & Ref & 15,3 & $>10$ & 67,2 & 2,5 & $\mathrm{~V}$ & 29,9 & 29,0 & ongestoorde bodem \\
\hline
\end{tabular}




\section{Bijlage 1 (vervolg).}

\begin{tabular}{|c|c|c|c|c|c|c|c|c|c|c|c|c|}
\hline $\inf \mathrm{nr}$ & locatie & jaar & bekken & type & diepte (NAP) & anal diepte & $\%$ droog & \% organisch & type sed & $\%<90 \mu \mathrm{m}$ & sal & type bodem \\
\hline 151 & Zuidbout & 2013 & OS & Ref & 7,5 & $5-10$ & 68,7 & 2,2 & $\mathrm{~V}$ & 31,5 & 29,1 & ongestoorde bodem \\
\hline 152 & Zuidbout & 2013 & OS & Ref & 4,7 & $0-5$ & 77,0 & 1,1 & $\mathrm{~V}$ & 7,2 & 29,1 & ongestoorde bodem \\
\hline 153 & Westbout & 2013 & os & Ref & 15,0 & $>10$ & 79,2 & 0,9 & V & 17,4 & 30,2 & ongestoorde bodem \\
\hline 154 & Westbout & 2013 & OS & Ref & 7,2 & $5-10$ & 75,6 & 1,6 & V & 10,0 & 30,2 & ongestoorde bodem \\
\hline 155 & Westbout & 2013 & OS & Ref & 4,0 & $0-5$ & 50,2 & 6,1 & $\mathrm{~V}$ & 17,7 & 30,2 & ongestoorde bodem \\
\hline BfN 1 & Sch-wII & 2014 & os & $\mathrm{BfN} / \mathrm{T0}$ & $15.0 \mathrm{~m}$ & $>10$ & 58,0 & 4,8 & VI & 25,1 & & ongestoorde bodem \\
\hline BfN 2 & Sch-wII & 2014 & OS & $\mathrm{BfN} / \mathrm{T} 0$ & $10.0 \mathrm{~m}$ & $5-10$ & 59,6 & 4,3 & VI & 27,4 & & ongestoorde bodem \\
\hline BfN 3 & Sch-wII & 2014 & OS & $\mathrm{BfN} / \mathrm{T} 0$ & $3.5 \mathrm{~m}$ & $0-5$ & 54,9 & 6,2 & VI & 41,5 & & ongestoorde bodem \\
\hline $\operatorname{linf} 156$ & Sch-w & 2014 & OS & T5 & $13.8 \mathrm{~m}$ & $>10$ & 67,7 & 2,8 & VI & 22,4 & & sediment op staalslak \\
\hline $\inf 157$ & Sch-w & 2014 & OS & T5 & $7.9 \mathrm{~m}$ & $5-10$ & 64,5 & 3,1 & VI & 34,7 & & sediment op staalslak \\
\hline $\inf 158$ & Sch-w & 2014 & OS & $\mathrm{T} 5$ & $4.0 \mathrm{~m}$ & $0-5$ & 44,3 & 6,6 & VIII & 48,9 & & sediment op staalslak \\
\hline $\operatorname{linf} 159$ & Sch-m & 2014 & OS & T5 & $15.0 \mathrm{~m}$ & $>10$ & 53,6 & 5,8 & VIII & 41,2 & & sediment tussen breuksteen op staalslak \\
\hline $\inf 160$ & Sch-m & 2014 & OS & T5 & $7.5 \mathrm{~m}$ & $5-10$ & 35,4 & 9,9 & VIII & 66,7 & & sediment tussen breuksteen op staalslak \\
\hline $\inf 161$ & Sch-m & 2014 & os & $\mathrm{T} 5$ & $3.5 \mathrm{~m}$ & $0-5$ & 39,0 & 9,5 & VIII & 71,7 & & sediment tussen breuksteen op staalslak \\
\hline $\inf 162$ & Sch-o & 2014 & OS & T5 & $15.0 \mathrm{~m}$ & $>10$ & 46,1 & 7,4 & $\mathrm{v}$ & 30,1 & & sediment op staalslak \\
\hline $\inf 163$ & Sch-o & 2014 & os & $\mathrm{T} 5$ & $7.5 \mathrm{~m}$ & $5-10$ & 37,7 & 9,2 & VIII & 61,9 & & sediment op staalslak \\
\hline $\inf 164$ & Sch-o & 2014 & os & $\mathrm{T} 5$ & $3.5 \mathrm{~m}$ & $0-5$ & 40,0 & 9,0 & VIII & 77,0 & & sediment op staalslak \\
\hline $\inf 165$ & Zeel-w & 2014 & os & Ref & $12.0 \mathrm{~m}$ & oud & 74,0 & 2,0 & $\mathrm{~V}$ (dis) & 8,0 & & oude bodem \\
\hline $\inf 166$ & Zeel-w & 2014 & os & $\mathrm{T} 5$ & $10.1 \mathrm{~m}$ & $>10$ & 54,5 & 6,3 & $V($ dis $)$ & 23,4 & & sediment op staalslak \\
\hline $\inf 167$ & Zeel-w & 2014 & os & T5 & $7.4 \mathrm{~m}$ & $5-10$ & 45,1 & 8,4 & VIII & 47,0 & & sediment op staalslak \\
\hline $\inf 168$ & Zeel-w & 2014 & os & $\mathrm{T} 5$ & $4.3 \mathrm{~m}$ & $0-5$ & 33,6 & 11,9 & VIII & 61,9 & & sediment tussen breuksteen op staalslak \\
\hline inf 169 & Zeel-o & 2014 & os & Ref & $21.4 \mathrm{~m}$ & oud & 78,6 & 1,7 & $\mathrm{v}$ & 7,6 & & oude bodem \\
\hline $\inf 170$ & Zeel-o & 2014 & OS & T5 & $14.8 \mathrm{~m}$ & $>10$ & 54,9 & 5,5 & $V($ dis $)$ & 32,4 & & sediment op staals lak \\
\hline $\inf 171$ & Zeel-o & 2014 & os & $\mathrm{T} 5$ & $7.8 \mathrm{~m}$ & $5-10$ & 54,9 & 5,1 & VIII & 42,1 & & sediment op staalslak \\
\hline $\inf 172$ & Zeel-o & 2014 & OS & $\mathrm{T} 5$ & $4.1 \mathrm{~m}$ & $0-5$ & 31,9 & 12,1 & $\mathrm{~V}$ (dis) & 61,8 & & sediment tussen breuksteen op staalslak \\
\hline $\inf 173$ & Westbout & 2014 & os & Ref & $15.0 \mathrm{~m}$ & $>10$ & 75,6 & 1,7 & $\mathrm{v}$ & 3,4 & & ongestoorde bodem \\
\hline $\inf 174$ & Westbout & 2014 & os & Ref & $7.5 \mathrm{~m}$ & $5-10$ & 81,4 & 0,8 & $\mathrm{~V}$ & 2,4 & & ongestoorde bodem \\
\hline $\inf 175$ & Westbout & 2014 & os & Ref & $3.5 \mathrm{~m}$ & $0-5$ & 79,6 & 0,8 & $\mathrm{~V}$ & 7,6 & & ongestoorde bodem \\
\hline $\inf 176$ & Rit-o & 2014 & ws & $\mathrm{T} 5$ & $6.4 \mathrm{~m}$ & $5-10$ & 53,5 & 5,4 & $V($ dis $)$ & 25,1 & & sediment tussen breuksteen op staalslak \\
\hline $\inf 177$ & Rit-o & 2014 & wS & T5 & $4.3 \mathrm{~m}$ & $0-5$ & 63,9 & 3,9 & $V($ dis $)$ & 20,9 & & sediment tussen breuksteen op staalslak \\
\hline $\inf 178$ & Rit-m & 2014 & ws & T5 & $13.6 \mathrm{~m}$ & $>10$ & 79,3 & 1,1 & $\mathrm{~V}(\mathrm{dis})$ & 6,3 & & sediment tussen breuksteen op staalslak \\
\hline $\inf 179$ & Rit-m & 2014 & ws & T5 & $7.5 \mathrm{~m}$ & $5-10$ & 75,6 & 1,7 & $\mathrm{~V}$ (dis) & 13,1 & & sediment tussen breuksteen op staalslak \\
\hline inf 180 & Ref-Rit & 2014 & ws & Ref & $13.6 \mathrm{~m}$ & $>10$ & 80,4 & 0,7 & $V($ dis $)$ & 2,4 & & ongestoorde bodem \\
\hline $\inf 181$ & Ref-Rit & 2014 & ws & Ref & $7.6 \mathrm{~m}$ & $5-10$ & 81,1 & 0,8 & $\mathrm{v}$ & 1,3 & & ongestoorde bodem \\
\hline $\inf 182$ & Ref-Rit & 2014 & ws & Ref & $3.7 \mathrm{~m}$ & $0-5$ & 81,0 & 0,8 & $\mathrm{v}$ & 0,6 & & ongestoorde bodem \\
\hline $\inf 183$ & Rit-w & 2014 & ws & $\mathrm{T} 5$ & $15.0 \mathrm{~m}$ & $>10$ & 69,7 & 2,4 & $V($ dis $)$ & 11,5 & & sediment op staalslak \\
\hline $\inf 184$ & Rit-w & 2014 & ws & T5 & $7.6 \mathrm{~m}$ & $5-10$ & 80,1 & 1,1 & $\mathrm{~V}(\mathrm{dis})$ & 12,5 & & sediment tussen breuksteen op staalslak \\
\hline $\inf 185$ & Rit-w & 2014 & ws & T5 & $3.6 \mathrm{~m}$ & $0-5$ & 79,7 & 1,0 & $\mathrm{v}$ & 4,2 & & sediment tussen breuksteen op staalslak \\
\hline $\operatorname{linf} 186$ & Gorishoek & 2014 & OS & Ref & $15.1 \mathrm{~m}$ & $>10$ & 68,7 & 2,3 & VI & 18,3 & & ongestoorde bodem \\
\hline $\inf 187$ & Gorishoek & 2014 & os & Ref & $7.6 \mathrm{~m}$ & $5-10$ & 65,0 & 2,9 & VI & 23,6 & & ongestoorde bodem \\
\hline $\inf 188$ & Gorishoek & 2014 & os & Ref & $3.6 \mathrm{~m}$ & $0-5$ & 75,2 & 1,4 & VI & 15,4 & & ongestoorde bodem \\
\hline $\inf 189$ & Zeel-m & 2014 & os & Ref & $14.4 \mathrm{~m}$ & oud & 71,1 & 2,5 & $\mathrm{~V}$ & 15,1 & & oude bodem \\
\hline $\inf 190$ & Zeel-m & 2014 & os & $\mathrm{T} 5$ & $12.5 \mathrm{~m}$ & $>10$ & 57,2 & 4,7 & $\mathrm{~V}(\mathrm{dis})$ & 24,9 & & sediment op staalslak \\
\hline $\inf 191$ & Zeel-m & 2014 & os & $\mathrm{T} 5$ & $7.6 \mathrm{~m}$ & $5-10$ & 48,3 & 7,0 & VIII & 54,4 & & sediment tussen breuksteen op staalslak \\
\hline inf 192 & Zeel-m & 2014 & os & $\mathrm{T} 5$ & $3.8 \mathrm{~m}$ & $0-5$ & 45,6 & 7,9 & $\mathrm{~V}$ (dis) & 41,5 & & sediment tussen breuksteen op staalslak \\
\hline $\inf 193$ & Zuidbout & 2014 & OS & Ref & $15.0 \mathrm{~m}$ & $>10$ & 72,8 & 1,8 & $\mathrm{~V}$ & 19,7 & & ongestoorde bodem \\
\hline $\inf 194$ & Zuidbout & 2014 & OS & Ref & $7.6 \mathrm{~m}$ & $5-10$ & 59,3 & 4,5 & $\mathrm{~V}$ & 24,2 & & ongestoorde bodem \\
\hline $\inf 195$ & Zuidbout & 2014 & OS & Ref & $3.6 \mathrm{~m}$ & $0-5$ & 76,0 & 1,2 & $\mathrm{~V}$ & 4,2 & & ongestoorde bodem \\
\hline inf 196 & Wem-w & 2014 & os & T0 & $30.3 \mathrm{~m}$ & 30 & 70,8 & 2,4 & VI & 24,7 & & ongestoorde bodem \\
\hline $\inf 197$ & Hoed-h & 2014 & ws & $\mathrm{T} 3$ & $13.3 \mathrm{~m}$ & $>10$ & 52,0 & 5,3 & VIII & 45,7 & & sediment op staalslak \\
\hline $\inf 198$ & Hoed-h & 2014 & ws & $\mathrm{T} 3$ & $7.6 \mathrm{~m}$ & $5-10$ & 50,6 & 5,7 & VIII & 57,5 & & sediment op staalslak \\
\hline $\inf 199$ & Hoed-h & 2014 & ws & $\mathrm{T} 3$ & $3.5 \mathrm{~m}$ & $0-5$ & 56,7 & 4,4 & VIII & 54,9 & & sediment tussen breuksteen op staalslak \\
\hline $\inf 200$ & Hoed-n & 2014 & WS & $\mathrm{T} 3$ & $14.1 \mathrm{~m}$ & $>10$ & 65,2 & 3,0 & VIII & 37,2 & & sediment op staalslak \\
\hline $\operatorname{linf} 201$ & Hoed-n & 2014 & ws & $\mathrm{T} 3$ & $7.6 \mathrm{~m}$ & $5-10$ & 57,1 & 4,2 & VIII & 47,2 & & sediment op staalslak \\
\hline $\inf 202$ & Hoed-n & 2014 & ws & $\mathrm{T} 3$ & $3.7 \mathrm{~m}$ & $0-5$ & 43,9 & 6,7 & VIII & 69,0 & & sediment tussen breuksteen op staalslak \\
\hline $\inf 203$ & Kapb & 2014 & ws & Ref & $14.5 \mathrm{~m}$ & $>10$ & 47,4 & 6,4 & VIII & 62,4 & & ongestoorde bodem \\
\hline $\inf 204$ & Kapb & 2014 & ws & Ref & $7.4 \mathrm{~m}$ & $5-10$ & 58,2 & 4,7 & VIII & 57,0 & & ongestoorde bodem \\
\hline $\inf 205$ & Kapb & 2014 & ws & Ref & $3.4 \mathrm{~m}$ & $0-5$ & 50,7 & 5,8 & VIII & 87,0 & & ongestoorde bodem \\
\hline $\inf 206$ & Wem-o & 2014 & os & T0 & $15.3 \mathrm{~m}$ & $>10$ & 59,5 & 3,9 & VI & 38,9 & & ongestoorde bodem \\
\hline $\inf 207$ & Wem-o & 2014 & os & T0 & $7.9 \mathrm{~m}$ & $5-10$ & 53,8 & 5,1 & VI & 30,7 & & ongestoorde bodem \\
\hline $\inf 208$ & Wem-o & 2014 & OS & T0 & $4.0 \mathrm{~m}$ & $0-5$ & 52,9 & 4,9 & VIII & 49,7 & & ongestoorde bodem \\
\hline $\inf 209$ & Wem-w & 2014 & OS & T0 & $15.0 \mathrm{~m}$ & $>10$ & 55,5 & 4,8 & VI & 30,4 & & ongestoorde bodem \\
\hline $\inf 210$ & Wem-w & 2014 & OS & T0 & $7.6 \mathrm{~m}$ & $5-10$ & 68,2 & 2,5 & VI & 15,0 & & ongestoorde bodem \\
\hline $\inf 211$ & Wem-w & 2014 & OS & T0 & $3.6 \mathrm{~m}$ & $0-5$ & 64,0 & 3,4 & VI & 19,3 & & ongestoorde bodem \\
\hline $\inf 212$ & Zeelandbrug-west & 2015 & os & Ref & 11,7 & oud & 42,9 & 9,6 & $V($ dis $)$ & 29,6 & & oude bodem \\
\hline $\inf 213$ & Zeelandbrug-west & 2015 & os & T6 & 9,6 & $>10$ & 61,0 & 4,1 & $\mathrm{~V}(\mathrm{dis})$ & 37,5 & & bodem op staalslakken \\
\hline $\inf 214$ & Zeelandbrug-west & 2015 & os & T6 & 7,2 & $5-10$ & 48,8 & 6,5 & VIII & 39,8 & & bodem op staalslakken \\
\hline inf 215 & Zeelandbrug-west & 2015 & os & $\mathrm{T} 6$ & 4,1 & $0-5$ & 35,2 & 11,0 & $\mathrm{~V}(\mathrm{dis})$ & 52,5 & & bodem tussen breuksteen \\
\hline $\inf 216$ & Zeelandbrug-midden & 2015 & OS & Ref & 16,3 & oud & 57,7 & 5,1 & $\mathrm{~V}$ (dis) & 33,8 & & oude bodem \\
\hline $\inf 217$ & Zeelandbrug-midden & 2015 & os & T6 & 12,1 & $>10$ & 70,5 & 2,9 & $V($ dis $)$ & 28,8 & & bodem op staalslakken \\
\hline $\inf 218$ & Zeelandbrug-midden & 2015 & OS & T6 & 7,7 & $5-10$ & 47,1 & 6,6 & $V($ dis $)$ & 37,3 & & bodem op staalslakken \\
\hline inf 219 & Zeelandbrug-midden & 2015 & OS & $\mathrm{T} 6$ & 4,5 & $0-5$ & 42,0 & 8,3 & $\mathrm{~V}(\mathrm{dis})$ & 41,9 & & bodem tussen breuksteen \\
\hline
\end{tabular}




\section{Bijlage 1 (vervolg).}

\begin{tabular}{|c|c|c|c|c|c|c|c|c|c|c|c|c|}
\hline $\inf n \mathrm{nr}$ & locatie & jaar & bekken & type & diepte (NAP) & $\begin{array}{l}\text { anal diepte } \\
\text { a }\end{array}$ & $\%$ droog & \% organisch & type sed & $\%<90 \mu \mathrm{m}$ & sal & type bodem \\
\hline $\inf 220$ & Zeelandbrug-oost & 2015 & OS & T6 & 6,8 & $5-10$ & 40,7 & 8,5 & $\mathrm{~V}(\mathrm{dis})$ & 52,7 & & bodem op staalslakken \\
\hline $\inf 221$ & Zeelandbrug-oost & 2015 & OS & T6 & 4,0 & $0-5$ & 43,0 & 8,8 & VIII & 49,0 & & bodem tussen breuksteen \\
\hline $\inf 222$ & Zeelandbrug-oost & 2015 & os & Ref & 19,5 & oud & 75,1 & 1,4 & $\mathrm{~V}(\mathrm{dis})$ & 10,4 & & oude bodem \\
\hline inf 223 & Zeelandbrug-oost & 2015 & OS & T6 & 13,9 & $>10$ & 53,5 & 5,5 & $\mathrm{~V}(\mathrm{dis})$ & 36,8 & & bodem op staalslakken \\
\hline $\inf 224$ & Zuidbout & 2015 & os & Ref & 13,4 & $>10$ & 74,7 & 1,5 & $\mathrm{v}$ & 13,2 & & ongestoorde bodem \\
\hline $\inf 225$ & Zuidbout & 2015 & os & Ref & 7,4 & $5-10$ & 72,3 & 1,7 & $\mathrm{v}$ & 16,4 & & ongestoorde bodem \\
\hline $\inf 226$ & Zuidbout & 2015 & OS & Ref & 4,1 & $0-5$ & 78,6 & 0,8 & $\mathrm{~V}$ & 7,8 & & ongestoorde bodem \\
\hline $\inf 227$ & Lokkersnol & 2015 & OS & Ref & 16,1 & oud & 59,2 & 4,8 & $V($ dis $)$ & 44,2 & & oude bodem \\
\hline $\inf 228$ & Westbout & 2015 & OS & Ref & 15,2 & $>10$ & 42,2 & 8,8 & $V($ dis $)$ & 91,6 & & ongestoorde bodem \\
\hline $\inf 229$ & Westbout & 2015 & OS & Ref & 8,2 & $5-10$ & 77,3 & 1,2 & $\mathrm{~V}$ & 7,2 & & ongestoorde bodem \\
\hline $\inf 230$ & Westbout & 2015 & OS & Ref & 4,3 & $0-5$ & 78,9 & 0,9 & $\mathrm{v}$ & 5,8 & & ongestoorde bodem \\
\hline $\inf 231$ & Lokkersnol & 2015 & OS & $\mathrm{T} 6$ & 12,1 & $>10$ & 58,8 & 3,8 & $V($ dis $)$ & 21,9 & & bodem op staalslakken \\
\hline $\inf 232$ & Lokkersnol & 2015 & OS & T6 & 8,3 & $5-10$ & 54,9 & 5,4 & VIII & 62,2 & & bodem op staalslakken \\
\hline $\inf 233$ & Lokkersnol & 2015 & OS & T6 & 4,3 & $0-5$ & 60,9 & 3,8 & $V($ dis $)$ & 40,0 & & bodem tussen breuksteen \\
\hline BfN 4 & Sch-wII-west-mid & 2016 & os & $\mathrm{T} 2$ & 7,5 & $5-10$ & 40,3 & 8,0 & VIII & 57,3 & & bodem op zeegrind, tussen riffen \\
\hline BfN 5 & Sch-wII-west-mid & 2016 & OS & $\mathrm{T} 2$ & 4,5 & $0-5$ & 38,1 & 8,9 & VIII & 65,4 & & bodem op zeegrind, tussen riffen \\
\hline BfN 6 & Sch-wII-oost & 2016 & OS & $\mathrm{T} 2$ & 14,2 & $>10$ & 47,5 & 6,9 & VIII & 58,9 & & bodem op zeegrind, tussen riffen \\
\hline BfN 7 & Sch-wII-oost & 2016 & OS & $\mathrm{T} 2$ & 4,7 & $0-5$ & 39,3 & 8,0 & VIII & 76,5 & & bodem op zeegrind, tussen riffen \\
\hline BfN 8 & Sch-wII-oost & 2016 & OS & $\mathrm{T} 2$ & 13,4 & $>10$ & 35,1 & 10,0 & VIII & 83,3 & & bodem op zeegrind, tussen riffen \\
\hline BfN 9 & Sch-wII-oost & 2016 & OS & $\mathrm{T} 2$ & 4,7 & $0-5$ & 34,4 & 9,5 & VIII & 83,9 & & bodem op zeegrind, tussen riffen \\
\hline BfN 10 & Sch-wII-west-mid & 2016 & OS & T2 & 7,5 & $5-10$ & 49,7 & 5,8 & VIII & 48,6 & & bodem op zeegrind, tussen riffen \\
\hline BfN 11 & Sch-wII-west-mid & 2016 & OS & $\mathrm{T} 2$ & 3,5 & $0-5$ & 33,3 & 9,8 & VIII & 73,9 & & bodem op zeegrind, tussen riffen \\
\hline $\inf 234$ & Sch-wII-mid-oost & 2016 & OS & $\mathrm{T} 2$ & 15,5 & $>10$ & 63,0 & 4,5 & VIII & 39,9 & & bodem op zeegrind, tussen riffen \\
\hline $\inf 235$ & Sch-wII-mid-oost & 2016 & os & $\mathrm{T} 2$ & 8,5 & $5-10$ & 38,3 & 9,1 & VIII & 92,5 & & bodem op zeegrind, tussen riffen \\
\hline $\inf 236$ & Sch-wII-mid-oost & 2016 & os & $\mathrm{T} 2$ & 4,7 & $0-5$ & 33,0 & 10,3 & VIII & 76,7 & & bodem op zeegrind, tussen riffen \\
\hline $\inf 237$ & Schelphoek-west & 2016 & OS & $\mathrm{T} 7$ & 15,5 & $>10$ & 64,5 & 3,6 & $V($ dis $)$ & 21,1 & & bodem op staalslakken \\
\hline $\inf 238$ & Schelphoek-west & 2016 & OS & $\mathrm{T} 7$ & 7,5 & $5-10$ & 49,8 & 5,6 & $V($ dis $)$ & 46,8 & & bodem op staalslakken \\
\hline $\inf 239$ & Schelphoek-west & 2016 & OS & $\mathrm{T} 7$ & 4,0 & $0-5$ & 35,3 & 10,3 & VIII & 84,7 & & bodem op staalslakken \\
\hline $\inf 240$ & Zierikzee & 2016 & os & $\mathrm{T} 2$ & 13,5 & $>10$ & 41,0 & 8,1 & VIII & 67,4 & & bodem op zeegrind \\
\hline $\inf 241$ & Zierikzze & 2016 & OS & $\mathrm{T} 2$ & 11,4 & $5-10$ & 36,3 & 10,1 & VIII & 77,5 & & bodem op zeegrind \\
\hline $\inf 242$ & Zierikzee & 2016 & OS & $\mathrm{T} 2$ & 6,0 & $0-5$ & 28,3 & 11,7 & VIII & 80,0 & & bodem op zeegrind \\
\hline $\inf 243$ & Burghsluis & 2016 & OS & $\mathrm{T} 2$ & 11,0 & $>10$ & 64,3 & 3,3 & VI & 12,6 & & bodem op zeegrind \\
\hline $\operatorname{linf} 244$ & Burghsluis & 2016 & os & $\mathrm{T} 2$ & 7,5 & $5-10$ & 63,4 & 3,6 & VI & 25,7 & & bodem op zeegrind \\
\hline inf 245 & Burghsluis & 2016 & OS & $\mathrm{T} 2$ & 4,0 & $0-5$ & 39,0 & 8,4 & VIII & 65,4 & & bodem op zeegrind \\
\hline $\inf 246$ & Schelphoek-oost & 2016 & OS & Ref & 15,0 & $>10$ & 65,8 & 3,3 & VI & 28,4 & & ongestoorde bodem \\
\hline $\inf 247$ & Schelphoek-oost & 2016 & os & Ref & 7,5 & $5-10$ & 62,0 & 4,0 & VI & 22,9 & & ongestoorde bodem \\
\hline $\inf 248$ & Schelphoek-oost & 2016 & OS & Ref & 4,8 & $0-5$ & 59,3 & 4,5 & VIII & 42,4 & & ongestoorde bodem \\
\hline $\inf 249$ & Schelphoek-midden & 2016 & os & $\mathrm{T} 7$ & 15,9 & $>10$ & 59,6 & 4,6 & VIII & 37,7 & & slib tussen breuksteen op staalslakken \\
\hline vv 1 & Burghsluis & 2016 & OS & & 19,9 & & 57,7 & 5,3 & $V($ dis $)$ & 33,3 & & bodem op zeegrind \\
\hline $\mathrm{vv} 2$ & Burghsluis & 2016 & OS & & 29,0 & & 55,3 & 5,2 & $V($ dis $)$ & 37,0 & & bodem op zeegrind \\
\hline $\mathrm{vv} 3$ & Burghsluis & 2016 & OS & & 34,8 & & 67,3 & 2,6 & $\mathrm{v}$ & 22,7 & & bodem op zeegrind \\
\hline $\mathrm{vv} 4$ & Schelphoek-west & 2016 & os & & 22,6 & & 76,6 & 2,1 & VIII & 34,3 & & bodem op staals lakken \\
\hline vv 5 & Schelphoek-west & 2016 & OS & & 29,7 & & 63,9 & 3,9 & V(dis) & 26,9 & & bodem op staalslakken \\
\hline vv 6 & Schelphoek-west & 2016 & OS & & 34,4 & & 45,6 & 8,7 & VIII & 34,5 & & bodem op staals lakken \\
\hline vv 8 & Schelphoek-midden & 2016 & OS & & 45,7 & & 37,9 & 9,8 & VIII & 47,9 & & bodem op breuksteen \\
\hline vv 9 & Schelphoek-oost & 2016 & OS & & 32,0 & & 46,9 & 8,5 & VIII & 48,0 & & bodem op staalslakken \\
\hline $\mathrm{vv} 10$ & Schelphoek-oost & 2016 & OS & & 38,5 & & 47,1 & 8,3 & VIII & 40,9 & & bodem op staals lakken \\
\hline vv 11 & Schelphoek-oost & 2016 & os & & 34,8 & & 48,7 & 7,0 & VIII & 42,1 & & bodem op staalslakken \\
\hline vv 12 & Schelphoek-oost & 2016 & OS & & 40,2 & & 52,8 & 6,2 & $V($ dis $)$ & 39,6 & & bodem op staalslakken \\
\hline vv 13 & Schelphoek-oost & 2016 & os & & 40,4 & & 40,9 & 9,1 & VIII & 38,2 & & bodem op staalslakken \\
\hline vv 15 & Schelphoek-Referentie & 2016 & OS & & 21,9 & & 73,3 & 2,3 & $\mathrm{~V}$ & 17,8 & & oude bodem \\
\hline vv 16 & Schelphoek-Referentie & 2016 & os & & 30,6 & & 68,9 & 3,1 & VI & 27,6 & & oude bodem \\
\hline vv 17 & Schelphoek-Referentie & 2016 & OS & & 28,8 & & 73,3 & 2,4 & $\mathrm{~V}$ & 14,4 & & oude bodem \\
\hline
\end{tabular}




\section{Bijlage 2 - sedimentkarakteristieken}

\section{Sedimentkarakteristieke infauna stations.}

\begin{tabular}{|c|c|c|c|c|c|c|c|c|c|c|}
\hline \multirow[t]{3}{*}{ in $\%$} & BfN4 & BfN5 & BfN6 & BfN7 & BfN8 & BfN9 & BfN10 & BfN11 & & \\
\hline & west-mid & west-mid & oost & oost & oost & oost & west-mid & west-mid & & \\
\hline & 7,5 & 4,5 & 14,2 & 4,7 & 13,4 & 4,7 & 7,5 & 4,5 & & \\
\hline \multicolumn{11}{|l|}{$>2.8$} \\
\hline $2.8-1.4$ & 0,0 & 0,0 & 0,0 & 0,0 & 0,0 & 0,0 & 0,0 & 0,0 & & \\
\hline $1.4-0.6$ & 0,0 & 0,0 & 0,5 & 0,0 & 0,0 & 0,0 & 0,0 & 0,0 & & \\
\hline $0.6-0.3$ & 0,7 & 0,6 & 1,0 & 0,0 & 0,0 & 0,0 & 0,0 & 0,0 & & \\
\hline $0.3-0.15$ & 9,8 & 11,1 & 11,2 & 5,9 & 6,7 & 3,2 & 9,4 & 7,2 & & \\
\hline $0.15-0.09$ & 32,2 & 22,8 & 28,4 & 17,6 & 10,0 & 12,9 & 42,0 & 18,8 & & \\
\hline $0.09-0.05$ & 16,1 & 19,1 & 13,7 & 13,7 & 6,7 & 9,7 & 15,6 & 11,6 & & \\
\hline$<0.05$ & 41,3 & 46,3 & 45,2 & 62,7 & 76,7 & 74,2 & 33,0 & 62,3 & & \\
\hline type & VIII & VIII & VIII & VIII & VIII & VIII & VIII & VIII & & \\
\hline$\%<90$ & 57,3 & 65,4 & 58,9 & 76,5 & 83,3 & 83,9 & 48,6 & 73,9 & & \\
\hline$\%$ droge stof & 40,3 & 38,1 & 47,5 & 39,3 & 35,1 & 34,4 & 49,7 & 33,3 & & \\
\hline$\%$ org stof & 8,0 & 8,9 & 6,9 & 8,0 & 10,0 & 9,5 & 5,8 & 9,8 & & \\
\hline \multirow{3}{*}{ in $\%$} & inf & $\inf$ & inf & $\inf$ & inf & inf & inf & inf & inf & inf \\
\hline & 234 & 235 & 236 & 237 & 238 & 239 & 240 & 241 & 242 & 243 \\
\hline & Sch-wII & Sch-wII & Sch-wII & Sch-w & Sch-w & Sch-w & Zie & Zie & Zie & Burgh \\
\hline \multicolumn{11}{|l|}{$>2.8$} \\
\hline 2.8-1.4 & 1,2 & 0,0 & 0,0 & 3,8 & 0,0 & 0,0 & 0,0 & 0,0 & 0,0 & 0,1 \\
\hline $1.4-0.6$ & 1,7 & 0,0 & 0,0 & 5,5 & 1,4 & 0,0 & 0,0 & 0,0 & 0,0 & 0,4 \\
\hline $0.6-0.3$ & 1,7 & 0,0 & 0,0 & 24,5 & 8,3 & 0,0 & 0,7 & 0,7 & 0,0 & 1,3 \\
\hline $0.3-0.15$ & 23,1 & 2,5 & 3,6 & 30,0 & 24,1 & 2,7 & 8,7 & 5,6 & 8,6 & 39,4 \\
\hline $0.15-0.09$ & 32,4 & 5,0 & 19,7 & 15,2 & 19,4 & 12,7 & 23,2 & 16,2 & 11,4 & 46,1 \\
\hline $0.09-0.05$ & 10,4 & 7,5 & 14,0 & 4,2 & 12,0 & 12,0 & 18,8 & 16,9 & 14,3 & 5,4 \\
\hline$<0.05$ & 29,5 & 85,0 & 62,7 & 16,9 & 34,7 & 72,7 & 48,6 & 60,6 & 65,7 & 7,3 \\
\hline type & VIII & VIII & VIII & $V($ dis $)$ & $\mathrm{V}(\mathrm{dis})$ & VIII & VIII & VIII & VIII & VI \\
\hline$\%<90$ & 39,9 & 92,5 & 76,7 & 21,1 & 46,8 & 84,7 & 67,4 & 77,5 & 80,0 & 12,6 \\
\hline$\%$ droge stof & 63,0 & 38,3 & 33,0 & 64,5 & 49,8 & 35,3 & 41,0 & 36,3 & 28,3 & 64,3 \\
\hline$\%$ org stof & 4,5 & 9,1 & 10,3 & 3,6 & 5,6 & 10,3 & 8,1 & 10,1 & 11,7 & 3,3 \\
\hline
\end{tabular}

\begin{tabular}{|c|c|c|c|c|c|c|c|c|c|c|}
\hline \multirow[t]{3}{*}{ in $\%$} & inf & inf & inf & inf & inf & imf & sed & sed & & \\
\hline & 244 & 245 & 246 & 247 & 248 & 249 & 250 & 251 & & \\
\hline & Burgh & Burgh & Sch-o-R & Sch-o-R & Sch-o-R & Sch-m & Sch-m & Sch-m & & \\
\hline \multicolumn{11}{|l|}{$>2.8$} \\
\hline $2.8-1.4$ & 0,0 & 0,0 & 0,0 & 1,0 & 0,3 & 4,2 & 4,5 & 18,4 & & \\
\hline $1.4-0.6$ & 0,2 & 0,0 & 1,2 & 1,6 & 1,5 & 3,1 & 4,5 & 16,7 & & \\
\hline $0.6-0.3$ & 0,4 & 0,0 & 0,6 & 1,1 & 1,5 & 3,7 & 6,4 & 9,2 & & \\
\hline $0.3-0.15$ & 23,1 & 10,0 & 31,5 & 18,5 & 13,5 & 24,6 & 16,4 & 14,5 & & \\
\hline $0.15-0.09$ & 50,6 & 24,6 & 38,3 & 54,8 & 40,9 & 26,7 & 23,6 & 18,9 & & \\
\hline $0.09-0.05$ & 11,7 & 14,6 & 7,4 & 10,4 & 14,7 & 8,9 & 8,2 & 6,6 & & \\
\hline$<0.05$ & 14,0 & 50,8 & 21,0 & 12,5 & 27,6 & 28,8 & 36,4 & 15,8 & & \\
\hline type & $\mathrm{VI}$ & VIII & $\mathrm{VI}$ & VI & VIII & VIII & VIII & VIII & & \\
\hline$\%<90$ & 25,7 & 65,4 & 28,4 & 22,9 & 42,4 & 37,7 & 44,5 & 22,4 & & \\
\hline$\%$ droge stof & 63,4 & 39,0 & 65,8 & 62,0 & 59,3 & 59,6 & 47,9 & 63,3 & & \\
\hline$\%$ org stof & 3,6 & 8,4 & 3,3 & 4,0 & 4,5 & 4,6 & 6,8 & 3,6 & & \\
\hline \multirow{3}{*}{ in $\%$} & & & vy 3 & vy 4 & vy 5 & $8 y^{6}$ & $y=8$ & yy 9 & & 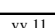 \\
\hline & Burgh & Burgh & Burgh & Sch-w & Sch-w & Sch-w & Sch-m & Sch-o & Sch-o & Sch-o \\
\hline & $19,3 \mathrm{~m}$ & $28,5 \mathrm{~m}$ & $35,2 \mathrm{~m}$ & $19,2 \mathrm{~m}$ & $29,4 \mathrm{~m}$ & $35,2 \mathrm{~m}$ & $46,7 \mathrm{~m}$ & $32,3 \mathrm{~m}$ & $39,8 \mathrm{~m}$ & $39,5 \mathrm{~m}$ \\
\hline \multicolumn{11}{|l|}{$>2.8$} \\
\hline $2.8-1.4$ & 1,5 & 0,0 & 0,9 & 3,4 & 1,7 & 2,4 & 11,6 & 6,1 & 2,2 & 3,5 \\
\hline $1.4-0.6$ & 1,8 & 1,0 & 0,9 & 5,2 & 4,9 & 2,4 & 9,9 & 7,1 & 4,3 & 4,4 \\
\hline $0.6-0.3$ & 2,4 & 3,3 & 2,3 & 8,2 & 10,5 & 2,9 & 5,0 & 5,1 & 3,2 & 3,5 \\
\hline $0.3-0.15$ & 31,2 & 35,3 & 50,4 & 16,8 & 26,2 & 28,2 & 12,4 & 15,8 & 23,7 & 18,4 \\
\hline $0.15-0.09$ & 29,7 & 23,4 & 22,7 & 32,1 & 29,7 & 29,6 & 13,2 & 17,9 & 25,8 & 28,1 \\
\hline $0.09-0.05$ & 9,1 & 7,9 & 5,8 & 11,2 & 7,3 & 7,2 & 6,6 & 9,2 & 7,5 & 13,2 \\
\hline$<0.05$ & 24,2 & 29,0 & 16,9 & 23,1 & 19,6 & 27,2 & 41,3 & 38,8 & 33,3 & 28,9 \\
\hline type & $\mathrm{V}(\mathrm{dis})$ & $\mathrm{V}(\mathrm{dis})$ & V & VIII & $\mathrm{V}(\mathrm{dis})$ & VIII & VIII & VIII & VIII & VIII \\
\hline$\%<90$ & 33,3 & 37,0 & 22,7 & 34,3 & 26,9 & 34,5 & 47,9 & 48,0 & 40,9 & 42,1 \\
\hline$\%$ droge stof & 57,7 & 55,3 & 67,3 & 76,6 & 63,9 & 45,6 & 37,9 & 46,9 & 47,1 & 48,7 \\
\hline$\%$ org stof & 5,3 & 5,2 & 2,6 & 2,1 & 3,9 & 8,7 & 9,8 & 8,5 & 8,3 & 7,0 \\
\hline
\end{tabular}

\begin{tabular}{|c|c|c|c|c|c|c|c|c|c|c|}
\hline in \% & vv 12 & vv 13 & vv 14 & vv 15 & vv 16 & vv 17 & & & & \\
\hline & Sch-o & Sch-o & Sch-o & Sch-R & Sch-R & Sch-R & & & & \\
\hline & $40,6 \mathrm{~m}$ & $31,5 \mathrm{~m}$ & $35 \mathrm{~m}$ & $23,9 \mathrm{~m}$ & $31,4 \mathrm{~m}$ & $30,5 \mathrm{~m}$ & & & & \\
\hline$>2.8$ & & & & & & & & & & \\
\hline $2.8-1.4$ & 2,1 & 3,7 & 4,8 & 0,0 & 3,7 & 4,1 & & & & \\
\hline $1.4-0.6$ & 4,2 & 10,6 & 6,5 & 0,4 & 3,4 & 6,8 & & & & \\
\hline $0.6-0.3$ & 2,1 & 6,1 & 4,8 & 1,2 & 2,5 & 20,3 & & & & \\
\hline $0.3-0.15$ & 31,3 & 19,1 & 21,0 & 50,2 & 27,4 & 36,0 & & & & \\
\hline $0.15-0.09$ & 20,8 & 22,4 & 17,7 & 30,4 & 35,4 & 18,4 & & & & \\
\hline $0.09-0.05$ & 8,3 & 10,2 & 8,1 & 3,6 & 8,0 & 4,8 & & & & \\
\hline$<0.05$ & 31,3 & 28,0 & 37,1 & 14,2 & 19,5 & 9,6 & & & & \\
\hline type & $\mathrm{V}$ (dis) & VIII & $\mathrm{V}(\mathrm{dis})$ & V & VI & V & & & & \\
\hline$\%<90$ & 39,6 & 38,2 & 45,2 & 17,8 & 27,6 & 14,4 & & & & \\
\hline$\%$ droge stof & 52,8 & 40,9 & 43,0 & 73,3 & 68,9 & 73,3 & & & & \\
\hline \% org stof & 6,2 & 9,1 & 9,6 & 2,3 & 3,1 & 2,4 & & & & \\
\hline
\end{tabular}




\section{Bijlage 3 - dikte sedimentlaag}

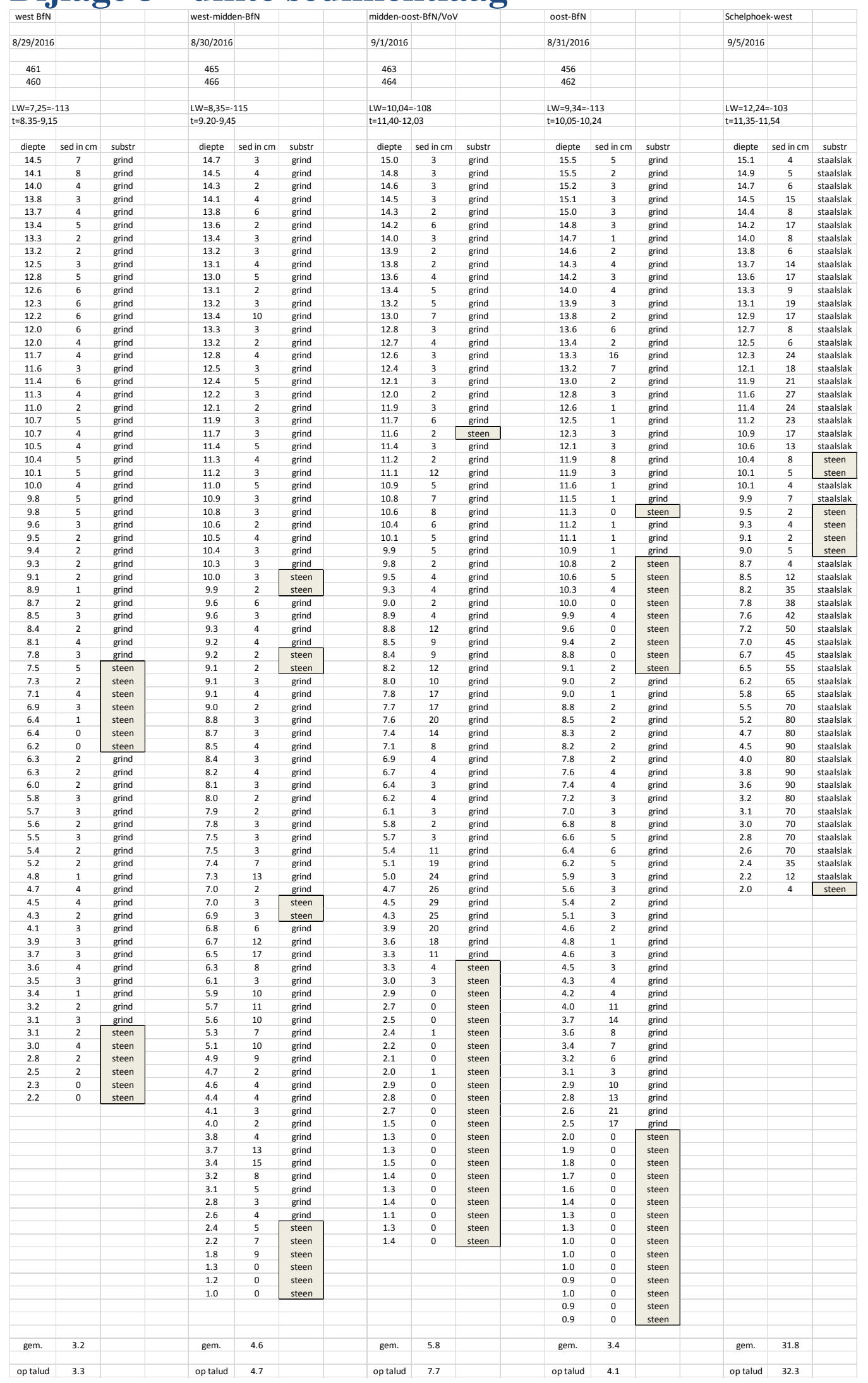




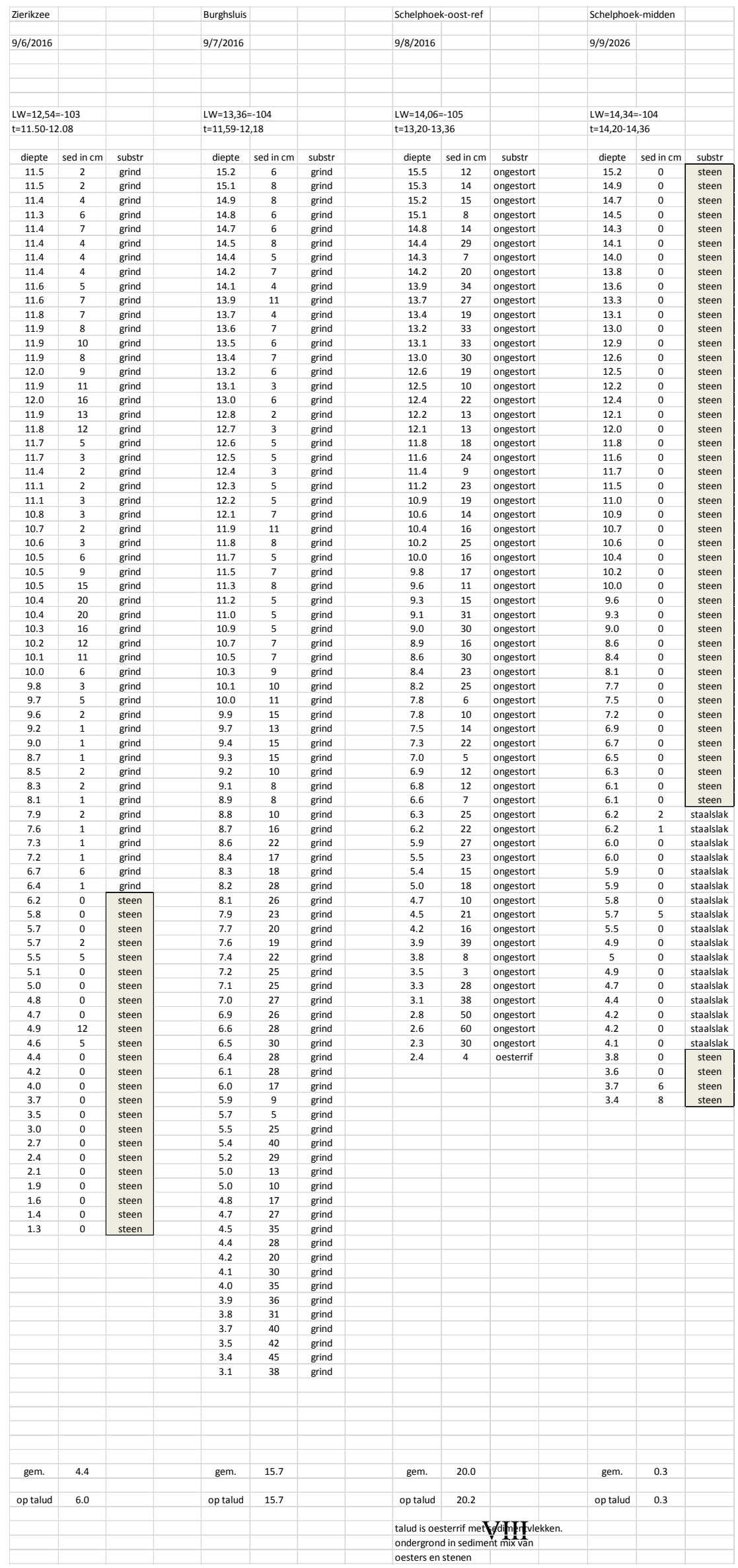

